H. RICHARO SEIWELL' 


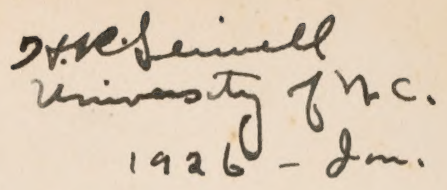



ARTIFICIAL PARTHENOGENESIS AND FERTILIZATION 
THE UNIVERSITY OF CHICAGO PRESS CHICAGO, ILLINOIS

\section{Agents}

THE CAMBRIDGE UNIVERSITY PRESS

LONDON AND EDINBURGH

THE MARUZEN-KABUSHIKI-KAISHA

TOKYO, OSАKA, КYัOTO

KARL W. HIERSEMANN

LEIPZIG

THE BAKER \& TAYLOR COMPANY

NEW YORK 


\title{
ARtificial Parthenogenesis AND FERTILIZATION
}

\author{
BY \\ JACQUES LOEB \\ MEMBER OF THE ROCKEFELLER INSTITUTE FOR MEDICAL RESEARCH
}

ORIGINALLY TRANSLATED FROM THE GERMAN

BY W. O. REDMAN KING, B.A., ASSISTANT LECTURER IN ZOÖLOGY AT THE UNIVERSITY OF LEEDS, ENGLAND.

SUPPLEMENTED AND REVISED BY THE AUTHOR
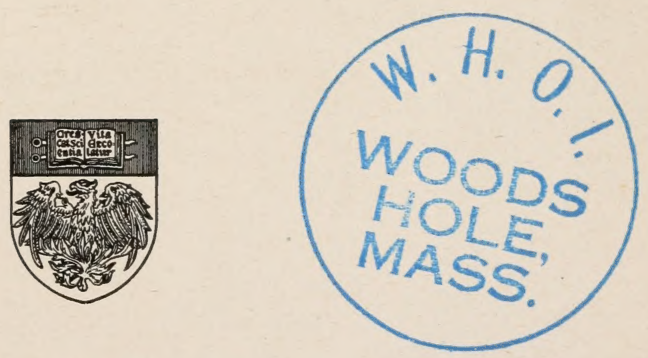

THE UNIVERSITY OF CHICAGO PRESS

CHICAGO, ILLINOIS 
Copyright 1913 By

The University of Chicago

All Rights Reserved

Published November 1913

Composed and Printed By

The University of Chicago Press

Chicago, Illinois, U.S.A. 
To

PROFESSOR SVANTE ARRHENIUS 



\section{PREFACE}

In 1909 the author published a book entitled Die chemische Entwicklungserregung des tierischen Eies (Springer, Berlin), in which he gave an account of his experiments on artificial parthenogenesis. The object of these experiments was the substitution of physicochemical agencies for the mysterious complex "living spermatozoon." The book has been translated into English by Mr. W. O. R. King, but, owing to the new observations since made, the author has found it necessary to revise and enlarge the translation.

The book gives a survey of the methods by which the unfertilized egg can be caused to develop into an embryo and the conclusions which can be drawn concerning the mechanism by which the spermatozoon produces this effect. The theory, which the author published in 1905 and 1906, that at least two factors are involved in this process, namely, one which brings about a change in the surface of the egg (the essential factor), and a second, corrective factor, seems to explain all the phenomena observed in the new territory and has proved a reliable guide.

In developing the new field of investigation, the writer endeavored to select those variables and methods which would lend themselves to a quantitative treatment.

The problem of fertilization is intimately connected with many different problems of physiology and pathology. We may mention, among others, the natural death of the egg cell and the prolongation of its life by fertilization; the fertilization of the egg by foreign blood and the immunity of the egg to blood of its own species; the relations between heterogeneous hybridization and artificial parthenogenesis, between fertilization and cytolysis, and between permeability and physiological 
efficiency of acids and bases. The facts recorded and discussed in the book therefore go beyond the special problem indicated by the title.

The Rockefeller Institute for Medical Research

September 6, 1913 


\section{CONTENTS}

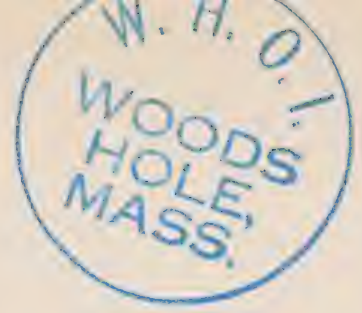

I. Introductory Remarks - - $\quad$ - $\quad$ - 1

II. Some Remarks on the Morphology of Development - 17

III. Fertilization and Oxidation - $\quad-\quad-\quad-\quad 25$

IV. Hydrolytic Processes in the Germination of Oilcontaining Seeds - $\quad$ - $\quad$ - $\quad$ - $\quad$ - $\quad$ - $\quad$ - 39

V. Some Earlier Observations on Natural Parthenogenesis in Insects - $\quad$ - $\quad$ - $\quad$ - $\quad$ -

VI. On the History of the Earlier Experiments on Artificial Parthenogenesis - $\quad$ - $\quad$ - $\quad$ - $~-~-~$

VII. The First Experiments upon the Osmotic Activation of the Unfertilized Egg of the Sea-Urchin (Arbacia) - $\quad$ - $\quad$ - $\quad$ - $\quad$ -

VIII. The Improved Method of Artificial Parthenogenesis in the Sea-Urchin Egg - $\quad$ - $\quad$ - $\quad$ - $\quad$ -

IX. The Effect of Artificial Membrane Formation on the Egg

X. Further Examples of the Prolongation of the Life of the Egg by Lack of Oxygen - _ _ _ _

XI. Further Experiments on the Action of the Hypertonic Solution after Membrane Formation - -

XII. The Effect of the Agencies of Artificial Parthenogenesis upon the Oxidations. The Cytological Changes in the Parthenogenetic Egg - - -

XIII. The Relative Physiological Efficiency of Various Isosmotic Solutions - $\quad$ - $\quad$ - $\quad$ - $\quad$ - $\quad$ - 127

XIV. Chemical Constitution and Relative Physiological

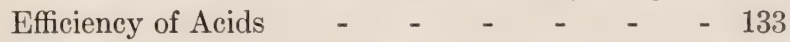

XV. The Activation of the Unfertilized Egg by Bases - 147 ix

$$
25358
$$


XVI. Analysis of the Original Method of Producing Artificial Parthenogenesis by Hypertonic Solutions

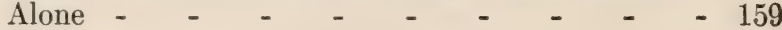

XVII. Membrane Formation and Cytolysis - - - 173 XVIII. The Fertilizing Effect of Foreign Blood and Foreign

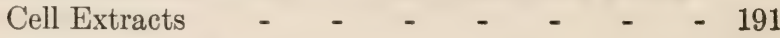

XIX. The Fertilizing Effect of Sperm Extract - - - 201

XX. The Mechanism of the Formation of the Fertilization

Membrane - - - - - _ - - 207

XXI. Is Development of the Sea-Urchin Egg Possible without Membrane Formation or without the Second (Corrective) Factor? - _ _ _ _ - 219

XXII. The Action of the Spermatozoon upon the Egg. I. Heterogeneous Hybridization - - - - 225

XXIII. The Action of the Spermatozoon upon the Egg. II. The Combination of Artificial Parthenogenesis and Fertilization with Sperm in the Same Egg - - 233

XXIV. Conditions for the Maturation of the Egg - $\quad$ - 243

XXV. Artificial Parthenogenesis in the Eggs of the Starfish - 249

XXVI. Artificial Parthenogenesis in the Eggs of Annelids - 257

XXVII. Experiments with the Eggs of Molluses - - - $\quad 267$

XXVIII. Artificial Parthenogenesis in the Eggs of Frogs - $\quad$ - 271

XXIX. Artificial Parthenogenesis in Plants - - - $\quad 277$

XXX. Preservation of the Life of the Egg by the Act of

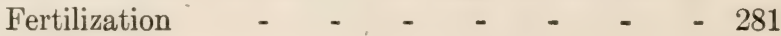

XXXI. Artificial Parthenogenesis and Heredity - - $\quad$ - 291

XXXII. Can an Embryo Develop from a Spermatozoon ? - 303 


\section{INTRODUCTORY REMARKS}

1. The analysis of the mechanism by which the male sex cell, the spermatozoon, causes the animal egg to develop is the subject of this book. This analysis was rendered possible through the fact that we are now able to imitate the action of the spermatozoon upon the egg by physicochemical means. The problem of fertilization is intimately connected with another problem, namely, that of natural death and immortality of the cell. Weismann enunciated the fact that the protozoa are immortal; and that the same immortality exists for the sex cells of metazoa. ${ }^{1}$

The writer showed in 1902 that the problem of fertilization is intimately connected with the problem of the prolongation of the life of the egg cell. The unfertilized mature egg dies in a comparatively short time, which may vary from a few hours to a few weeks according to the species or the conditions under which the egg lives. The fertilized egg, however, lives indefinitely, inasmuch as it gives rise, not only to a new individual, but, theoretically at least, to an endless series of generations. The death of the unfertilized egg is possibly the only clear case of natural death of a cell, i.e., of death which is not caused by external injuries, and the act of fertilization is thus far the only known means by which the natural death of a cell can be prevented. The two problems, fertilization and prolongation of life, are thus interwoven, and the experiments on the mechanism of fertilization become at the same time studies on the problem of natural death and prolongation of the life of the egg cell.

${ }^{1}$ Leo Loeb pointed out ten years ago that his experiments on the transplantation of cancer also proved the immortality of the cancer cell, since the same cancer cell can be transplanted on endless generations of animals and live indefinitely. 
The eggs of a small number of species can develop "spontaneously," but in the majority of animals no development is possible until a male sex cell, the spermatozoon, enters the egg.

2. The spermatozoon is a living motile organism, resembling a certain class of protozoa, the flagellates. All the mystery which surrounds the term "life" formerly surrounded also the action of the spermatozoon upon the egg. The interest of the experiments reported in this book lies in the fact that they substitute the action of well-known chemical and physical agencies for that of the mysterious complex called "living spermatozoon."

The spermatozoon has two kinds of effects upon the egg: in the first place, it causes its development, and secondly it transmits the paternal characters to the developing embryo. Now it is probable that the developmental and hereditary effects of the spermatozoon are connected with different materials contained therein. For it is possible to fertilize the eggs of the sea-urchin with the spermatozoa of quite different species or genera, e.g., starfish, brittlestars, holothurians," crinoids, ${ }^{2}$ and even of mollusca (Mytilus ${ }^{3}$ and Chlorostoma ${ }^{4}$ ). Strangely enough, however, all these cases of heterogeneous fertilization give rise to the development of a typical seaurchin larva, viz., a pluteus; hence the spermatozoon exerts here only a developmental, but no hereditary, effect. These experiments show that we must distinguish between the developmental and the hereditary effect of the spermatozoon, and that each of these effects depends probably upon different materials in the spermatozoon.

In this treatise we shall consider only the developmental effect of the spermatozoon; or rather, we will describe

${ }_{1}^{1}$ Loeb, Untersuchungen zur künstlichen Parthenogenese, Leipzig, 1906, pp. 382483; Pflüger's Archiv, XCIX, 323, 1903; CIV, 325, 1904.

2 Godlewski, Archiv f. Entwicklungsmechanik, XX, 579, 1906.

3 Kupelwieser, Biolog. Centralbl., XXVI, 744, 1906.

4 Loeb, Archiv f. Entwicklungsmechanik, XXVI, 476, 1908. 
experiments through which it is possible to cause, by chemical means, the unfertilized eggs of various animals to develop into larvae.

Such a study could not be undertaken without applying the methods of experimental and, more especially, quantitative research. As long as the spermatozoon was the only means of calling forth the development of the egg it was impossible to undertake a physicochemical analysis of this process. The work on artificial parthenogenesis, i.e., the substitution of wellknown physicochemical forces for the spermatozoon, made such an analysis possible.

The older so-called theories of fertilization were merely metaphors. The egg was compared to a clock, and it was said that the spermatozoon set this clock in motion. Others said that the spermatozoon communicated to the egg a peculiar mode of vibration, and still others maintained that the spermatozoon imparted a "stimulus" to the egg. "Stimulus" is a technical term, but scientific problems are not solved by mere acts of nomenclature or rhetoric.

With the rise of cytology more definite ideas in regard to the mechanism of fertilization were expressed. O. Hertwig defined fertilization as the fusion of the sperm nucleus with the egg nucleus. While this fusion has a bearing upon the transmission of the paternal characters to the offspring, it does not give us any insight into the nature of the forces by which the egg is caused to develop. Hertwig's definition is also incorrect, as was clearly demonstrated by Boveri who found that the fusion of the egg and sperm nucleus had nothing at all to do with the causation of the development of the egg. For he was able to show that an egg deprived of its nucleus can actually develop into an embryo if a spermatozoon enters it. In this case no union of two nuclei takes place.

Boveri replaced Hertwig's definition by a hypothesis that was more in accordance with the facts. According to him, the 
unfertilized egg is unable to develop because it lacks the "organ" for cell division. According to Boveri, this organ is the centrosome, and it is introduced into the egg by the "middle piece" of the spermatozoon. During nuclear division there appear in the egg radiating figures, the astrospheres, whose physical nature is at present unknown. Some eggs, but by no means all, show at the center of a radiating system a granule, the centrosome, and in this Boveri sees the "organ of cell division." According to him the unfertilized egg lacks this granule which is introduced at fertilization by the spermatozoon.

Boveri's view that the centrosomes or astrospheres cannot be formed by the unfertilized egg was disproved by Morgan, who showed, as a sequel to my experiments on the effects of hypertonic solutions upon the egg, that such treatment can lead to the formation of astrospheres in the unfertilized egg, and that these eggs can even begin to segment.

In certain eggs, e.g. that of Chaetopterus, the spermatozoon has to accomplish another task aside from fertilizing the egg, namely, it must bring about the so-called maturation of the egg. This consists in the reduction of the nucleus by two subsequent nuclear divisions and the throwing-out of two fragments of the nucleus, the so-called polar bodies. For the maturation division, centrosomes and astrospheres are also required. Mead showed that in the egg of Chaetopterus the two astrospheres for the maturation division are present in the egg before the spermatozoon enters it, but that this maturation division cannot take place unless a spermatozoon does enter. On the other hand, the maturation division occurred without a spermatozoon entering, if some potassium was added to the sea-water. Hence the effect of the spermatozoon is in this case not due to the introduction of a centrosome into the egg.

3. Investigations into the effects of ions had led the writer to believe that in them we possess very potent factors in life 
phenomena, and that with their help we should succeed in controlling such phenomena to a much greater extent than by any other means. Organic chemistry has thrown but little light upon the dynamics of living matter: and this may be partly due to the fact that insufficient attention has been paid to the electrolytes. It appeared to me that nothing would more clearly demonstrate the sovereign rôle that electrolytes play in the phenomena of life than by causing, if possible, with their help, unfertilized eggs to develop into larvae. The ions by whose aid I confidently expected to achieve success were the hydroxylions. I had found that the development of fertilized sea-urchin eggs depended upon the reaction of the solution, and that a faintly alkaline solution was more favorable than a slightly acid solution. This I attributed to an influence upon oxidations in the eggs. For I had previously discovered that without oxygen the fertilized sea-urchin egg can neither segment nor develop.

My first experiments toward causing unfertilized eggs to develop by means of alkali consisted in exposing the eggs to seawater to which some sodium hydrate had been added, so as to increase the alkalinity. These experiments were only partially successful. In such sea-water, the eggs divided only once or twice without developing into larvae. On the other hand, in 1899 I succeeded in inducing unfertilized sea-urchin eggs to develop into larvae by exposing them for two hours to hypertonic sea-water, i.e., sea-water to which had been added sufficient salt or sugar to raise its concentration about 60 per cent. Even pure (hypertonic) cane-sugar solutions were found to induce development, but the larvae obtained in this case were unable to develop to the pluteus stage. Six years later I found that, within certain limits, the developmental effect of the hypertonic solution increases with the concentration of the hydroxylions. Moreover the hypertonic solution is only able to produce its developmental effect if it contains free oxygen 
in sufficient concentration. If the oxygen is driven out of the hypertonic solution, or if the oxidations in the egg are prevented by the addition of some KCN to the sea-water, the developmental effect of the hypertonic solution is lacking.

Shortly after obtaining larvae from unfertilized sea-urchin eggs by means of hypertonic sea-water, I was able to obtain swimming larvae from the unfertilized eggs of Chaetopterus by the use of potassium and acids, and of starfish eggs by means of acids, without it being necessary to increase the osmotic pressure of the sea-water.

With these experiments one task was accomplished, namely, the substitution of physicochemical agencies for the mysterious complex "living spermatozoon." But these experiments did not yet allow us to draw any conclusions concerning the nature of the process of fertilization.

4. Every biologist knew that the eggs of many marine animals underwent a characteristic change immediately after the entrance of the spermatozoon, namely, the formation of the so-called fertilization (vitelline) membrane. This phenomenon was always considered to be something of very secondary importance, and I therefore attached no significance to the fact that after the osmotic treatment the egg formed no typical fertilization membrane. However, in $1905 \mathrm{I}$ discovered that a short exposure of the sea-urchin egg to a monobasic fatty acid, or to $\mathrm{CO}_{2}$, led to the formation of a typical fertilization membrane by all the eggs of Strongylocentrotus purpuratus; and, moreover, that all these eggs could be induced to develop into larvae after artificial membrane formation by a subsequent short exposure, some thirty to fifty minutes, to hypertonic sea-water. If membrane formation alone is evoked, without subsequent exposure of the eggs to hypertonic sea-water, they begin to segment, but then disintegration sets in; and the higher the temperature, the sooner does this disintegration make its appearance. If the temperature is very low, the eggs can develop to early larval 
stages without it being necessary to expose them in addition to hypertonic sea-water. At room temperature, on the other hand, the eggs after artificial membrane formation go to pieces in the course of a few hours. Hence it is the artificial membrane formation which starts the development, but starts at the same time a tendency to disintegration. The latter, however, can be counteracted by a short exposure of the eggs to a hypertonic solution; but in order to produce this effect the hypertonic solution must contain a sufficient quantity of free oxygen, and the higher the concentration of hydroxylions, within certain limits, the more effective is the hypertonic solution.

In 1906 I discovered still another method of overcoming the injurious secondary effect connected with membrane formation, which consists in arresting the development of the eggs for two or three hours. This is effected by putting the eggs after membrane formation into sea-water from which the oxygen has been displaced by a current of hydrogen, or to which some KCN has been added. As long as the eggs are in such a solution they cannot develop on account of the cessation of their oxidations. If the eggs are replaced some two or three hours later (at $15^{\circ} \mathrm{C}$.) in normal aerated sea-water, practically all the eggs segment and develop in a perfectly normal manner. Hence there must have occurred during that time a change in the egg which allows it to develop normally.

Further proof can be given that membrane formation is really the essential step in the activation of development; for in the eggs of many forms membrane formation is sufficient to allow them to develop into normal larvae, at room temperature. I found that if membrane formation is produced in the eggs of a starfish, Asterina, by the use of a fatty acid, some of the eggs are able to develop into normal larvae; and I afterward found the same to be the case with Polynoe, a polychaet, while Lefevre established the same fact for the eggs of another marine worm, Thalassema. Now these eggs differ from 
those of the sea-urchin only in that either the secondary effects set up by membrane formation are less injurious, or that the eggs of these forms can recover more quickly from them than sea-urchin eggs. We shall see later that the eggs of different forms vary in this respect quantitatively, but not in principle.

It can be shown in still another way that it is the process of membrane formation and not any other effect of the fatty acid which starts the development of the egg. For membrane formation induced in any other way always evokes development, whereas mere exposure to the fatty acid does not lead to development unless membrane formation also takes place.

5 . In this way, the process of membrane formation, which had hitherto been regarded as of quite secondary importance so far as development was concerned, was identified as the immediate cause of the activation of development in the egg. The next step was to determine the substances and processes by which membrane formation might be evoked.

I had already observed in 1904 that whenever an egg undergoes cytolysis it passes through a similar process of membrane formation, and further research along this line showed that indeed all cytolytic agencies cause membrane formation. A relatively short exposure to a cytolytic agent leads only to membrane formation, whereas a longer exposure entails cytolysis. Hence we can say that membrane formation (and the activation of development) is due to a cytolysis of the surface or the cortical layer of the egg. Certain glucosides, such as saponin, solanin, and digitalin, produce strong haemolytic or cytolytic effects. If eggs are exposed for a short time to a very dilute solution of these substances in sea-water, they form a typical fertilization membrane, and, if removed from the solution immediately after the formation of this membrane, they will begin to develop. For the eggs of Polynoe this treatment is sufficient to induce the development to the larval stage; but the eggs of Strongylocentrotus require a subsequent exposure to hypertonic sea-ivater 
in order to counteract the injurious secondary effects of membrane formation. If the eggs are not removed from the saponin solution immediately after membrane formation, cytolysis supervenes in a few minutes. Similar results are obtained with soap. A short exposure of the eggs to an alkaline soap solution in $\mathrm{NaCl}$ leads to membrane formation (and to development if the eggs are subsequently treated for a short while with a hypertonic solution). A longer exposure of the eggs to a soap solution leads to cytolysis.

The same behavior can be demonstrated for all cytolytic reagents, even those of a physical nature, as, for example, rise of temperature. A sufficient increase of temperature causes membrane formation in the unfertilized sea-urchin egg and one of longer duration leads to cytolysis. R. Lillie has found that the eggs of starfish can develop into larvae after membrane formation caused by raising the temperature. Sea-urchin eggs are too much injured by the increase of temperature necessary for membrane formation to be able to develop.

We know that the blood corpuscles of any species of animal are often cytolyzed by the body fluids of different species. In 1907 I found that the blood of certain worms, to wit, the Gephyrea, causes membrane formation in the sea-urchin egg, even when greatly diluted. This power is also possessed by the blood of other forms, especially of mammals. This phenomenon is, however, not exhibited by the eggs of every female, and I believe that this is due to a difference in the permeability of the eggs of different females. Only those eggs that are permeable to the "lysins" of the foreign blood form membranes under its influence. If such eggs are exposed for a short while to hypertonic sea-water, after membrane formation has been produced by the blood, they develop into larvae. The cytolysis of these egg: with foreign blood is impossible, or proceeds only very slowly; this, I think, is due to the fact that the fertilization membrane prevents the further diffusion of the "lysins" into the egg. 
The most remarkable fact, however, is this: that it is possible to cause artificial parthenogenesis in eggs which are refractory to any other method of artificial parthenogenesis. All attempts to cause artificial parthenogenesis in the eggs of Cumingia, a marine mollusc, had failed. But Mr. Wasteneys and the writer found in 1912 that these eggs can be caused to develop into larvae if they are treated with ox blood or serum. In order to accomplish this they must first be sensitized by a treatment with a solution of $\mathrm{SrCl}_{2}$. The writer had previously found that sea-urchin eggs which cannot be caused to form membranes under the influence of ox serum will do so if they are first treated for some time with a solution of $\mathrm{SrCl}_{2}$.

Not only foreign blood but the extract of foreign cells is efficient in inducing membrane formation and development in the unfertilized egg. Blood of the species to which the eggs belong is, however, entirely ineffective for this purpose. This is analogous to the fact that foreign "lysins" may destroy the cells of an animal while the cells are immune against the lysins of their own species. The experiments on artificial parthenogenesis indicate that this immunity is due to the fact that the lysins are prevented from diffusing into the cells of the same species while they can diffuse into the cells of foreign species.

6 . The question may next be raised whether the spermatozoon also effects membrane formation by means of a cytolytic substance, a "lysin," and whether, in that event, it must carry into the egg yet another substance besides the lysin for the purpose of preventing the disintegration following membrane formation. This is what actually appears to be the case. Ten years ago I discovered a method of fertilizing the eggs of the sea-urchin with the sperm of widely different species, e.g., of the starfish. In employing this method, I found that not all the eggs of the sea-urchin which form membranes with (living) starfish sperm develop. Some of the eggs form membranes and 
begin to develop, but then disintegrate unless the harmful secondary effects of membrane formation are counteracted by some further manipulation. Hence some of the sea-urchin egg: treated with starfish sperm behave as though membrane formation had only been caused by virtue of some haemolytic substance carried by the sperm. But if these eggs are first treated with starfish sperm and then, after membrane formation, exposed for a short while to hypertonic sea-water, they can develop into larvae. The other sea-urchin eggs, however, that formed membranes with starfish sperm developed into larvae without the necessity for any further exposure to hypertonic sea-water or to lack of oxygen.

These facts are intelligible on the following assumption. The spermatozoon causes membrane formation by a substance which is comparatively soluble in the egg; in addition to this membrane-forming substance the spermatozoon carries a second substance into the egg which prevents the disintegration which follows after mere membrane formation. Those eggs of the sea-urchin which upon contact with the sperm of the starfish formed membranes but then began to disintegrate absorbed only this membrane-forming substance; while into those eggs which formed a membrane and developed into larvae the whole spermatozoon had entered.

These observations upon the effect of starfish sperm on the sea-urchin egg lead to the interesting problem of why the treatment of sea-urchin eggs with their own sperm never causes membrane formation alone (without complete development following). For when sea-urchin eggs are fertilized with seaurchin sperm, all the eggs that form membranes invariably develop, and it never happens that some begin to develop and afterward decompose. The answer is that the "lysins" of foreign sperm can penetrate into the egg in two ways, by diffusion or by being carried by a spermatozoon; the "lysins" of the spermatozoa of the same species, however, never can get into 
the egg by diffusion, but only if carried into the egg by a living spermatozoon. And when a spermatozoon enters the egg it introduces also into the egg the second substance which prevents the disintegration following membrane formation.

7. The question as to how cytolytic agents cause membrane formation is connected with that of the nature of cytolysis itself. We shall not in this treatise consider the answer to this question, but in order to fix our ideas provisionally, we may assume that the surface of the egg consists of an emulsion whose stability is destroyed by cytolytic agents. This supposition gives us an explanation of the fact that the eggs of some animals show a slight natural tendency to parthenogenesis. In such eggs the stability of the emulsion may be relatively small, so that the $\mathrm{HO}$ ions of the sea-water, or the carbonic acid produced by the eggs or by bacteria, are in themselves sufficient to destroy the emulsion and to cause membrane formation. This hypothesis is supported by observations upon the eggs of starfish. Unlike most seaurchin eggs, those of starfish show occasionally a tendency to develop spontaneously (without the addition of sperm). As a rule one finds that a few starfish eggs begin to divide after lying for some time in sea-water, and in many cases this is followed by the spontaneous development to the larval stage without the necessity for any artificial manipulation. Mathews found that the number of such spontaneously developing starfish eggs can be increased by slight mechanical agitation. I found the same to be the case for the eggs of Amphitrite, a marine worm, which also show a tendency toward spontaneous parthenogenesis. These facts, of which there had hitherto been no explanation, can be understood upon the assumption that this parthenogenetic tendency depends upon the slight stability of the emulsion at the surface of the eggs of these forms. At the lower limit of this stability, a slight shaking is enough to destroy it. I have also found that if the eggs of Asterias are 
compressed in the ovary, they can be caused to form membranes and to cytolyze. Moreover, starfish eggs that are caused to develop by shaking form membranes first of all; this is the immediate effect of the mechanical agitation.

8. We may now raise the question as to how the artificial membrane formation induces the development of the egg. The writer reached the conclusion that for the sea-urchin egg this was due to an acceleration of oxidations. This suggestion was confirmed by Warburg, and since by Wasteneys and the writer. The entrance of the spermatozoon raises the rate of oxidations in the egg of the sea-urchin to from four to six times its usual amount; and the artificial membrane formation has the same effect. There are two possibilities by which this result can be produced: either a catalyzer (an oxidase) is carried into the egg by the spermatozoon; or the change in the surface layer itself causes the increased rate of oxidation. Everything speaks in favor of the second assumption. We know that with the concentration of the catalyzer the rate of chemical reactions increases either in proportion to the concentration of the catalyzer or in the ratio of the square root of the concentration; and the investigations of the temperature coefficient of development of the egg show that the rate of development is determined by chemical reactions. If therefore the spermatozoon increased the rate of oxidation by carrying an oxidase into the egg the rate of segmentation in an egg fertilized by more than one spermatozoon should be increased in the ratio of $1: 2$ or $1: \sqrt{2}$. Observations show that the velocity of segmentation in eggs fertilized by two spermatozoa is identical with that found in eggs fertilized by one spermatozoon. This fact proves that the spermatozoon causes development, not by carrying an oxidase or some other catalyzer into the egg, but by removing an obstacle to development. The same must hold for the explanation of the influence of membrane formation upon development. Through the cytolysis of the cortical layer 
of the egg the oxidations in the unfertilized egg are accelerated from four to six times their natural rate.

This idea is further supported by the fact observed by Wasteneys and the writer that if we cause complete cytolysis of the unfertilized eggs of the sea-urchin by saponin or by distilled water, the rate of oxidation is thereby raised to the same amount as if the eggs were fertilized by sperm, although these eggs are dead. This suggests the idea that the cytolysis of the cortical layer removes an obstacle by which the oxidations become possible. It may be that the cortical layer of the unfertilized egg contains an oxidase which cannot act, or an oxidizable substance which cannot readily undergo oxidation, unless the cortical layer is liquefied (cytolyzed). R. Lillie assumes that the cortical layer of the unfertilized egg prevents the diffusion of $\mathrm{CO}_{2}$ from the egg and that this $\mathrm{CO}_{2}$ prevents oxidation. This view meets with the difficulty that $\mathrm{CO}_{2}$ is a good agency for calling forth the membrane formation in unfertilized eggs, and we shall see that only such substances can do this as diffuse into the egg.

9. The earlier biologists had realized that the unfertilized egg dies quickly and that the act of fertilization prevents its death. The question arises: How can the spermatozoon accomplish this act? The causation of development requires two factors, the one is the membrane-forming factor, the other the corrective factor which in the methods of artificial parthenogenesis is supplied by the hypertonic solution. We may raise the question: Is only one of these factors responsible for the prolongation of the life of the egg, or are both responsible? At first sight it would seem as if the second factor alone were responsible for this effect, since the membrane formation alone raises the rate of oxidations and also hastens the disintegration of the egg. If, however, the eggs are treated with the hypertonic solution they live and develop. This would make it appear as if the membrane formation alone only hastened the natural death 
of the egg, while the second factor, the treatment of the egg with the hypertonic solution, was the life-saving factor. Yet this conclusion is unwarranted. It makes no difference whether the treatment of the unfertilized egg with a hypertonic solution follows or precedes the artificial membrane formation (except that the length of time of exposure of the eggs to the hypertonic solution differs in both cases). The writer found recently that if once the unfertilized eggs have been treated with a hypertonic solution they possess the second factor or substance necessary for development, as long as they are alive. If at any time 24 or 48 hours later they are submitted to the process of artificial membrane formation they will not disintegrate, but develop normally at room temperature. Now if the treatment with the hypertonic solution-our second factor-were really the life-saving agency in fertilization or artificial parthenogenesis, unfertilized eggs which had been treated with a hypertonic solution alone (without membrane formation) should live indefinitely. This is, however, not the case. If we treat unfertilized eggs with a hypertonic solution only, such eggs will die just as fast as unfertilized eggs not treated in this way. If, however, such eggs are subsequently submitted to the process of artificial membrane formation they will develop and live indefinitely. To such eggs the artificial membrane formation becomes a life-saving agency. From these facts we must conclude that both factors of artificial parthenogenesis are required to preserve the life of the egg and prevent its death.

This conclusion is supported by the fact that for a small percentage of starfish eggs or annelid eggs the mere act of membrane formation suffices for development and the prevention of the death of these eggs. We are forced to conclude that such eggs contain or form a substance which prevents the disintegration hastened as a rule by the process of membrane formation; and which in the sea-urchin egg must be produced by the 
treatment with the hypertonic solution or with the temporary suppression of oxidations.

Ten years ago the writer found that the life of the untreated unfertilized egg can be prolonged for some time (though not indefinitely) by suppressing the oxidations in the egg. This indicated that the oxidations in the unfertilized egg are one of the causes which lead to the premature death of the unfertilized egg. This conclusion is supported by the fact that the mature unfertilized egg of the starfish dies much more quickly than the unfertilized egg of the sea-urchin; the rate of oxidations in the mature but unfertilized egg of the starfish is comparatively much greater than in the mature but unfertilized egg of the sea-urchin.

We must therefore conclude that the oxidations going on in the mature but unfertilized egg are one of the causes that lead directly or indirectly to its death; and that in the light of this fact it appears as if the process of fertilization rendered the egg immune against oxidations, or, in other words, transformed the egg from an anaerobe into an aerobe.

10. Since physiologists who are not familiar with the literature often state that artificial parthenogenesis does not lead to the production of larvae capable of development, it might be well to point out that such statements are contrary to fact. Delage has raised two parthenogenetic larvae of the sea-urchin during sixteen months to the stage of sexual maturity. ${ }^{1}$ Both were males. Loeb and Bancroft raised a parthenogenetic frog through metamorphosis and found that its sex glands contained eggs. ${ }^{2}$ If the raising of larvae were not such a tedious process, parthenogenetic animals would exist today in large numbers, since parthenogenetic larvae may be normal and apparently healthy.

1 Delage, Compt. rend. Acad. d. Sc., CXLVIII, 453, 1909.

${ }^{2}$ Loeb and Bancroft, Jour. Exper. Zool., XIV, 275, 1913. 


\section{SOME REMARKS ON THE MORPHOLOGY OF DEVELOPMENT}

Since this book is intended not only for the zoologist, but more especially for the physiologist, pathologist, and chemist, it is necessary to give a sketch of the development of the animal egg. As an example we will use the egg of the sea-urchin, upon which the majority of experiments on the chemical activation

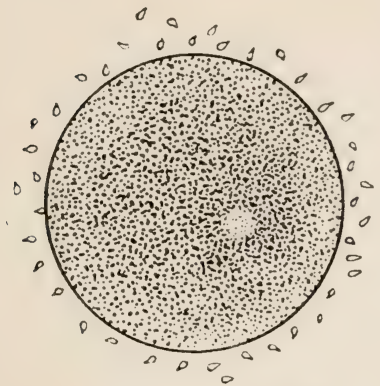

Fig. 1.-Unfertilized egg of the sea-urchin, S. purpuratus, surrounded by spermatozoa.

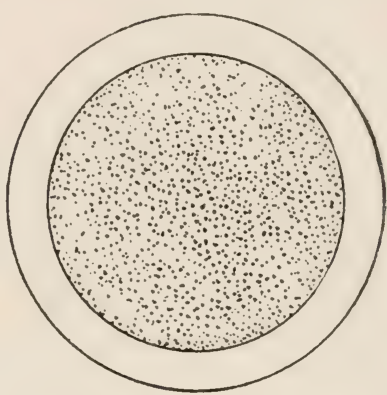

Fig. 2.-The same egg about two minutes later, after the entrance of the spermatozoon and the formation of the fertilization membrane.

of development have been performed. The reason for this is to be found in the fact that the eggs of the sea-urchin can usually be obtained in large quantities and that they form the most suitable material for our problem.

Fig. 1 is a picture of the unfertilized egg surrounded by spermatozoa. (The flagella of the spermatozoa have been omitted in the drawing.) As soon as a spermatozoon has entered, a very characteristic alteration takes place in the egg; it becomes surrounded by the so-called fertilization membrane (Fig. 2). The mechanism of this membrane formation can be 
more distinctly followed in the egg of Strongylocentrotus purpuratus by lowering the temperature of the sea-water; by this means, the process of membrane formation is retarded, and it
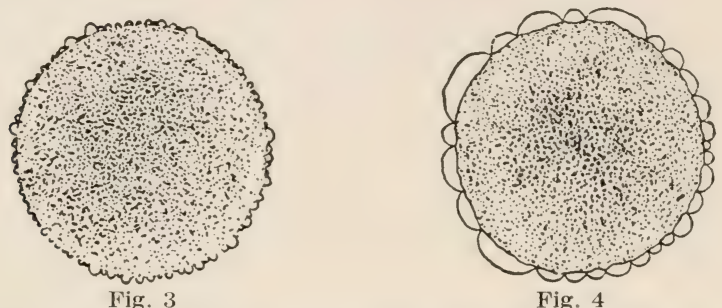

FIGS. 3 and 4.--Origin of the fertilization membrane through the formation of small vesicles on the surface of the egg.

can be observed in its separate phases. Since we shall see later that this process of membrane formation is the essential part in the activation of the egg, we will trace it through its separate stages.

The beginning of the process shows itself in a roughening of the hitherto smooth surface of the egg (Fig. 3). This is due to the formation of countless tiny vesicles which stand

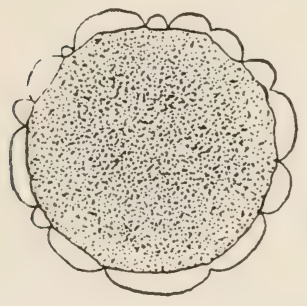

Fig. 5

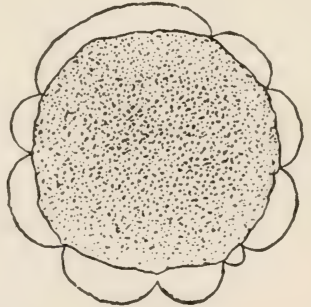

Fig. 6

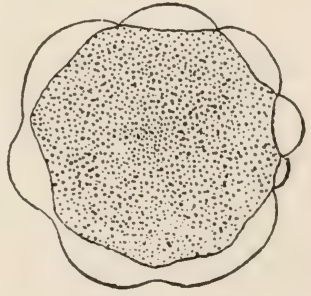

Fig. 7

Fras. 5, 6, and 7.-Further stages of the process of membrane formation.

out on the surface of the egg. ${ }^{1} \quad$ These small droplets quickly increase in size (through absorption of sea-water) and flow together into larger drops (Fig. 4). This goes on (Figs. 5, 6, 7) Hole.

1 I have never observed this phenomenon in the eggs of Arbacia in Woods 
until finally the contents of all the drops have run together into a continuous layer around the $\mathrm{egg}^{1}$ (Fig. 2). Hence the surface lamellae of the tiny droplets form later the fertilization membrane.

At higher temperatures the process of membrane formation in freshly removed eggs usually proceeds so quickly that the stages depicted in Figs. 3 to 7 are not distinctly seen and the egg passes directly from the condition of Fig. 1 to that of Fig. 2. At first the membrane adheres closely to the egg, and then of a sudden the space between the cytoplasm and the membrane increases enormously. In this latter way the process of membrane formation occurs in the egg of Arbacia.

After the formation of this fertilization membrane a second change takes place in the surface of the egg, inasmuch as a gelatinous film or membrane (G.M. Fig. 8) gradually appears on the surface of the cytoplasm. This gelatinous film does not form as suddenly or quickly as the fertilization membrane, but only begins to appear after ten minutes or more. The writer considers it possible that the formation of this film depends upon processes of oxidations, since its formation is delayed if the oxidations in the egg are retarded by the presence of $\mathrm{KCN}$.

After membrane formation, the chemical processes which underlie de-

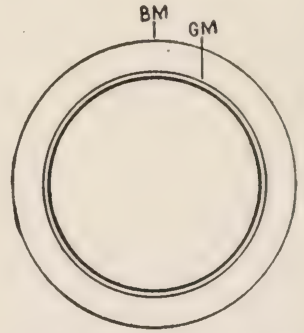

Fig. 8-Formation of a gelatinous film G.M. around the protoplasm of the egg, about 15 minutes after the formation of the fertilization membrane B.M. velopment set in in the egg. The nuclear material grows and nuclear division occurs; this nuclear division, or rather the so-called nuclear spindle, is visible in the egg which we have chosen for description, viz., that of Strongylocentrotus purpuratus (Fig. 9). The spindle formation visible in this figure is immediately followed by cleavage or cell division, i.e., the partition

${ }_{1}$ So-called "perivitelline space." 
of the egg into two spheres or cells. The various consecutive stages of this process are depicted in Figs. 10 to 13 . First we see that the egg becomes somewhat elongated in the direction

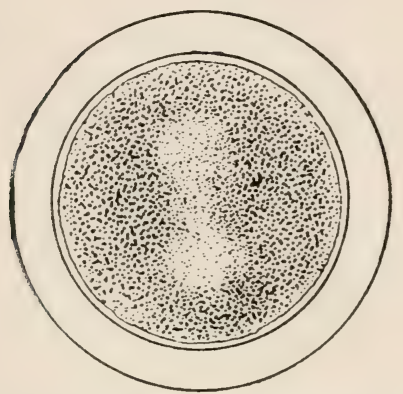

Fig. 9.-Nuclear division (spindle formation) in the egg of $S$. purpuratus.

of the axis of the spindle (Figs. 10, 11). This is probably due to the fact that the protoplasm flows to the poles of the spindle and away from its equator. Then there begins a cleavage of the protoplasm in the equatorial plane (Fig. 12), until the egg consists of two cells, each of which possesses a nucleus (Fig. 13). This process is called the segmentation of the egg.

We will now examine somewhat more closely this process of cell division or cleavage. We know two types of cell division; one corresponds to the type of separation described here. The

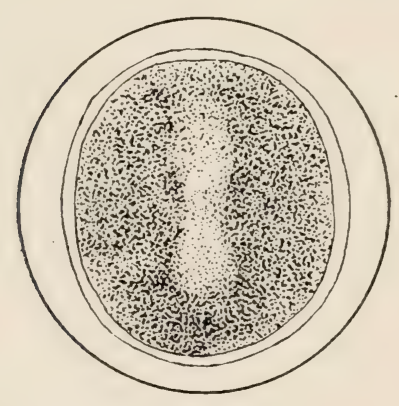

Fig. 10

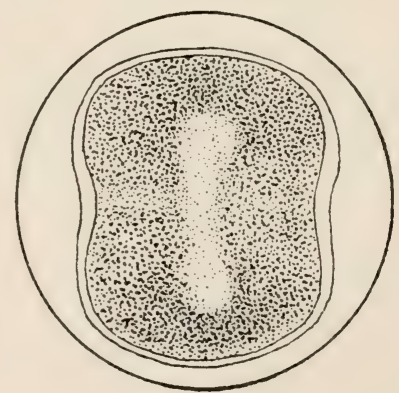

Hig. 11

FIgs. 10 and 11.-Beginning of segmentation in the egg.

second occurs in plants and consists in the formation of a solid membrane at the equator of the cell, without the two cells actually separating. At a certain stage, both types of divisions are identical, for in both certain materials are carried to the 
equatorial plane of the cell during the spindle stage. In plants these materials consist of cellulose which hardens and forms a membrane separating the two cells. In animals they consist of a different substance which possibly forms soaps (Quincke's albumin soap?) at the surface of the egg. These substances (soaps?) induce streaming phenomena, which according to the writer lead to the division of the egg into two spheres. ${ }^{1}$

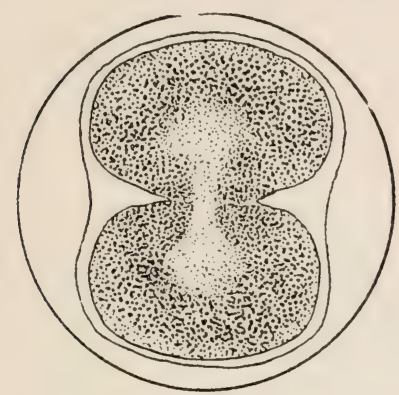

Fig. 12

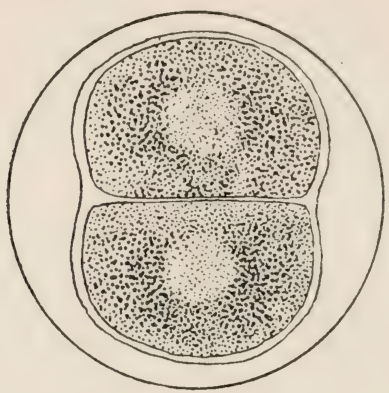

Fig. 13

Figs. 12 and 13--The first cell division completed.

T. B. Robertson has lately brought forward a pretty demonstration of this view. ${ }^{2}$ If a drop of olive oil is placed on the surface of water and upon one diameter of the drop there is laid a thread which has been previously moistened with an alkaline fluid (e.g. $\mathrm{N} / 10 \mathrm{NaOH}$ ), the drop divides into two drops, just like the sea-urchin egg in the previously described figures. By suitably varying the viscosity of the oil and other conditions one can reproduce all the phases of cell division which can be observed at cleavage during the separation of the cells. The alkali on the thread forms a soap with the oleic acid, and this soap induces streaming phenomena which lead to the splitting of the drop into two. ${ }^{3}$ In discussing the possibility of a synthe-

${ }_{1}^{1}$ Loeb, Archiv f. Entwicklungsmechanik, I, 468-70, 1896; XXVII, 138, 1909 ; Bütschli, ibid., X, 52, 1900.

2 T. B. Robertson, Archiv f. Entwicklungsmechanik, XXVII, 29, 1909.

${ }^{3}$ Loeb, The Dynamics of Living Matter, New York, 1906, pp. 55-58. 
sis of nucleins from lecithin, I have indicated that cholin must be set free in the hydrolysis of lecithin. ${ }^{1}$ Robertson assumes that this cholin, which is an alkali, may be the substance which serves to form the soap, and hence induces cell division. ${ }^{2}$ Obviously other alkalies may also be concerned. Perhaps in plants an acid substance-cellulose-is conveyed to the equatorial plane, and hence in this case a separation of the two cells does not take place, but only the formation of a solid separating membrane.

This process of cell division is now repeated for each cell. From the two-cell stage (Fig. 13) the egg goes naturally to the four-cell stage (Fig. 14), eight-cell stage (Fig. 15), etc.

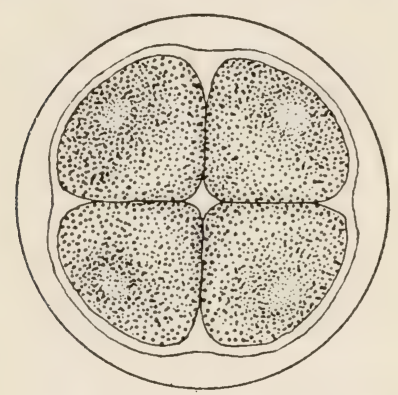

Frg. 14.-Four-cell stage of the egg of $S$. purpuratus.

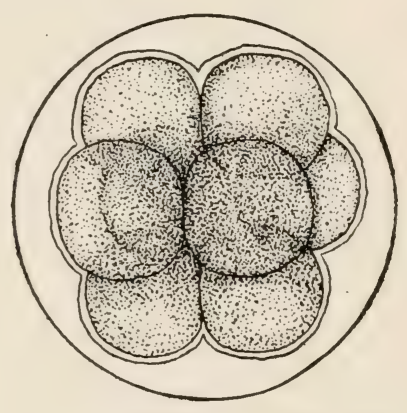
egg.

From the early stages there is a marked tendency for the single cells to creep to the surface of the egg; this may depend upon a tropism, perhaps a positive chemotropism of the cells toward oxygen. Owing to this creeping of the cells to the surface the first larval stage of the sea-urchin is a hollow sphere, the so-called blastula (Fig. 16). In this stage there appear on the outer surface of the cells cilia (which are omitted in Fig. 16)

${ }^{1}$ Loeb, Ueber den chemischen Charakter des Befruchtungsvorgangs, und seine Bedeutung für die Theorie der Lebenserscheinungen, Leipzig, 1908.

2 The interpretation of Robertson's experiment was combated by McClendon, Am. Jour. Physiol., XXVII, 240, 1910, and Archiv f. Entwicklungsmechanit, XXXIV, 263, 1912. See also T. B. Robertson, Archiv f. Entwicklungsmechanik, XXXV, 692, 1913. 
by means of which the blastula swims about. At this period, the membrane is burst by some unknown influence, and the blastula, which at first swam around within the egg sheath

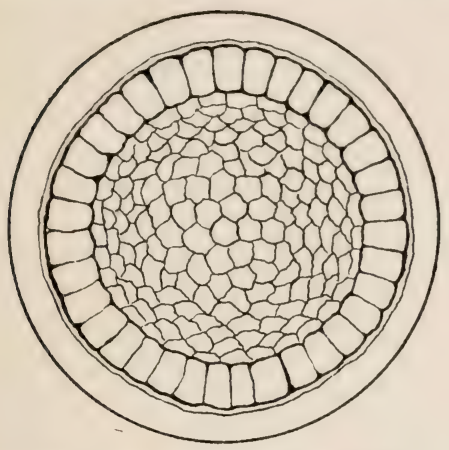

Fig 16.-Early blastula stage of the sea-urchin egg.

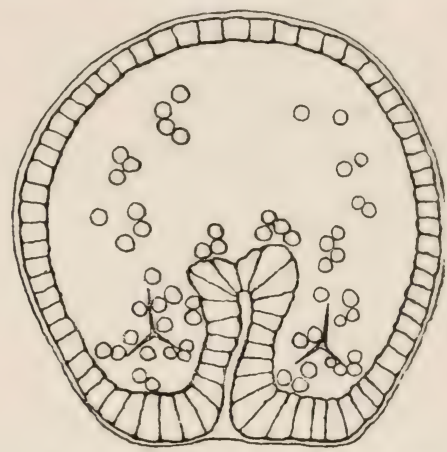

Fig. 17.-Gastrula stage of the sea-urchin egg.

(fertilization membrane), now moves about freely in the water. The larva very soon rises to the surface. The next step in the development is the gastrula stage (Fig. 17). On one side the cells grow into the blastocele and this sac or tube growing into the cavity is the rudiment of the gut. On each side of the gut can be seen indicated the rudiment of the skeleton in the form of two crystals or triasters. The further developmental stages consist in the organization of the gut into further divisions, and the outgrowth of the triasters into a larger skeleton. The originally spherical larva at the same time assumes a

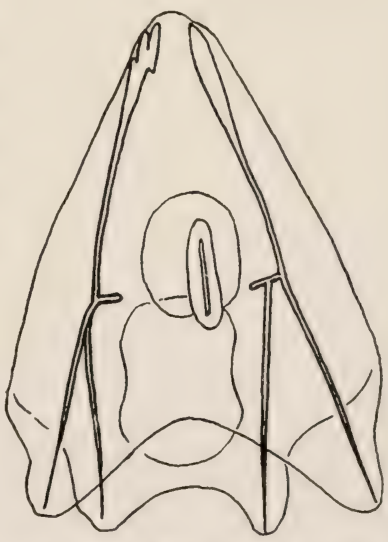

Fig. 18. - The pluteus stage of the larva of S. purpuratus. pyramidal form. It is called a pluteus (Fig. 18).

If the larvae are not fed, they live some 14 to 18 days at a temperature of about $15^{\circ}$. The further rearing is very tedious 
and difficult, as the right food of the larvae must be raised in the form of cultures. For our experiments we shall consider only the rearing of the pluteus stage. The kind of chemical activation of the egg, called in this book "improved method," causes a development in the unfertilized sea-urchin egg which in a great number of cases corresponds to the form of development of the fertilized egg just described. The first division alone usually shows small irregularities, but these disappear in later divisions. On the whole, the reader can also apply the foregoing descriptions to artificial parthenogenesis.

The experiments described in this book were performed upon eggs such as are deposited by the female in the water. Usually males and females of these forms are found together in great numbers, and on certain days both sexes in one region simuitaneously pour their sexual cells into the ocean. On the days on which a widely spread form spawns, the sea resembles a suspension of spermatozoa. The enormous numerical superiority of the spermatozoa over the eggs insures the fertilization of each egg. The view that the spermatozoon is chemotactically attracted by the egg apparently does not hold for the eggs of animals, although from time to time statements to the contrary have been published. 


\section{III}

\section{FERTILIZATION AND OXIDATION}

1. Eighteen years ago the writer showed that if freshly fertilized animal eggs (of sea-urchins and fishes) are deprived of all oxygen, no nuclear or cell division is possible. ${ }^{1}$ Godlewski $^{2}$ and Samassa ${ }^{3}$ have found the same with frog eggs, and since then I have convinced myself that it holds for the eggs: of the starfish, annelids, molluses, and probably generally. In the same way oxygen is necessary for the maturation of the egg.

In these experiments on the prevention of development of the egg by lack of oxygen, one must guard against a source of error which lies in the fact that some time must elapse before the air or oxygen has been driven out of the dish containing the egg. Since in many forms the first division of the nucleus takes place in a little less than an hour, if the temperature is high enough, and since it often requires as long, or even a longer period, to replace all the oxygen by hydrogen, it may easily happen that a nuclear, or even a cell division, may take place after the egg has been placed in the stream of hydrogen. ${ }^{4}$ I avoided this source of error by cooling with ice the vessel containing the eggs to $0^{\circ}$ for as long as appeared necessary from the foregoing experiments to replace all the oxygen by hydrogen.

${ }^{1}$ Loeb, "Die physiologische Wirkung des Sauerstoffmangels," Pflüger's Archiv, LXII, 249, 1895.

2 Godlewski, "Die Einwirkung des Sauerstoffs auf die Entwicklung von Rana, etc.," Archiv f. Entwicklungsmechanik, XI, 585, 1901.

${ }^{3}$ Samassa, Verhandl. d. naturh.-med. Vereins zu Heidelberg, IV, 1898, and Verhandl. d. deutsch. Zool. Gesellsch., 1896 (quoted from Godlewski).

${ }^{4}$ It must not be taken for granted in general that oxygen is unimportant, if the experimenter does not succeed in suppressing all signs of life after a short passage of hydrogen or nitrogen through a vessel. It must not be forgotten that it takes a long time before the last trace of oxygen is driven out, and that often a trace of oxygen is quite sufficient to render possible the life phenomenon under investigation. 
At this temperature the velocity of the chemical reactions in the egg is reduced almost to zero. On raising the temperature again, no division of the fertilized egg takes place in the hydrogen atmosphere; but on allowing air to enter the receptacle, the processes of nuclear and cell divisions are again at once resumed. Perhaps it can be still more strikingly demonstrated that oxidation is necessary for the development of the egg, by suppressing the oxidation processes by certain poisons. It has long been known that oxidations in the cell can be prevented by the addition of a little potassium cyanide, even when oxygen is present. I have found that the addition of 0.5 c.c. of a $1 / 20$ per cent $\mathrm{KCN}$ solution to 50 c.c. of sea-water is sufficient to stop almost immediately the effect of the spermatozoon in the fertilized sea-urchin egg. When, however, such an egg has been transferred to normal sea-water and good aeration has been established, its development proceeds normally, provided that the eggs have not remained too long in the potassium cyanide solution.

From these facts the writer came to the conclusion that one essential effect of the entrance of the spermatozoon into the egg of the sea-urchin is the acceleration of processes of oxidation. ${ }^{1}$ Oxidations go on also in the unfertilized egg. He concluded this from the fact that the unfertilized eggs in general disintegrate in a comparatively short time, while the addition of $\mathrm{KCN}$ or the withdrawal of oxygen prevented this disintegration, ${ }^{2}$ and he explained this phenomenon on the assumption that the oxidations in the unfertilized eggs accelerated their disintegration. The correctness of these ideas has since been proved by direct measurements.

O. Warburg was the first to measure the consumption of oxygen in the unfertilized and fertilized sea-urchin egg, Arbacia

1 Loeb, "Ueber den chemischen Charakter des Befruchtungsvorgangs," Biochem. Zeitschr., I, 183, 1906, and also preface to Untersuchungen ueber künstliche Parthenogenese, Leipzig, 1906.

${ }^{2}$ Loeb, Pflüger's Archiv, XCIII, 59, 1902. 
pustulosa, at Naples, by Winkler's method, and found that after fertilization the egg consumes from six to seven times as much oxygen as before fertilization. ${ }^{1}$ Wasteneys and I determined the consumption of oxygen in unfertilized eggs of Arbacia at Woods Hole. We found that immediately after fertilization the egg consumes almost four times as much oxygen as before fertilization. ${ }^{2}$ In experiments on Strongylocentrotus purpuratus in Pacific Grove we found that immediately after fertilization the egg consumed five to seven times as much oxygen as before fertilization. ${ }^{3}$

This difference in the rate of oxidations in the unfertilized and fertilized eggs of the sea-urchin is probably due to the fact that the unfertilized egg of the sea-urchin is usually in the resting stage, i.e., no nuclear divisions are going on in it, when it is taken out of the ovary and it generally remains in this state if no spermatozoon enters.

2. The conditions are, however, entirely different in the starfish egg. This egg is, as a rule, immature when taken out of the ovary, but as soon as it gets into the sea-water, it may become mature; i.e., two nuclear divisions take place in succession and the polar bodies are thrown out. I have shown in a former paper that this process requires the presence of free oxygen in the same way as the developing sea-urchin egg. Lack of oxygen or presence of $\mathrm{KCN}$ prevents these nuclear maturation divisions in the starfish egg with the same certainty as it does the nuclear divisions in the fertilized sea-urchin egg. ${ }^{4}$ And, moreover, I was able to show that a slightly alkaline reaction of the surrounding solution is as favorable to the process of maturation of the starfish egg as it is to the segmentation of the fertilized egg of Strongylocentrotus purpuratus.

1 O. Warburg, Zeitschr. f. physiol. Chem., LVII, 6, 1908.

2Loeb and Wasteneys, Biochem. Zeitschr., XXXVI, 351, 1911.

${ }^{3}$ Loeb and Wasteneys, Jour. Biol. Chem., XIV, 469, 1913.

"Loeb, "Maturation, Natural Death and the Prolongation of the Life of Unfertilized Starflsh Eggs," Biol. Bull., III, 295, 1902. 
All these observations point to the conclusion that the processes determining or underlying nuclear division depend upon oxidations.

The eggs of the starfish must be fertilized at the time the second polar body is given off or immediately afterward, since otherwise they disintegrate and cannot be fertilized at all. When we compare the rate of oxidations in starfish eggs immediately before and after fertilization, we find no difference, as Table I shows. It should be remarked that while as a rule 100 per cent of the sea-urchin eggs can be fertilized by sperm, in the case of starfish eggs a much smaller percentage is usually fertilized since in most cases not all the eggs become mature simultaneously.

TABLE $I^{1}$

\begin{tabular}{|c|c|c|c|}
\hline Number of Experiment & $\begin{array}{c}\text { Consumption of } \\
\text { Oxygen of the } \\
\text { Unfertilized Eggs }\end{array}$ & $\begin{array}{l}\text { Consumption of } \\
\text { Oxygen of the } \\
\text { Fertilized Eggs }\end{array}$ & $\begin{array}{l}\text { Percentage of } \\
\text { Fertilized Eggs }\end{array}$ \\
\hline $\begin{array}{l}\text { I } \\
\text { II } \\
\text { III } \\
\text { IV } \\
\text { IV } \\
\text { V. }\end{array}$ & $\begin{array}{l}0.67 \mathrm{mg} . \\
0.64 \\
0.78 \\
0.34 \\
0.26\end{array}$ & $\begin{array}{l}0.51 \mathrm{mg} . \\
0.52 \\
0.85 \\
0.31 \\
0.33\end{array}$ & $\begin{array}{l}11 \\
20 \\
25 \\
71 \\
52\end{array}$ \\
\hline
\end{tabular}

It is obvious that no noticeable increase in the rate of the oxidation is caused in this egg through the entrance of the spermatozoon. This is intelligible from the fact that those oxidations which lead to nuclear division were already going on in the eggs at the time the spermatozoon entered.

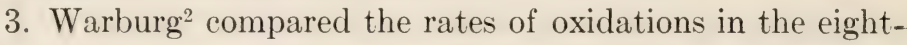
cell stage and the thirty-two-cell stage. Their ratio was as $4 \cdot 2$ to $6 \cdot 8$; a slight increase. Wasteneys and $\mathrm{I}^{3}$ measured the change in the rate of oxidations each hour for five consecutive hours after fertilization in the eggs of Arbacia at Woods

${ }^{1}$ Loeb and Wasteneys, Archiv f. Entwicklungsmechanik, XXXV, 556, 1912.

2 Warburg, Zeitschr. f. physiol. Chem., LVII, 1, 1908.

${ }^{3}$ Loeb and Wasteneys, Biochem. Zeitschr., XXXVI, 351, 1911. 
Hole. The same eggs served as material for these determinations. Temperature, $23^{\circ} \mathrm{C}$.

Consumption of oxygen per hour before fertilization $0.24 \mathrm{mg}$. 1st hour after fertilization $0.94 \mathrm{mg}$. $2 \mathrm{~d}$ hour after fertilization $0.80 \mathrm{mg}$. 3d hour after fertilization $0.87 \mathrm{mg}$. 4th hour after fertilization $0.91 \mathrm{mg}$. 5 th hour after fertilization $1.05 \mathrm{mg}$.

The value for the hour following fertilization is probably a little too high on account of the presence of sperm, which was washed away after the first determination. That this assumption is correct is shown by a repetition of the experiment.

Consumption of oxygen per $1 \frac{1}{2}$ hours in fertilized egg-

$\begin{aligned} \text { first } 1 \frac{1}{2} \text { hours } & 0.67 \mathrm{mg} . \\ \text { second } 1 \frac{1}{2} \text { hours } & 0.74 \mathrm{mg} . \\ \text { third } 1 \frac{1}{2} \text { hours } & 0.83 \mathrm{mg} .\end{aligned}$

The consumption of oxygen increased about 24 per cent in $4 \frac{1}{2}$ hours. During this same time the eggs developed from the one-cell stage to the thirty-two-cell stage or beyond.

The question arises, What causes this increase? The question cannot be answered definitely. During the division the total surface of the egg increases. But it must be remembered that the blastomeres are in close contact with each other and that hence only a fraction of their surface is exposed to the surrounding medium. If the intensity of oxidations increases with the total free surface of the eggs, the slight increase of the rate of oxidations with the process of segmentation might be intelligible.

But this is not the only possibility. It had been stated by Boveri that in each cell division the mass of the nucleus doubled, so that in the eight-cell stage the total nuclear mass would be eight times as great as in the one-cell stage. But this has been denied by more recent workers like Miss Erdmann and Conklin. ${ }^{1}$

${ }^{1}$ Conklin, "Cell Size and Nuclear Size," Jour. Exper. Zool., XII, 1, 1912. 
According to Conklin, the average nuclear growth during cleavage is not more than 5 per cent to 9 per cent for each division up to the thirty-two-cell stage. The possibility remains that the slight increase in the rate of oxidations with progressive cell divisions is due to the increase of the mass of the nuclei. This would be intelligible on the assumption that the rate of oxidation is in proportion to the mass of the nuclei. Such a view would harmonize with the suggestion expressed formerly by the writer, that the nucleus might be the main (although not the only) oxidizing organ of the cell. ${ }^{1}$

4. The observation that the nucleus of the fertilized egg remains unaltered during lack of oxygen or presence of potassum cyanide shows that oxidations are the prerequisites of the mechanical processes of nuclear and cell division. It can, however, be shown that aside from oxidations other chemical processes are accelerated in the sea-urchin egg by the process of fertilization. When fertilized eggs of Strongylocentrotus purpuratus are left in sea-water free from oxygen for twentyfour hours at $15^{\circ} \mathrm{C}$., they will not develop during that time, but they will begin to develop at once if oxygen is admitted. It will be found, however, that their development is no longer normal, since they form abnormal blastulae and never or rarely reach the gastrula stage. If unfertilized eggs are kept for twenty-four hours without oxygen they remain perfectly normal, since upon addition of sperm they develop normally and reach the pluteus stage. The result is the same if instead of withdrawing the oxygen we retard the oxidations by the addition of $\mathrm{KCN}$.

Unfertilized and fertilized eggs of the same female were placed in a bowl with 50 c.c. of sea-water +2 c.c. $1 / 20$ per cent KCN solution. ${ }^{2}$ At different intervals, samples of these eggs

1 Loeb, Archiv f. Entwicklungsmechanik, VIII, 689, 1899. Some authors attribute to me the opinion that in the protoplasm no oxidations occur. I have never expressed such an opinion.

2 Such a solution stops the segmentation in fertilized eggs. 
were replaced in normal sea-water. Sperm was added to the unfertilized eggs after their transference to ordinary sea-water. The unfertilized eggs, which had been in the sea-water containing potassium cyanide for two days, developed in quite a normal manner, whereas the eggs which had been fertilized before they were put into the cyanide sea-water were no longer able to develop beyond the blastula stage after an exposure of only twenty-four hours to this solution. An exposure of five hours' duration to the cyanide sea-water was already harmful to the fertilized eggs; this was shown by the fact that while such eggs did develop after transference to ordinary sea-water, many larvae died during the first two days. ${ }^{1}$

These experiments leave no doubt that fertilization gives rise to a class of chemical reactions in the egg which can proceed independently of oxidations. It is very likely that other reactions besides oxidations, e.g., hydrolyses, take place in the egg. If such hydrolyses lead to the formation of harmful oxidizable substances, e.g., lactic acid, it can be understood why lack of oxygen must in time lead to the death of the fertilized egg; without oxygen the harmful substances, which are quickly rendered harmless by oxidation (or converted into substances like $\mathrm{CO}_{2}$, which can be eliminated), can now accumulate in the cell. Assuming that such hydrolyses are set up in the egg by fertilization, while they are lacking or are very slow in the unfertilized egg, we could understand why the fertilized egg suffers more quickly than the unfertilized egg from lack of oxygen or from the prevention of oxidations by potassium cyanide.

5. Wasteneys and the writer raised the question whether the oxidations are the independent variable in the development of the egg. ${ }^{2} \quad$ From all we know, we should expect that hydrolyses

${ }^{1}$ Loeb, "Versuche ueber den chemischen Charakter des Befruchtungsvorgangs," Biochem. Zeitschr., I, 189, 1906.

${ }^{2}$ Loeb and Wasteneys, "Sind die Oxydationsvorgänge die unabhängige Variable in den Lebenserscheinungen ?" Biochem. Zeitschr., XXXVI, 345-56, 1911. 
are the independent variable, and that the oxidations are determined or regulated by the hydrolytic processes. Our investigations do not contradict such a view. Since we are not able to measure the hydrolytic processes in the egg directly, we tried to solve our problem with the aid of the temperature coefficient. We determined the temperature coefficient for the velocity of segmentation in the egg of Arbacia by measuring the time which elapses from the moment of fertilization to the moment of the division of the egg into two cells for various temperatures. Then we measured the influence of the same variation of temperature upon the rate of oxidations in the cell. If the oxidations were the independent variable for the development of the egg the temperature coefficients for both processes should be identical or run parallel. This is, however, not the case. The experiments were made on the eggs of Arbacia at Woods Hole.

The time which elapsed between fertilization and the first segmentation was as follows:

TABLE II

\begin{tabular}{|c|c|c|c|}
\hline Temp. Deg. C. & $\begin{array}{c}\text { Time Required for } \\
\text { First Segmentation } \\
\text { Minutes }\end{array}$ & Temp. Deg. C. & $\begin{array}{l}\text { Time Required for } \\
\text { First Segmentation } \\
\text { Minutes }\end{array}$ \\
\hline $\begin{array}{r}7 \ldots \ldots \ldots \\
8 \ldots \ldots \\
9 \ldots \ldots \\
10 \ldots \ldots \\
12 \ldots \ldots \\
15 \ldots \ldots \\
16 \ldots \ldots \\
17 \frac{1}{2} \ldots \ldots \\
18 \ldots \ldots \\
18 \ldots \\
\end{array}$ & $\begin{array}{l}498 \\
410 \\
308 \\
217 \\
4+143^{*} \\
3 \frac{1}{2}+96 \frac{1}{2} \\
2+83 \frac{1}{2} \\
2 \frac{1}{2}+68 \\
68\end{array}$ & 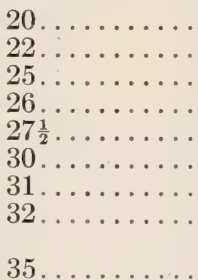 & $\begin{array}{l}56 \\
4+43 \\
3 \frac{1}{2}+36 \frac{1}{2} \\
2+31 \frac{1}{2} \\
2 \frac{1}{2}+31 \frac{1}{2} \\
33 \\
37 \\
\text { No segmentation; } \\
\quad \text { eggs suffered }\end{array}$ \\
\hline
\end{tabular}

* Where the times are given in the form of a sum the eggs were put into the thermostat as many minutes after fertilization as the first figure indicates.

The temperature coefficients for segmentation are the greater the lower the temperature. For the interval $7^{\circ}-17^{\circ}$ the coefficient is more than three times as large as for the interval $17.5^{\circ}-27.5^{\circ}$ (Table III). 
TABLE III

\begin{tabular}{|c|c|c|c|}
\hline $\begin{array}{l}\text { Interval of } \\
\text { Temperature }\end{array}$ & $\begin{array}{l}\text { Temperature Co- } \\
\text { efficient for } 10^{\circ} \mathrm{C} \text {. } \\
\text { for the Velocity of } \\
\text { Segmentation in } \\
\text { the Egg of Arbacia }\end{array}$ & $\begin{array}{l}\text { Interval of } \\
\text { Temperature }\end{array}$ & $\begin{array}{l}\text { Temperature Co- } \\
\text { efficiont for } 10^{\circ} \mathrm{C} \text {. } \\
\text { for the Velocity of } \\
\text { Segmentation in } \\
\text { the Egg of Arbacia }\end{array}$ \\
\hline $\begin{array}{r}7^{\circ}-17^{\circ} \ldots \ldots \\
8^{\circ}-18^{\circ} \ldots \ldots \\
9^{\circ}-19^{\circ} \ldots \ldots \\
10^{\circ}-20^{\circ} \ldots \ldots \\
12^{\circ}-22^{\circ} \ldots \ldots\end{array}$ & $\begin{array}{r}7.3 \\
6.0 \\
\geq 4.0 \\
3.9 \\
3.3\end{array}$ & $\begin{array}{l}15^{\circ}-25^{\circ} \ldots \ldots \\
16^{\circ}-26^{\circ} \cdots \\
17.5^{\circ}-27.5^{\circ} \cdots \\
20^{\circ}-30^{\circ} \ldots\end{array}$ & $\begin{array}{l}2.6 \\
2.6 \\
2.2 \\
1.7\end{array}$ \\
\hline
\end{tabular}

A determination of the temperature coefficient of oxidations in the egg of Arbacia did not show such a variation.

TABLE IV

\begin{tabular}{c|c||c|c}
\hline $\begin{array}{c}\text { Interval of } \\
\text { Temperature }\end{array}$ & $\begin{array}{c}\text { Temperature Co- } \\
\text { efficient for } 10^{\circ} \\
\text { for the Velocity of } \\
\text { Oxidations }\end{array}$ & $\begin{array}{c}\text { Interval of } \\
\text { Temperature }\end{array}$ & $\begin{array}{c}\text { Temperature Co- } \\
\text { efficient for 10 } \\
\text { for the Velocity of } \\
\text { Oxidations }\end{array}$ \\
\hline $3^{\circ}-13^{\circ} \ldots \ldots \ldots \ldots$ & 2.18 & $15^{\circ}-25^{\circ} \ldots \ldots \ldots \ldots$ & 2.24 \\
$5^{\circ}-15^{\circ} \ldots \ldots \ldots \ldots$ & 2.16 & $17^{\circ}-27^{\circ} \ldots \ldots \ldots \ldots$ & 2.00 \\
$7^{\circ}-17^{\circ} \ldots \ldots \ldots \ldots$ & 2.00 & $20^{\circ}-30^{\circ} \ldots \ldots \ldots \ldots$ & 1.96 \\
$10^{\circ}-20^{\circ} \ldots \ldots \ldots \ldots$ & 2.17 & $22^{\circ}-32^{\circ} \ldots \ldots \ldots \ldots$ & 1.40 \\
$13^{\circ}-23^{\circ} \ldots \ldots \ldots \ldots$ & 2.45 & & \\
\hline
\end{tabular}

The temperature coefficients of oxidations for a difference of $10^{\circ} \mathrm{C}$. are practically identical throughout. For the interval $7^{\circ}-17^{\circ}$ the coefficient is 2.0 and for $17^{\circ}-27^{\circ}$ it is also 2.0 . This result points toward the probability that the rate of cell division is not directly determined by the rate of oxidations, although the possibility exists that besides the influence of temperature upon the velocity of chemical reactions an influence upon some physical property of the egg is superposed (e.g., viscosity) which makes itself felt only or chiefly at the lower temperatures and becomes the stronger the lower the temperature.

6 . The writer has shown that segmentation and development can go on only if the concentration of the $\mathrm{HO}$ ions in the surrounding solution reaches a certain height; this height is 
greater for the egg of Strongylocentrotus purpuratus than for Arbacia.

Sea-water is, according to van't Hoff, a mixture of the following composition: 100 molecules $\mathrm{NaCl}, 2.2$ molecules $\mathrm{KCl}$, 1.5 molecules $\mathrm{CaCl}_{2}, 7.8$ molecules $\mathrm{MgCl}_{2}$, and 3.8 molecules $\mathrm{MgSO}_{4} \cdot{ }^{1}$ To this, traces of $\mathrm{NaHCO}_{3}$ and $\mathrm{Na}_{2} \mathrm{HPO}_{4}$ are to be added. The osmotic pressure of the ocean water shows local variations. The eggs of the animals in Pacific Grove develop best if the salts are used in a half grammolecular concentration. For the fauna in Woods Hole, on the Atlantic, a slightly higher concentration, about $21 / 40 \mathrm{~m}$ is, perhaps, the optimum, although $\mathrm{m} / 2$ solutions give almost the same result. Solutions of $25 / 40 \mathrm{~m}$ are decidedly injurious.

The reaction of the sea-water is slightly alkaline. In Pacific Grove the concentration of the free $\mathrm{HO}$ ions of the sea-water seems to lie between $10^{-6}$ and $10^{-5} \mathrm{~N}$, since it is alkaline to neutral red but not to phenolphthalein. The concentration of the $\mathrm{HO}$ ions in the sea-water at Woods Hole is slightly higher and may reach $10^{-5} \mathrm{~N}$.

If we make $\mathrm{m} / 2$ solutions containing $\mathrm{NaCl}, \mathrm{KCl}, \mathrm{CaCl}_{2}$, $\mathrm{MgCl}_{2}$, and $\mathrm{MgSO}_{4}$ in the right proportion, the newly fertilized eggs of Strongylocentrotus will, as a rule, not be able to develop to the larval stage in such a solution, unless the $\mathrm{C}_{\mathrm{HO}}$ is above $10^{-7} \mathrm{~N}$. The eggs of various females differ slightly in their minimum $\mathrm{C}_{\mathrm{HO}}$. It is, of course, necessary to free the eggs carefully from all traces of sea-water by washing them repeatedly in neutral solutions before submitting them to the experiment.

A van't Hoff solution was prepared. The $\mathrm{C}_{\mathrm{HO}}$ was about $10^{-7} \mathrm{~N}$, i.e., the solution was neutral. To 50 c.c. of this solution were added $0,0.1,0.2,0.4$, and $0.8 \mathrm{~N} / 100 \mathrm{KOH}$. Newly fertilized eggs of Strongylocentrotus purpuratus were put into these solutions. In the neutral solution no egg developed

1 We will call this solution for the sake of brevity the van't Hoff solution. 
beyond the four- to eight-cell stage. Addition of 0.1 c.c. $\mathrm{N} / 100$ $\mathrm{KOH}$ allowed a few eggs to reach the blastula stage; addition of 0.2 c.c. $\mathrm{N} / 100 \mathrm{KOH}$ allowed 60 per cent to reach the blastula stage and with 0.4 and 0.8 c.c. $\mathrm{N} / 100 \mathrm{KOH}$ all the eggs developed into larvae.

If we add more $\mathrm{KOH}$ to 50 c.c. of the van't Hoff solution, we find that the addition of 0.4 c.c. $\mathrm{N} / 10 \mathrm{KOH}$ interferes already with their development; if we add 0.8 c.c. $\mathrm{N} / 10 \mathrm{KOH}$, or more, to 50 c.c. van't Hoff solution, no egg can segment. ${ }^{1}$

If one wishes to obtain the best type of larvae it is better to add varying concentrations of $\mathrm{NaHCO}_{3}$. If to 50 c.c. of the neutral van't Hoff solution are added $0,0.1,0.2,0.4,0.8,1.0$, 2.0 c.c. $\mathrm{m} / 20$ solution of $\mathrm{NaHCO}_{3}$; in the solution without and with only 0.1 c.c. $\mathrm{NaHCO}_{3}$ only early segmentations take place; in all the other solutions the eggs will develop into larvae. In the solution with 1.0 c.c. or more $\mathrm{NaHCO}_{3}$ the eggs already suffer.

It seems that the faintly alkaline solution is chiefly necessary only for the first development of the eggs of purpuratus. Later they are able to develop in a neutral but not in an acid solution. The lowest $\mathrm{C}_{\mathrm{HO}}$ for the development of the egg of Arbacia at Woods Hole is about $10^{-10} \mathrm{~N}$, i.e., these eggs can begin to develop not only in a neutral but even in a faintly acid solution. This difference between the two kinds of eggs may be of some importance in regard to the difference in their response to the agencies of artificial parthenogenesis, as we shall see later.

The writer published years ago a paper in which he showed that the development of the eggs of Arbacia is retarded and finally inhibited if increasing quantities of acid are added to the sea-water. He has since vainly attempted to show that the rate of development of the sea-urchin egg can be increased with the increase of the concentration of hydroxylions in the

${ }^{1}$ Loeb, Biochem. Zeitschr., II, 88, 1906. 
sea-water. This leads him to believe that these eggs develop best in a solution in which the concentration of hydroxylions equals that of the sea-water; and that while it is possible to delay their development by a lowering of this concentration, no acceleration can be produced if the $\mathrm{C}_{\mathrm{OH}}$ in the sea-water is raised. This statement is corroborated by the fact referred to above that the addition of some $\mathrm{NaHCO}_{3}$ is more favorable for the development of the larvae than the addition of $\mathrm{NaOH}$.

7. Warburg states that it is possible to raise the rate of oxidations in the fertilized egg through the addition of $\mathrm{NaOH}$, but not by the addition of $\mathrm{NH}_{4} \mathrm{OH}$. Since he was able to show that $\mathrm{NH}_{4} \mathrm{OH}$ diffuses into the cell while $\mathrm{NaOH}$ does not, he concludes from this and a similar observation" "that all the substances which increase the oxidations in the fertilized eggs belong to that class which according to Overton cannot enter into the living cell" (p. 328). "The influence of an increase of the concentration of the $\mathrm{HO}$ ions upon respiration is neither determined by the entrance of ions into the eggs, nor by their reacting with the membrane of the cytoplasm, but merely by their presence in the solution surrounding the egg" (p. 314). Warburg quotes determinations of the oxygen consumption of newly fertilized eggs of Strongylocentrotus at Naples for three different concentrations of $\mathrm{NaOH}, 10^{-8} \mathrm{~N}, 10^{-6} \mathrm{~N}$, and $10^{-3} \mathrm{~N}$. The ratio of these oxidations in three solutions was $1.4: 3.9: 8$. 1 . Only in one of these three solutions did the eggs develop, namely, in the one with the $\mathrm{C}_{\mathrm{OH}} 10^{-6} \mathrm{~N}$. Of the two others the one was too acid, the other too alkaline. $\mathrm{NH}_{4} \mathrm{OH}$ did not raise the rate of oxidations perceptibly.

${ }^{1}$ Warburg, "Ueber die Oxydationen in lebenden Zellen nach Versuchen am Seeigelei," Zeitschr. f. physiol. Chem., LXVI, 305, 1910. The other observation not discussed in the text refers to an increase of oxidations in the fertilized egg under the influence of hypertonic solution. Wasteneys and I were not able to confirm this statement of Warburg; we found that the oxidations in the fertilized egg of Strongylocentrotus purpuratus are not increased if the eggs are put into a hypertonic solution. 
These experiments might give the reader two impressions, first, that the rate of oxidation increases steadily with the concentration of hydroxylions or of the $\mathrm{NaOH}$ in the surrounding solution; and, second, that the normal oxidations take place at the surface of the egg. Experiments made by Wasteneys and the writer, however, do not warrant such conclusions. The experiments were made on the eggs of Strongylocentrotus purpuratus in Pacific Grove and consisted in a more complete determination of the effect of varying concentrations of $\mathrm{NaOH}$ and $\mathrm{NH}_{4} \mathrm{OH}$ upon the oxidations. ${ }^{1}$

TABLE V

\begin{tabular}{|c|c|c|c|}
\hline $\begin{array}{c}\text { Amount of } \mathrm{NaOH} \text { Added to } \\
50 \text { c.c. } \mathrm{m} / 2 \mathrm{NaCl}^{\mathrm{NaCl}}{ }_{2}\end{array}$ & $\begin{array}{c}\text { Coeffi- } \\
\text { cient of } \\
\text { Oxida- } \\
\text { tions }\end{array}$ & $\begin{array}{c}\text { Amount of } \mathrm{NaOH} \text { Added to } \\
50 \text { c.c. } \mathrm{m} / 2 \mathrm{NaCl}^{2} \mathrm{KCl}+ \\
\mathrm{CaCl}_{2}\end{array}$ & $\begin{array}{l}\text { Coeffi- } \\
\text { cient of } \\
\text { Oxida- } \\
\text { tions }\end{array}$ \\
\hline 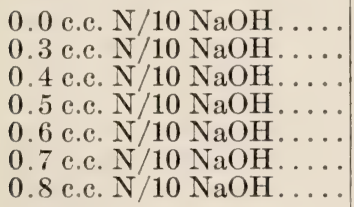 & $\begin{array}{l}1.00 \\
1.08 \\
1.08 \\
1.13 \\
1.18 \\
1.17 \\
1.51(?)\end{array}$ & $\begin{array}{l}0.9 \text { c.c. } \mathrm{N} / 10 \mathrm{NaOH} \ldots \\
1.0 \text { c.c. } \mathrm{N} / 10 \mathrm{NaOH} \ldots \\
1.1 \text { c.c. } \mathrm{N} / 10 \mathrm{NaOH} \ldots \\
1.2 \text { c.c. } \mathrm{N} / 10 \mathrm{NaOH} \ldots \\
1.3 \text { c.c. } \mathrm{N} / 10 \mathrm{NaOH} \ldots \\
1.4 \text { c.c. } \mathrm{N} / 10 \mathrm{NaOH} \ldots\end{array}$ & $\begin{array}{l}1.44 \\
1.55 \\
1.87 \\
1.93 \\
2.12 \\
\text { Eggs } \\
\text { injured }\end{array}$ \\
\hline
\end{tabular}

This and similar experiments show very plainly that the addition of even 0.5 c.c. or 0.7 c.c. $\mathrm{N} / 10 \mathrm{NaOH}$ to 50 c.c. $\left(\mathrm{m} / 2 \mathrm{NaCl}+\mathrm{KCl}+\mathrm{CaCl}_{2}\right)$ does not raise the rate of oxidations noticeably; and that a considerable rise in the rate of oxidations does not take place until more than 0.8 c.c. $\mathrm{N} / 10 \mathrm{NaOH}$ has been added. These concentrations can no longer be considered normal, since an addition of from 0.2 to 0.4 c.c. $\mathrm{N} / 10 \mathrm{NaOH}$ to 50 c.c. $\left(\mathrm{NaCl}+\mathrm{KCl}+\mathrm{CaCl}_{2}\right)$ suffices already to suppress the development of the egg. It is therefore obvious that the increase of the rate of oxidations in the unfertilized egg, under the influence of excessive quantities of $\mathrm{NaOH}$, cannot be utilized for any conclusions upon the

${ }^{1}$ Loeb and Wasteneys, Jour. Biol. Chem., XIV, 459, 1913. 
normal oxidations in the sea-urchin egg. On the contrary, our experiments prove definitely that low concentrations of $\mathrm{NaOH}$ have practically no effect upon the rate of oxidations.

All the facts become intelligible on the assumption that the increase in oxidations under the influence of high concentrations of $\mathrm{NaOH}$ is due to an injurious (a kind of etching?) effect of the latter; this would make it clear why the weak bases, such as $\mathrm{NH}_{4} \mathrm{OH}$, do not produce an increase in the rate of oxidations and why low concentrations of $\mathrm{NaOH}$ have no effect either. The fact that $\mathrm{NH}_{4} \mathrm{OH}$ enters the egg, while $\mathrm{NaOH}$ does not, has probably nothing to do with this result.

The energetics of development-the nature of the substances which undergo oxidation, and the way the energy is utilized-has been investigated by Tangl ${ }^{1}$ and his pupils, by Bohr and Hasselbalch, ${ }^{2}$ and by Meyerhof. ${ }^{3} \quad$ Since the experiments on artificial parthenogenesis are not so intimately connected with these experiments as with those on oxidation, we may be pardoned for not discussing them in this book.

1 Tangl, Pfüger's Archiv, XCIII, 327; XCVIII, 490; CIV, 624; CXXI, 437; Biochem. Zeitschr., XLIV, 180, 1912.

2 Skand. Arch., XIV, 398, 1903.

3 Yleyerhof, Biochem. Zeitschr., XXXV, 246, 1911. 


\section{IV}

\section{HYDROLYTIC PROCESSES IN THE GERMINATION OF OIL-CONTAINING SEEDS}

Since we mentioned the fact that in the fertilized egg hydrolytic processes (or at least reactions other than oxidations) take place, and since little or nothing is known about these reactions in animal eggs, a discussion of the processes occurring in germinating oily seeds may be of interest. As an example, the investigations of Hoyer with Connstein and Wartenberg may be used. The experiments were earried out by Hoyer.

If castor beans are ground up with water, and the resulting seedoil emulsion (seed-milk) is left, alone for a few days, there is observed after a time a sudden, rapid increase of the mass of acid, whereby the neutral oil contained in the castor bean is converted into acid and glycerin. This observation, made for the first time some four years ago, was the starting-point for the investigation of the decomposition of fat by means of the lipolytic ferments contained in plant seeds, and especially in those of the castor bean. This ferment, which has been worked at ever since from several sides, has been used successfully as a technical fat-splitting process.

On the establishment of the conditions mentioned, i.e., the grinding up of the seeds, the fat-splitting effect of the castor bean ferment does not set in for some time, but then it occurs suddenly. We recognized the reason for the appearance of this sudden action in the fact that an intensification of the decomposition of the fat only occurs when a sufficient mass of acid is present. For the fat-splitting effect of the castor bean can be at once produced, if at the start a certain small quantity of aeid or the salt of an acid be added to the mass. This amount differs according to the kind of acid. In a later publication of mine the amounts of these acids have been accirately determined; whence it appears that of the acids examined, butyric allows the widest latitude with regard to the quantity employed, whilst sulphuric and oxalic, for example, require a very close adherence to their proportionate quantities. ${ }^{1}$

1 Hoyer, "Ueber fermentative Fettspaltung," Zeitschr. f. physiol. Chem., L, 414, 1907 . 
The many researches of Hoyer next aimed at ascertaining what was the nature of the acid which is formed in the seed itself and conditions the sudden increase in the hydrolysis of the oil in the germinating seed. It is found to depend mainly upon lactic and carbonic acids, together with a relatively small amount of acetic and formic acids. There occur therefore two fundamental processes in the conversion of the oil in germination. One process is the fermentative production of acids: lactic, carbonic, acetic, and formic; the second process, which depends upon the first, is the "activation" of the lipolytic enzyme through the acid produced in the seed.

Investigations with the acids produced in the seed itself elicited the fact that these acids are able to produce the fatsplitting effect in the castor bean. One fact, which is of biological importance, may be mentioned here. If Hoyer chose for his investigation a castor bean that had hardly begun to germinate, and cut it in half (after washing it), it appeared that the oil-splitting enzyme had a weaker effect in the half of the seed which contained the embryo than in the half separated from the embryo. In well germinated seeds there was practically no more ferment present. "In the life history of the castor bean, the ferment becomes inoperative after the performance of its fat-splitting function in the same proportion as the castor oil is prepared for the growth of the embryo."1

These investigations give us an idea of the complicated character of the processes in the development of the embryo. The taking-up of water leads to a process of hydrolysis in the seed, of which the end-products are certain acids-lactic and carbonic. These acids serve, according to Hoyer's description, for the "activation" of the lipase contained in the castor bean. As in all analyses of life phenomena, we are here too dealing with a catenary series of reactions. It seems that in the sea-urchin $S$. purpuratus also a sudden increase in the acid

${ }_{1}^{1}$ Hoyer, Ber. d. deutsch. chem. Ges., XXXVII, 1436, 1904. 
content takes place upon fertilization. When two drops of a $1 / 100$ grammolecular solution of neutral red are added to 50 c.c. of sea-water, the sea-water immediately assumes a yellow color, owing to its alkaline reaction.

If now unfertilized and freshly fertilized eggs of the sea-urchin Strongylocentrotus purpuratus are placed at the same time in this solution, both kinds of eggs quickly take on a red color. But if, after 20 to 40 minutes, they are brought back into normal colorless sea-water, the unfertilized eggs gradually lose their color, while the fertilized eggs become a still deeper red. One receives the impression that, while the unfertilized eggs give up again the coloring matter to the surrounding sea-water, the fertilized eggs continue to take it up. After about an hour, therefore, two kinds of eggs are to be found in the bowl of sea-water, some colorless, or very slightly colored, and others colored a deep red; the latter are, without exception, eggs which possess a membrane and, later on, segment-being therefore fertilized eggs, while the colorless eggs possess no membrane and are unfertilized. Neutral red is an alkaline coloring matter, and therefore combines in the egg with an acid. This retention of neutral red indicates that it is held in closer combination in the fertilized than in the unfertilized egg, where it can be quickly lost. ${ }^{1}$

The yolk of the egg contains a relatively large amount of fat and lipoids. The eggs of most invertebrates are small, not very far from the limit of vision of the unaided eye. Nevertheless they contain reserve materials in relatively large quantities, and among these reserve substances are found fats or lipoids. Now it is quite possible, if not probable, that the commencement of development in plant embryos possesses certain points in common with that in the eggs of animals, viz., in regard to the rôle of the decomposition of fats or lipoids. But it must also be borne in mind that the fats or lipoids require a somewhat different treatment, according as they are the more solid or liquid. In oil-containing plant seeds we have to deal mostly with liquid oils; in animals the solid palmitin and stearin fats

1 Loeb, "Weitere Beobachtungen ueber den Einfluss der Befruchtung und der Zahl der Zellkerne auf die Säurebildung im Ei," Biochem. Zeitschr., II, 34, 1906. 
predominate. One can understand that for the utilization of such solid fats in the egg, a process must come into play, which is superfluous in seeds that contain oil, on account of the original fluid state of the oil: that process is the liquefaction of the fat. We have already mentioned that this circumstance can be taken into consideration in the membrane formation of eggs. It may, in a word, depend upon the fact that at membrane formation the fats or lipoids are converted into a form in which they can be more easily decomposed or oxidized.

A clearer analogy between the germination of the seed and the development of the egg is the fact, already proved by Moritz Traube, ${ }^{1}$ that the germination of the seed too is only possible in the presence of free oxygen. In the beginning of germination in the seed, just as in the beginning of development in the egg, we are dealing with a causation of syntheses out of the constituent parts of the cytoplasm, and for this process free oxygen is necessary; and moreover, nuclear and cell division are also concerned, for which, likewise, free oxygen is necessary.

${ }_{1}^{1}$ Moritz Traube, Gesammelte Abhandlungen, Berlin, 1896, p. 148. 


\section{SOME EARLIER OBSERVATIONS ON NATURAL PAR- THENOGENESIS IN INSECTS}

Long before the importance of the spermatozoon in fertilization was fully recognized, Réaumur, Bonnet, and a number of other eighteenth-century authors had established the fact that plant lice bring forth living young without previously pairing. Kirby ${ }^{1}$ found that under ordinary conditions of temperature and moisture, the parthenogenetic generations of aphides can follow one another for four years (possibly indefinitely) without as a rule giving rise to males. Only under special conditions do plant lice produce both sexes, which then pair. This pairing leads to the laying of eggs from which hatch, without exception, parthenogenetic females that give birth to living young.

These observations led entomologists to search for further cases of parthenogenesis. It was soon discovered that certain butterflies, belonging to the genus Solenobia, lay unfertilized eggs $^{2}$ which develop eventually in a thoroughly normal manner into butterflies. Von Siebold, who repeated and confirmed these investigations, also found parthenogenetic reproduction in another butterfly, Psyche helix, ${ }^{3}$ of which the males were quite unknown at that time. In all these cases not only were the larvae arising from the unfertilized eggs normal, but they also developed into perfectly normal sexually mature insects.

But the greatest sensation was aroused by the observations of Dzierzon on parthenogenesis in bees. ${ }^{4}$ He was led to the

${ }^{1}$ Quoted after Ratzeburg, Die Forstinsekten, Part III, 1844.

2 We gather from von Siebold's monograph that these facts were first discovered by DeGeer. 1856.

${ }^{3}$ Von Siebold, Wahre Parthenogenese bei Schmetterlingen und Bienen, Leipzig,

4 According to von Siebold, Dzierzon first published his observations and conclusions in the year 1845 (in the Eichstädter Bienenzeitung). 
conclusion that male bees-the drones-arise from unfertilized eggs, workers and queens, on the other hand, from fertilized eggs. He discovered that the queen copulates only once in her life, and that this never takes place in the hive, but in the air, during the so-called nuptial flight. After pairing, the sperm remains in a vesicle, the female's receptaculum, the duct of which is passed by the egg. If, now, the queen is laying an egg in a worker cell, a trace of sperm is pressed out of the receptaculum when the egg passes the opening of its duct, and so the egg is fertilized. But when the queen lays an egg in the larger drone cell, the egg passes the duct without any sperm being pressed out. Von Siebold represented that bees behave consciously; but it is more likely that a purely physiological explanation may be found. It is, e.g., possible that in the narrower worker cells the muscles which empty the receptaculum are reflexly or mechanically set in activity, while the mechanical stimulus thereto is lacking in the wider drone cells. ${ }^{1}$ Dzierzon was able to bring to the support of this view a series of observations; thus, for example, queens which have been prevented from taking the nuptial flight by defective wing development invariably give rise to drones; the same is the case in old queens which continue to lay eggs when their receptaculum contains no more sperm; and workers, which cannot copulate owing to the rudimentary development of their sexual organs, occasionally lay eggs from which without exception males are hatched.

Dzierzon's views and observations were confirmed and completed by the investigations of von Siebold, Leuckart, and von Berlepsch. ${ }^{2}$

Among silkworm breeders the opinion had been repeatedly mooted that Bombyx mori could also develop from the unfertilized egg, and the observations made on this point by von Siebold

1 According to the recent researches of $\mathrm{E}$. Bresslau, the case is still more complicated.

2 The assertions of the incorrectness of Dzierzon's conclusions which have recently been vociferously maintained have been proved erroneous. 
and by others in addition have led to remarkable results. Herold had already observed in 1838 that a certain percentage of the unfertilized eggs of the silkworm begin to develop, but that, in contradistinction to the fertilized eggs, the development of the unfertilized ones comes to a halt in the first stages, and that such parthenogenetic eggs never succed in forming eaterpillars. ${ }^{1}$ Schmid and von Siebold ${ }^{2}$ observed the hatching of caterpillars from unfertilized eggs of Bombyx mori, and these caterpillars developed into sexually mature animals. But the results of other observers remained in part contradictory. All found that the first developmental stages occurred also in the unfertilized eggs, but in the majority of cases the eggs died during the winter. In the year 1871 von Siebold returned ${ }^{3}$ to the question of parthenogenesis in Bombyx mori once more, and mentioned the investigations of Barthélémy. This author found that development starts very much later in the unfertilized eggs of Bombyx mori than in the fertilized ones.

The number of the unfertilized eggs, in which the actual hatching of the caterpillar through parthenogenetic development was reached, was also extraordinarily variable; only once in Barthélémy's investigations did it happen that nearly all the unfertilized eggs of a virgin silkworm developed, while those cases in which all the unfertilized eggs laid by Bombyx mori remained sterile were very abundant. For in cases where development does take place among the eggs laid by a female silkworm, only three or four eggs at most accomplish the last stage of development, i.e., the hatching of a caterpillar; the rest remain at various earlier degrees of development, and dry up.

Further, Barthélémy remarks that these strains bred from virgin silkworms proved just as strong as those produced under the influence of the male silkworm; moreover, these individuals sprung from virgin silkworms showed perfectly normal sexual instincts. Of the highest importance is Barthélémy's observation that only virgin silkworms from the summer brood produce a parthenogenetic brood, and that in the same year; while, on

${ }^{3}$ Von Siebold, Beiträge zur Parthenogenese der Arthropoden, Leipzig, 1871, p. 232. 
the other hand, no offspring was hatched from parthenogenetic eggs of either the summer or autumn brood when kept over winter. Von Siebold brings forward observations by himself and Schmid which confirm Barthélémy's latter contention, at least in part.

These investigations on silkworms are of especial interest to us, because we are here concerned with a transition form in the sense that the eggs of the silkworm show a tendency toward spontaneous parthenogenesis; but it depends upon certain as yet unknown conditions whether or not the eggs develop spontaneously, i.e., without fertilization, and whether development stops in the initial stages, or whether the complete development to caterpillar or imago takes place. This is supported by the fact that different authors have achieved such contradictory results. It is possible that not only external circumstances, but also conditions which belong to the egg itself (e.g., the nature of the shell) here come into play. We shall meet later a similar case in the parthenogenesis of starfish eggs.

Von Siebold, Leuckart, and other authors have extended the observations on natural parthenogenesis with reference to the importance which these observations possess for another fundamental problem of biology - the determination of sex. In the Psychidae and in Solenobia the parthenogenetic eggs give rise only to females, in bees only to males. Leuckart and von Siebold discovered that in other hymenoptera too (Polistes, Vespa, and Nematus) similar things take place, and that here too parthenogenesis occurs, leading, however, exclusively to the production of males. In crustacea, such as Apus, Artemia, and Luimadia, von Siebold likewise found parthenogenetic development; but here it led to the production of females only.

This sketch of the earlier observations upon spontaneous parthenogenesis will suffice for the comprehension of the experiments on artificial parthenogenesis with which they are historically connected. 


\section{VI}

ON THE HISTORY OF THE EARLIER EXPERIMENTS ON ARTIFICIAL PARTHENOGENESIS

The observations upon the natural parthenogenesis of Bombyx mori were the starting-point for investigations upon artificial parthenogenesis. In the year 1847 a French author, Boursier, stated "that he had placed a female silkworm moth, which had not paired with a male, first in the sunlight and then in the shade, where (in both cases) it had laid many eggs. Caterpillars had been produced from each of those eggs laid in the sunlight."1

Von Siebold comments upon this: "Since in the foregoing cases nobody attributed the fertilization of the eggs to the influence of the light and warmth of the sun, as Boursier has done, one cannot abstain from regarding this phenomenon as a case of parthenogenesis." Considering the above-mentioned observation of Barthélémy upon the difference in behavior of the summer and winter eggs, and also the theoretical results of the investigations upon artificial parthenogenesis to be mentioned later, it is a priori not impossible that the temperature to which the newly laid egg of Bombyx mori is exposed may be of importance for its development.

In the year 1886, Tichomiroff ${ }^{2}$ published a short note on "Artificial Parthenogenesis in Insects," the object of which was to lend fresh support to the work of Herold and von Siebold upon natural parthenogenesis in the silkworm. "It has long been known that the éggs of Bombyx mori can develop parthenogenetically; yet one is always hearing doubts expressed about

${ }_{1}^{1}$ Von Siebold, Wahre Parthenogenese, p. 126, Leipzig, 1856.

"A. Tichomiroff, "Die künstliche Parthenogenese bei Insekten," Arch. f. Anat. u. Physiol., Physiol. Abt., 1886, Suppl., p. 35; Zoologischer Anzeiger, XXV, $386,1902$. 
it even after the work of Herold and von Siebold." In order to increase the number of Bombyx eggs that develop without fertilization, Tichomiroff used a method of which the breeders avail themselves in order to accelerate the development of fertilized eggs. Certain kinds of silkworms lay their eggs in the summer and these eggs begin to develop at once; but during the winter the development ceases, and the caterpillars do not hatch till the spring. Now it appears that it is customary among the breeders to hasten the development of the fertilized eggs by special "stimuli," so that the caterpillars hatch out in the same summer in which the eggs are laid. Tichomiroff applied the same methods to unfertilized eggs.

The experiments consisted in stimulating eggs mechanically and chemically in the same way as is done in order to obtain caterpillars in the same summer from fertilized eggs which normally only develop to a certain stage in summer. I plunged thirty-six unfertilized eggs into concentrated sulphuric acid and left them there two minutes (afterward the eggs were scrupulously washed). Thirteen of these eggs began to change color on the fourteenth day. On the sixteenth day an embryo could be perceived in these eggs. Both the embryo and the serous envelope consisting of magnificent pigment cells appeared quite normal.

Sixteen other eggs were rubbed quite lightly with a brush. Up till now (after one week [?]) the result has remained negative: not a single egg has developed. A third batch of ninety-nine eggs were brushed hard. On the fourth day the color change characteristic of developing eggs was observed in six of these eggs. Not a single parthenogenetically developing egg was observed among all the unfertilized eggs which remained unstimulated.

The breeders' experience that the immersion of eggs in concentrated sulphuric acid, or brushing them, accelerates development, is hard to explain. Both rubbing the eggs with a brush and plunging them into sulphuric acid may serve, perhaps, to injure or alter the skin of the egg, whereby it becomes more permeable to oxygen. We shall see later that 
the egg of the frog can be induced to develop parthenogenetically by a puncture with a needle. It is not impossible that in the experiments mentioned here on silkworms also a rupture or puncture of the surface layer was the cause of the development.

Tichomiroff's researches caused Dewitz ${ }^{1}$ to interpret as parthenogenesis a previous observation of his upon frog eggs.

When I was working in the spring of 1885 under Professor Zuntz in the physiological institute of the agricultural college in Berlin, I placed, for certain reasons, unfertilized eggs of Rana fusca in a solution of corrosive sublimate. The next morning, to my astonishment, I found them swollen and segmented. In some of the eggs only one division had taken place, in others more than one; in some the cleavage was irregular, but in very many perfectly normal. . . . Moreover, this occurred just as well if the eggs remained lying in the sublimate as also when they had remained there only a few minutes. .... Hence it can be concluded that sublimate exerts a stimulus which causes the first division.

There can be no doubt that the last conclusion is incorrect. What Dewitz observed was obviously a coagulation phenomenon which led to a wrinkling of the surface of the egg and in which the essence of cell division, viz., nuclear division, was absent. This was afterward pointed out by Roux. ${ }^{2}$

In the eighties and nineties, the attention of morphologists was directed to the finer processes of nuclear and cell division. This line of work yielded to the domain of facts in which we are interested here, the observation that the unfertilized eggs of certain sea-urchins may show the beginning of nuclear or even a cell division if they remain long enough in sea-water. The first systematic observation on this count probably originated from Richard Hertwig. ${ }^{3}$

${ }^{1}$ J. Dewitz, "Kurze Notiz ueber die Furchung von Froscheiern in Sublimatlösung," Biol. Centralbl., VII, 93, 1888.

2 W. Roux, Gesammelte Abhandl., 1I, 432.

${ }^{3}$ R. Hertwig, "Ueber die Entwicklung des unbefruchteten Seeigeleies," Festschrift für Gegenbaur, Leipzig, 1896. (Hertwig had already reported on these observations in the German Zoological Association in 1892.) 
When in the spring of 1887 my brother and I performed experiments upon the fertilization of sea-urchin eggs, we had before us the question as to what influence the concentration of sperm exerted upon the polyspermous fertilization of injured eggs, and especially those whose life functions had been interfered with through treatment with reagents. Thus eggs were treated for thirty minutes with a 1 per cent solution of strychnin and then mixed with sperm of the same species at various dilutions. In one case the sperm was so much diluted with sea-water that on the evidence both of observation in the living condition and of a very thorough examination of preserved material more than 90 per cent remained unfertilized owing to the addition of insufficient sperm. Fifty minutes after fertilization the control material was preserved. As before, 89 per cent of them were unfertilized. In these I found the beginning of an interesting change, which I will here describe.

Briefly, this alteration consisted in the fact that the nucleus showed changes similar to those occurring after fertilization. The division processes started in the nucleus, but, "in the majority of cases a nuclear or cell division did not take place. In exceptional cases a single division of the egg into two cells occurred, and each of these was provided with a nucleus. These cases which approach nearest to a normal division process are rare, and they also differ from the normal" (p. 44). Later Hertwig convinced himself that the longer sea-urchin eggs had lain in sea-water without the addition of sperm, the more of such divisions incidentally occurred. We shall later return to this phenomenon.

In 1892 the writer ${ }^{1}$ found that if the freshly fertilized eggs of a sea-urchin (Arbacia) are brought into hypertonic sea-water (about 100 c.c. of sea-water $+2 \mathrm{~g}$. $\mathrm{NaCl}$ ) the eggs do not divide in such a solution; but if they are returned to normal sea-water after two, three, or four hours, in quite a short time, after twenty or even ten minutes, the egg breaks up into several cells at once; and indeed the longer the eggs remain in the hypertonic solution, the greater the number of the cells into which

Loeb, "Experiments on Cleavage," Jour. Morphol., VII, 253, 1892. 
they suddenly divide. Since cell division follows nuclear division, I concluded that in this experiment nuclear division went on in the hypertonic solution, while cell division was stopped. I held the loss of water which the egg had suffered in the hypertonic solution answerable for the prevention of cell division. If the eggs remain too long in the hypertonic solution or if its concentration is too high, nuclear division also comes to a stop. W. W. Norman ${ }^{1}$ later undertook a histological examination of such eggs and confirmed this conclusion.

I suggested that the hypertonic solution produces a kind of "rigor" in the cytoplasm by the withdrawal of water, and that in consequence the movements necessary for cell division can no longer proceed. If one adds a little more $\mathrm{NaCl}$ to the sea-water than is absolutely necessary to stop cell division, the breaking-up of the nucleus does not take place either, for movements of the protoplasm are very probably necessary for this also. This explains the results of Morgan, ${ }^{2}$ who repeated my experiments, but observed no nuclear division. He found, however, as I did, that eggs treated for the same time with hypertonic sea-water suddenly divide into several cells about ten minutes after they have been returned to normal sea-water. Obviously he was dealing with eggs in which the changes in the nucleus necessary for segmentation had all taken place, but in which the movements of the protoplasm necessary for the pulling apart of the chromosomes had been suppressed. Morgan observed, however, that the astrospheres were formed in these eggs. ${ }^{3}$

At the same time Mead also, independently of Morgan, and from another point of view, attacked experimentally the question of the importance of the centrosomes. Boveri had put forward the view that the unfertilized egg is unable to

${ }_{1}^{1}$ Norman, Archiv f. Entwicklungsmechanik, III, 106, 1896.

2 Morgan, Anat. Anzeiger, IX, 149, 1894.

3 Morgan, "The Production of Artificial Astrospheres," Archiv f. Entwicklungsmechanik, III, 339, 1896. 
develop because it lacks the apparatus for cell division-the centrosome. According to Boveri, the spermatozoon starts the development of the egg by introducing into it a centrosome. The egg is thus placed in a position to begin its development. Only the centrosome can be the cause of division. Now Mead points out that in certain eggs, e.g., that of Chaetopterus, the spermatozoon has quite a different effeet. As long as the egg of Chaetopterus is in the ovary, no polar bodies are given off; but as soon as it reaches sea-water maturation starts and a spindle is formed preliminary to the extrusion of the first polar body.

The egg remains at this stage so long as no spermatozoon enters it.

In the egg of Chaetopterus a perfect amphiaster with centrosomes, centrospheres, astral rays, and spindle fibres is developed and the egg remains for hours in the metaphase, if it is left unfertilized in seawater; and the same appears to be true of many other marine annelids. This elaborate machinery of mitotic division is immediately set in motion upon the entrance of the spermatozoon, though the sperm and its centrosomes are in a distant portion of the egg. All the phases of this and the subsequent mitosis are independent of the karyokinetic changes in the vicinity of the sperm. Since in one form the oocyte will not divide until the sperm enters the cell, even though the centrosomes and the whole amphiaster are present, the suspicion is warranted that in the ripe egg of other forms-the sea-urchin, for example-the mitosis is not inhibited merely on account of the lack of a centrosome, nor is it incited merely because a new centrosome is introduced to organize the mitotic figure. ${ }^{1}$

Mead concludes that for cell division "a stimulus is required, analogous, perhaps, to that which starts into activity the motor apparatus of pigment cells, leucocytes or muscle cells." In order to pursue this idea farther he made some experiments upon the effect of salts, on the advice of C. W. Green. He employed the salts of the Ringer solution and found that if

1A. D. Mead, "The Rate of Cell Division and the Function of the Centrosome," Biological Lectures delivered at Woods Hole, 1896-97, p. 211, Boston, 1898. 
a small amount ( $\frac{1}{4}$ to $\frac{1}{2}$ of 1 per cent) of $\mathrm{KCl}$ is added to the sea-water, the amphiaster of the first oocyte stage at once resumes its activity. "The maturation processes, including the extrusion of the first and second polar bodies and the concomitant changes in the form of the egg, succeed one another with the same regularity that obtains when the egg is fertilized." Mead, however, observed no further development in these eggs. From these experiments he concludes that, in the normal fertilization of Chaetopterus, "the entering sperm stimulates these mitotic activities in a similar manner, i.e., by exerting a chemical influence on the egg and not by furnishing the egg with the organs of division." This work of Mead's which, in my opinion, occupies a distinguished position among cytological treatises, has been but little noticed in the literature of the subject.

In 1899 Morgan $^{1}$ published some new and important observations on the effect of hypertonic solutions upon the unfertilized egg. He had discovered that if unfertilized eggs were treated with hypertonic sea-water, they began to divide without, however, developing into larvae. Morgan considered this cleavage an abnormal phenomenon, which was in no way comparable to normal segmentation. "The form of the cleavage is totally different from that of the normal cleavage." According to Morgan's illustrations, the eggs appear to have developed to about the sixteen-cell stage, but not farther. "The time that it takes for a cleavage plane to pass through the egg is often very long in comparison to the time of normal division. The result is a mass of extremely minute granules or pieces. These pieces never acquire cilia and do not produce any form that resembles any stage of the normal embryo. Later the masses disintegrate" (pp. 454 and 455). Morgan's aim was not to obtain artificial parthenogenesis, but to corroborate his former

${ }^{1}$ Morgan, "The Action of Salt Solutions on the Unfertilized and Fertilized Eggs of Arbacia and of Other Animals," Archiv f. Entwicklungsmechanik, VIII, 448 1899. 
statement that the effect of the hypertonic solutions upon the egg consisted in the production of artificial astrospheres and centrosomes, and that such astrospheres and centrosomes were the organs of cell division. He considered that a development of unfertilized eggs treated with hypertonic sea-water to larvae was quite excluded.

Meanwhile I had been led by the results of my investigations upon the effects of ions to the question whether it might not be possible to cause unfertilized eggs to develop into larvae by treating them with modified sea-water. Experiments upon the physiological effect of the galvanic current had led me to the conclusion that in such cases we are dealing with an ion effect-an idea which was new at that time but which is considered a matter of fact today-and since the galvanic current is a sovereign method of stimulating muscle and nerve, it gave me the idea that perhaps ion effects might really underlie the action of all stimuli which had not hitherto been closely analyzed. Ringer's and my own experiments with certain salts showed that solutions of sodium, lithium, calcium, and rubidium salts could send skeletal muscles into rhythmic or at least fibrillar contractions, while salts of calcium, magnesium, and strontium prevented these contractions. Hence we owe it to the presence of the calcium salts or ions in our blood that our muscles do not continually contract.

Now as mentioned above, it had been made known by Hertwig and others, and I myself had often enough observed in Arbacia, that the unfertilized eggs of certain animals occasionally begin to divide provided they remain long enough in seawater. This suggested that the unfertilized egg might be in just the same condition as the muscle in that the egg could develop without fertilization, but that something contained in the sea-water prevents its development, just as the Ca and $\mathrm{Mg}$ contained in the blood prevent fibrillar contractions of the muscles. Hence I decided to perform experiments in 
order to see whether it were not possible to cause unfertilized sea-urchin eggs to develop into larvae by altering the constitution of the sea-water. My chief idea was that it must take place by means of hydroxylions or of hydrions. For earlier experiments had shown that an addition of acid to sea-water retards the development of sea-urchin eggs. ${ }^{1}$

Moreover, it was conceivable that the alkali of the seawater or the formation of carbonic acid in the unfertilized eggs was itself the cause that they began occasionally to divide spontaneously after a prolonged sojourn in sea-water. So I then tried whether it was possible to cause the development of the unfertilized sea-urchin egg into a larva by means of alkalies or acids. ${ }^{2}$ My later investigations have shown that I was right in this idea, but through a curious accessory circumstance I did not at that time succeed in my object. For I was then of the opinion that only the hydrions are of importance in the physiological effect of acid, and hence I used only strong mineral acids. I have since found that in this case only the weak acids are effective. Had I used fatty instead of mineral acids, the development of this branch of biology would have been shortened by five years.

On the other hand the experiments on the addition of $\mathrm{MgCl}_{2}$ to the sea-water were successful, provided that at the same time the osmotic pressure of the sea-water was raised. ${ }^{3}$ Unfertilized sea-urchin eggs which had been exposed for two hours to such a mixture developed afterward into larvae, some of which reached the normal pluteus stage. In this way the first step was taken which rendered possible the systematic analysis of the nature of the process of fertilization. For we possess only

${ }^{1}$ Loeb, "Ueber den Einfluss von Säuren und Alkalien auf die embryonale Entwicklung und das Wachstum," Archiv f. Entwicklungsmechanik, VII, 631, 1898.

${ }^{2}$ Loeb, Am. Jour. Physiol., III, 434, 1900.

${ }^{3}$ Loeb, "On the Nature of the Process of Fertilization, and the Production of Normal Larvae (Plutei) from the Unfertilized Eggs of the Sea-Urchin," $A m$. Jour. Physiol., III, 135, 1899. 
a single criterion which allows us to decide whether an agent has an effect upon the egg similar to that of the entry of the spermatozoon; this criterion is the development of the egg into a larva. The mere initiation of cell division is not sufficient since, for example, cell divisions occur in the cases of the growth of tumors and galls, which do not lead to the formation of a larva. This distinction between a cell division which forms the basis of normal development and growth and one which leads to the formation of pathological products is also of practical importance.

It is not our purpose in this book to report all the investigations upon artificial parthenogenesis. We shall rather confine ourselves to those experiments which help us to obtain an insight into the physicochemical character of the process of development. We will start with the experiments upon seaurchin eggs, which appear to be best suited to such investigations. The forms of sea-urchins with whose eggs I have worked are Arbacia of the Atlantic Ocean (at Woods Hole) and Strongylocentrotus purpuratus and franciscanus of the Pacific Ocean (at Pacific Grove).

The eggs of both these forms develop only when incited thereto either by sperm or by the chemical methods hereafter to be described. 


\section{VII}

THE FIRST EXPERIMENTS UPON THE OSMOTIC ACTIVATION OF THE UNFERTILIZED EGG OF THE SEA-URCHIN (Arbacia)

1. As already mentioned, I began my investigations with the anticipation that it must be possible to induce the unfertilized eggs to develop by treating them with bases or acids. For several weeks in the summer of 1899 I conducted experiments in this direction on the eggs of a sea-urchin, Arbacia, at Woods Hole, without obtaining any other result than that the unfertilized eggs of Arbacia placed in 100 c.c. of sea-water + 1 c.c. of $\mathrm{N} / 10 \mathrm{NaOH}$ begin to segment after remaining in the solution for about five hours. The cleavage, however, was very irregular and did not go beyond the early stages - two or four cells. At the same time the eggs showed a tendency to become amoeboid. The experiments with acids $\left(\mathrm{HCl}, \mathrm{HNO}_{3}, \mathrm{H}_{2} \mathrm{SO}_{4}\right)$ showed that no cleavage took place in acidified sea-water, but that a few divisions might be observed in unfertilized eggs if they were placed for about ten minutes in 100 c.c. of sea-water + 2 or 3 c.c. of $\mathrm{N} / 10 \mathrm{HCl}$ and then replaced in normal sea-water. ${ }^{1}$ Experiments with salt solutions which were isosmotic with sea-water gave no better results. When the summer of 1899 had almost entirely elapsed in this manner without any success, I at last investigated the effects of hypertonic solutions. $10 / 8 \mathrm{~m}$ (grammolecular) solutions of $\mathrm{NaCl}, \mathrm{KCl}, \mathrm{CaCl}_{2}$, and $\mathrm{MgCl}_{2}$, were prepared and mixed in different proportions with sea-water. After prolonged experiments I found that if unfertilized sea-urchin eggs were exposed for two hours to a mixture of 50 c.c. of sea-water +50 c.c. $10 / 8 \mathrm{~m} \mathrm{MgCl}_{2}$ and then

${ }^{1}$ Loeb, "On the Artificial Production of Normal Larvae from the Unfertilized Eggs of the Sea-Urchin," Am. Jour. Physiol., III, 434, 1900; Untersuchungen zur künstlichen Parthenogenese, p. 77, 1906. 
replaced in normal sea-water they developed into swimming plutei. ${ }^{1} \quad$ I expected that the same result would also be obtained with $\mathrm{NaCl}, \mathrm{KCl}$, and $\mathrm{CaCl}_{2}$, but to my surprise this was not the case. Meanwhile since the spawning season had expired, and there were less than a dozen sea-urchins at my disposal, I used this material to confirm at least the main and most important result, that it is really possible to produce larvae from unfertilized sea-urchin eggs. Eight series of experiments, each with a large number of different solutions, which I was still able to carry out together with many control experiments, convinced me that I had succeeded in the artificial production of larvae from unfertilized eggs. Not only blastulae but also gastrulae and plutei, some of them entirely normal in appearance, had been produced. Then, however, the further question arose whether this was an effect of the hypertonic sea-water alone or whether a specific action of magnesium was responsible for the result. Lack of material made it impossible for me to decide this question the same summer at Woods Hole. In February, 1900, I took up this investigation at Pacific Grove on the California coast. Dr. Garrey, my assistant at that time, accompanied me; and we were able to prove that an increase of concentration of sea-water, not only by $\mathrm{MgCl}_{2}$, but also by $\mathrm{NaCl}$ and sugar, incited the development of the sea-urchins of that coastStrongylocentrotus purpuratus and franciscanus. We made sure also of the fact that the most scrupulous sterilization of the seawater and of the instruments and the elimination of all possible sources of error did not invalidate the results. However, besides these gratifying results we also had a very unwelcome experience which long remained inexplicable to me: The results in Pacific Grove were not so constant as in Woods Hole. On some days the experiments went very well, but then there followed days on which the same solution which had hitherto given good results

${ }^{1}$ In the previously quoted detailed account of this first investigation (1900) I expressly mentioned that the raising of the osmotic pressure of the solution was a necessary condition of the experiment. 
remained entirely, or almost entirely, ineffectual. I could at that time assign no reason for this, and postponed the publication of these results until I had the opportunity of repeating them once more in Woods Hole. In the summer of $1900 \mathrm{I}$ convinced myself at Woods Hole that for Arbacia also $\mathrm{Mg}$ ions $\checkmark$ play no specific rôle, but that it is merely a case of appropriate increase of osmotic pressure. ${ }^{1}$ As long as the osmotic pressure of sea-water is raised about 50 per cent, it is immaterial whether the rise of pressure is caused by electrolytes like $\mathrm{MgCl}_{2}, \mathrm{NaCl}$, $\mathrm{KCl}$, or $\mathrm{CaCl}_{2}$, or by the addition of non-electrolytes such as cane sugar and urea. The experiments upon the eggs of Arbacia at Woods Hole gave much more constant results than the experiments on Strongylocentrotus in Pacific Grove. The reason that in the previous year artificial parthenogenesis was successful only when the concentration of the sea-water was raised by $\mathrm{MgCl}_{2}$ was due to the fact that the solutions of salts with which I worked were not isosmotic, as I had supposed.

Now as in this treatise we are especially interested in the quantitative aspect of this experiment, we must discuss somewhat more thoroughly the amount of increase of osmotic pressure that is necessary for development. According to W. E. Garrey, in the sea-water at Woods Hole the freezingpoint is lowered by $1.818^{\circ}$, while the water flowing in the laboratory has a somewhat higher concentration, viz., $\Delta=$ $1.83^{\circ} .^{2}$ Freezing-point determinations on pure $\mathrm{NaCl}$ solutions gave for a $\mathrm{m} / 2 \mathrm{NaCl}$ solution $\Delta=1.75^{\circ}$, and for a $\mathrm{m} / 2$ van't Hoff solution (i.e., for a mixture of 100 c.c. $\mathrm{m} / 2 \mathrm{NaCl}: 2.2$ c.c. $\mathrm{m} / 2 \mathrm{KCl}: 2$ c.c. $\mathrm{m} / 2 \mathrm{CaCl}_{2}: 12$ c.c. $\mathrm{m} / 2 \mathrm{MgCl}_{2}$ ) the lowering of the freezing-point is somewhat greater, viz., about $1.84^{\circ}$.

${ }^{1}$ Loeb, "Further Experiments on Artificial Parthenogenesis and the Nature of the Process of Fertilization," Am. Jour. Physiol., IV, 178, 1900; Untersuchungen ueber künstliche Parthenogenese, p. 154.

${ }^{2}$ W. E. Garrey, "The Osmotic Pressure of Sea-Water and of the Blood of Marine Animals," Biol. Bull., VIII, 257, 1905. 
This is due to the fact that $\mathrm{MgCl}_{2}$ and $\mathrm{CaCl}_{2}$ dissociate into three ions. In sea-water, however, there are not 12 c.c. of $\mathrm{MgCl}_{2}$, but 7.8 c.c. $\mathrm{MgCl}_{2}+3.8$ c.c. $\mathrm{MgSO}_{4}$, and hence a really $\mathrm{m} / 2$ van't Hoff solution has a little weaker osmotic pressure. At the same time, the difference in osmotic pressure between a van't Hoff solution and $\mathrm{a} \mathrm{m} / 2 \mathrm{NaCl}$ solution is small. ${ }^{1}$

Now I found that in Woods Hole artificial parthenogenesis may be produced in sea-urchin eggs if they are left for between one and two hours in a mixture of 90 c.c. of sea-water +10 c.c. of $2 \frac{1}{2} \mathrm{~m} \mathrm{NaCl}$ or $\mathrm{KCl}$. The increase of osmotic pressure of this solution was relatively small, amounting to about 40 per cent of the osmotic pressure of the sea-water. ${ }^{2}$ I also obtained swimming larvae when the eggs of Arbacia were put for about two hours in the following solutions:

100 c.c. of sea-water +25 c.c. $2 \mathrm{~m}$ cane sugar.

80 c.c. of sea-water $+17 \frac{1}{2}$ c.c. $2 \frac{1}{2} \mathrm{~m}$ urea.

In this case also only a very slight increase of molecular concentration takes place.

A pure cane-sugar solution of relatively low molecular concentration is alone sufficient to cause unfertilized eggs of seaurchins to develop. Thus eggs of Arbacia were placed for two hours in a solution of 60 c.c. $2 \mathrm{~m}$ cane sugar +40 c.c. distilled water or even in 55 c.c. $2 \mathrm{~m}$ cane sugar +45 c.c. distilled water. ${ }^{3}$ In the last case there is only a very slight increase of molecular concentration. ${ }^{4}$ Nevertheless this treatment activates the egg, though its development never goes farther than the blastula stage, and, as a rule, not even so far. The development of the egg generally ceases in the early segmentation stages. We shall see later that the production of plutei is favored if the

${ }^{1}$ According to Garrey, the sea-water at Pacific Grove lowers the freezingpoint by $1.90^{\circ}$.

2 Am. Jour. Physiol., IV, 178, 1900.

${ }^{3}$ Ibid.

1 We shall see later that the osmotic effect of a pure cane-sugar solution is considerably higher than its theoretically calculated value. 
hypertonic solution possesses a rather high concentration of $\mathrm{HO}$ ions. This is more important for the eggs of $S$. purpuratus than for those of Arbacia, since the latter can be caused to develop even by a neutral hypertonic solution. We pointed out already that the eggs of Arbacia require for their development a lower concentration of hydroxylions than the eggs of purpuratus. I published the sugar experiment in order to leave no doubt that the hypertonic solution produces its effect only in virtue of its capacity for withdrawing water, and that we are not dealing with a specific action of salts or their ions. ${ }^{1}$

This series of investigations established still another point of theoretical importance. The egg loses water in the hyper-r tonic solution; but when replaced into normal sea-water it naturally takes up water again. The question now arose whether the causation of development depended in this case upon the withdrawal of water, or whether the swelling of the egg, when it was replaced in normal sea-water, had something: to do with the result. With this object in view, unfertilized sea-urchin eggs were placed for a long time in slightly hypertonic sea-water, viz., 93 c.c. of sea-water +7 c.c. $2 \frac{1}{2} \mathrm{~m} \mathrm{NaCl}$ solution. Now it turned out that some eggs began to segment in that solution and that a few reached an early blastula stage and swam about. That they developed no farther is due to the fact that even so weak a hypertonic solution harmed the eggs when they remained in it too long. Hence the experiment showed that, so far as the developmental effect of the hypertonic solution is concerned, it is unnecessary to replace the eggs in normal sea-water. The latter is only necessary if we wish to maintain the eggs in their complete vitality and to allow them to develop into plutei.

At that time I was inclined to assume that the effect of the hypertonic solution consisted in the liquefaction of the

1 The eggs of different females show a different degree of sensitiveness to the treatment with hypertonic sea-water. The eggs of S. purpuratus are more often refractory than those of Arbacia. 
nuclear membrane and other nuclear constituents. ${ }^{1}$ Such a liquefaction must of course occur at each nuclear division; but I believe that it is only an indirect result of chemical processes set up in the egg by the hypertonic solution, and not a direct effect of the hypertonic solution.

Now since the hypertonic solution works entirely in virtue of its osmotic pressure, and since the osmotic pressure depends only upon the number of molecules or ions in the unit volume of the solution, and not upon the chemical nature of the molecules or ions, all isosmotic solutions should be equally effective in causing the unfertilized egg to develop. This is approximately true (see also chap. xiii), except that solutions containing poisonous salts, e.g., copper salts or others, cannot be used for this purpose.

The closer the hypertonic solution approaches sea-water in its composition, the less harmful become the secondary effects of the hypertonic solution. For this reason I generally use for the preparation of the hypertonic solution sea-water whose concentration has been raised to the desired pitch by the addition of a suitable amount of a $2 \frac{1}{2} \mathrm{~m} \mathrm{NaCl}$, or Ringer, solution. The minimal concentration in which different hypertonic solutions are effective varies somewhat with the different substances under consideration.

2. My next experiments aimed at determining whether the results here detailed are only a peculiarity of sea-urchin eggs: or whether artificial parthenogenesis can be produced in the eggs of all animals. In so doing it was at first immaterial to me through what method the activation of the egg succeeded, so long as it was only possible to cause the unfertilized eggs to develop. But the experiments must be briefly mentioned here, since the experience obtained thereby had an influence upon the further development of this line of research. I had already been able to show in the year 1900 that the eggs of a marine worm,

1. Loeb, Am. Jour. Physiol., IV, 178, 1900. 
Chaetopterus, can be caused to develop by the addition of acid or of any potassium salt to the sea-water without raising its osmotic 1 pressure. $^{1}$

Later Neilson and I showed that the unfertilized eggs of the starfish (Asterias forbesii) can be made to develop into larvae by any inorganic acid, i.e., by hydrions.

In collaboration with Fischer I discovered that the addition of a calcium salt to the sea-water causes the development of the unfertilized eggs of a marine worm, Amphitrite. ${ }^{2}$ Later on we will return to these investigations.

${ }^{1}$ Loeb, Am. Jour. Physiol., IV, 423, 1901.

2 Loeb, Fischer, and Neilson, "Weitere Versuche ueber künstliche Parthenogenese," Pflüger's Archiv, LXXXVII, 594, 1901. 



\section{VIII}

\section{THE IMPROVED METHOD OF ARTIFICIAL PARTHENO-}

GENESIS IN THE SEA-URCHIN EGG

The first method of producing larvae from the unfertilized egg of the sea-urchin by a mere increase of osmotic pressure only sufficed to show that the mysterious complex "living spermatozoon" might be replaced by well-known physicochemical agencies. It did not lend itself well to a physicochemical analysis, since the method was not always reliable. We have already mentioned that with the Californian seaurchin S. purpuratus the method worked only with the eggs of a small percentage of females and even the eggs of different females of Arbacia did not yield equally well to this method. For a further investigation of the nature of the process of fertilization this method was therefore very unsatisfactory.

There were other reasons which indicated that a better method for artificial parthenogenesis was needed. The larvae of normally fertilized eggs rise to the surface of the water; they are pelagic. The larvae produced by means of a hypertonic solution rarely or never rose to the surface of the sea-water, but swam at the bottom of the dish. And finally, the eggs form, upon the entrance of a spermatozoon, the fertilization membrane. The unfertilized eggs which developed after treatment with a hypertonic solution never formed a characteristic fertilization membrane, but only a fine gelatinous film instead of the clear fertilization membrane.

This led me to think that the osmotic activation of the egg was only an incomplete imitation of the fertilization process, and that the fertilization by the spermatozoon perhaps depended not upon a single chemical agent, but upon a combination of two or more which were only fortuitously combined in the 
spermatozoon. This idea proved to be correct. I had just previously found different esters to be especially active in heliotropic experiments, and now I tried the effect of ethyl acetate upon the unfertilized eggs of $S$. purpuratus.

1. It turned out that if these eggs are placed in sea-water to which a little ethyl acetate has been added, they form a typical fertilization membrane and begin to divide when replaced in normal sea-water. As long as the eggs were left in the sea-water that contained ethyl acetate, they formed no membrane; further, they lost the power to form a membrane if they remained too long in such sea-water. However, they did form a membrane if they were exposed to the ethyl acetate in sea-water for not more than a couple of minutes and were then replaced in normal sea-water. Eggs treated in this manner all formed a perfectly normal nuclear spindle after an hour, and began to divide. As a rule they did not develop into larvae; on the contrary, the eggs went to pieces in less than twenty-four hours (at about $19^{\circ} \mathrm{C}$.) without reaching the blastula stage. But the following result was extremely surprising. If the eggs of Strongylocentrotus were exposed for two hours to hypertonic sea-water, often only a fraction of 1 per cent of the eggs began to segment. If, however, a part of these eggs were subsequently treated with ethyl acetate long enough to cause the formation of a membrane upon transference to normal sea-water, the majority of the eggs developed and many in quite a normal manner. In the latter case segmentation followed its normal course and at normal speed, and some of the larvae-probably those arising from normally segmented eggs-rose to the surface of the water. Here then we had a much more precise imitation of the process of fertilization. ${ }^{1}$

2. The next step was to determine whether this depended upon a specific action of the ester or of one of its hydrolytic

${ }^{1}$ Loeb, "On an Improved Method of Artificial Parthenogenesis," University of California Publications, Physiology, II, 83, 1905. 
products. It turned out that the latter was the case, and that any monobasic fatty acid, formic, acetic, propionic, butyric, valerianic, etc., induced membrane formation.

If the unfertilized eggs of $S$. purpuratus are placed in 50 c.c. of sea-water +2.8 c.c. $\mathrm{N} / 10$ butyric acid at $15^{\circ} \mathrm{C}$. and left in this solution for one and one-half to two and one-half minutes, all the eggs form membranes when replaced in normal sea-water. If they are transferred earlier from the acid to normal seawater, they form no membrane; nor do the eggs form a membrane after remaining too long in the acid, because the acid injures the eggs.

The lower monobasic fatty acids, formic, acetic, propylic, valerianic, and capronic acids, behave like butyric acid, i.e., when these acids are added to sea-water the eggs do not form membranes while they are in the acidulated sea-water, but only after they are transferred to normal sea-water. If, however, the higher monobasic fatty acids are used, e.g., heptylic, caprylic, nonylic, and caprinic acids, the eggs form a fertilization membrane while they are in the sea-water containing the acid. Carbonic acid behaves like the higher fatty acids. The different behavior of these acids finds its explanation in the fact that a high concentration of hydrogen ions in the surrounding solution inhibits the membrane formation. We shall come back to this point later on.

Hence. if one of these lower monobasic fatty acids or carbonic acid penetrates into the egg, it acts like ethyl acetate in producing membrane formation. If now the unfertilized eggs of Strongylocentrotus were first placed for two hours in hypertonic sea-water and then treated with a monobasic fatty acid, i.e., put for one and one-half to two and one-half minutes at $15^{\circ} \mathrm{C}$. into 50 c.c. of sea-water +2.8 c.c. $\mathrm{N} / 10$ butyric acid, so that all formed membranes upon transference to normal sea-water, all the eggs, or the majority of them, developed into larvae; while, as I have said, less than 1 per cent of the 
eggs of the same female developed when treated with hypertonic sea-water alone. ${ }^{1}$

3. The next question which arose was whether the fatty acid starts the development directly, or whether its action is only limited to the setting-off of the process of membrane formation; in that event, this process, formerly regarded as something very secondary, would be established as the essential factor in development. The question was answered in the latter sense, as the following facts show. If the unfertilized eggs of the sea-urchin $S$. purpuratus are placed for one and onehalf to two and one-half minutes at $15^{\circ} \mathrm{C}$. in 50 c.c. of sea-water +2.8 c.c. of a $\mathrm{N} / 10$ monobasic fatty acid, all the eggs form a membrane upon transference to ordinary sea-water. This result is so constant that $I$ have only rarely found an exception to it. But if the eggs are removed a little earlier from the acid to normal sea-water, one can find a period of time in which no longer all the eggs but only some of them form membranes. It will be found that only such eggs as have formed membranes develop, if they are subsequently or previously treated with hypertonic sea-water. ${ }^{2}$ Membrane formation is therefore the deciding condition for development.

A further proof is afforded by the following fact. We shall see in the following chapters that any substance which causes haemolysis also calls forth membrane formation, e.g., saponin, bile salts, hydrocarbons, ether, etc. No matter by what means the membrane formation has been called forth, it induces the development of the egg, provided that the eggs are taken out of these solutions at the proper time. If such eggs which possess a membrane are afterward subjected to treatment with hypertonic sea-water they develop like fertilized eggs.

${ }^{1}$ Loeb, "On an Improved Method of Artificial Parthenogenesis," 2d and 3d communications, University of California Publications, Physiology, II, 1905; Untersuchungen zur künstlichen Parthenogenese, pp. 322 and 329, Leipzig, 1906.

2 The beginner must bear in mind that the membrane occasionally adheres closely to the egg and that occasionally the process of membrane formation is not completed. However, such eggs can develop. 
Hence membrane formation is essential for development, and it is immaterial how the membrane formation has been produced; except that the membrane formation induced by a fatty acid injures the egg less than that provoked by most of the other substances.

4. In the experiments thus far discussed the treatment with the hypertonic solution preceded the artificial membrane formation with the fatty acid. Fertilization with sperm, however, begins with membrane formation; and hence it was natural to find out, whether in artificial parthenogenesis also, membrane formation by means of a fatty acid might not be applied as the first step.

The unfertilized eggs were therefore subjected to treatment with a fatty acid until they all formed membranes. Ten to twenty minutes later they were placed in hypertonic sea-water. It turned out that in this order of events the eggs of $S$. purpuratus need remain in the hypertonic solution only a relatively short time, some thirty to sixty minutes at about $15^{\circ} \mathrm{C} 0^{1}$ The derelopment of the eggs is nearly identical with that evoked by sperm, and practically all the eggs develop; provided that the details of the method are correctly carried out.

The procedure for the chemical activation of the unfertilized egg of $S$. purpuratus is therefore as follows. The eggs are placed in 50 c.c. of sea-water +2.8 c.c. of $\mathrm{N} / 10$ butyric acid (which must be thoroughly mixed beforehand). At $15^{\circ} \mathrm{C}$. a portion of the eggs is transferred after one and one-half, two and one-half, and three or four minutes to 200 c.c. of seawater which had previously been made ready for this purpose. In one or all of the dishes all the eggs form a normal fertilization membrane.

It may be observed, by the way, that too many eggs must not be put into the acid sea-water, since otherwise the mass of acid

1 The eggs of Arbacia need remain in the hypertonic solution only about 20 minutes at a temperature of $22^{\circ} \mathrm{C}$. 
is not sufficient. It is also necessary to collect the eggs into a heap by gentle rotation of the dish before transferring them to normal sea-water, so that they can be transferred in a pipette with as little acid as possible. This gentle agitation also prevents the eggs from sticking to the glass.

After the eggs are transferred from the acid to normal seawater, they should not be placed at once in the hypertonic sea-water, but only after from fifteen or twenty minutes, or even later still. The hypertonic sea-water used in this case is a mixture of 50 c.c. of sea-water +8 c.c. $2 \frac{1}{2} \mathrm{~m} \mathrm{NaCl} .{ }^{1}$ From this they are transferred to normal sea-water after from thirty to sixty minutes at $15^{\circ} \mathrm{C}$., at intervals of from two and onehalf to five minutes. After transference to normal sea-water, those eggs which have been just long enough in the hypertonic solution begin to segment and develop. Usualiy only two astrospheres or centrosomes are formed by this method. When the length of exposure is correct, the first division is a cleavage of the egg into two cells as in normal fertilization, although the cleavage in the first division is often somewhat asymmetrical. That is probably a result of treating the egg with hypertonic sea-water. This anomaly, however, only presents itself in the first division and has no further influence on the development. All the eggs that divide into two cells develop into apparently normal larvae, while eggs which go into more than two cells at one division develop into crippled larvae and most of them die in or before the gastrula stage. This latter abnormal kind of development is obtained regularly if the eggs remain too long in the hypertonic solution and an over-exposure of only a few minutes may produce this fatal effect. This shows how necessary it is that the eggs be transferred from the hypertonic solution to normal sea-water at the right time. ${ }^{2}$

${ }_{1}$ A mixture of $2 \frac{2}{2} \mathrm{~m} \mathrm{NaCl}+\mathrm{KCl}+\mathrm{CaCl}_{3}$ in the proportions in which these salts exist in the sea-water is still better than $2 \frac{1}{2} \mathrm{~m} \mathrm{NaCl}$, since it is less injurious.

${ }^{2}$ This time varies somewhat for the different eggs even of the same female. 
It is, moreover, necessary that not too many eggs be put into one bowl of hypertonic sea-water, since otherwise a mutual struggle for oxygen takes place. The eggs should also be kept in shallow dishes so that the layer of water which covers them may not be too deep and the diffusion of oxygen from the air to the eggs not too greatly hindered. I usually cover the bowls loosely with a glass plate. ${ }^{1}$

I have since tried the same method with success on the eggs of Arbacia at Woods Hole. As was to be expected, the quantitative data of the method are a little different in this case from those found in S. purpuratus. The eggs were put into a mixture of 50 c.c. sea-water +2 c.c. $\mathrm{N} / 10$ butyric acid for from one and one-half to three minutes. When transferred to sea-water they did not form a conspicuous fertilization membrane, as did the eggs of $S$. purpuratus under the same circumstances, but only a fine gelatinous layer which was not easily visible. Ten or fifteen minutes later the eggs were transferred to hypertonic sea-water ( 50 c.c. sea-water +8 c.c. $2 \frac{1}{2} \mathrm{~m} \mathrm{NaCl}$ ). In this solution the eggs remained at a temperature of about $23^{\circ}$ only from seventeen and one-half to twenty-five minutes, after which they were transferred to normal sea-water. Since the time during which the eggs must remain in the hypertonic solution varies for the individual eggs and since a slight over-exposure in the hypertonic solution seriously injures the eggs, it is advisable to transfer the eggs not all at the same time but at intervals, e.g., after seventeen and one-half, twenty, twenty-two and one-half, and twenty-five minutes. Eggs which were exposed longer than twenty-five minutes to the hypertonic solution did not develop.

The same method has been applied successfully, among others at Naples by Herbst, Warburg, and by Meyerhof, and at Plymouth by Shearer and his pupils.

1 Other factors which have to be considered in this method will be mentioned in the next chapter. 



\section{IX}

\section{THE EFFECT OF ARTIEICIAL MEMBRANE FORMATION ON THE EGG}

We shall see later that for the eggs of starfishes and various annelids (Polynoe and Thalassema) the induction of artificial membrane formation is sufficient to cause some of the unfertilized eggs to develop. into larvae. According to the experiments of Herbst, to which we shall return later, something similar appears to be the case exceptionally with the eggs of the Neapolitan sea-urchins also. Neither the eggs of the Californian sea-urchins, nor those of Arbacia at Woods Hole, do as a rule develop into larvae if artificial membrane formation alone is produced in them. They do, however, without exception exhibit the initial changes of development after such treatment. It depends upon the temperature how far they will develop. If the temperature is very low (from $2^{\circ}$ to $5^{\circ}$ ) the eggs divide very slowly and regularly, and a few may develop into swimming larvae, ${ }^{1}$ although they do not survive the blastula stage. If the temperature is a little higher, some $6^{\circ}$ to $8^{\circ}$, the eggs go into the two-, four-, eight-, and even sixteen-cell stage, but no farther. At higher temperatures still, say $15^{\circ}$ to $18^{\circ} \mathrm{C}$, a formation of astrospheres and nuclear division takes place; but then the development comes to a standstill and the eggs do not divide, but slowly disintegrate.

The fact that the egg can develop at a low temperature to the blastula stage, and that nuclear division and cell division begin always after the membrane formation, proves that this process suffices to set the whole apparatus of development in motion. The subsequent treatment with a hypertonic solution

${ }^{1}$ Loeb, Untersuchungen ueber künstliche Parthenogenese, p. 490; Biochem. Zeitschr., I, 203, 1906. 
has, therefore, nothing to do with the activation of the egg. The question arises: What is its function?

We receive an answer to this question when we observe what becomes of the eggs at room temperature after the

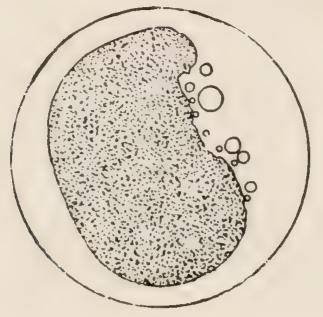

Fig. 19

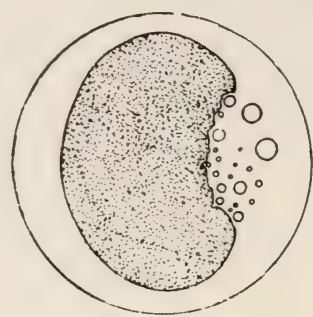

Fig. 20

FIGS. 19 and 20.-Beginning of the process of disintegration after the artificial membrane formation in the egg of $S$. purpuratus. Small droplets appear at the equator of the elongated egg.

membran formation. In this case the centrosomes and two astrospheres are formed and the nucleus may divide, but then a process of disintegration begins in the egg. Small droplets appear usually on one side of the egg (Figs. 19, 20). One gains the impression that these droplets begin to be extruded at the

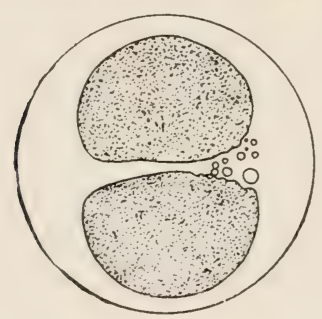

Fig. 21

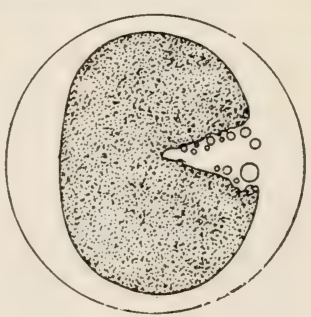

Fig. 22

Figs. 21 and 22.-Eggs of the same lot, showing more plainly that the droplet formation and disintegration begin in the plane of cell-division.

time of the first cell division. This is obvious from Figs. 21 and 22 , where the droplets appear in the plane of segmentation. In Figs. 19 and 20 they appear in the equatorial plane of eggs which are not segmented, but which show the elongation in the direction of the two poles. 
When the disintegration has once commenced, it continues until, after a certain time which varies inversely with the temperature, the whole egg is disintegrated. Fig. 23 represents an egg a few hours after artificial membrane formation, in

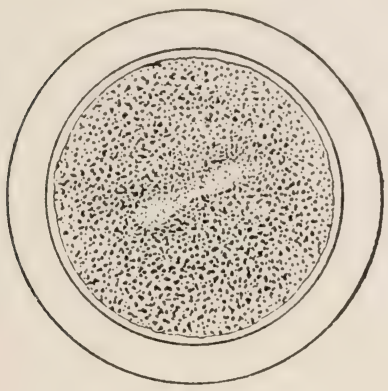

Fig. 23

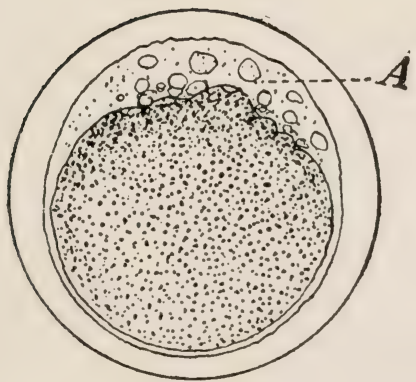

Fig. 25

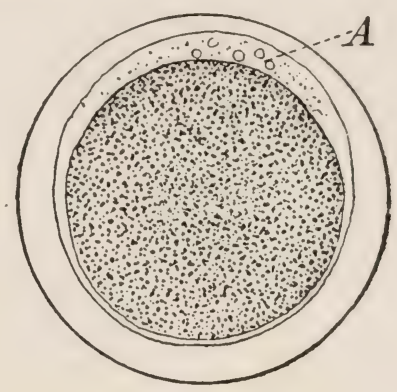

Fig. 24

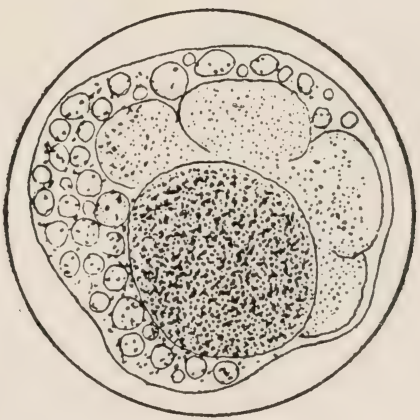

Fig. 26

Frgs. 23-26.-Disintegration of the sea-urchin egg after artificial membrane formation, if it is not submitted to treatment with a hypertonic solution or an inhibition of oxidations.

which the nuclear spindle is visible. It did not develop farther, but a little later a few clear drops (Fig. 24), resembling polar bodies, appeared to exude from the egg; I suspect that this extravasation of drops took place in the equatorial plane. This disintegration then proceeds farther (Fig. 25), until finally the egg is almost completely destroyed (Fig. 26). 
While Figs. 24-26 give a picture of the decay of an egg at room temperature, the start of disintegration at a somewhat lower temperature is represented in Figs. 27-31. The eggs were kept at a temperature between $5^{\circ}$ to $10^{\circ} \mathrm{C}$. after membrane formation with butyric acid. Many divided and the disintegration began later. Drawings were made of a series of differ-

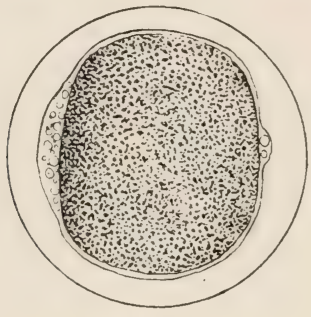

Fig. 27

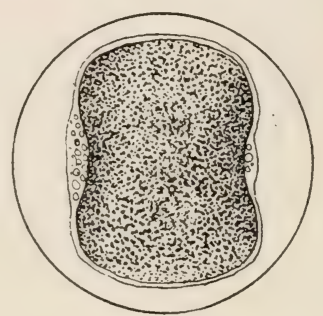

Fig. 28

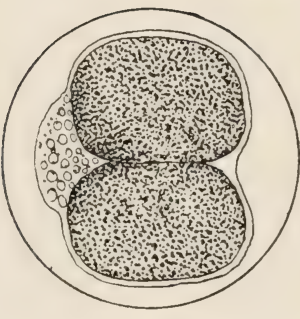

Fig. 29

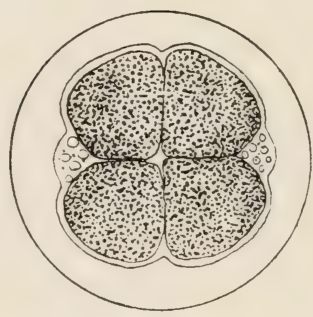

Fig, 30

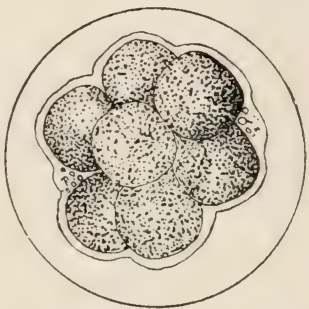

Fig. 31

FIGS. 27-31.-Slow disintegration of the egg of the sea-urchin at low temperature. The egg can reach the eight-cell stage under such conditions.

ent eggs in incipient disintegration. In all cases this started with the formation of small drops, usually in the plane of division; the result is always similar to that shown in Fig. 26.

We now can answer the question, what is the rôle of the subsequent treatment of the egg with the hypertonic solution: it serves the purpose of preventing the disintegration which begins at the time of the first cell division. The conditions for this action of the hypertonic solution will be considered in a subsequent chapter. 
It is of interest to add that fertilized eggs can also be caused to show this process of droplet formation during the first segmentation, namely if they are caused to segment in an abnormal solution. It depends upon the degree of abnormality whether or not such eggs can afterward develop into normal larvae. When unfertilized eggs of S. purpuratus were exposed for about two hours to a hypertonic solution and fertilized with sperm immediately after they were taken out of the solution they were able to develop, but the first segmentation occurred often with droplet formation in the plane of division. When they were fertilized after they had been in the normal sea-water for some time they segmented normally.

While the artificial membrane is enough to initiate the act of development, something is abnormal in the egg in so far as the process of cell division leads to its destruction. We should therefore expect that if we inhibit the process of cell division, the eggs would not perish. This conclusion is correct.

It has been mentioned that cell division can be prevented in the fertilized sea-urchin egg by depriving it of oxygen or stopping oxidation by certain poisons, such as KCN. IVe will now proceed to show that if we deprive the sea-urchin egg of oxygen after artificial membrane formation, or put it in seawater with a little $\mathrm{KCN}$ or chloral hydrate, we then inhibit the disintegration described above. ${ }^{1}$ Membrane formation was produced in the eggs of a sea-urchin by treating them with butyric acid. The eggs were then divided into three portions. One remained exposed to the air, a second was placed in a flask through which was passed a stream of pure oxygen, the third in a flask of sea-water out of which practically all air had been driven by a stream of hydrogen, and in which the current of hydrogen passed through the vessel during the whole of the experiment. The eggs which had been exposed to oxygen in

${ }^{1}$ Loeb, Untersuchungen ueber künstliche Parthenogenese, p. 483; Biochem. Zeitschr., I, 192, 1906. 
the first two vessels had all formed nuclear spindles at the right time, and began to disintegrate after four or five hours. After ten hours none of these eggs could be induced to develop by treatment with hypertonic sea-water. On the other hand, the eggs which had been in the current of hydrogen had formed no spindle and were perfectly intact when disconnected from it. They could still be induced to develop by treatment with hypertonic sea-water. Even after remaining twenty-four hours in the stream of hydrogen the eggs maintained their shape intact. Just the same sort of results were obtained upon the addition of a little KCN to the sea-water, by which means the development was arrested. By stopping development (as a result of inhibiting oxidations) the eggs are kept from that disintegration after membrane formation to which they would be condemned at room temperature. Hence we must come to the conclusion that membrane formation does indeed initiate development, but that it leaves the egg in a condition in which the cell division becomes fatal to it. If we prevent cell division the egg survives. ${ }^{1}$

This conclusion is supported by the observation that if the development of the eggs after artificial membrane formation be stopped for several hours, they are then able to develop even at room temperature, and not only to blastulae but also to plutei. ${ }^{2}$ I first became aware of this fact when I put eggs after membrane formation (with butyric acid) into sea-water from which the air had been displaced by a current of hydrogen. At various intervals eggs were replaced in normal sea-water from that lacking oxygen. It turned out that eggs which at $15^{\circ} \mathrm{C}$. had been less than three hours in the sea-water that lacked oxygen all disintegrated after the return to normal sea-water; but that of the eggs which had been three hours or a little longer

1 Chloral hydrate acts in the same way, although it does not diminish the rate of oxidation; but it inhibits the developmental process and cell division and thus prevents the fatal disintegration of the egg.

${ }^{2}$ Loeb, op. cit. 
in the sea-water poor in oxygen, some (about 1 per cent) developed to perfectly normal plutei after they were transferred to normal sea-water. Experiments with potassium cyanide gave the same results. Unfertilized eggs in which a butyric acid membrane had been formed were placed in 50 c.c. of sea-water +1 c.e. of a 1 per cent KCN solution. Here the concentration was forty times as large as is necessary for the inhibition of the division of the fertilized egg and for the prevention of the disintegration process. Some of the eggs were transferred to normal sea-water after $18,30,45,65$, and 85 minutes. Of the eggs placed in normal sea-water after 45 and 65 minutes a small number, about 5 per cent, developed. In this case, however, the development did not start till fourteen hours after the eggs were taken out of the sea-water that contained the potassium cyanide. I suppose that several hours are necessary for all the hydrocyanic acid to disappear from the egg. This conjecture is supported by the fact that only those eggs developed which were placed after treatment with potassium cyanide in flat watch glasses in which they were covered only by a shallow layer of water, and in which therefore the evaporation of the HCN could proceed quickly. The development of the eggs was also favored by passing a stream of oxygen through the watch glasses for a minute. But similar results could also be obtained with smaller quantities of KCN. Thus, in one experiment, the eggs were placed after artificial membrane formation in 50 c.c. of sea-water to which $1,2,4$, and 8 c.c. of $1 / 10$ of 1 per cent $\mathrm{KCN}$ had been added. They remained in these solutions for from one to twenty-three hours. A few of the eggs which had been transferred from the solutions with 2 and 4 c.c. of $1 / 10$ of 1 per cent KCN to normal sea-water after from three to seven hours developed into larvae.

It struck me in these experiments that the development of the eggs appeared wonderfully normal, and so several years ago I took up these experiments afresh. In order to convince 
myself that membrane formation is the real force that activates the unfertilized egg, it was necessary to show that all sea-urchin egg's can be caused to develop through this agent alone.

In my earlier experiments the eggs were placed in the potassium cyanide sea-water very soon after membrane formation. Now this is in great part answerable for the fact that the number of eggs which afterward developed into larvae remained so small. For I have recently found that if the eggs are placed in this solution a little later a large percentage of larvae can be obtained and in many experiments all the eggs developed into larvae after transference to normal sea-water. In this experiment a very weak solution of $\mathrm{KCN}$ was used, viz., a mixture of 50 c.c. of sea-water +1 or 2 c.c. $1 / 20$ of 1 per cent $\mathrm{KCN}$.

Membrane formation was produced in the eggs of a seaurchin (S. purpuratus) by means of butyric acid. Some of the eggs were transferred immediately (i.e., two minutes) after membrane formation in 50 c.c. of sea-water +2 c.c. $1 / 20$ of 1 per cent KCN. After three, four, and five hours the eggs were transferred to normal sea-water (after they had been freed from KCN by thrice washing in sea-water). The temperature was $11.5^{\circ} \mathrm{C}$. Not a single egg developed into a larva.

A second portion of the eggs was placed in the sea-water and potassium cyanide twenty minutes after membrane formation. After three hours some of these eggs were transferred to normal sea-water and about 5 per cent developed into larvae. About 10 per cent and 20 per cent of larvae respectively were produced by the eggs removed from the cyanide sea-water after four and five hours.

A third portion of the eggs was transferred to the cyanide sea-water forty-three minutes after membrane formation. Practically all of the eggs transferred to normal sea-water after three hours developed into larvae. The eggs that remained longer in the cyanide were injured and did not develop so well.

Eggs transferred to the cyanide sea-water fifty-seven 
minutes after membrane formation behaved in a similar manner. Others, transferred eighty-two minutes after membrane formation, gave few larvae.

These experiments were repeated quite often, but the results were not always equally good. It is possible that the eggs of various females did not react equally well to this method.

In the more recent experiments the eggs were first washed two or three times with ordinary sea-water after being taken from that containing potassium cyanide.

In all these experiments the perfect regularity of the segmentation was very striking; the segmentation is almost as good as in eggs fertilized with sperm. This is an important fact, in view of the experiments in which the disintegration of the eggs after membrane formation is prevented by hypertonic sea-water. In this case the first division is often somewhat irregular. The experiments with potassium cyanide show that this irregularity is essentially a secondary effect of the hypertonic salt solution, and that membrane formation alone leads to a normal segmentation.

Secondly it must be remarked that in these experiments the larvae stayed on the surface of the sea-water as in normal development, and gave large numbers of plutei. The shorter the time that the eggs had remained in the potassium cyanide solution, the larger the number of eggs that developed into normal plutei. The reason is obvious. Membrane formation sets going (or accelerates) the chemical reactions which determine development. If we interrupt the oxidations in such an egg, there will accumulate in it decomposition products which ought to be removed by oxidation. I suppose that this accumulation of decomposition products leads to the injury of the egg, which is shown by the fact that the longer the eggs remain in the cyanide solution, the more their vitality is impaired. We have had the same experience with sea-urchin eggs fertilized with sperm, which also lose their vitality more quickly 
and die in an earlier larval stage the longer they have been exposed to lack of oxygen (or to KCN). Eggs which remained in the cyanide sea-water only two or three hours after membrane formation produced plutei in relatively greater numbers than those that remained longer in this solution (see chap. iii).

The optimum length of exposure of the eggs to the potassium cyanide solution depends also upon the concentration of KCN in it. In a mixture of 50 c.c. of sea-water +2 c.c. $1 / 20$ of 1 per cent $\mathrm{KCN}$, three hours seem to represent the optimum length of exposure. If the eggs remain only two hours in the cyanide solution, larvae are usually, but not always, obtained. Thus, in one experiment the eggs were placed two hours after artificial membrane formation in 50 c.c. of sea-water +2 c.c. of $1 / 20$ of 1 per cent $\mathrm{KCN}$. Of the eggs which were removed from this solution after two hours, washed twice in sea-water, and then transferred to normal sea-water, 50 per cent developed into good larvae; 90 per cent of those removed after three hours grew into larvae; but the length of life of the former was greater than that of the latter.

The method of treating the eggs after membrane formation with lack of oxygen or with $\mathrm{KCN}$ has, however, the disadvantage that it is technically very difficult and, secondly, that the time that must elapse between artificial membrane formation and transference to the potassium cyanide solution is obviously not always the same. I have always found that if the eggs are transferred to the cyanide solution immediately after membrane formation, none, or only a few, of the eggs develop; but I am unable to say how long after membrane formation one ought to wait before placing the eggs in the cyanide solution.

These experiments prove at least that it is possible to substitute for the corrective influence of a short treatment with a hypertonic solution a suppression of the development of the egg for a longer period of time. After such a treatment the egg 
seems to be able to segment without disintegrating in the process. While the eggs are without oxygen or in the cyanide solution changes occur in the eggs which allow them to undergo cell division in a normal way, when put back into normal seawater. While this method is theoretically of interest, the method of treating the eggs with hypertonic sea-water after the membrane formation is for practical purposes preferable, since it is absolutely reliable.

The experiments thus far reported show therefore that the artificial membrane formation starts the development of the sea-urchin egg, but that it leaves the egg in a sickly condition which causes it to disintegrate rapidly at room temperature. In order to make such eggs normal, they must undergo a second treatment: they must either be exposed for a short time to a hypertonic solution or for a somewhat longer time to normal sea-water in which the oxidations of the egg are suppressed. 

FURTHER EXAMPLES OF THE PROLONGATION OF THE LIFE OF THE EGG BY LACK OF OXYGEN

1. It is rather curious that lack of oxygen, or probably the suppression of cell division, should be able to delay the disintegration with which the egg of the sea-urchin is threatened after artificial membrane formation. We found an explanation for this phenomenon in the fact that the process of nuclear or cell division is critical for the egg in danger of disintegration. If one suppresses this process the disintegration is markedly retarded. The cell division can be suppressed or retarded by the suppression of oxidations as well as by narcotics. ${ }^{1}$ We also called attention to the fact that if we allow normally fertiiized eggs to segment in abnormal solutions, the process of cell division is also accompanied by processes of disintegration (droplet formation) comparable to those which are characteristic for the egg after artificial membrane formation. We should therefore have a right to expect that if we put fertilized eggs into abnormal solutions, their lives will be prolonged if we inhibit cell division either by lack of oxygen or by $\mathrm{KCN}$ or by other means which inhibit cell division, e.g., narcotics. We should also logically be led to suppose that unfertilized eggs will live longer in such abnormal solutions than fertilized eggs, simply for the reason that they are not threatened with nuclear or cell division.

The writer has made a series of observations which show that quite generally unfertilized eggs suffer less in abnormal solutions than fertilized eggs; and that fertilized eggs suffer less rapidly if their oxidations are suppressed.

1 The narcotics suppress or retard the process of cell division and development without diminishing the rate of oxidation in the egg noticeably. Loeb and Wasteneys, Jour. Biol. Chem., XIV, 518, 1913. 
2. The writer pointed out in 1906 that the fertilized egg of the sea-urchin is injured much more rapidly by abnormal solutions than the unfertilized egg. Fertilized and unfertilized eggs of the same purpuratus female were put into a neutral $\mathrm{m} / 2$ solution of $\mathrm{NaCl}$. From time to time specimens of these eggs were transferred to sea-water to test whether or not they were normal. The fertilized eggs ceased to develop into b'astulae when they were more than three hours in the $\mathrm{m} / 2$ $\mathrm{NaCl}$; while the unfertilized eggs developed normally when sperm was added after they had been in the $\mathrm{NaCl}$ solution for forty-eight hours. The same could be proved for solutions of $\mathrm{KCl}, \mathrm{CaCl}_{2}, \mathrm{MgCl}_{2}$, and other salts. ${ }^{1}$

When we put fertilized and unfertilized eggs of purpuratus into a mixture of $\mathrm{NaCl}+\mathrm{KCl}$ to which some strong base has been added, the fertilized eggs are destroyed much more rapidly than the unfertilized eggs. In fact, the unfertilized eggs can resist a much higher concentration of a strong base than the fertilized eggs. That this difference is due, partly at least, to the difference in the rate of oxidations (and the developmental changes dependent upon these) is proved by the fact that the destructive action of the alkali can be inhibited by the addition of some KCN. Newly fertilized eggs of purpuratus were distributed into the following two solutions:

(1) 50 c.c. $\mathrm{m} / 2 \mathrm{NaCl}+1.1$ c.c. $\mathrm{m} / 2 \mathrm{KCl}+0.2$ c.c. $\mathrm{N} / 10 \mathrm{NaOH}$

(2) 50 c.c. $\mathrm{m} / 2 \mathrm{NaCl}+1.1$ c.c. $\mathrm{m} / 2 \mathrm{KCl}+0.2$ c.c. $\mathrm{N} / 10 \mathrm{NaOH}$ +0.5 c.c. $1 / 10$ of 1 per cent $\mathrm{KCN}$.

The eggs that had been in the first solution for three and one-half hours were all destroyed when they were transferred to normal sea-water. Those that had been in solution (2) were still alive at that time and could continue to develop when transferred into normal sea-water.

${ }^{1}$ Loeb, " Ueber die Ursachen der Giftigkeit einer reinen Chlornatriumlösung, ' Biochem. Zeitschr., II, 81, 1906. It is perhaps worthy of notice that the unfertilized eggs of Arbacia are more quickly injured by solutions of $\mathrm{NaCl}$ than are those of $S$. purpuratus. 
In order to indicate the greater resistance of the unfertilized eggs the following experiments may be mentioned. Unfertilized eggs of purpuratus were distributed into the following two solutions:

(1) 50 c.c. $0.54 \mathrm{~m} \mathrm{NaCl}+1.1$ c.c. $\mathrm{m} / 2 \mathrm{KCl}+1.0$ c.c. $\mathrm{N} / 10 \mathrm{NaOH}$

(2) 50 c.c. $0.54 \mathrm{~m} \mathrm{NaCl}+1.1$ c.c. $\mathrm{m} / 2 \mathrm{KCl}+1.0$ c.c. $\mathrm{N} / 10 \mathrm{NaOH}+$ 0.5 c.c. $1 / 10$ of 1 per cent $\mathrm{KCN}$.

The eggs kept in solution (1) were disintegrated in about six hours. The eggs of solution (2) were still alive after forty-one hours and could still be fertilized after they were transferred into normal sea-water. ${ }^{1}$ (In such experiments the eggs should not be fertilized immediately after they are transferred, but several hours later.)

It could be shown that lack of oxygen acts like the addition of $\mathrm{KCN}^{2}$ The unfertilized eggs resist a concentration of $\mathrm{NaOH}$ five times as great as that used for the fertilized eggs. This experiment also shows that if the oxidations are retarded in the egg by the addition of $\mathrm{KCN}$ it is able to resist the $\mathrm{NaOH}$ much longer.

But it may be doubtful whether we can account in this way for the entire difference between the sensitiveness of fertilized and unfertilized eggs. We must possibly take into consideration the fact that while the fertilized egg is in direct contact with the alkali, the unfertilized egg is surrounded by two shells, the chorion and the cortical layer. The cytoplasm of the unfertilized egg is therefore in all probability not exposed to the same concentration of $\mathrm{NaOH}$ to which the fertilized egg is, which has lost these two layers.

3. The writer was able to show generally that in many abnormal solutions in which the unfertilized egg lives longer than the fertilized egg, the life of the latter may be prolonged by lack of oxygen or by the suppression of oxidations. In a

${ }^{1}$ Loeb, "Ueber die Hemmung der Giftwirkung der Hydroxylionen auf das Seeigelei mittels Cyankalium," Biochem. Zeitschr., XXVI, 279, 1910.

${ }^{2}$ Loeb, ibid., 289. 
mixture of 50 c.c. $\mathrm{m} / 2 \mathrm{NaCl}+2.5$ c.c. $\mathrm{m} / 2 \mathrm{CaCl}_{2}$ the fertilized eggs of Arbacia were injured after three hours and ten minutes to such an extent that they were not able to develop after they were transferred to sea-water. All the fertilized eggs of the same female if kept the same length of time in the same solution free from oxygen developed and many reached the pluteus stage. Some of the eggs taken out after seven hours from this solution free from oxygen were still able to develop into larvae. The addition of five drops of a $1 / 10$ of 1 per cent $\mathrm{KCN}$ solution to 50 c.c. of the abnormal solution acted just as well if not better than lack of oxygen. (This may have been due to the fact that the solution was slightly alkaline which often acts beneficially in solutions containing Ca.) The same could be shown for analogous solutions in which the $\mathrm{CaCl}_{2}$ was replaced by $\mathrm{MgCl}_{2}, \mathrm{SrCl}_{2}$, or $\mathrm{BaCl}_{2}$.

In a mixture of 49 c.c. $6 / 8 \mathrm{~m}$ grape sugar +1 c.c. sea-water which was exposed to oxygen the eggs were injured to such an extent after three hours that practically no egg was able to develop when transferred into sea-water. Eggs which had been for three hours in the same solution freed from oxygen were practically all able to develop.

In this case we were dealing with solutions of substances for which the egg is normally impermeable. It was of considerable interest to find out whether lack of oxygen has the same life-saving effect if the harmful substance diffuses easily into the egg. For this purpose distilled water and narcotics were selected. Newly fertilized eggs of Arbacia were distributed into the following solutions:

(1) 27.5 c.c. sea-water +22.5 c.c. distilled water

(2) 27.5 c.c. sea-water +22.5 c.c. distilled water +5 drops $1 / 10$ of 1 per cent $\mathrm{NaCN}$.

The eggs in the first solution had suffered in five hours and forty minutes to such an extent that no egg was able to develop into a larva, after they were transferred to sea-water. The 
eggs in the second solution when transferred at the same time to sea-water all developed into larvae. The fact that the $\mathrm{NaCN}$ inhibited the development of the eggs in the hypotonic solution saved their lives. An experiment with 27.5 c.c. sea-water + 22.5 c.c. $6 / 8 \mathrm{~m}$ ethylalcohol with and without 5 drops of $1 / 10$ of 1 per cent $\mathrm{NaCN}$ gave a similar result. In the same way it could be shown that excessive amounts of chloroform, chloral hydrate, phenylurethane, when applied in a definite concentration, injured the fertilized eggs much more rapidly if oxygen was present and oxidations were going on in the egg, than if the oxygen was removed from the solution or the oxidations were suppressed through the addition of $\mathrm{KCN}{ }^{1}$

4. The most striking experiments of this kind are perhaps those published by the writer on the inhibition of the toxic effects of hypertonic solutions on the eggs of purpuratus by lack of oxygen or the addition of $\mathrm{KCN}$, or of chloral hydrate. A few examples may be given:

Eggs were fertilized with sperm and put eleven minutes later into three flasks, each of which contained 100 c.c. of seawater +16 c.c. $2 \frac{1}{2} \mathrm{~m} \mathrm{CaCl}_{2}$. One flask was in contact with air, while the other two flasks were connected with a hydrogen generator. The air was driven out from these two flasks before the beginning of the experiment. The eggs were transferred from one of these flasks after four hours and fourteen minutes, from the second flask after five hours and twenty-nine minutes, into normal (aerated) sea-water. The eggs that had been in the hypertonic sea-water exposed to air were transferred simultaneously with the others into separate dishes with aerated normal sea-water. The result was most striking. Those eggs that had been in the hypertonic sea-water with air were all completely disintegrated in a way which I will, for the sake of briefness, designate as "black cytolysis" (Figs. 36, 37, 38).

${ }^{1}$ Loeb, "Die Hemmung verschiedener Giftwirkungen auf das befruchtete Seeigelei durch Hemmung der Oxydationen in demselben," Biochem. Zeitschr., XXIX, 80, 1910. It might be well to indicate that these experiments also contradict the idea that narcosis is due to asphyxiation. 


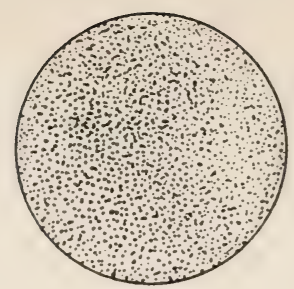

Fig. 32

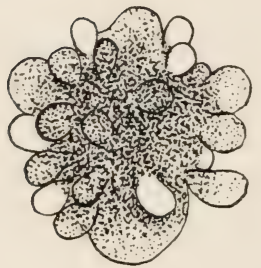

Fig. 34

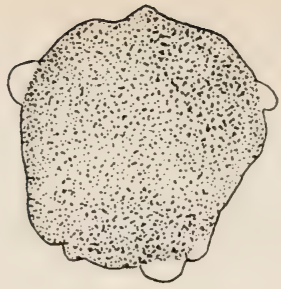

Fig. 33

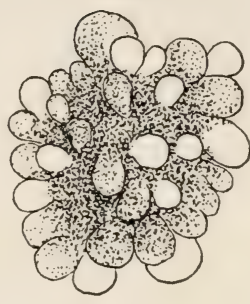

Fig. 35

$$
\begin{aligned}
& \circ \circ: 00^{\circ} \\
& 0.000
\end{aligned}
$$

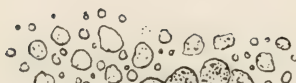$$
\begin{array}{cc}
0 \\
1000
\end{array}
$$$$
\text { Ios } 00^{\circ} 0^{\circ} \circ
$$

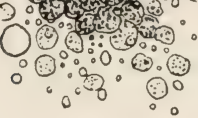

Fig. 36

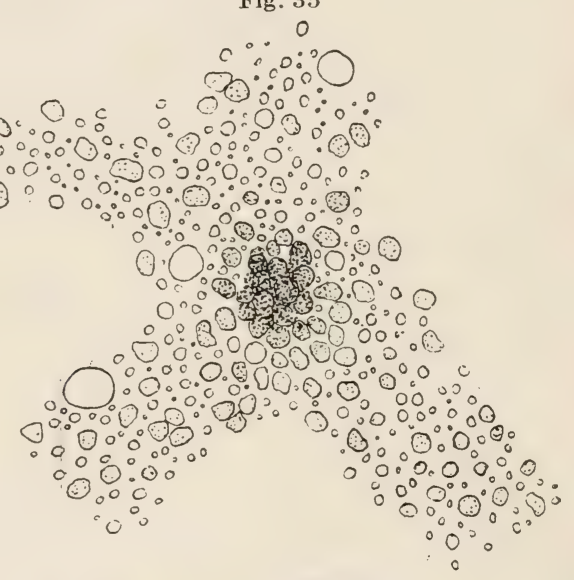

Fig. 37

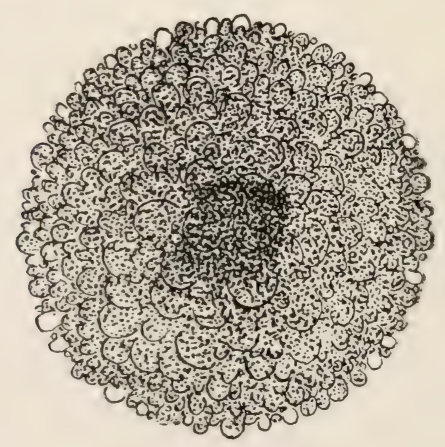

Fig. 38

Frgs. 32-37.-Typical disintegration of a sea-urchin egg, which had been treated for some time with aerated hypertonic sea-water.

Fig. 38.-Another type of "black cytolysis." 
Ten per cent of the eggs had been transformed into "shadows" (white cytolysis). It goes without saying that all the eggs that had been in the aerated hypertonic sea-water five and a half hours were also dead. The eggs that had been in the same solution in the absence of oxygen appeared all normal when they were taken out of the solution, and three hours laterthe temperature was only $15^{\circ} \mathrm{C}$.- they were all, without exception, in a perfectly normal two- or four-cell stage. The further development was also in most cases normal. They swam as larvae at the surface of the vessel and went on the third day (at the right time) into a perfectly normal pluteus stage, after which their observation was discontinued. Of the eggs that had been five and a half hours in the hypertonic sea-water deprived of oxygen, about 90 per cent segmented. ${ }^{1}$

In another experiment newly fertilized eggs of purpuratus were put into two dishes each containing 50 c.c. sea-water + 15 c.c. $2 \frac{1}{2} \mathrm{~m} \mathrm{NaCl}$. To the one dish was added 1 c.c. $1 / 10$ of 1 per cent KCN. The eggs remained 305 minutes in the solution. When they were put back into normal sea-water many of those that had been in the dish containing $\mathrm{KCN}$ developed perfectly normally into plutei, while those that had been in the solution without $\mathrm{KCN}$ all disintegrated into droplets in about one-half hour. These experiments were often repeated and they are indeed very striking demonstration experiments. They show that the inhibition of oxidations in these experiments protects the egg against the injurious effects of the hypertonic solution for a considerable time.

Chloral hydrate had also a very slight protective action. When 2.5 c.c. $\mathrm{N} / 10$ chloral hydrate were added to 68 c.c. of the hypertonic solution, about 5 per cent of the eggs were saved under conditions under which $\mathrm{KCN}$ saved all the eggs. ${ }^{2}$

${ }^{1}$ Loeb, University of California Publications, Physiology, III, 49, 1906.

${ }^{2}$ Loeb, "Ueber die Hemmung der toxischen Wirkung hypertonischer Lösungen auf das Seeigelei durch Sauerstoffmangel und Cyankalium," Pflüger's Archiv, CXIII, 487, 1906. 
It is very characteristic that the eggs usually disintegrate not while they are in the hypertonic solution but after they have been put back into the normal sea-water. This agrees with the observation we made on the disintegration of the egg after membrane formation, namely, that this disintegration begins at the time of the first cell division. The hypertonic solution does not permit cell division, while the cell division begins in an irregular way after the eggs are transferred to normal sea-water. Such eggs disintegrate into little droplets.

The unfertilized eggs do not suffer as quickly in the hypertonic solution as the fertilized eggs. In the unfertilized egg the hypertonic solution must first induce some parthenogenetic changes before it can produce its destructive action.

5. We must in this connection consider an idea emphasized by various authors that the fertilized egg is more permeable than the unfertilized. On this assumption we might understand why the fertilized egg is more easily destroyed in abnormal salt solutions than the unfertilized egg. Leaving aside temporarily the fact that the fertilized egg is protected for some time against the action of the same agencies if its development is prevented by lack of oxygen, this idea meets with other difficulties. If this view were correct, the egg should be permeable for such substances as $\mathrm{NaOH}$, and the fertilized egg much more so than the unfertilized egg. The observations of Warburg and Harvey to be mentioned later have definitely shown that this is not the case. But how are we then to explain such phenomena as the following? The egg of Arbacia possesses a red pigment. If fertilized and unfertilized eggs are put into an alkaline solution, e.g., 50 c.c. $\mathrm{m} / 2 \mathrm{NaCl}+1$ c.c. $\mathrm{m} / 2 \mathrm{BaCl}_{2}+0.2$ c.c. $\mathrm{N} / 10$ $\mathrm{NaOH}$, the fertilized eggs lose their pigment almost instantly while the unfertilized eggs keep it for a long time. ${ }^{1}$ The explanation lies probably in the fact that the alkaline solution comes into direct contact with the cytoplasm of the fertilized egg,

${ }_{1}^{1}$ Loeb, Biochem. Zeitschr., XXIX, 93, 1910. 
while the cytoplasm of the unfertilized egg is surrounded by a chorion and by the cortical layer, which protect it. Hence the surface layer of the fertilized egg is more rapidly injured than that of the unfertilized egg, and this may account for the more rapid escape of pigment from the former.

The fact that KCN or lack of oxygen prolongs the life of the egg in abnormal solutions might be interpreted as indicating that the KCN prevents the diffusion of abnormal solutions into the egg. Wasteneys and the writer investigated this possibility in the fertilized eggs of purpuratus which were stained red with neutral red. Such eggs are rapidly destroyed in a mixture of $\mathrm{NaCl}+\mathrm{KCl}$ to which some $\mathrm{N} / 10 \mathrm{NH}_{4} \mathrm{OH}$ is added; while the addition of KCN prolongs their life in such a solution. This action was not caused by a retardation of the diffusion of $\mathrm{NH}_{4} \mathrm{OH}$ into the egg through the presence of $\mathrm{KCN}$, for it was found that the eggs were just as quickly stained yellow in the solutions of $\mathrm{NH}_{4} \mathrm{OH}$ containing $\mathrm{KCN}$ as in those free from it. The life-saving action of KCN is therefore not due to any effect upon the permeability of the egg.

All the facts agree with the assumption that the egg is more sensitive to abnormal solutions when its rate of oxidations is high or when certain developmental changes, e.g., cell divisions, take place than when it is at rest.

There is, however, an apparent exception to the rule that the fertilized egg is more easily injured than the unfertilized; weak bases like $\mathrm{NH}_{4} \mathrm{OH}$ or the amines injure unfertilized eggs more rapidly than fertilized eggs. When we put unfertilized eggs of Arbacia for twenty minutes at $23^{\circ} \mathrm{C}$. into a mixture of 50 c.c. $\mathrm{m} / 2 \mathrm{NaCl}+\mathrm{KCl}+\mathrm{CaCl}_{2}+0.3$ c.c. $\mathrm{N} / 10 \quad \mathrm{NH}_{4} \mathrm{OH}$ and then transfer them to sea-water, they will begin to segment but will disintegrate very rapidly. If we put newly fertilized eggs for twenty minutes into the same solution we find that the short stay in the ammonia solution does not hurt them. In this experiment the injury to the unfertilized eggs is only the 
indirect effect of the ammonia solution. The latter induces the development in the unfertilized eggs, but if they are not treated with the hypertonic solution they will disintegrate.

The case is similar to our experience with artificial membrane formation by weak acids. The eggs will die after this treatment if they do not receive the necessary second treatment. It is not the weak acid which kills the eggs in this case but the membrane formation without the addition of the second factor. If fertilized eggs receive the same treatment with a weak acid they will not suffer at all. 


\section{XI}

\section{FURTHER EXPERIMENTS ON THE ACTION OF THE}

HYPERTONIC SOLUTION AFTER MEMBRANE

\section{FORMATION}

1. The most convenient and reliable method of saving the eggs of the sea-urchin from disintegrating after artificial membrane formation consists in subjecting them to a short exposure to hypertonic sea-water. If they are then transferred at the right time from this hypertonic solution to normal sea-water, they all segment and develop into larvae; and in a certain percentage of these larvae the development is perfectly normal.

Why do not all the eggs so treated produce normal larvae? In order to understand this we must consider two facts. If the eggs are left too short a time in the hypertonic solution, the threatening disintegration is not prevented and the eggs go to pieces precisely as though no hypertonic solution had been used. If the eggs are left too long in the solution they do indeed all develop into larvae, but the larvae are abnormal; the farther the proper moment for transference of the eggs to normal sea-water has been overshot, the more abnormal the larvae are and the earlier they die.

Now the proper length of exposure to the hypertonic solution is not the same for all eggs. Even if the eggs of the same female are used, exposed for the same length of time to the fatty acid and placed for the same time in the same hypertonic solution, it will be found that the correct time of exposure varies within fairly wide limits for different eggs. This can easily be seen if the eggs are brought back from the hypertonic solution into normal sea-water at intervals of five minutes. Perhaps none of the eggs first returned to normal sea-water develop, until one reaches a portion in which all grow into larvae; but 
not all form normal larvae. Some of the eggs have remained too long in the hypertonic solution and this over-exposure injures the eggs concerned. This is proved by the fact that the number of injured larvae is always the greater the later the eggs were taken out of the hypertonic solution. What determines this individual variation we cannot say. In part it is connected with the unequal distribution of the eggs in the vessel, whereby the access of oxygen to some eggs is more complete than to others. This is, however, only one of several factors. It is an important fact that even a slight over-exposure to the hypertonic solution injures the eggs.

How long ought the eggs to remain in the hypertonic solution? This again depends upon how long after membrane formation they are placed in the hypertonic solution. A. R. Moore has carried out some experiments on this subject in my laboratory on $S$. purpuratus. He determined the time which is necessary to cause all the eggs to develop into larvae. When the eggs are placed in the hypertonic sea-water (50 c.c. of sea-water +8 c.c. $2 \frac{1}{2} \mathrm{~m} \mathrm{NaCl}$ ) immediately, i.e., two to four minutes after membrane formation, they must remain sixty to seventy minutes in the hypertonic solution before all can be caused to develop. When placed in the hypertonic solution thirty minutes after membrane formation, they must remain in it forty to fifty minutes in order to obtain the best results. If transferred to the hypertonic solution one or two hours after artificial membrane formation, it was only necessary to leave them in it thirty to forty minutes in order to get all the eggs to develop into larvae. If a still longer interval elapses before the eggs are put in the hypertonic sea-water after membrane formation, the results again become worse. In these experiments the temperature was about $12^{\circ} \mathrm{C}$.

In order to give the reader a more perfect idea of what has been said I will describe more completely one of my own observations. Membrane formation was produced in the eggs by 
treating them for two minutes with 50 c.c. of sea-water +2.9 c.c. $\mathrm{N} / 10$ butyric acid (which was thoroughly mixed). One portion of the eggs (A) was placed at once in hypertonic sea-water (50 c.c. of sea-water +8 c.c. $2 \frac{1}{2} \mathrm{~m} \mathrm{NaCl}$ ), a second portion (B) thirty minutes later, and a third portion (C) after two hours. At intervals of five minutes a portion of the eggs was replaced in normal sea-water, the number of eggs undergoing segmentation ascertained, and, on the following day, the number of larvae that had been produced was counted. Table VI gives the result. The upper horizontal line shows how long (in minutes) the eggs remained in the hypertonic solution and underneath is shown the percentage of the eggs in each part that grew into larvae.

\section{TABLE VI}

Percentage of the Eggs Which Developed into Larvae after Remaining in the Solution

\begin{tabular}{|c|c|c|c|c|c|c|c|c|c|c|}
\hline & $5^{\prime}$ & $10^{\prime}$ & $15^{\prime}$ & $20^{\prime}$ & $25^{\prime}$ & $30^{\prime}$ & $35^{\prime}$ & $40^{\prime}$ & $45^{\prime}$ & $50^{\prime}$ \\
\hline & 0 & 0 & 0 & 0 & 0 & 1 & 30 & 90 & 99 & 100 \\
\hline B & 0 & 0 & $\frac{1}{2}$ & 40 & 70 & 90 & 98 & . & . . & .. \\
\hline C & 0 & $\frac{1}{4}$ & 10 & 30 & 70 & 90 & 100 & . & . & . \\
\hline
\end{tabular}

The temperature of the hypertonic solution was $15^{\circ} \mathrm{C}$.

What is the cause of this variation in time required for the exposure to the hypertonic solution? I suspect that it has something to do with changes which occur in the egg after the membrane formation. One of these changes is the formation of a fine gelatinous layer around the cytoplasm, which does not begin until at least ten or fifteen minutes after the membrane formation. It may be that the hypertonic solution only or mainly takes effect after a definite change has taken place in the egg.

In all the experiments hereafter mentioned, the eggs were transferred some ten minutes after membrane formation; hence the length of exposure is somewhat as in series A. 
2. We will now inquire how the time which the eggs must remain in the hypertonic solution varies with the osmotic pressure of the latter. ${ }^{1}$

The eggs of a sea-urchin were treated with sea-water containing butyric acid, and all formed membranes. The eggs were then distributed among solutions consisting of 50 c.c. of sea-water +respectively, $0,1,2,3,4,5,6,7,8,10,12$, and 14 c.c. of $2 \frac{1}{2} \mathrm{~m}$ (grammolecular) $\mathrm{NaCl}$ solution. A portion of the eggs was transferred from each of these solutions to normal sea-water after $33,45,57,68,98$, and 128 minutes, and the percentage that developed into larvae determined for each portion. Table VII gives the result. The temperature of the hypertonic solution was $16^{\circ} \mathrm{C}$.

\section{TABLE VII}

\begin{tabular}{|c|c|c|c|c|c|c|}
\hline \multirow[t]{2}{*}{ NATURE OF THE SOLUTION } & \multicolumn{6}{|c|}{ 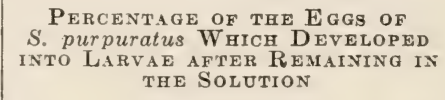 } \\
\hline & $\begin{array}{c}33 \\
\text { min. }\end{array}$ & $\begin{array}{c}45 \\
\text { min. }\end{array}$ & $\begin{array}{l}57 \\
\min .\end{array}$ & $\begin{array}{c}68 \\
\text { min. }\end{array}$ & $\begin{array}{c}98 \\
\text { min. }\end{array}$ & $\begin{array}{c}128 \\
\text { min. }\end{array}$ \\
\hline 50 c.c. of sea & 0 & 0 & 0 & 0 & 0 & 0 \\
\hline 50 c.c. of sea-water +4 c.c. $2 \frac{1}{2} \mathrm{~m}$ & 0 & 0 & 0 & 0 & 0 & a few \\
\hline 50 c.c. of sea-water +5 c.c. $2 \frac{1}{2} \mathrm{~m} \mathrm{NaCl}$ & 0 & 0 & 0 & 1 & 30 & 60 \\
\hline 50 c.c. of sea-water +6 c.c. $2 \frac{1}{2} \mathrm{~m} \mathrm{NaCl}$ & 0 & 0 & 2 & 50 & 100 & 10 \\
\hline 50 c.c. of sea-water +7 c.c. $2 \frac{1}{2}$ in $\mathrm{NaCl}$ & 0 & 1 & 30 & 70 & 70 & 0 \\
\hline 50 c.c. of sea-water +8 c.c. $2 \frac{1}{2} \mathrm{~m} \mathrm{NaCl}$ & 0 & 1 & 50 & 80 & a few & 0 \\
\hline 50 c.c. of sea-water +10 c.c. $2 \frac{1}{2} \mathrm{~m} \mathrm{NaCl}$ & 0 & 0 & 10 & 10 & 1 & 0 \\
\hline 50 c.c. of sea-water +12 c.c. $2 \frac{1}{2} \mathrm{~m} \mathrm{NaCl}$ & 0 & 0 & a few & 0 & 0 & 0 \\
\hline 50 c.c. of sea-water +14 c.c. $2 \frac{1}{2} \mathrm{~m} \mathrm{NaCl}$ & 0 & 0 & 0 & 0 & 0 & 0 \\
\hline
\end{tabular}

This brings out two facts. In the first place the effectiveness of the hypertonic solution has definite limits. The addition of 4 c.c. of $2 \frac{1}{2} \mathrm{~m} \mathrm{NaCl}$ is too small, the addition of 12 c.c. too much, and in the latter case the eggs go to pieces by disintegrating into drops. Secondly, we see that when once the optimum concentration is reached, i.e., that which produces the

${ }^{1}$ Loeb, "Ueber den Unterschied zwischen isosmotischen und isotonischen Lösungen bei der künstlichen Parthenogenese," Biochem. Zeitschr., XI, 144, 1908. 
highest percentage of larvae (viz., 7 c.c. of $2 \frac{1}{2} \mathrm{~m} \mathrm{NaCl}$ ), a further increase in concentration does not decrease the time during which the egg has to remain in the hypertonic solution. This has some bearing on the theory of the action of the hypertonic solution. Since the loss of water by the egg in this solution increases with its concentration, it is obvious that the effect of the hypertonic solution does not grow in proportion with the loss of water on the part of the egg.

This experiment has been very often repeated with an essentially similar result. The addition of only 3 c.c. of $2 \frac{1}{2} \mathrm{~m} \mathrm{NaCl}$ to 50 c.c. of sea-water has never led to the development of a larva of $S$. purpuratus after membrane formation, however long the eggs are left in the solution.

An example of such an experiment with a longer range of time should be mentioned. The unfertilized eggs of a female S. purpuratus were placed after artificial membrane formation in 50 c.c. of sea-water $+0,1,2,3$, 4 , etc., of $2 \frac{1}{2} \mathrm{~m} \mathrm{NaCl}$. After 37 , $47,57,110,150,200,280$, and 340 minutes a portion of eggs from each bowl was replaced into normal sea-water. Temperature $16.5^{\circ}$ to $17.5^{\circ} \mathrm{C}$.

This experiment described by Table VIII again demonstrates that the addition of less than 4 c.c. of $2 \frac{1}{2} \mathrm{~m} \mathrm{NaCl}$ to 50 c.c. of sea-water is not sufficient to protect the eggs from decay and evoke development even after prolonged exposure. Moreover, it is clear that when once the optimum is reached the time of exposure cannot be decreased by a further raising of the concentration of the sea-water. When 8 c.c. of $2 \frac{1}{2} \mathrm{~m}$ $\mathrm{NaCl}$ is added, the minimum length of exposure is 47 minutes, and the same is the case when 12 c.c. of $2 \frac{1}{2} \mathrm{~m} \mathrm{NaCl}$ is added. ${ }^{1}$

Perhaps the following facts explain why it is not possible to save eggs from disintegrating by the addition of less than 4 c.c. of $2 \frac{1}{2} \mathrm{~m} \mathrm{NaCl}$ to 50 c.c. of sea-water after artificial membrane

\footnotetext{
${ }^{1}$ In these experiments the eggs were placed in the hypertonic solution very soon after membrane formation; otherwise the times would have been shorter.
} 
formation. If eggs fertilized with sperm are placed in 50 c.c. of sea-water, to which increasing amounts of $2 \frac{1}{2} \mathrm{~m} \mathrm{NaCl}$ are added, it can be seen that the addition of 1 c.c. of $2 \frac{1}{2} \mathrm{~m} \mathrm{NaCl}$ to 50 c.c. of sea-water has no effect on the development; the addition of 2 c.c. of $2 \frac{1}{2} \mathrm{~m} \mathrm{NaCl}$ retards the first division, but to a scarcely noticeable degree; while the addition of 3 c.c. increases

TABLE VIII

\begin{tabular}{|c|c|c|c|c|c|c|c|c|}
\hline \multirow{2}{*}{ Nature of the Solution } & \multicolumn{8}{|c|}{$\begin{array}{c}\text { Percentage of Egga That Developed into Larvae } \\
\text { after Remaining in the Solution }\end{array}$} \\
\hline & $\begin{array}{c}37 \\
\text { min. }\end{array}$ & $\begin{array}{c}47 \\
\text { min. }\end{array}$ & $\begin{array}{c}57 \\
\text { min. }\end{array}$ & $\begin{array}{c}110 \\
\text { min. }\end{array}$ & $\begin{array}{l}150 \\
\text { min. }\end{array}$ & $\begin{array}{l}200 \\
\min .\end{array}$ & $\begin{array}{l}280 \\
\text { min. }\end{array}$ & $\begin{array}{l}340 \\
\text { min. }\end{array}$ \\
\hline 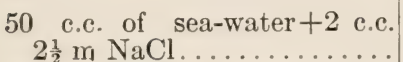 & 0 & 0 & 0 & 0 & 0 & 0 & 0 & 0 \\
\hline 50 c.c. of sea-water +3 c.c. & & & & & & & & \\
\hline $\begin{array}{l}2 \frac{1}{2} \mathrm{~m} \mathrm{NaCl} \ldots \ldots \ldots \ldots \ldots \\
50 \text { c.c. of sea-water }+4 \text { c.c. }\end{array}$ & 0 & 0 & 0 & 0 & 0 & 0 & 0 & 0 \\
\hline 50 m NaCl. . . . & 0 & 0 & 0 & 1 & 5 & 8 & . & 30 \\
\hline $2 \frac{1}{2} \mathrm{~m} \mathrm{NaCl} \ldots \ldots \ldots \ldots$ & 0 & 0 & 30 & 50 & 80 & 90 & 90 & 40 \\
\hline $\begin{array}{l}50 \text { c.c. of sea-water }+6 \quad \text { c.c. } \\
2 \frac{1}{2} \mathrm{~m} \mathrm{NaCl} \ldots \ldots \ldots \ldots \ldots\end{array}$ & $\cdots$ & $\cdots$ & 80 & 95 & $\cdots$ & $\ldots$ & $\cdots$ & $\ldots$ \\
\hline $\begin{array}{l}50 \text { c.c. of sea-water }+8 \text { c.c. } \\
2 \frac{1}{2} \mathrm{~m} \mathrm{NaCl} \ldots \ldots \ldots \ldots \ldots\end{array}$ & 0 & 10 & 100 & & $\cdots$ & $\cdots$ & $\cdots$ & . \\
\hline $\begin{array}{l}50 \text { c.c. of sea-water }+10 \text { c.c. } \\
2 \frac{1}{2} \mathrm{~m} \text { NaCl. } \ldots \ldots \ldots \ldots \ldots \\
50 \text { c.c. of sea-water }+12 \text { c.c. }\end{array}$ & a few & 8 & 30 & & & & $\ldots$ & . \\
\hline $2 \frac{1}{2} \mathrm{~m} \mathrm{NaCl} \ldots \ldots \ldots \ldots \ldots$ & 0 & 1 & 2 & 0 & 0 & 0 & 0 & 0 \\
\hline $\begin{array}{l}50 \text { c.c. of sea-water }+14 \text { c.c. } \\
2 \frac{1}{2} \mathrm{~m} \mathrm{NaCl} \ldots \ldots \ldots \ldots \ldots \ldots\end{array}$ & 0 & 0 & 0 & a few & 0 & 0 & 0 & 0 \\
\hline
\end{tabular}

the time of the first division by about 12 per cent of its usual length, although the development of the eggs proceeds almost normally. The addition of 4 c.c. of $2 \frac{1}{2} \mathrm{~m} \mathrm{NaCl}$ to 50 c.c. of sea-water is the first to delay the first cleavage for several hours (over 100 per cent of the normal length); it is true that the eggs can develop very slowly in this solution, but not all the eggs are able to develop. Hence it appears that here too the addition of 4 c.c. of $\mathrm{NaCl}$ is of critical importance. In 50 c.c. of seawater +5 c.c. $2 \frac{1}{2} \mathrm{~m} \mathrm{NaCl}$ the eggs do not develop beyond the thirty-two- to sixty-four-cell stage. Probably, therefore, in a 
solution of 50 c.c. of sea-water +4 c.c. of $2 \frac{1}{2} \mathrm{~m} \mathrm{NaCl}$ considerable changes take place in the chemical reactions within the egg. These changes lead to those effects which, after membrane formation, allow the egg to develop normally upon transference to ordinary sea-water.

3. The third factor which determines the length of exposure to the hypertonic solution is the temperature. In my first papers upon artificial parthenogenesis I was undecided as to whether the hypertonic solution has a purely physical or a purely chemical action. I had found in 1892 that it prevents cell division more quickly than nuclear division. Since a hypertonic solution prevents cell division more easily than nuclear division, one can obtain, at a certain minimal grade of the hypertonicity of the solution, nuclear division without cell division. It is quite possible (though not proven) that this prevention of cleavage depends upon the rise in viscosity of the protoplasm, owing to the withdrawal of water from it in the hypertonic solution. On the other hand, it was not very probable that the activation of the unfertilized egg by a hypertonic solution could be referred to a physical effect.

The determination of the temperature coefficient affords us a ready means of differentiating whether a given physiological process depends upon a chemical reaction or upon a purely physical change. As van't Hoff and Arrhenius have shown, the temperature coefficient for chemical reactions is relatively high, viz., not less than 2 for $10^{\circ} \mathrm{C}$., while physical processes possess in general a lower temperature coefficient. We can in this way set up a criterion whether the effect of the hypertonic solution upon the egg after artificial membrane formation depends upon the influence of a chemical reaction within the egg or a physical process. ${ }^{1}$

1 In my first researches upon the effects of salts, I was troubled because I possessed no criterion to decide whether I had to deal with purely physical phenomena, e.g., coagulations, or with chemical processes. Cohen's admirable

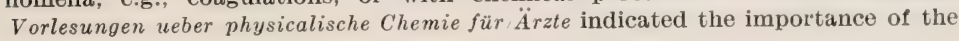


With this object in view, the following experiments were performed. Membrane formation was produced by treating eggs of $S$. purpuratus with butyric acid. The eggs were then divided into two dishes containing the same hypertonic solution ( 50 c.c. of sea-water +8 c.c. $2 \frac{1}{2} \mathrm{~m} \mathrm{NaCl}$ ). One of these dishes was maintained at a certain temperature, the other at a temperature $10^{\circ}$ higher. At different intervals, portions of the eggs were replaced in normal sea-water of room temperature, and the minimum exposure necessary to allow a certain percentage of the eggs to develop was noted. The results for the eggs of five different sea-urchins ( $S$. purpuratus) are contained in Table IX. One noteworthy result was that at temperatures above $20^{\circ} \mathrm{C}$. the eggs were harmed by the hypertonic solution. Of course, this does not hold for the eggs of all sea-urchins, as my experiments at Woods Hole were usually performed at a temperature of over $20^{\circ} \mathrm{C}$. It is probably connected with the fact that the temperature of the water at Pacific Grove never is as high as that at Woods Hole in summer.

\section{TABLE IX}

\begin{tabular}{|c|c|c|}
\hline Temperature & $\begin{array}{l}\text { Minimum Exposure } \\
\text { for Production of } \\
\text { Numerous Larvae }\end{array}$ & $\begin{array}{c}\text { Temperature Coefficient } \\
Q_{\text {10 }} \text { for } 10^{\circ} \mathrm{C} \text {. }\end{array}$ \\
\hline 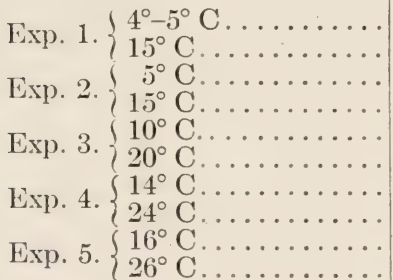 & $\begin{array}{l}210 \text { minutes } \\
40 \text { minutes } \\
160 \text { minutes } \\
\text { about } 55 \text { minutes } \\
\text { about } 112 \text { minutes } \\
\text { about } 32 \text { minutes } \\
\text { about } 50 \text { minutes } \\
\text { all eggs die } \\
\text { about } 35 \text { minutes } \\
\text { all eggs die }\end{array}$ & $\begin{array}{l}\mathrm{Q}_{\mathrm{IO}}=5 \\
\mathrm{Q}_{\mathrm{X} 0}=3 \\
\mathrm{Q}_{\mathrm{I0}}=3.5 \\
?\end{array}$ \\
\hline
\end{tabular}

temperature coefficient in settling this question. I myself applied this criterion to the sphere of the physiology of development, and caused my pupils, C. D. Snyder and S. S. Maxwell, to employ it in settling the question whether the heart beat and the transmission of nervous impulses depend upon chemical or physical processes. The temperature coefficient found in the heart beat was of the order of magnitude for chemical processes. 
It is clear that the temperature coefficient $\mathrm{Q}_{10}$ is higher than 2 , in the neighborhood of 3 , and that it quickly increases at temperatures which are close to $0^{\circ}$, and reaches the value 5 or perhaps still higher values. ${ }^{1}$ Hence the order of magnitude of the temperature coefficient indicates that we are dealing here with a chemical effect of the hypertonic solution.

4. We are in a position to determine more closely the nature of the chemical processes upon which the efficiency of the hypertonic solution depends, namely oxidations. The efficacy of the hypertonic solution is completely removed if we inhilit oxidations in the egg by means of potassium cyanide or by the withdrawal of oxygen. ${ }^{2}$

It can be shown that the treatment of eggs after artificial membrane formation with hypertonic sea-water remains ineffective if the latter contains an insufficient amount of oxygen, or if it contains KCN. After removal from such solutions, the eggs behave as if only membrane formation had been produced, i.e., they begin to develop, but quickly disintegrate in the manner described in the previous chapter. A single example will suffice to illustrate this.

Unfertilized eggs of $S$. purpuratus were placed for one and one-half to two minutes in 50 c.c. of sea-water +3 c.c. $\mathrm{N} / 10$ butyric acid, and, as usual, all formed a perfect fertilization membrane upon transference to sea-water. They were then distributed over the following solutions:

(1) 50 c.c. of sea-water +8 c.c. of $2 \frac{1}{2} \mathrm{~m} \mathrm{NaCl}$

(2) 50 c.c. of sea-water +8 c.c. of $2 \frac{1}{2} \mathrm{~m} \mathrm{NaCl}+2$ c.c. $1 / 20$ of 1 per cent $\mathrm{KCN}$.

After $30,40,50,135,195,285,335,385,450$, and 1,320 minutes, a sample of the eggs was transferred to normal sea-water. The temperature was $18^{\circ} \mathrm{C}$. For the eggs in the first solution, the

${ }^{1}$ Loeb, Untersuchungen, p. 494; University of California Publications, Physiology, III, 39, 1906.

${ }^{2}$ Loeb, Biochem. Zeitschr., I, 194, 1906. 
result was as follows. Thirty minutes in the hypertonic solution was not enough, and all the eggs disintegrated except a few which developed. Forty and fifty minutes were sufficient and about 50 per cent of the eggs developed into larvae. The eggs that had been 135 minutes and longer in the hypertonic solution went to pieces. None of the eggs, on the otber hand, which had been in the hypertonic solution with potassium cyanide (in which the oxidations were inhibited) developed, whose exposure to that solution had been less than 385 minutes. All such eggs disintegrated in the course of the next twenty-four hours, and in the same manner as eggs which are left in normal sea-water, not transferred to hypertonic solutions after membrane formation. Hence the effect of the hypertonic solution was nullified by the addition of potassium cyanide. A small number-some two to four in a watch glass containing many thousands of eggs - of the eggs, which were in the hypertonic solution for more than 385 minutes, developed into blastulae. Again, the eggs which had been longest in the hypertonic seawater with potassium cyanide did not go to pieces so rapidly when transferred to normal sea-water, as those whose exposure thereto had been of shorter duration. This probably is connected with the fact that eggs which remain longer in the cyanide sea-water take up more $\mathrm{KCN}$ or $\mathrm{HCN}$. This experiment was repeated very often, and always with the same result. Usually the addition of a sufficient quantity of potassium cyanide to the hypertonic sea-water completely inhibited the action of the latter. It is worthy of mention that the $\mathrm{KCN}$ does not prevent but only retards the oxidations, and this retardation is less the less $\mathrm{KCN}$ is added.

It might be objected that in the previous experiment potassium cyanide had killed the eggs, or, at all events, rendered them incapable of development. The following experiment, however, will overthrow this idea.

After artificial membrane formation (by means of butyric 
acid) the eggs of a female were divided between two dishes, each containing 50 c.c. of sea-water +8 c.c. of $2 \frac{1}{2} \mathrm{~m} \mathrm{NaCl}$. To one dish 2 c.c. of $1 / 20$ of 1 per cent KCN were added. Samples of the eggs were transferred at intervals of ten minutes from the hypertonic to normal sea-water.

We will consider first the behavior of the eggs which had been in the hypertonic solution without potassium cyanide. None of the eggs transferred from the hypertonic to normal sea-water before thirty-five minutes had elapsed developed; some 5 per cent of those transferred to normal sea-water after thirty-five minutes developed into good larvae; practically all of those transferred after forty-five minutes developed, and the majority to normal larvae. Of those transferred after fifty-five minutes practically all developed, but only 20 per cent gave rise to normal larvae, while with eggs left still longer in the hypertonic solution the results became worse with increasing length of exposure.

Not a single one of the eggs which had been in the hypertonic sea-water with potassium cyanide for from thirty-five to fifty-five minutes developed when transferred to normal sea-water; the majority disintegrated in the course of the next twenty-four hours. But the greater part of the eggs which had been taken from the hypertonic sea-water with KCN after fifty-five minutes were then placed not in normal sea-water, but in hypertonic sea-water (50 c.c. sea-water +8 c.c $2 \frac{1}{2} \mathrm{~m}$ $\mathrm{NaCl}$ ), which this time contained no potassium cyanide. Samples of these eggs were transferred to normal sea-water $20,30,40,50$, and 60 minutes later. Of these eggs taken out of the hypertonic sea-water after forty minutes, some 5 per cent developed, of those taken out after fifty minutes some 30 per cent, while practically all of those transferred after sixty minutes developed, though some already showed the effects of over-exposure by abnormal cleavage. This experiment, which was repeated several times with the same result, shows that the 
hypertonic solution remains practically ineffective in the presence of a minute quantity of potassium cyanide, but that the eggs are not in the least injured by the latter in so short a time.

It can be directly shown that the hypertonic solution is effective only in the presence of free oxygen, by simply expelling the air from the hypertonic solution. But this experiment can very easily miscarry on account of the interference of a troublesome source of error. Usually the hypertonic solution can be frecd as far as possible from oxygen by passing through it for several hours a current of scrupulously purified hydrogen. Then a drop or two of eggs are placed in the solution. And herein lies the source of error. On opening the flask, of course some oxygen enters it, and for a short time the hypertonic solution is acting, not in the absence, but in the presence, of some oxygen. Now obviously only a little oxygen is sufficient to maintain the processes of oxidation which underlie the development of the egg. I had already noticed this eighteen years ago in my first experiments upon the necessity of oxygen for normal cleavage. But, as already mentioned, the eggs need to remain only a short time--some thirty to fifty minutes -in the hypertonic solution after membrane formation, and it is clear that in so short a time the introduction of a little oxygen into the hypertonic solution may easily frustrate the whole experiment. I reduced this risk by opening the stopper of the flask with the aid of a skilled assistant for only about a second and for a distance of only a millimeter in order to introduce the eggs. Before, during, and immediately after the opening a very strong current of hydrogen was passed through the flask. Negative experiments, i.e., ones in which the hypertonic solution caused a few or many of the eggs to develop, even after the passing of a current of hydrogen, do not prove much ; but

1 They only show that too much oxygen was present inadvertently in the hypertonic solution. I indicated this source of error in my first note upon the subject: Loeb, "On the Necessity of the Presence of Free Oxygen in the Hypertonic Sea-Water for the Production of Artificial Parthenogenesis," University of California Publications, Physiology, III, 39, 1906. 
on the other hand, those experiments are important in which the hypertonic solution remains ineffective in the absence of oxygen, but regains its powers if oxygen be afterward admitted.

The eggs of $S$. purpuratus were treated with butyric acid in the usual manner, and all formed membranes. These eggs were then divided between two flasks containing the same hypertonic solution. Through one flask bubbled a stream of oxygen, and through the other a stream of hydrogen, by means of which it had been previously freed from oxygen. The temperature was $14^{\circ} \mathrm{C}$. After one hour the eggs were transferred to normal sea-water (in contact with air). Practically all the eggs which had been in the oxygenated hypertonic seawater developed into larvae, while only a small number of larvae, amounting to perhaps one-half of 1 per cent of the eggs, developed from those eggs which had been in the hypertonic sea-water that was free from, or more strictly poor in, oxygen. The remaining eggs disintegrated in the manner characteristic of eggs that have undergone artificial membrane formation without exposure to hypertonic sea-water. I now wished to convince myself that the eggs which go to pieces after exposure to hypertonic sea-water that is free from or poor in oxygen do develop, if they are exposed afterward in the same hypertonic solution to the air. To this end not all of the eggs were removed after the conclusion of the above experiment from the hypertonic solution out of which the oxygen had been driven, but some of them were left in this hypertonic solution. This time, however, the latter was exposed to the air. At intervals of 14, 26, 36, 46,56 , and 116 minutes samples of the eggs were transferred to normal sea-water. The result is given in Table $\mathrm{X}$.

From this experiment we can with certainty draw the conclusion that the hypertonic solution in these experiments is effective only when it contains a sufficient quantity of free oxygen. 
5. It appeared interesting to determine in what way an increase of the concentration of $\mathrm{HO}$ ions in the hypertonic solution would increase the rapidity of its action. To this end not sea-water, but a neutral mixture of $\mathrm{m} / 2 \mathrm{NaCl}, \mathrm{KCl}, \mathrm{CaCl}_{2}$, and $\mathrm{MgCl}_{2}$ (in the proportion in which these salts are present

TABLE $\mathrm{X}$

\begin{tabular}{|c|c|}
\hline $\begin{array}{c}\text { TIME oF EXPOSURE of THE } \\
\text { EgGSTOHYPERTONIC } \\
\text { SEA-WATER }\end{array}$ & $\begin{array}{l}\text { Percentage of the Egga } \\
\text { That Developed into }\end{array}$ \\
\hline $\begin{array}{l}\text { Without } \\
\text { Oxygen }\end{array}$ & \\
\hline $\begin{array}{l}60 \text { minutes }+\quad 0 \text { minutes } \\
60 \text { minutes }+14 \text { minutes } \\
60 \text { minutes }+26 \text { minutes } \\
60 \text { minutes }+36 \text { minutes } \\
60 \text { minutes }+46 \text { minutes } \\
60 \text { minutes }+56 \text { minutes } \\
60 \text { minutes }+116 \text { minutes }\end{array}$ & $\begin{array}{c}\frac{1}{2} \\
4 \\
30 \\
30 \\
90 \\
\text { a few } \\
\text { no larvae, all the } \\
\text { eggs died }\end{array}$ \\
\hline
\end{tabular}

in sea-water) was used. To each 50 c.c. of this solution, 8 c.c. of $2 \frac{1}{2} \mathrm{~m} \mathrm{NaCl}$ solution, also neutral, were added to produce the necessary hypertonicity; then, $0,0.1,0.2,0.4,0.8$, and 1.6 c.c. of $\mathrm{N} / 50 \mathrm{NaOH}$ were added each to 50 c.c. of this mixture. The eggs of a $S$. purpuratus were divided among these solutions after membrane formation had been produced by the use of butyric acid. Table XI gives the percentage of larvae resulting.

TABLE XI

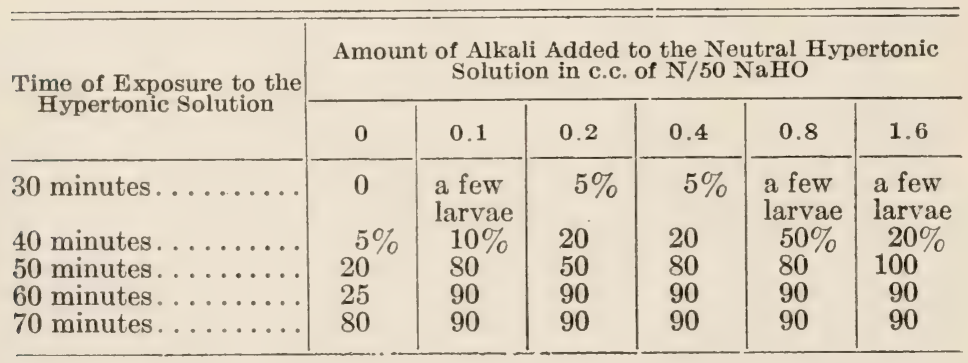


The larvae were crippled by too long an exposure. I also found that one could even obtain larvae if a trace of $\mathrm{HCl}$ was added to the hypertonic solution. I have not yet determined the lower limit of the concentration of hydroxylions in the hypertonic solution. ${ }^{1}$

6 . We will now proceed to the discussion of an apparent contradiction between the results of this and of the previous chapter. In the latter we saw that the eggs can be made to develop after membrane formation by keeping them for three hours or more in water that is poor in oxygen, or by preventing the oxidations by the addition of KCN. In this chapter we saw that the eggs after membrane formation can be made to develop by putting them afterward into hypertonic sea-water for some thirty to fifty minutes; but that this is only possible if the hypertonic sea-water contains a sufficient amount of free oxygen. How are these apparently contradictory statements to be reconciled?

The essence of the activation of the unfertilized egg consists in the production of membrane formation. This process is certainly not one of oxidation, since it can take place in the absence of oxygen or in the presence of KCN. Perhaps it depends ultimately upon a purely physical process (such as the liquefaction of a lipoid or the dissociation of a [hypotl ctical] lipoid-protein combination).

As soon as this process has taken place, development sets in in the egg. Why this is the case, we do not at present know. But at the same time this process leaves the egg in an abnormal or sickly condition. If the egg begins to develop while in this injured condition, it disintegrates. But if we prevent the egg from developing for some hours, by depriving it of oxygen, or stopping oxidations by the addition of $\mathrm{KCN}$, the egg can develop normally. We must seek the reason for this in the

${ }^{1}$ Loeb, "Zur Analyse der osmotischen Entwicklungserregung unbefruchteter Seeigeleier," Pflüger's Archiv, CXVIII, 197, 1907. 
assumption that, while the oxidations are inhibited, certain other processes, such as hydrolyses, go on in the egg, and that these processes lead to the formation of substances which now allow the egg to develop without disintegrating in this process. But the same result can be obtained more quickly if we modify the process of oxidation or some of its effects by putting the eggs for a short time into a hypertonic solution.

We have already mentioned that it makes no difference in principle whether the eggs are first caused to form membranes, or whether they are first placed in hypertonic sea-water and the membrane formation is instigated afterward. ${ }^{1}$ The only difference between the two procedures consists in the fact that in the latter case the eggs must remain much longer in the hypertonic sea-water.

7. If the egg is treated with hypertonic sea-water before the artificial membrane formation, it has to remain about twice as long in the hypertonic solution as if the order of events is reversed. The unfertilized eggs of $S$. purpuratus were put into hypertonic sea-water (50 c.c. sea-water +8 c.c. $2 \frac{1}{2} \mathrm{~m}$ Ringer) and portions of these eggs were transferred to normal sea-water after $30,60,90,120,150$, and 180 minutes. Ten minutes after they were transferred artificial membrane formation was called forth by butyric acid. The eggs which had been 30 and 60 minutes in the hypertonic solution all disintegrated in the way characteristic for eggs in which membrane formation has been called forth, but which have not undergone this treatment with hypertonic sea-water. A few of the eggs that had been 90 minutes in hypertonic sea-water developed. Practically all of those that had been 150 minutes in the hypertonic sea-water developed. Those eggs which had only undergone the treatment with the hypertonic solution without being subsequently treated with butyric acid did not develop into larvae. We

${ }_{1}^{1}$ For practical purposes the natural order, membrane formation followed by hypertonic solution, is preferable. 
have already stated that the treatment of unfertilized eggs of S. purpuratus with hypertonic sea-water alone leads to the formation of larvae, not with the eggs of all females, but with only a small percentage.

When the order of events was reversed and the treatment with hypertonic sea-water followed the artificial membrane formation all the eggs developed if they remained in the seawater from about 50 to 60 minutes. The reason for this difference is easily understood if we compare the rate of oxidations before and after membrane formation. After membrane formation the rate of oxidations is more than four times as large in the egg as before (chap. xii). With this fast rate of oxidation the eggs need remain only a short time in the hypertonic solution. If, however, we put the eggs in the hypertonic solution before the membrane is formed, they have to stay more than twice as long in the hypertonic solution because the rate of oxidations is at first so much slower. 



\section{XII}

THE EFFECT OF THE AGENCIES OF ARTIFICIAL PARTHENOGENESIS UPON THE OXIDATIONS. THE CYTOLOGICAL CHANGES IN THE PARTHENOGENETIC EGG

1. The experiments thus far considered have shown that it is possible to imitate the activating effect of the spermatozoon upon the egg of the sea-urchin approximately by submitting the egg to two different processes. The first process consists in calling forth the membrane formation in the egg by a fatty acid (or as we shall see later by a number of other chemicals). This process seems to be the essential feature in the activation of the egg, since it suffices to set in motion the whole apparatus of nuclear and cell division. The second process has only a corrective effect, since the membrane formation alone leads to a rapid disintegration of the egg, unless the temperature is very low. The prevention of this disintegration is brought about by the second process. This second process consists in submitting the egg for a short period to a hypertonic solution containing oxygen (or for a longer period to sea-water free from oxygen).

We will now consider the effects of these two processes upon the oxidations in the egg, and afterward gain an insight into the cytological changes produced in the egg by these agencies.

We will first consider the effect of the membrane formation. The reader will remember that I had shown that the disintegration of the egg which follows the artificial membrane formation at room temperature (if the egg is not treated also with a hypertonic solution or lack of oxygen) can be retarded for a long time if the egg is kept without oxygen. From this fact I 
concluded that the artificial membrane formation increases the rate of oxidations in the egg.

The correctness of this surmise was proven by $\mathrm{O}$. Warburg, who compared the effect of the artificial membrane formation upon the oxidations in the egg with that of fertilization by sperm. The ratio was 10.5 for eggs fertilized by sperm and 9.0 for eggs after artificial membrane formation. ${ }^{1}$ Hence the effect of the artificial membrane formation upon the rate of oxidations was nearly the same as that of fertilization by sperm. Warburg's experiments were performed on the egg of S. lividus at Naples. Wasteneys and I repeated the experiments ${ }^{2}$ on the eggs of S. purpuratus at Pacific Grove.

In three experiments on $S$. purpuratus the ratio of oxygen consumption between unfertilized and fertilized eggs was $1 / 6.87,1 / 5.45$, and $1 / 5.60$.

A comparison of the oxygen consumption of unfertilized eggs before and after membrane formation by butyric acid gave in one experiment a ratio of $1 / 4.72$; in a second experiment a ratio of $1 / 4.28$. Since this figure was a little lower than the ratio found between unfertilized and fertilized eggs, part of the eggs of the same females were utilized to determine the rate of oxidation in the unfertilized and fertilized egg. It was found to be $1 / 4.55$. We may therefore state that the artificial membrane formation raises the rate of oxidations to approximately the same height as the entrance of a spermatozoon. This confirms the conclusion the writer had drawn concerning the rôle of the artificial membrane formation, namely, that it is the essential feature in the activation of the egg; and second, that the activation consists in an increase in the rate of oxidations. The question then arises, In which way can the artificial membrane formation increase the rate of oxidation? We may anticipate here what will be proved extensively in subsequent chapters, that the membrane formation may be considered as a

1 Warburg, Zeitschr. f. physiol. Chem., LXVI, 305, 1910.

${ }_{2}^{2}$ Loeb and Wasteneys, Jour. Biol. Chem., XIV, 469, 1913. 
superficial cytolysis or a cytolysis of the cortical layer of the egg. It is obviously this cytolysis and no subsequent morphological change in the egg which causes the increase in the rate of oxidation. We can cause complete cytolysis of the eggs of the sea-urchin by adding a trace of saponin to the sea-water. Wasteneys and I measured the rate of oxidations in a lot of unfertilized eggs in sea-water and found that they consumed $0.15 \mathrm{mg} . \mathrm{O}_{2}$ per hour at $15^{\circ} \mathrm{C}$. Then the eggs were cytolyzed with saponin and the amount of oxygen consumed in one hour at $15^{\circ} \mathrm{C}$. was measured again. It was $1.07 \mathrm{mg}$. The cytolysis of the eggs increased the rate of oxidation 700 per cent, as much as, or possibly a trifle more than, fertilization. In a similar experiment in which dilute sea-water was used for cytolysis and in which not all the eggs cytolyzed, the rate of oxidation was increased 2.74 times after the cytolysis. The cytolyzed eggs are no longer able to undergo any development or structural change. It is therefore obvious that the increase in the rate of oxidation after membrane formation as well as after fertilization is due to the mere cytolysis. How the cytolysis can bring about such a result is unknown.

2. The greatest interest was attached to the question as to how the hypertonic solution affected the oxidations in the eggs after membrane formation. It was found that the eggs in which the artificial membrane formation had been induced with butyric acid consumed oxygen in the hypertonic solution at the same rate as in normal sea-water.

Some of the eggs of the last-mentioned experiments were also used to compare the rate of oxidation in such eggs in normal sea-water and in hypertonic sea-water (50 c.c. sea-water +8 c.c. $2 \frac{1}{2} \mathrm{~m} \mathrm{NaCl}+\mathrm{KCl}+\mathrm{CaCl}_{2}$ ).

Oxygen consumption of unfertilized eggs after artificial membrane formation

In normal sea-water............. $0.85 \mathrm{mg}$.

In hypertonic sea-water. ........... $0.88 \mathrm{mg}$. 
The values are practically identical. The eggs treated with the hypertonic solution developed after being put in normal sea-water.

In a second experiment the unfertilized eggs consumed after membrane formation with butyric acid in normal sea-water $0.52 \mathrm{mg} . \mathrm{O}_{2}$ in 65 minutes. The same eggs were then put into hypertonic sea-water (50 c.c. sea-water +8 c.c. $2 \frac{1}{2} \mathrm{~m}$ Ringer) and consumed here in 65 minutes $0.54 \mathrm{mg}$. $\mathrm{O}_{2}$. The temperature was in both cases $18^{\circ}$. These eggs developed after being transferred to sea-water.

In another experiment the unfertilized eggs consumed, after the artificial membrane formation with butyric acid, $0.83 \mathrm{mg}$. in 60 minutes in normal sea-water; during the next hour they were put into hypertonic sea-water and consumed in 60 minutes $0.74 \mathrm{mg}$. During the next 60 minutes they were again put into normal sea-water where they consumed $0.70 \mathrm{mg} . \mathrm{O}_{2}$ in 60 minutes (at the same temperature). ${ }^{1}$

It is obvious from these experiments that the hypertonic solution does not act by increasing the rate of oxidations. This agrees with the conclusion we reached before, that the membrane formation is the real activating agent while the hypertonic solution acts only as a corrective.

3. Warburg ${ }^{2}$ states that if the eggs of $S$. lividus are fertilized with sperm and afterward put into a hypertonic solution the rate of oxidations is thereby increased 300 per cent. Since Wasteneys and the writer found that the hypertonic solution of the concentration required for artificial parthenogenesis does not raise the oxidations of the eggs of $S$. purpuratus after artificial membrane formation, we were curious to know whether such a hypertonic solution raises the rate of oxidations in the eggs of S. purpuratus fertilized with sperm. Table XII gives the result. ${ }^{3}$

1 Loeb and Wasteneys, Jour. Biol. Chem., XIV, 469, 1913.

2 Warburg, Zeitschr. f. physiol. Chem., LX, 443, 1909.

Loeb and Wasteneys, op. cit. 
These and other similar experiments show that the rate of oxidations in the fertilized eggs of Strongylocentrotus is not altered if the eggs are put into a hypertonic solution of that concentration and during that period of time which is required in the method of artificial parthenogenesis. Only if the fertilized eggs remain a much longer period, 90 minutes or longer, in the hypertonic sea-water is the rate of oxidation alteredhowever, not increased but diminished.

TABLE XII

\begin{tabular}{|c|c|c|}
\hline Fertilized Eggs in & $\begin{array}{l}\text { Duration of } \\
\text { Experiment }\end{array}$ & $\begin{array}{c}\text { Oxygen } \\
\text { Consumption }\end{array}$ \\
\hline $\begin{array}{l}\text { Exp. I. Normal sea-water.............. } \\
\text { Hypertonic sea-water }(50 \text { c.c. sea- } \\
\text { water+8 } \\
\text { c.c. } 2 \frac{1}{2} \mathrm{~m} \\
\mathrm{NaCl}+\mathrm{KCl}+\end{array}$ & $75 \mathrm{~min}$. & $0.87 \mathrm{mg}$ \\
\hline $\left.\mathrm{CaCl}_{2}\right) \ldots \ldots \ldots \ldots \ldots \ldots \ldots \ldots \ldots \ldots \ldots \ldots \ldots$ & 75 & 0.86 \\
\hline $\begin{array}{l}\text { Exp. II. Normal sea-water } \ldots \ldots \ldots . \\
\text { Hypertonic sea-water }(50 \text { c.c. sea- } \\
\text { water }+8 \text { c.c. } 2 \frac{1}{2} \mathrm{~m} \quad \mathrm{NaCl}+\mathrm{L} \mathrm{Cl}+\end{array}$ & 90 & 0.60 \\
\hline $\left.\mathrm{CaCl}_{2}\right)_{2} \ldots \ldots \ldots \ldots \ldots \ldots \ldots \ldots \ldots \ldots$ & 90 & 0.52 \\
\hline $\begin{array}{l}\text { Exp. III. Normal sea-water } \ldots \ldots . . . . . \\
\text { Hypertonic sea-water }(50 \text { c.c. sea- }\end{array}$ & 60 & 0.55 \\
\hline $\begin{array}{l}\text { water }+8 \text { c.c. } 2 \frac{1}{2} \text { m } \quad \mathrm{NaCl}+\mathrm{KCl}+ \\
\mathrm{CaCl}_{2}{ }_{2} \ldots \ldots \ldots \ldots \ldots \ldots \ldots \ldots \ldots \ldots\end{array}$ & 60 & 0.59 \\
\hline
\end{tabular}

It may also be stated that Wasteneys and I tried the effect of hypertonic solutions of various concentrations upon the fertilized eggs of $S$. purpuratus. The result was always the same: The hypertonic solution did not increase the rate of oxidations in the fertilized egg of $S$. purpuratus, no matter how high the concentration was raised, as Table XIII shows. Temperature $18^{\circ} \mathrm{C}$.

It is obvious that the increase in the concentration, even beyond that used in the experiments on artificial parthenogenesis, does not increase the rate of oxidations in the fertilized eggs of $S$. purpuratus.

4. This result creates an apparent difficulty, namely, why the hypertonic solution does not produce its corrective effect upon the egg (after artificial membrane formation) in the absence of 
oxygen or if the oxidations in the egg are retarded through the presence of KCN (see chap. $\mathrm{x}$ ). This difficulty is, however, not real, if we assume that the corrective effect of the hypertonic solution consists in the production of a substance or a condition in the egg which cures it from the threatening disintegration or in the destruction of a substance or a condition which causes this disintegration. Such effects might be produced by a slight modification of the character of the processes of oxidation without its being necessary that the rate of oxidation be altered.

TABLE XIII

\begin{tabular}{|c|c|c|}
\hline Fertilized Eggs in & $\begin{array}{l}\text { Duration of } \\
\text { Experiment }\end{array}$ & $\begin{array}{c}\text { Oxygen } \\
\text { Consumption }\end{array}$ \\
\hline 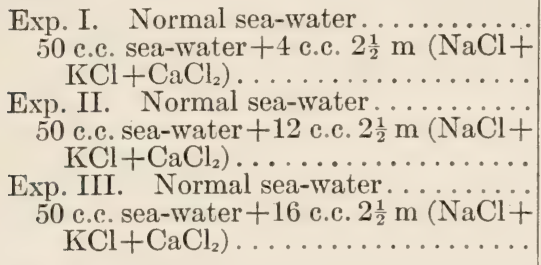 & $\begin{array}{l}60 \mathrm{~min} . \\
60 \\
60 \\
60 \\
60 \\
60\end{array}$ & $\begin{array}{l}1.30 \mathrm{mg} . \\
1.27 \\
1.33 \\
1.53 \\
1.33 \\
1.57\end{array}$ \\
\hline
\end{tabular}

Meyerhof raised the objection that the ratio between the consumption of oxygen and the production of heat was the same in eggs in hypertonic solutions as in normal sea-water. But I do not think that this objection speaks against my hypothesis, since it is only necessary that the hypertonic solution lead to the formation of a by-product in a very minute quantity, while this by-product is not formed when the eggs develop in normal seawater. Such a slight qualitative modification of the oxidations could very well exist without resulting in a noticeable alteration of the ratio between oxidations and heat production in the egg. It is also possible that the effects of the products of oxidation are different in hypertonic and normal sea-water, and that this determines the corrective effect of the hypertonic solution.

Such an assumption would also enable us to understand why the withdrawal of oxygen for a longer period of time, namely, 
about three hours, or the addition of some $\mathrm{KCN}$ to the seawater for the same period of time after the artificial membrane formation, can act as a substitute for the 40 to 60 minutes of treatment of the eggs with the hypertonic solution. It is conceivable that the hydrolytic processes which continue to go on in the egg after the retardation of oxidations lead to the formation of a substance (or to a condition) which at the normal rate of oxidation could not be formed (or arise), or if formed would be rapidly destroyed, and which acts similarly as the substance formed in a much shorter time through the oxidations if the amount of water in the egg is diminished.

5. The idea that the curative or corrective effect of the hypertonic solution consists in the formation in the egg of a substance which remedies the danger of disintegration following artificial membrane formation is supported by another fact. We have already stated that the treatment of the egg with the hypertonic solution may precede the artificial membrane formation. But the writer succeeded in showing last winter that if the eggs are once treated with the hypertonic solution they are permanently immune against the disintegration which follows artificial membrane formation. ${ }^{1}$

Unfertilized eggs of $S$. purpuratus were put for 2 and $2 \frac{1}{2}$ hours into hypertonic sea-water (50 c.c. sea-water +8 c.c. $2 \frac{1}{2} \mathrm{~m}$ Ringer). Some of them were treated about ten minutes later with butyric acid, and the majority of them developed into larvae. Others were treated with butyric acid 24 hours, 48, and 72 hours later. Those treated 24 hours later with butyric acid developed also and about as well as those treated immediately. After 48 hours a great many eggs were dead, but those that were still alive or had not suffered too much still developed into larvae when treated with butyric acid. After three days almost all the eggs were dead, but those that were still intact segmented and developed into swimming larvae after the butyric-acid treatment.

${ }_{1}^{1}$ Loeb, Jour. Exper. Zool., XV, 201, 1913. 
Hence by a treatment with a hypertonic solution for a sufficient length of time unfertilized eggs retain as long as they live the quality of being immune against the disintegration which follows artificial membrane formation. What is the nature of this alteration? Warburg found that in unfertilized eggs without membranes the rate of oxidation is increased by hypertonic solutions, and we were able to confirm his observation. This suggested the idea that possibly a treatment of such eggs with a hypertonic solution would raise their rate of oxidation permanently and that this might be the cause of their immunity against the disintegrating processes following artificial membrane formation. This was a priori not very probable since we found that the corrective effect of the hypertonic solution after artificial membrane formation in the egg of $S$. purpuratus is not due to an increase in the rate of oxidations.

6. We were therefore anxious to see if the rate of oxidation caused by the treatment of unfertilized eggs of S. purpuratus (without membrane formation) was permanently maintained. For this purpose the consumption of oxygen in an unfertilized lot of eggs of S. purpuratus was measured at $18^{\circ} \mathrm{C}$. in four successive periods.

Oxygen

Consumption in 90 Minutes

In normal sea-water. ...................... In hypertonic sea-water $\left(50\right.$ c.c. sea-water +9 c.c. $2 \frac{1}{2} \mathrm{~m}$

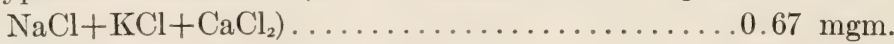
In normal sea-water half an hour later............. In normal sea-water twenty-one hours later......... $0.48 \mathrm{mgm}$.

While it is obvious that these eggs continue to show an increased rate of oxidation for at least 22 hours, the rate is very much lower than after fertilization or after the artificial membrane formation. Through the treatment of the eggs in the above-mentioned experiment the rate was increased 2.2 times and the next day it had fallen to 1.6 times. This 
increase is so small that it is not likely to be responsible for the corrective action of the hypertonic solution.

It is more probable that the treatment of the egg with the hypertonic solution brings about a permanent change in the egg by which it can now undergo the process of membrane formation at any time without danger of subsequent disintegration. This irreversibility of the corrective effect of the hypertonic solution would be intelligible on the assumption that it is due to the formation of a definite substance which is retained by the egg and which is a preventive against the disintegration following membrane formation.

7. We may here discuss parenthetically a hypothesis put forward by R. Lillie ${ }^{1}$ concerning the nature of the corrective action of the hypertonic solution. Lillie suggests that the essential feature in the act of fertilization is an increase in the surface permeability of the egg of which the membrane formation is the consequence; and that the effect of the "aftertreatment with a hypertonic solution is to bring the permeability again to normal."

We are able to investigate the relative permeability of fertilized and unfertilized eggs for bases with the aid of a color test, and this color test shows that both unfertilized as well as fertilized eggs are permeable for weak and impermeable for strong bases. ${ }^{2}$ As far as acids are concerned, the fact found by the writer that weak acids like $\mathrm{CO}_{2}$ and the fatty acids cause membrane formation in the unfertilized egg shows that such an egg must be permeable for these substances. McClendon ${ }^{3}$ has published experiments which he thinks support Lillie's view of an increased ion-permeability of the egg after membrane formation, but the writer does not feel

1 R. Lillie, Jour. Morphol., XXII, 695, 1911; Am. Jour. Physiol., XXVII, 289, 1911.

${ }^{2}$ O. Warburg, Zeitschr. f. physiol. Chem., LXVI, 305, 1910; N. Harvey, Jour. Exper. Zool., X, 507, 1911.

${ }^{3}$ McClendon, Am. Jour. Physiol., XXVII, 240, 1910. 
that McClendon's interpretation of the experiment is the only one admissible.

McClendon investigated the electrical conductivity of unfertilized and fertilized eggs and found that the conductivity of the egg is increased by fertilization. He concludes that this proves an increased permeability of the egg for ions, but the same result would be produced if in consequence of fertilization or membrane formation the degree of electrolytic dissociation in the surface film of the egg should be increased. The egg or its surface film must be considered as a non-aqueous phase and the conductivity in this phase depends among others upon the degree of electrolytic dissociation of the electrolytes dissolved in it. It is quite conceivable that so considerable a change in the cortical layer as that taking place in membrane formation might influence the degree of solubility or of electrolytic dissociation in the surface film of the egg.

McClendon made also the interesting observation that "if fertilized and unfertilized eggs of Arbacia are placed in an isotonic sugar solution containing little sea-water, through which a current of gradually increasing density is passed, the unfertilized eggs begin to disintegrate, at their anode ends, sooner than the fertilized eggs." He interprets this as "indicating that the fertilized eggs are more permeable to anions, which therefore accumulate in them to a less extent, or the fertilized eggs are more permeable to electrolytes, which therefore have passed out into the sugar solution to a greater extent, and therefore the current passes through them less, than in the case of the unfertilized eggs." I believe that the phenomenon described by $\mathrm{McClendon}$ is not sufficiently understood to lend itself to conclusions concerning the permeability of the egg. But these questions do not concern us here so much as the action of the hypertonic solution.

The idea that the treatment of the egg with the hypertonic solution serves the purpose of restoring the increased permeability 
of the egg to its normal limit might fit those cases in which the hypertonic treatment follows the artificial membrane formation, but it is difficult to understand how it can be made to harmonize with the fact that the treatment of the egg with a hypertonic solution is equally efficient if it precedes the artificial membrane formation by twenty-four hours or more. Moreover, we shall see later on that bases act somewhat like acids in inducing membrane formation, and that the eggs must also be exposed to the hypertonic solution. In this case both agencies, the base and the hypertonic solution, may be combined to act simultaneously upon the egg with good results. This fact seems also unintelligible on the assumption that the bases increase the permeability of the egg (to allow some of its contents to escape), while the hypertonic solution has the opposite effect. And finally one does not understand that a hypertonic solution of $\mathrm{NaCl}$ (e.g., 50 c.c. $\mathrm{m} / 2 \mathrm{NaCl}+12$ or 16 c.c. $2 \frac{1}{2} \mathrm{~m}$ $\mathrm{NaCl}$ ), which acts as a corrective agent upon the eggs after membrane formation, should diminish their permeability, since all our experience indicates that such a solution injures the surface of the egg and increases its permeability.

\section{II}

8. We will now briefly mention some cytological points worthy of discussion. E. Hindle has investigated the cytological changes in the eggs of $S$. purpuratus which had been treated with butyric acid and subsequently with a hypertonic solution. He found that the changes taking place in such eggs were almost identical with those which take place after the entrance of a spermatozoon. Hindle ${ }^{1}$ gives the following description:

The interval (about 20 minutes) between the transference of the eggs from butyric acid to normal sea-water and their subsequent treatment with hypertonic salt solution is characterized by the alterations in the appearance of the cytoplasm and nucleolus, and the

${ }^{1}$ E. Hindle, Archio f. Entwicklungsmechanik, XXXI, 145, 1911. 
subsequent development of a perinuclear zone, as described above. The nucleus then commences to grow and faint radiations can sometimes be seen extending from the perinuclear zone into the surrounding cytoplasm.

During immersion in the hypertonic solution there are no apparent changes beyond a slight reduction of the clear zone of hyaloplasm surrounding the nucleus.

After the eggs are put back into normal sea-water the internal changes resulting in the first cleavage follow each other in quick succession. The first change noticed is an increase in the development of the perinuclear zone, followed by further growth of the nucleus. Meanwhile, the meshwork of chromatin becomes coarser and more aggregated together and the nucleolus gradually disappears. This stage is succeeded by a reduction of the perinuclear zone together with its radiations.

About half an hour after transference to normal sea-water, from one pole of the nucleus a definite aster begins to develop, its rays focusing in a more or less indistinct centrosome situated on the nuclear membrane. ${ }^{1}$ By division of the centrosome a typical amphiaster is formed in the nuclear area and as it develops the nuclear membrane disappears. At the same time the chromatin assumes the form of a spireme, which subsequently breaks up into about 18 long and slender chromosomes. At this stage it is impossible to clearly distinguish their number, but, as the chromosomes are gradually drawn into the equator of the cleavage amphiaster, they shorten considerably and become quite distinct by the time that the equatorial plate is formed.

At this stage we have made numerous counts of the chromosomes and invariably found it in the neighborhood of 18 , which is half the number that is normally present in this species.

This behavior is very similar to the one found in the egg. after fertilization by sperm.

${ }^{1}$ It may be well to call special attention to the fact that the centrosomes and astrospheres are not formed while the eggs are in the hypertonic solution but some time after they are put back into the normal sea-water. Only if the eggs remain ton long in the hypertonic sea-water centrosomes and cytasters may form while the eggs are in the hypertonic sea-water, not, however because they are in this solution but in spite of it. The hypertonic solution allows the internal process leading to the formation of astrospheres to go on for some time. This led to the erroneous idea that the hypertonic solution was the direct cause of the formation of centrosomes and astrospheres. 
In naturally fertilized eggs a distinct aster (cleavage aster) appears at one pole of the nucleus, its rays centering in a clear area which represents a diffuse centrosome. This area divides and the two halves move apart until they come to lie at opposite sides of the nucleus and form the poles of a typical amphiaster which is developed in the nuclear region. Meanwhile the chromatin assumes the form of a spireme, which breaks up into 36 chromosomes that arrange themselves about the equator of this amphiaster to form a nuclear spindle. In the chemically fertilized eggs a nuclear spindle arises in a similar way and the chromatin assumes the form of a spireme preparatory to breaking up into chromosomes, but, instead of 36 , only 18 of these latter bodies appear. The subsequent changes are identical in both kinds of eggs. The chromosomes split longitudinally and each half moves along the spindle fibres toward its respective pole. As they approach the poles the chromosomes swell up and eventually fuse together to form a single nucleus in the region occupied by each of the diffuse centrosomes. Meanwhile a cell wall develops between the two nuclei dividing the cytoplasm into two, and finally the spindle fibres disappear. The succeeding processes of development, both internal and external, are similar in both naturally and chemically fertilized eggs, with the exception that at each succeeding division only 18 chromosomes appear in the latter instead of the normal number, $36 .{ }^{1}$

We had mentioned that the eggs which formed a membrane upon butyric-acid treatment begin to divide and may go through a series of divisions if the temperature is sufficiently low. According to Hindle, at room temperature only a monaster is formed with the nucleus as a center, while at a low temperature a typical amphiaster is formed. The subsequent changes in the latter case are the same as with the treatment with hypertonic sea-water.

1 Hindle, op. cit. 



\section{XIII}

\section{THE RELATIVE PHYSIOLOGICAL EFFICIENCY OF VARIOUS ISOSMOTIC SOLUTIONS ${ }^{x}$}

As already mentioned, I had in 1900 published the observation that the development of the egg of Arbacia can be initiated by a pure sugar solution. ${ }^{2}$ These experiments had already shown that the pure sugar solution exerted a stronger osmotic effect than it should theoretically.

The following experiments were performed upon the eggs of S. purpuratus in which membrane formation had been previously produced by treating them with butyric acid. The eggs were placed in the hypertonic solution some ten minutes after membrane formation, and hence the time of exposure is longer than it would be had they been transferred to the hypertonic solution half an hour after membrane formation. We will start with experiments with pure sodium chloride solution.

The experiments with pure hypertonic solutions of $\mathrm{NaCl}$ gave results that are, at first glance, paradoxical; for the eggs after membrane formation can tolerate a higher concentration of $\mathrm{NaCl}$ solution than of hypertonic sea-water. We shall see, however, that this paradox finds a simple explanation. The unfertilized eggs of a female were made to form membranes by treating them with butyric acid, and then (about ten minutes later) they were divided among 50 c.c. $\frac{1}{2} \mathrm{~m} \mathrm{NaCl}+3,4,5,6$, $7,8,10,12,14$, and 16 c.c. $2 \frac{1}{2} \mathrm{~m} \mathrm{NaCl}$; some of the eggs were transferred to normal sea-water after 55, 90, and 120 minutes. The temperature was $13^{\circ} \mathrm{C}$.

${ }^{1}$ Loeb, "Ueber den Unterschied zwischen isosmotischen und isotonischen Lösungen bei der künstlichen Parthenogenese," Biochem. Zeitschr., XI, 144, 1908.

${ }^{2}$ Loeb, Am. Jour. Physiol., IV, 178, 1900. 
If we compare these results with those obtained in chapter xi, we find that 50 c.c. of $\mathrm{m} / 2 \mathrm{NaCl}+5$ c.c. of $2 \frac{1}{2} \mathrm{~m} \mathrm{NaCl}$ produce the same effect as 50 c.c. of sea-water +4 c.c. of $2 \frac{1}{2} \mathrm{~m} \mathrm{NaCl}$; in other words, that a mixture of 50 c.c. of $\frac{1}{2} \mathrm{~m}$ $\mathrm{NaCl}+1$ c.c. of $2 \frac{1}{2} \mathrm{~m} \mathrm{NaCl}$ is about isotonic with sea-water.

TABLE XIV

\begin{tabular}{|c|c|c|c|}
\hline \multirow[t]{2}{*}{ Composition of the Solution } & \multicolumn{3}{|c|}{$\begin{array}{l}\text { PERcentage of EgGs That } \\
\text { DEVELOPED INTO LARVAE } \\
\text { AFTER AN EXPOSUE OF }\end{array}$} \\
\hline & $55 \mathrm{~min}$. & $90 \mathrm{~min}$. & $120 \mathrm{~min}$. \\
\hline 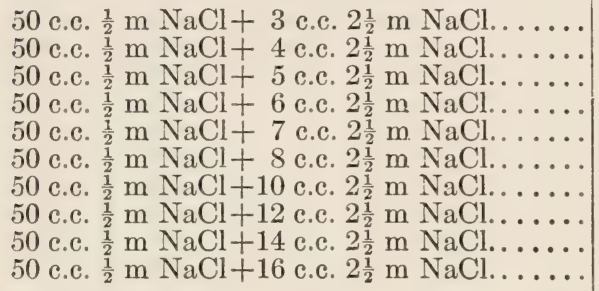 & $\begin{array}{r}0 \\
0 \\
0 \\
0 \\
2 \\
30 \\
80 \\
80 \\
80 \\
80\end{array}$ & $\begin{array}{l}0 \\
0 \\
0 \\
1 \\
50 \\
80 \\
90 \\
\cdots \\
\cdots\end{array}$ & $\begin{array}{r}0 \\
0 \\
1 \\
5 \\
70 \\
90 \\
\cdots \\
\cdots \\
\cdots\end{array}$ \\
\hline
\end{tabular}

Now whereas a mixture of 50 c.c. of sea-water +10 c.c. of $2 \frac{1}{2} \mathrm{~m} \mathrm{NaCl}$ injures the eggs so badly in 60 minutes that only a small number develop, and a mixture of 50 c.c. of sea-water+ 12 c.c. of $2 \frac{1}{2} \mathrm{~m} \mathrm{NaCl}$ kills practically all eggs with artificial membranes in 60 minutes, in a mixture of 50 c.c. of $\frac{1}{2} \mathrm{~m} \mathrm{NaCl}+16$ c.c. of $2 \frac{1}{2} \mathrm{~m} \mathrm{NaCl} 80$ per cent of the eggs develop after an exposure of 55 minutes. The explanation of this paradox lies in the fact that the $\mathrm{NaCl}$ solution was practically neutral, while the seawater is slightly alkaline. We shall see in a later chapter that the harmful effect of hypertonic solutions upon the egg is much greater if they are slightly alkaline than when they are neutral; slightly acid hypertonic solutions are still less injurious than neutral ones, or, in other words, the harmful effect of hypertonic solutions increases, within the limits considered, with the concentration of the hydroxylions. The injurious effect of these hypertonic solutions is diminished, if not absent, in a solution 
which is free from oxygen: hence it is possible that there is a connection between these two facts.

We now come to the experiments with cane sugar. Acrording to freezing-point determinations performed by Dr. WV. E. Garrey, the sea-water in Pacific Grove lowers the freezing-point to the same extent as a $0.54 \mathrm{~m} \mathrm{NaCl}$ solution. This agrees pretty well with the above-mentioned data. Since, according to Kohlrausch and Holborn, some 74 per cent of the molecules of $\mathrm{NaCl}$ are dissociated at this concentration, a $0.94 \mathrm{~m}$ canesugar solution is theoretically isosmotic with sea-water. But if experiments are performed on the sea-urchin egg with pure cane-sugar solutions, it will be found that such a solution acts as though it were not isotonic but strongly hypertonic. $0,1,2$, $3,4,5,6,7$, and 8 c.c. of $2 \frac{1}{2} \mathrm{~m}$ cane-sugar solution were added each to 50 c.c. of $3 / 4 \mathrm{~m}$ sugar solution and the unfertilized egg of a sea-urchin divided among these after artificial membrane formation. ${ }^{1}$ Temperature $12^{\circ} \mathrm{C}$. The eggs remained 58 minutes in the solution. The percentage of larvae formed is given in Table XV.

TABLE XV

\begin{tabular}{|c|c|}
\hline Composition of Solution & $\begin{array}{l}\text { Percentage of } \\
\text { Eggs Developing } \\
\text { into Larvae }\end{array}$ \\
\hline 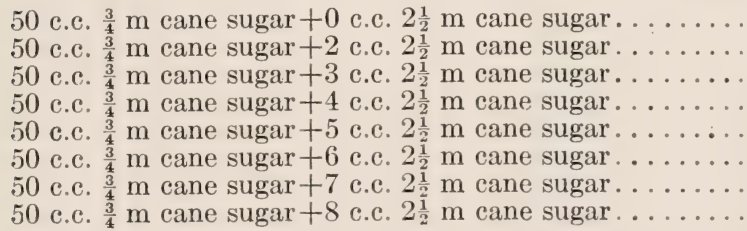 & $\begin{array}{l}0 \\
0 \\
\text { a few larvae } \\
2 \\
20 \\
60 \\
98 \\
98\end{array}$ \\
\hline
\end{tabular}

Hence a mixture of 50 c.c. $3 / 4 \mathrm{~m}+6$ c.c. $2 \frac{1}{2} \mathrm{~m}$ cane-sugar solution acts just as effectively as a mixture of 50 e.c. of seawater +8 c.c. $2 \frac{1}{2} \mathrm{~m} \mathrm{NaCl}$ or 50 c.c. $\frac{1}{2} \mathrm{~m} \mathrm{NaCl}+8$ or 10 c.c. $2 \frac{1}{2} \mathrm{~m}$ $\mathrm{NaCl}$. A mixture of 50 c.c. of $3 / 4 \mathrm{~m}+6$ c.c. $2 \frac{1}{2} \mathrm{~m}$ cane sugar

1 The eggs were put into the sugar solution a fow minutes after membrane formation. 
is, however, $0.94 \mathrm{~m}$, or isosmotic with sea-water. But this solution acts just as hypertonically upon the sea-urchin egg as a $0.80 \mathrm{~m} \mathrm{NaCl}$ solution, i.e., a solution whose osmotic pressure is about 50 per cent higher than that of a $0.94 \mathrm{~m}$ cane-sugar solution.

It can be directly shown that a solution of cane sugar, which is theoretically isosmotic with sea-water, is actually hypertonic for the sea-urchin egg. For the eggs shrivel in such a solution; they even shrink in a $7 / 8 \mathrm{~m}$ cane-sugar solution; in a $6 / 8 \mathrm{~m}$ solution they retain their volume and in a $5 / 8 \mathrm{~m}$ solution they increase in size. Eight years ago I also observed that medusae (Polyorchis) shrink considerably in a pure cane-sugar solution that is theoretically isosmotic with sea-water.

It can be indirectly shown that a $3 / 4 \mathrm{~m}$ cane-sugar solution is about the concentration that is isotonic for the sea-urchin egg, by placing sea-urchin eggs that have been fertilized with sperm in pure cane-sugar solutions of different concentrations immediately after fertilization. Experiments of this description showed that in a $6 / 8 \mathrm{~m}$ cane-sugar solution the first cell division occurs in all the eggs of purpuratus, and indeed at almost the same time as in normal sea-water; while in $5 / 8$ and $7 / 8 \mathrm{~m}$ solutions its onset is delayed and occurs in only a few eggs. In cane-sugar solutions below $5 / 8 \mathrm{~m}$ and above $7 / 8 \mathrm{~m}$ as a rule not a single egg divided. In $6 / 8 \mathrm{~m}$ cane-sugar solution, again, the cleavage did not go beyond the four- or eight-cell stage, which is in accordance with the experience in muscle. But if the eggs are replaced in sea-water they develop normally. This behavior of the egg in a cane-sugar solution corresponds to the behavior of a medusa in the same solution: for in the latter, also, as well as in the heart, the spontaneous contractions cease in a pure cane-sugar solution. ${ }^{1}$ These observations have a bearing upon a controversy between Delage and the writer. Delage used in his experiments on artificial parthenogenesis cane-sugar solu-

1 Loeb, Am. Jour. Physiol., III, 384, 1900. 
tions which were $1.135 \mathrm{~N}$, e.g., a mixture of 40 c.c. of such a cane-sugar solution +10 c.c. of sea-water. He insisted that these solutions were isotonic for the sea-urchin eggs, since their molecular concentration was equal to that calculated from the depression of the freezing-point of the sea-water which he used. Our experiments show that a saccharose solution which is theoretically isosmotic with the sea-water is nevertheless physiologically hypertonic. Theoretically a $0.94 \mathrm{~m}$ saccharose solution is isosmotic with the sea-water in Pacific Grove. Yet a $0.94 \mathrm{~m}$ saccharose solution was not physiologically isotonic with sea-water, but acted physiologically like a solution equal in osmotic pressure to a mixture of 50 c.c. seawater +8 c.c. $2 \frac{1}{2} \mathrm{~m} \mathrm{NaCl}$, i.e., a hypertonic solution. This discrepancy can be explained partly or wholly from the fact that the osmotic pressure of cane-sugar solutions is greater than we should expect from their molecular concentration (according to the direct measurements of Lord Berkeley and of Morse). This discrepancy between the theoretical and real osmotic pressure of cane-sugar solutions may possibly increase with the concentration.

In order to elucidate whether besides the merely physical a physiological factor was also involved in this discrepancy between theoretically isosmotic and physiologically isotonic solutions some experiments with other substances were tried.

TABLE XVI

\begin{tabular}{|c|c|}
\hline Constitution of the Solution & $\begin{array}{c}\text { Percentage of } \\
\text { Eggs That } \\
\text { Produced Larvae }\end{array}$ \\
\hline 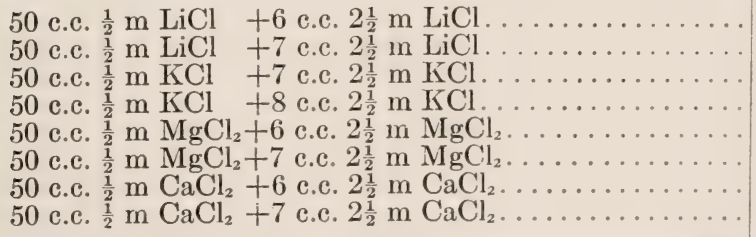 & $\begin{array}{r}5 \\
70 \\
1 \\
60 \\
50 \\
80 \\
20 \\
90\end{array}$ \\
\hline
\end{tabular}


It can be seen from this that solutions of various substances which are all theoretically isosmotic do not on that account possess the same degree of physiological activity. It is therefore necessary to differentiate between theoretically isosmotic and physiologically isotonic solutions. The two values are more nearly identical for the red blood corpuscles than for the sea-urchin egg. This will be made clear by the following table in which is set forth the optimum concentration of solutions of various substances with regard to artificial parthenogenesis. For this optimum concentration can be very sharply determined by choosing a definite length of exposure, such as 55 minutes at about $15^{\circ} \mathrm{C}$.

\section{TABLE XVII}

Optimom Concentration of Solutions of Variods Substances for Artificial Parthenogenesis

\begin{tabular}{|c|c|c|c|}
\hline $\begin{array}{l}\text { Constitution of the } \\
\text { Solution }\end{array}$ & $\begin{array}{l}\text { Optimum Con- } \\
\text { centration in } \\
\text { Grammolecules }\end{array}$ & $\begin{array}{l}\text { Dissociation of } \\
\text { the Solution }\end{array}$ & $\begin{array}{l}\text { Osmotic Pressure } \\
\text { of the Solution in } \\
\text { Atmospheres }\end{array}$ \\
\hline 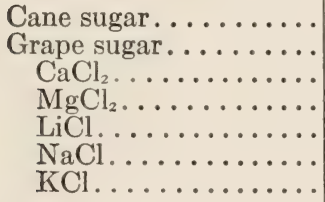 & $\begin{array}{l}0.96 \mathrm{~m} \\
1.04 \\
0.50 \\
0.49 \\
0.74 \\
0.79 \\
0.78\end{array}$ & $\begin{array}{l}\cdots \\
\ddot{64} \\
70 \\
66 \\
71 \\
77\end{array}$ & $\begin{array}{l}21.53 \\
23.33 \\
25.57 \\
26.47 \\
27.59 \\
30.28 \\
30.95\end{array}$ \\
\hline
\end{tabular}

Of course these values which were obtained with $S$. purpuratus at Pacific Grove do not apply as they stand to any given form of sea-urchin in any given locality. We have no explanation to offer for these discrepancies except in the case of sugars where the discrepancy seems to find its explanation in the abnormal physical behavior of concentrated solutions. It is possible that these salts modify the permeability of the egg in a different degree or sense and that this accounts for the discrepancies between calculated and observed results. 


\section{XIV}

CHEMICAL CONSTITUTION AND RELATIVE PHYSIOLOGICAL EFFICIENCY OF ACIDS ${ }^{1}$

In my first experiments upon membrane formation I found that the chemical constitution of acids is of great importance with regard to their effect upon membrane formation. For whereas carbonic acid and the weak monobasic fatty acids were very effective, the strong acids, such as $\mathrm{HCl}, \mathrm{HNO}_{3}$, and $\mathrm{H}_{2} \mathrm{SO}_{4}$ or oxalic acid, had so little effect as to be practically useless for these experiments. The oxy-acids were effective, but not to the same degree as the monobasic fatty acids. The further investigation of the relation that exists between constitution and effect seemed to be full of promise, as it was to be expected that it would give some information upon the rôle of acids in membrane formation, and that the results might be of general importance.

The following was the procedure adopted in the experiments. The eggs were first freed from all sea-water by being twice washed in an $\mathrm{m} / 2 \mathrm{NaCl}$ solution. They were then put into solutions of the various fatty acids in $\mathrm{m} / 2 \mathrm{NaCl}$ solution, since it was necessary to make the acid solution isosmotic with the sea-water. At definite intervals a portion of the eggs was transferred by a pipette to normal sea-water, and the percentage of eggs which formed membranes determined.

I had discovered in my earliest experiments that the higher fatty acids had more effect than the lower. Hence I suspected that the activity of the monobasic fatty acids increased with the number of carbon atoms. The results of one of a series of experiments performed to decide this question are given in Table XVIII. The temperature was about $15^{\circ} \mathrm{C}$.

${ }_{1}$ Loeb, Biochem. Zeitschr., XV, 25t, 1909; "An Improved Method of Artificial Parthenogenesis," University of California Publications, Physiology, II, 1905; Untersuchungen, p. 329, Leipzig, 1906. 
The first vertical column of Table XVIII gives the length of time that the eggs had remained in the acid, and the other vertical columns give the percentage of the eggs which formed membranes after this exposure to the different acids.

TABLE XVIII

\begin{tabular}{|c|c|c|c|c|c|c|}
\hline $\begin{array}{l}\text { Length of Exposure to } \\
\text { N/1,000 }\end{array}$ & $\begin{array}{c}\text { Formic } \\
\text { Acid }\end{array}$ & $\begin{array}{l}\text { Acetic } \\
\text { Acid }\end{array}$ & $\begin{array}{l}\text { Pro- } \\
\text { pionic } \\
\text { Acíd }\end{array}$ & $\begin{array}{l}\text { Butyric } \\
\text { Acid }\end{array}$ & $\begin{array}{c}\text { Caprylic } \\
\text { Acid }\end{array}$ & $\begin{array}{l}\text { Nonylic } \\
\text { Acid }\end{array}$ \\
\hline 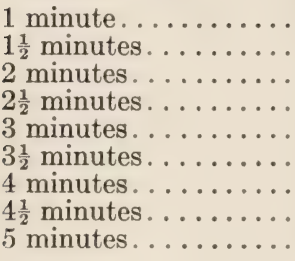 & $\begin{array}{l}0 \\
0 \\
0 \\
0 \\
0 \\
11 \frac{1}{2} \% \\
30 \\
90 \\
100\end{array}$ & $\begin{array}{l}0 \\
0 \\
0 \\
\frac{1}{4} \% \\
5 \\
60 \\
\cdots \\
\cdots \\
\cdots\end{array}$ & $\begin{array}{l}0 \\
0 \\
10 \% \\
20 \\
50 \\
7 \ddot{5} \\
\cdots \\
\cdots\end{array}$ & $\begin{array}{l}0 \\
\frac{1}{10} \% \\
10 \\
40 \\
90 \\
95 \\
100 \\
\cdots \cdots \\
\cdots \cdots\end{array}$ & $\begin{array}{l}10 \% \\
80 \\
100 \\
\cdots \cdots \\
\cdots \cdots \\
\cdots \cdots \\
\cdots \cdots\end{array}$ & $\begin{array}{l}100 \% \\
\cdots \cdots \\
\cdots \cdots \\
\cdots \cdots \\
\cdots \cdots \\
\cdots \cdots \\
\cdots \cdots\end{array}$ \\
\hline
\end{tabular}

It will be seen that the greater the number of carbon atoms in the acid molecule the shorter is the time which is necessary to cause membrane formation in a definite percentage of eggs. This result is intelligible on the assumption that those acids which diffuse most rapidly into the egg call forth membrane formation in the shortest time. This behavior of the acids is analogous to that of the alcohols whose narcotic and haemolytic activity increases also for the same series with increase of the number of carbon atoms. ${ }^{1}$ In the alcohols, however, the increase of activity is much quicker than that found by us for the acids, for each member of the series is about two or three times as effective as the preceding one.

Although the question of the influence of the concentration of the acid upon its effect is not so intimately connected with our subject, one example may be noted here for the sake of completeness. I quote two sets of experiments, one with

1 Fühner and Neubauer, "Hämolyse durch Substanzen homologer Reihen," Arch. f. exper. Path. u. Pharm., LVI, 333, 1907; Overton, Studien ueber Narkose, Jena, 1901. 
butyric acid, the other with benzoic. As usual, the acid was diluted with half grammolecular sodium chloride solution.

TABLE XIX

\begin{tabular}{|c|c|c|c|c|c|c|}
\hline \multirow{2}{*}{$\begin{array}{c}\text { LENGTH OF } \\
\text { EXPOSURE TO- }\end{array}$} & \multicolumn{6}{|c|}{ Butyric Acid } \\
\hline & $\stackrel{3 / 5,000}{\mathbf{N}}$ & $\underset{N}{\mathbf{N}}$ & $\underset{\mathrm{N}}{6 / 5,000}$ & $\underset{N}{7 / 5,000}$ & $\stackrel{8 / 5,000}{N}$ & $10 / 5,000$ \\
\hline 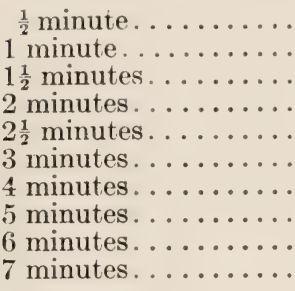 & $\begin{array}{l}0 \\
0 \\
0 \\
2 \% \\
3 \\
5 \\
30 \\
40 \\
80 \\
90\end{array}$ & $\begin{array}{l}0 \\
0 \\
48 \% \\
60 \\
95 \\
\cdots \\
\cdots \\
\cdots \\
\cdots \\
\cdots\end{array}$ & $\begin{array}{l}0 \\
14 \% \\
95 \\
100 \\
\cdots \cdots \\
\cdots \cdots \\
\cdots \cdots \\
\cdots \cdots \\
\cdots \cdots\end{array}$ & $\begin{array}{l}5 \% \\
100 \\
\cdots \cdots \\
\cdots \cdots \\
\cdots \cdots \\
\cdots \cdots \\
\cdots \cdots \\
\cdots \cdots \\
\cdots \cdots\end{array}$ & $\begin{array}{l}5 \% \\
100 \\
\cdots \cdots \\
\cdots \cdots \\
\cdots \cdots \\
\cdots \cdots \\
\cdots \cdots \\
\cdots \cdots\end{array}$ & $\begin{array}{l}5 \% \\
100 \\
\cdots \cdots \\
\cdots \cdots \\
\cdots \cdots \\
\cdots \cdots \\
\cdots \cdots \\
\cdots \cdots\end{array}$ \\
\hline
\end{tabular}

TABLE XX

\begin{tabular}{|c|c|c|c|}
\hline \multirow{2}{*}{$\begin{array}{l}\text { LENGTH OF EXPOSURE } \\
\text { TO- }\end{array}$} & \multicolumn{3}{|c|}{ Benzoic Acid } \\
\hline & $12 / 50,000 \mathrm{~N}$ & $18 / 50,000 \mathrm{~N}$ & $24 / 50,000 \mathrm{~N}$ \\
\hline 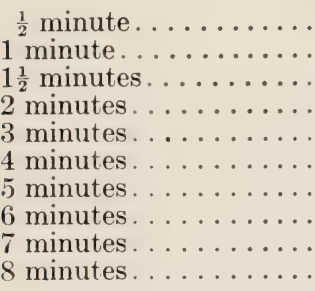 & $\begin{array}{l}0 \\
0 \\
0 \\
0 \\
0 \\
0 \\
0 \\
0 \\
0 \\
0\end{array}$ & 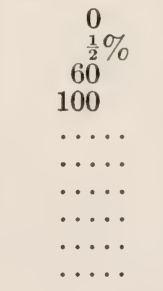 & $\begin{array}{l}30 \% \\
100 \\
\cdots \cdots \\
\cdots \cdots \\
\cdots \cdots \\
\cdots \cdots \\
\cdots \cdots\end{array}$ \\
\hline
\end{tabular}

As a rule membrane formation cannot be elicited by the use of butyric acid at a lower concentration than $3 / 5,000 \mathrm{~N}$. Even at concentrations of $3 / 5,000 \mathrm{~N}$ butyric acid is usually without effect. When, however, the effective value is attained, the optimum concentration is also quickly reached. The same is true of benzoic acid, only in this case the effective value is much lower than for butyric acid, being 18/50,000 N. 
Before going farther, we should point out that the minimal value of concentration for an acid to prove effective is not quite the same for eggs of different females. In my experiments upon the causation of development of sea-urchin eggs by means of the blood serum of warm-blooded animals, it has been an everrecurring observation that these experiments only succeed for a part of the eggs of a female, unless the eggs are previously sensitized by a treatment with $\mathrm{SrCl}_{2}$ (see chap. xviii). I regard the variation in permeability of the eggs of different females to acids or blood as responsible for these individual variations. The mass of the eggs also exerts some influence. If too many eggs are placed in the solution, the stated mass of acid is not enough.

Overton observes that the narcotic effect of the dihydric alcohols is much weaker than that of the monohydric alcohols. I find that the monobasic acids of the former series exhibit a much weaker effect with regard to membrane formation than the corresponding members of the series of acids of the monatomic alcohols. I may quote as evidence experiments with oxypropionic and oxybutyric acids.

TABLE XXI

\begin{tabular}{|c|c|c|c|c|c|}
\hline \multirow{2}{*}{ LENGTh of Exposure } & \multicolumn{2}{|c|}{ Oxypropionic Acid } & \multicolumn{3}{|c|}{$\beta$-Oxybutyric AcID } \\
\hline & $\mathrm{N} / 500$ & $4 / 500 \mathrm{~N}$ & $\mathrm{~N} / 500$ & $2 / 500 \mathrm{~N}$ & $4 / 500 \mathrm{~N}$ \\
\hline 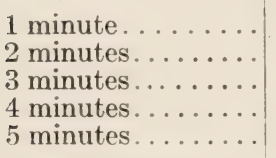 & $\begin{array}{l}0 \\
0 \\
0 \\
0 \\
0\end{array}$ & $\begin{array}{l}0 \\
2 \% \\
60 \\
90 \\
\cdots\end{array}$ & $\begin{array}{l}0 \\
0 \\
8 \% \\
\cdots \\
\cdots\end{array}$ & $\begin{array}{l}5 \% \\
100 \\
\cdots \\
\cdots \\
\cdots\end{array}$ & $\begin{array}{l}100 \% \\
\cdots \cdots \\
\cdots \cdots \\
\cdots \cdots\end{array}$ \\
\hline
\end{tabular}

It will be seen from a comparison between this and the preceding table that $\beta$-oxybutyric acid possesses only a quarter of the efficiency of butyric acid, and that propionic acid is more than four times as effective as lactic acid. The oxy-acids also 
show increasing effectiveness with the number of carbon atoms; for $\beta$-oxybutyric acid is about twice as active as oxypropionic acid. A comparison of oxybenzoic with benzoic acid showed that the latter is ten times as effective as the former.

Perhaps, however, the influence of the constitution of the acid is most clearly demonstrated by a comparison of the effect of $\beta$-oxybutyric acid and oxyisobutyric acid. $\beta$-oxybutyric acid has more than four times the effect of oxyisobutyric acid. This is probably connected with the fact that while $\beta$-oxybutyric acid has the same carbon chain as butyric acid, oxyisobutyric acid has a branched carbon chain.

Experiments upon di- or polybasic acids prove a trial of patience, as one cannot with certainty rely upon success. Whereas propionic, butyric, and valerianic acids cause membrane formation in all eggs of $S$. purpuratus practically without exception (provided that the concentration of acid and length of exposure are correctly chosen), the di- and polybasic organic acids do not affect the eggs of all females. Hence these acids behave like foreign blood sera, as regards membrane formation. This analogy indicates that the dibasic acids have a weaker effect than the monobasic acids, because they enter the egg more slowly. For obviously the degree of permeability of the egg differs in various females. In the next table I have put together results obtained from the eggs of an especially "favorable" female with oxalic, succinic, tartaric, and citric acids.

TABLE XXII

\begin{tabular}{|c|c|c|c|c|}
\hline Length of Exposure to- & $\begin{array}{l}1.7 / 500 \mathrm{~N} \\
\text { Oxalic Acid }\end{array}$ & $\begin{array}{l}7 / 500 \mathrm{~N} \\
\text { Succinic } \\
\text { Acid }\end{array}$ & $\begin{array}{c}7 / 500 \mathrm{~N} \\
\text { Tartaric } \\
\text { Acid }\end{array}$ & $\begin{array}{c}4 / 500 \mathrm{~N} \\
\text { Citric Acid }\end{array}$ \\
\hline 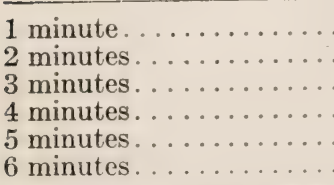 & $\begin{array}{l}0 \\
15 \% \\
20 \\
90 \\
90 \\
\cdots\end{array}$ & $\begin{array}{l}0 \\
0 \\
0 \\
0 \\
2 \% \\
\cdots\end{array}$ & $\begin{array}{l}10 \% \\
100 \\
\cdots \\
\cdots \\
\cdots \\
\cdots\end{array}$ & $\begin{array}{l}0 \\
0 \\
10 \% \\
60 \\
80 \\
90\end{array}$ \\
\hline
\end{tabular}


In order to make the above discrepancies comprehensible, we must remember how many variations of constitution come into play in this experiment. We saw first that the effect of the acid increases with the number of carbon atoms, secondly that the entry of an HO-group has the opposite effect, and thirdly that the "linear" coupling of the carbon atoms is more effective than the "branched" (oxybutyric and oxyisobutyric acids). All these and other conditions of constitution probably come under consideration in the explanation of this apparently irregular acid effect of the last table. The number of acids investigated is not sufficient for a detailed analysis.

It is even truer of the mineral than of the dibasic organic acids that they are able to cause membrane formation only in the eggs of some, but not all females. With sulphuric acid in particular I have never yet been able to evoke membrane formation in the sea-urchin egg; I have done so occasionally with $\mathrm{HNO}_{3}$ and $\mathrm{HCl}$, but not always. The most favorable results that I have obtained with these two acids are summed up in Table XXIII.

TABLE XXIII

\begin{tabular}{|c|c|c|c|c|}
\hline Length of Exposure to- & $\mathrm{N} / 500 \mathrm{HCl}$ & $\mathrm{N} / 500 \mathrm{HNO}_{3}$ & $\begin{array}{c}2 / 500 \mathrm{~N} \\
\mathrm{HNO}_{3}\end{array}$ & $\begin{array}{c}3 / 500 \mathrm{~N} \\
\mathrm{HNO}_{3}\end{array}$ \\
\hline 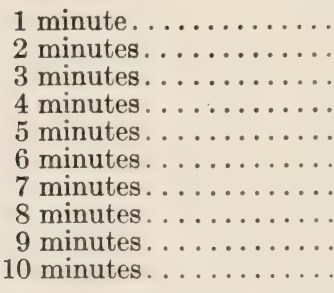 & $\begin{array}{l}0 \\
0 \\
\frac{1}{10} \% \\
10 \\
20 \\
30 \\
80 \\
80 \\
80 \\
90\end{array}$ & $\begin{array}{c}0 \\
10 \% \\
80 \\
90 \\
100 \\
\cdots \cdots \\
\cdots \cdots \\
\cdots \cdots \\
\cdots \cdots\end{array}$ & $\begin{array}{l}5 \% \\
90 \\
100 \\
100 \\
\cdots \cdots \\
\cdots \cdots \\
\cdots \cdots \\
\cdots \cdots \\
\cdots \cdots\end{array}$ & $\begin{array}{l}90 \% \\
\cdots \\
\cdots \\
\cdots \\
\cdots \\
\cdots \\
\cdots \\
\cdots \\
\cdots\end{array}$ \\
\hline
\end{tabular}

Usually, however, the results are more of the kind given for comparison in Table XXIV.

${ }^{1}$ It seems to be a general experience that sulphates diffuse less easily into living cells than chlorides. 
In this case then the paradoxical result is obtained that one-thousandth normal butyric acid is more effective in causing membrane formation than one-twelfth normal hydrochloric acid! A blind opponent of the dissociation theory could wish for no more striking material than that here adduced. Yet it would be a serious mistake to make use of these results against the theory of electrolytic dissociation.

TABLE XXIV

\begin{tabular}{l|c|c}
\hline $\begin{array}{c}\text { Length of Exposure } \\
\text { to }\end{array}$ & $15 / 500 \mathrm{~N} \mathrm{HCl}$ & $40 / 500 \mathrm{~N} \mathrm{HCl}$ \\
\cline { 1 - 2 } 2 minutes. . . . & 0 & $20 \%$ \\
3 minutes...... & $\frac{1}{4} \%$ & 20 \\
4 minutes...... & 1 & 20 \\
5 minutes...... & 5 & $\frac{1}{2}$ \\
6 minutes...... & 30 & \\
\hline
\end{tabular}

The disagreement of the facts here mentioned with the dissociation theory is only an apparent one and finds its solution in the consideration of the following two facts. In the first place, with regard to the causing of membrane formation, only the mass of acid that has actually entered the egg comes into consideration; and secondly, the velocity with which the different acids enter the egg is a function of their chemical constitution.

If this is true, we should find indications that the connections mentioned above between the constitution and physiological effect of acids in reality show relations between constitution and the rapidity of absorption of the acids by the egg. We will produce two proofs of this, one indirect and the other direct. The indirect evidence consists in the fact that the effects of the homologous alcohols in the experiments of Overton, Fühner and Neubauer are analogous to the effects of the fatty acids in ours. Now Hans Meyer as well as Overton has pointed out that the activity of the alcohols runs parallel to their coefficient of partition between lipoid and water. The relative physiological activity of the alcohols must therefore be determined 
chiefly by the relative velocity of their absorption by the cell, and analogy urges a similar supposition in the case of the acids.

The direct proof is as follows. If it is true that the weak monobasic fatty acids are more effective for the purpose of membrane formation than the strong mineral acids, for the very reason that the former are more quickly absorbed by the egg, it would be expected that the fatty acids are more injurious to the egg and kill it more quickly than the mineral acids; for in order to kill the egg the acids must enter it. Now this can be very easily tested by placing the eggs of the same female in different acids (diluted with $\frac{1}{2} \mathrm{~m} \mathrm{NaCl}$ solution), and determining how long they must remain in the various acids to lose their faculty of being fertilized and of developing.

Unfertilized sea-urchin eggs were therefore put into a N/12 solution of $\mathrm{HCl}$ (in $\frac{1}{2} \mathrm{~m} \mathrm{NaCl}$ solution), and transferred from this to normal sea-water every half-minute, when a sample of them was fertilized with sperm. Only a few had formed membranes as a result of treatment with $\mathrm{HCl}$, and, as usual, these all went to pieces. However, those eggs which had been up to three minutes in $\mathrm{N} / 12 \mathrm{HCl}$ and had formed no membranes formed them upon the addition of sperm and developed to swimming larvae. The addition of sperm caused development in 20 per cent of the eggs which had been four minutes in the $\mathrm{HCl}$ solution (and which had formed no membranes after transference to normal sea-water), and even after five minutes' exposure to the $\mathrm{N} / 12 \mathrm{HCl}$ solution, 10 per cent of the eggs could still be fertilized and caused to develop by sperm. It is scarcely necessary to mention that weaker concentrations of $\mathrm{HCl}$ were much less injurious.

Before we turn to the experiments upon the toxicity of the monobasic fatty acids, I must once again remind the reader that the eggs form no membrane so long as they are in the lower fatty acids, but only after they have been transferred to the (weakly alkaline) sea-water; and moreover that the membrane 
formation does not oceur after transference to normal sea-water if the eggs have been too long in the fatty acid solution. Why this should be so I camnot tell; possibly too much fatty acid enters the egg and the latter can no longer form a membrane. The following table gives a clear picture of this fact. The arid used was butyric.

\section{TABLE XXV}

Percentage of Eggs Which Formed Membranes after Expostre to Butyric Acid

\begin{tabular}{|c|c|c|c|c|}
\hline Length of Exposure to- & $\mathrm{N} / 500$ & $2 / 500 \mathrm{~N}$ & $3 / 500 \mathrm{~N}$ & $\begin{array}{c}4 / 500 \mathrm{~N} \\
\text { Butyric Acid } \\
\text { in } \mathrm{m} / 2 \mathrm{NaCl}\end{array}$ \\
\hline $\begin{array}{l}1 \text { minute } . . . \ldots \ldots \ldots \ldots \\
2 \text { minutes } . . \ldots \ldots \ldots \ldots \\
3 \text { minutes } \ldots \ldots \ldots \ldots \ldots \\
4 \text { minutes } \ldots \ldots \ldots \ldots \ldots \\
5 \text { minutes } \ldots \ldots \ldots \ldots \ldots\end{array}$ & $\begin{array}{l}100 \% \\
100 \\
100 \\
\cdots \\
\cdots\end{array}$ & $\begin{array}{l}100 \% \\
100 \\
1 \\
\frac{1}{2} \\
0\end{array}$ & $\begin{array}{c}100 \% \\
10 \\
0 \\
0 \\
0\end{array}$ & $\begin{array}{c}100 \% \\
10 \\
0 \\
0 \\
0\end{array}$ \\
\hline
\end{tabular}

It can be seen from this table that unfertilized sea-urchin eggs can no longer form membranes if they remain longer than two minutes in a $3 / 500 \mathrm{~N}$ solution of butyric acid (in $\frac{1}{2} \mathrm{~m}$ $\mathrm{NaCl}$ solution). If sperm now be added to such eggs after they are transferred to normal sea-water, no egg is fertilized and none develops. I thought at first that it depended upon a reversible acid effect and that the eggs would be able to recover after a long stay in sea-water. But that is not the case. As a control, the eggs of the same female were then placed in a N/50 solution of $\mathrm{HCl}$, in which they remained four minutes. Not one formed a membrane after transference to normal sea-water. But upon the addition of sperm 40 per cent of these eggs were fertilized and developed in a perfectly normal fashion. We have seen that benzoic acid is much better for causing membrane formation than butyric acid. We should expect that it is correspondingly more injurious. This is also the case. Eggs were placed in a N/500 benzoic acid solution. Every minute some of the eggs were transferred to normal sea-water. The 
eggs transferred from the benzoic acid after one minute all formed a fertilization membrane. But those eggs which had remained three minutes or more in the solution of benzoic acid formed no membranes. But the eggs could no longer be fertilized with sperm.

The objection may be raised against these experiments that the eggs are not killed by the fatty acid, but only made impermeable to spermatozoa. In order to test this objection, eggs were first fertilized with sperm and then exposed to the action of the acid mentioned. Fertilized eggs which had been longer than two minutes in a $4 / 500 \mathrm{~N}$ butyric-acid solution were unable to develop after transference to sea-water. We feel justified therefore in regarding it as certain that the influence of the chemical constitution of the acid upon its physiological action is to be referred to the velocity of its diffusion into the egg. (The latter influence is perhaps asserted in the sense that the velocity of absorption of acid into the egg cell increases with the increase of the coefficient of partition of the acid for oil and water.)

We must, however, give up the idea that the physiological action of the acids is determined by the diffusion of the hydrogen ion into the egg. Were that so, the activity of the acid ought to correspond to the concentration of free hydrogen ions, which is certainly not the case, as the inefficiency of the strong acids shows. Hence these experiments also furnish proof that the acids enter the egg cells in the form of undissociated molecules. In my earlier publications ${ }^{1}$ (1905) I had already been led to the conclusion that in the causation of membrane formation by acids it is not the hydrogen ion but the undissociated molecules which come into play. That the anions of the acids do not diffuse as such into the egg is shown by the fact that the addition of the salt of a fatty acid, such as sodium acetate, or sodium butyrate, to the sea-water causes as

${ }^{1}$ Loeb, University of California Publications, Physiology, II, May, 1905. 
a rule no membrane formation. This means that the latter must depend upon the diffusion of the undissociated acid molecule. These facts support the idea that only undissociated molecules and not ions diffuse into the cell. This should be taken into consideration by those who maintain that the effect of fertilization consists in an increased permeability of the egg for ions.

A fact which agrees well with the above statement is that carbonic acid is especially effective for membrane formation; I discovered this in my earlier experiments, ${ }^{1}$ and it has been confirmed by Godlewski. ${ }^{2}$ Carbonic acid is a very weak acid.

Now it is found that the eggs form no membranes upon treatment with the lower fatty acids while they are in the acid, but only after they are transferred to normal sea-water. This holds for formic, acetic, propionic, butyric, valerianic, and capronic acids. Heptylic, caprylic, nonylic, and caprinic acids, however, behave otherwise, for the eggs form membranes while they are in the solution of these higher acids. The explanation of this, I believe, is to be found in the fact that the higher monobasic fatty acids are but little soluble in water and very soluble in the cell. Hence the higher fatty acids are rapidly absorbed by the cell, and the sea-water is practically free from acid. Hence it is no longer necessary to transfer the eggs into seawater free from acid. It can be shown that membrane formation is prevented by hydrogen ions because no membrane formation occurs if the eggs are placed, after exposure to butyric acid, in sea-water to which some mineral acid has been added. For if sea-urchin eggs are transferred after treatment with butyric acid to 50 c.c. of sea-water +1.5 or 2 c.c. of $\mathrm{N} / 10 \mathrm{HCl}$, as a rule membrane formation no longer takes place. We have mentioned above that the eggs form membranes while in

${ }^{1}$ Loeb, U'ntersuchungen, p. 343; University of California Publications, Physiology, II, 1905.

${ }^{2}$ E. Godlewski, Archiv f. Entwicklungsmechanik, XXVI, 278, 1908. 
sea-water that contains benzol; but if $\mathrm{HCl}$ is added to this sea-water, this membrane formation does not take place. ${ }^{1}$

If the eggs are transferred from the butyric acid solution, not into sea-water, but into a neutral mixture of $\mathrm{NaCl}, \mathrm{KCl}$, and $\mathrm{CaCl}_{2}$, often no proper membrane is formed. But if the eggs are put into an alkaline mixture of $\mathrm{NaCl}, \mathrm{KCl}$, and $\mathrm{CaCl}_{2}$, proper membranes are formed by the egg.

The experiments, however, learl to still another unexpected result. If the eggs are transferred from the acid solution into the neutral mixture of $\mathrm{NaCl}, \mathrm{KCl}$, and $\mathrm{CaCl}_{2}$, they neither develop nor disintegrate. They appear rather to return into the resting condition in which they can be fertilized with sperm. I have fertilized such eggs with sperm even after two days, and could evoke development.

The following experiment also shows that such eggs remain in the resting condition if they are transferred from the acid solution to the neutral mixture of $\mathrm{NaCl}, \mathrm{KCl}$, and $\mathrm{CaCl}_{2}$. If the eggs are placed, after treatment with the fatty acid, in sea-water or in an alkaline solution of $\mathrm{NaCl}, \mathrm{KCl}$, and $\mathrm{CaCl}_{2}$ (in which they form a perfect membrane), a further short treatment with a neutral hypertonic solution is sufficient to cause all the eggs to develop into larvae. In such an experiment it was only necessary to leave the eggs from 20 to 50 minutes in a neutral hypertonic solution $(50$ c.c. $\mathrm{NaCl}+2.2$ c.c. $\mathrm{KCl}+$ 1.5 c.c. $\mathrm{CaCl}_{2}$, all $\mathrm{m} / 2,+9$ c.c. $2 \frac{1}{2} \mathrm{~m} \mathrm{NaCl}$ ), to cause all the eggs to develop into larvae. The eggs, however, which had been transferred from the acid solution into the neutral solution of $\mathrm{NaCl}, \mathrm{KCl}$, and $\mathrm{CaCl}_{2}$, could generally not be made to develop even by 120 minutes' exposure to the neutral hypertonic solution. This again shows that these eggs were really in the resting condition. These facts are a new proof for the statement made in a previous chapter, that the acid causes the development of the egg only indirectly through the membrane formation.

1 Loeb, op. cit. 
Why is it that, though the strong mineral acids do occasionally work, as a rule they fail? It has already been mentioned that if they produce any effect, membrane formation does not set in while the eggs are in the acid solution, but only after they have been transferred to normal sea-water. It is posible? that the mineral acids only cause membrane formation indirectly, their immediate effect being to liberate from its salts some fatty acid contained in the surface of the egg, and that then the fatty acid thus liberated instigates membrane formation. This hypothesis is supported by the following observation. If 2 or 3 c.c. of $\mathrm{N} / 10 \mathrm{HCl}$ are added to 50 c.c. of sea-water, and unfertilized eggs placed in this solution, no membranes are as a rule formed by the eggs after transference to normal sea-water. A similar result is obtained if, instead of $\mathrm{HCl}, 2$ or 3 c.c. of $\mathrm{N} / 2$ sodium butyrate are added to the seatwater. But if both $\mathrm{HCl}$ and sodium butyrate are added simultaneously to the sea-water, the eggs do form a membrane when transferred from this to normal sea-water. In this case butyric acid is produced and diffuses into the egg. And there is no reason for supposing that a similar reaction may not take place when $\mathrm{HCl}$ comes into contact with the surface of the egg; for it might liberate here one of the higher fatty acids contained in combination in the surface of the egg.

It may also be mentioned that the addition of a slightly effective mineral acid, such as $\mathrm{HCl}$, to butyric acid does not influence the activity of the latter. I have performed many experiments of the kind, to see how far $\mathrm{HCl}$ can replace the fatty acid. It appears that $\mathrm{HCl}$ can only enter as substitute for a small amount of the fatty acid; perhaps some acid is combined with the proteins of the egg (especially of the chorion), and only this amount of fatty acid can be replaced by $\mathrm{HCl}$. If more is added, everything proceeds as though the fatty acid concerned were in solution alone. The cnly effect of the surplus of $\mathrm{H}$ ions is that the confluence of the drops in membrine 
formation does not proceed so readily. All this harmonizes with the view that it is not the hydrogen ions but only the undissociated acid which diffuses into the egg and that the fatty acids diffuse much more quickly than the mineral acids which may not enter at all.

We may inquire whether the causation of membrane formation is a chemical or purely a physical effect of the acid. I asked Dr. Hagedoorn to determine the temperature coefficient of membrane formation by means of acids. He found that it is about 2 for a difference of temperature of $10^{\circ} \mathrm{C}$., which therefore indicates a chemical reaction. The procedure was to measure the minimum time which eggs must remain in a mixture of 50 c.c. of acid +2.5 c.c. of $\mathrm{N} / 10$ butyric acid to cause membrane formation in 95 per cent of the eggs. It turned out that this time is twice as long at $10^{\circ} \mathrm{C}$. as at $20^{\circ} \mathrm{C}$. This result was confirmed by other determinations at different temperatures.

All the experiments mentioned in this chapter were made on the eggs of the Californian sea-urchin S. purpuratus. 


\section{XV}

THE ACTIVATION OF THE UNFERTILIZED EGG BY BASES

1. The writer found in 1907 that strong bases are able to cause the unfertilized egg to develop, but that in some respects their effect differs from that of acids. While only a short treatment with acid suffices to induce membrane formation and while this action is not prevented by $\mathrm{KCN}$, the strong bases must act on the egg a comparatively long time before they can cause it to develop. And, moreover, their effect is prevented by lack of oxygen or by the presence of $\mathrm{KCN}{ }^{1}$

Like the acids, the bases cause development through a modification of the surface of the egg, but in the case of bases the resulting membrane is as a rule only a fine gelatinous layer, such as is formed through the influence of fatty acids in the egg of Arbacia, although occasionally a typical fertilization membrane is formed. The bases act therefore in one respect like the acids, inasmuch as both call forth a typical or atypical membrane formation and this membrane formation is the essential part of artificial parthenogenesis. In order to cause the unfertilized eggs of Arbacia to develop by bases, the following procedure was found to be effective. The eggs of Arbacia are put into 50 c.c. $\mathrm{m} / 2\left(\mathrm{NaCl}+\mathrm{KCl}+\mathrm{CaCl}_{2}\right)+0.3$ c.c. $\mathrm{N} / 10$ $\mathrm{NH}_{4} \mathrm{OH}$ for twenty-five minutes, at a temperature of about $22^{\circ} \mathrm{C}$. From here they are transferred directly to a neutral hypertonic solution, 50 c.c. $\mathrm{m} / 2$ Ringer +8 c.c. $2 \frac{1}{2} \mathrm{~m}$ Ringer, for fifteen minutes, and then they are put back into normal sea-water. In this case a large number of eggs develop into larvae, many of which are perfectly normal. It will be found that only those eggs develop into larvae which form the gelatinous film-.

${ }^{1}$ Loeb, "Ueber die allgemeinen Methoden der künstlichen Parthenogenese," Pflüger's Archiv, CXVIII, 572, 1907. 
the membrane. This membrane does not usually form while the eggs are in the alkaline solution but afterward either in the hypertonic solution or sometimes even later. ${ }^{1}$

'It is very important that the eggs should not remain too long in the hypertonic solution. The time they must remain in the hypertonic solution varies according to the length of time the eggs remained in the $\mathrm{NH}_{4} \mathrm{OH}$ solution. Eggs that were kept in the above-mentioned alkaline solution for ten minutes developed best when they were exposed to the hypertonic solution for twenty-four minutes; while eggs that were in the alkaline solution for thirty minutes developed best when put for fifteen minutes into the hypertonic solution. This observation finds its possible explanation in the fact that the hypertonic solution also causes an increase in the rate of oxidation of the unfertilized egg, and in this respect resembles the action of the alkaline solution. It is therefore not surprising that the two solutions can act as a partial substitute for each other. If the eggs remain only a few minutes too long in the hypertonic solution, they suffer considerably; if they are taken out of the hypertonic solution too soon, they will not develop.

2. A comparison of the relative efficiency of various alkalies for the causation of artificial parthenogenesis furnished the result that weak bases like $\mathrm{NH}_{4} \mathrm{OH}$ are much more effective than strong bases like $\mathrm{NaOH}, \mathrm{KOH}$, or tetraethylammoniumhydroxide. To three solutions of 50 c.c. $\mathrm{m} / 2$ Ringer were added 0.3 c.c. $\mathrm{N} / 10 \mathrm{NH}_{4} \mathrm{OH}, 0.3$ c.c. $\mathrm{N} / 10 \mathrm{NaOH}$, and 0.3 c.c. $\mathrm{N} / 10$ tetraethylammoniumhydroxide respectively. Unfertilized eggs of Arbacia were put into these solutions for twentysix minutes and were then transferred to the hypertonic Ringer solution (50 c.c. $\mathrm{m} / 2$ Ringer +8 c.c. $2 \frac{1}{2} \mathrm{~m}$ Ringer). They remained here for fifteen minutes and were then transferred to normal sea-water. Practically all the eggs that had been

1 Loeb, "The Comparative Efflieiency of Weak and Strong Bases in Artiflcial Parthenogenesis," Jour. Exper. Zool., XIII, 577, 1912. 
in 0.3 c.c. $\mathrm{N} / 10 \mathrm{HN}_{4} \mathrm{OH}$ developed into larvae, while only very few eggs developed that had been treated with the two strong bases. In order to cause artificial parthenogenesis with $\mathrm{NaOH}$ or tetraethylammoniumhydroxide, a longer exposure is necessary than with the weak base $\mathrm{HN}_{4} \mathrm{OH}$. This is in analogy with our experience with acids (see preceding chapter).

Not only $\mathrm{NH}_{4} \mathrm{OH}$ but other weak bases like the amines, e.g., butylamine or benzylamine, are effective. It is of great interest that the weak base protamine prepared from the sperm of the salmon is one of the most efficient substances for the causation of artificial parthenogenesis. These experiments were made on the eggs of Arbacia. An exposure of the eggs for only five minutes to a solution of 50 c.c. $\mathrm{m} / 2 \mathrm{NaCl}+\mathrm{KCl}$ $+\mathrm{CaCl}_{2}+0.3$ c.c. of a $\mathrm{N} / 10$ solution of one of these weak bases suffices to induce development in the egg of Arbacia. If the eggs are put afterward for the proper time (about twenty to twenty-five minutes at $26^{\circ} \mathrm{C}$.) into any hypertonic solution, e.g., 50 c.c. sea-water +8 c.c. $2 \frac{1}{2} \mathrm{~m} \mathrm{NaCl}$; or into sea-water whose concentration had been raised to the same degree by evaporation; or into a mixture of 10 c.c. sea-water +40 c.c. $m$ solution of cane sugar, a certain percentage will develop into plutei after they are transferred into sea-water.

These results were confirmed in experiments on an annelid (Polynoe) of the Pacific coast. It was found that the weak bases like amines (methyl-, ethyl-, butyl-, and benzylamine were tried) and $\mathrm{NH}_{4} \mathrm{OH}$ caused artificial parthenogenesis much more quickly than the strong bases $\mathrm{NaOH}$ or tetraethylammoniumbydroxide. The amines were more effective than $\mathrm{NH}_{4} \mathrm{OH}$.

The reason for this paradoxical behavior of the bases is the same as for that of the acids; the weaker bases are more efficient than the stronger for the reason that the weaker bases diffuse rapidly into the egg while the strong bases do not diffuse at all into the egg or only to a very slight extent. The direct proof 
of this statement has been furnished by eggs stained red with neutral red. Warburg has shown that if a small amount of $\mathrm{NH}_{4} \mathrm{OH}$ is added to the solution the eggs turn yellow, while when $\mathrm{NaOH}$ is added they remain red. ${ }^{1}$ Harvey has shown that not only the egg cells but cells in general behave this way, and that the cells are impermeable for all strong bases $(\mathrm{NaOH}$, $\mathrm{KOH}$, tetraethylammoniumhydroxide) while they are permeable for weak bases like $\mathrm{NH}_{4} \mathrm{OH}$ or the amines. ${ }^{2}$ The bases as well as the acids must be able to diffuse into the egg in order to cause artificial parthenogenesis. ${ }^{3}$

3. When a trace of $\mathrm{KCN}$ is added to the alkaline solution its effect is diminished and the eggs must either remain longer in the alkaline solution or longer in the hypertonic solution in order to produce larvae. In former experiments on the unfertilized eggs of Strongylocentrotus the writer could show that the parthenogenetic effects (as well as the destructive effects) of $\mathrm{NaOH}$ can be inhibited if the solution is deprived of oxygen. ${ }^{4}$

4. If the eggs of Arbacia are treated with alkali alone, without being afterward submitted to a treatment with a hypertonic solution, they may form fine gelatinous surface films (membranes) and begin to develop, but they will then disintegrate.

To 50 c.c. $\mathrm{m} / 2\left(\mathrm{NaCl}+\mathrm{KCl}+\mathrm{CaCl}_{2}\right)$ were added 0.3 c.c. $\mathrm{N} / 10 \mathrm{NH}_{4} \mathrm{OH}, 0.3$ c.c. $\mathrm{N} / 10 \mathrm{NaOH}$, and 0.3 c.c. $\mathrm{N} / 10$ tetraethylammoniumhydroxide respectively. Unfertilized eggs of Arbacia were put into these three solutions for forty-two minutes and then transferred to normal sea-water. All of the eggs that had been in the solution containing the $\mathrm{NH}_{4} \mathrm{OH}$ segmented in a rather amoeboid way into two or four cells, after which the cells fell apart and disintegrated. All of the eggs that had

1 Warburg, Zeitschr. f. physiol. Chem., LXVI, 305, 1910.

${ }^{2}$ Harvey, Jour. Exper. Zool., X, 507, 1911.

${ }^{3}$ Loeb, op. cit.

${ }^{4}$ Loeb, "Weitere Versuche ueber die Notwendigkeit von freiem Sauerstoff für die entwicklungserregende Wirkung hypertonischer Lösungen," Pfüger's Archiv, CXVIII, 30, 1907. 
been in 50 c.c. $\mathrm{m} / 2\left(\mathrm{NaCl}+\mathrm{KCl}+\mathrm{CaCl}_{2}\right)+0.3$ c.c. $\mathrm{N} / 10$ $\mathrm{NaOH}$ for forty-two minutes remained practically intact and the same was true for the eggs that had been in the tetraethylammoniumhydroxide for forty-two minutes. In order to make sure that they did not only appear normal but were normal, sperm was added to these eggs the next morning. All those that had been in $\mathrm{NaOH}$, and in tetraethylammoniumhydroxide, segmented normally and developed into normal embryos.

In this experiment part of the eggs were submitted for fifteen minutes to the action of the neutral hypertonic solution after they had been treated with alkali. Those that had been in $\mathrm{NH}_{4} \mathrm{OH}$ developed into larvae, the others did not. It is obvious that the changes leading to parthenogenetic development are brought about more rapidly by $\mathrm{NH}_{4} \mathrm{OH}$ than by the strong bases.

5. We have seen in the experiments with the fertilization of the eggs by fatty acid that the treatment with the hypertonic solution could either precede or follow the treatment with fatty acid. In case it preceded, the exposure to the hypertonic solution had to be considerably longer than when it followed the fatty acid treatment. The same is true for the fertilization by bases. If the eggs of purpuratus are submitted to the hypertonic solution first, they must remain much longer in the hypertonic solution than if they are put into it after having undergone a treatment with alkali. This is due to the difference in the rate of oxidations in the egg before and after membrane formation. When the rate of oxidation is higher in the egg the exposure to the hypertonic solution may be shorter.

It may be stated incidentally that artificial parthenogenesis by bases is less satisfactory in $S$. purpuratus than in Arbaciu since only the eggs of perhaps one-third of the females of purpuratus develop into larvae through the influence of bases. Where the method is successful it can be shown that $\mathrm{NH}_{4} \mathrm{OH}$, and to some degree the amines, are more effective than $\mathrm{NaOH}$. 
6. The inhibitive effect of $\mathrm{KCN}$ and lack of oxygen upon the activation of the unfertilized egg by bases suggested an investigation of the influence of the various bases upon the rate of oxidations in the unfertilized egg, to find out whether the weaker bases raised the rate of oxidations more than the stronger ones. ${ }^{1}$

The experiments were carried out on the unfertilized egg of S. purpuratus. The oxygen content was determined according to Winkler's method. The experiments were made in a half grammolecular mixture of $\mathrm{NaCl}+\mathrm{KCl}+\mathrm{CaCl}_{2}$ in that proportion in which these three salts are contained in the seawater.

We first give the results of a series of experiments in which the relative influence of various bases was compared. The

TABLE XXVI

\begin{tabular}{|c|c|c|c|}
\hline $\begin{array}{c}\text { Number } \\
\text { of } \\
\text { Experi- } \\
\text { ment }\end{array}$ & Nature of the solution & $\begin{array}{c}\text { mgm. of } \\
\text { Oxygen } \\
\text { Consumed }\end{array}$ & $\begin{array}{l}\text { Acceleration } \\
\text { of Rate of } \\
\text { Oxidations } \\
\text { by the Base }\end{array}$ \\
\hline $\begin{array}{c}\text { I. . } \\
\text { II. . }\end{array}$ & 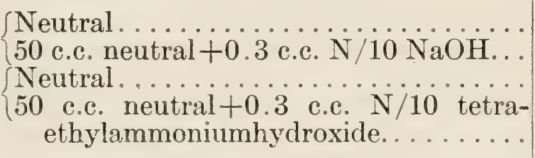 & $\begin{array}{r}0.28 \\
0.40 \\
-\quad 0.15 \\
0.22\end{array}$ & $\begin{array}{l}1.43 \\
1.50\end{array}$ \\
\hline $\begin{array}{l}\text { III. } \\
\text { IV. }\end{array}$ & $\left\{\begin{array}{l}\text { Neutral } \\
50 \text { e.c. neutral }+0.3 \text { c.c. } \mathrm{N} / 10 \mathrm{NH}_{4} \mathrm{OH} \\
50 \text { c.c. neutral }+0.3 \text { c.c. } \mathrm{N} / 10 \text { tri- } \\
\text { methylamine } \ldots \ldots \ldots \ldots \ldots \ldots\end{array}\right.$ & $\begin{array}{l}0.30 \\
0.81 \\
0.40 \\
1.19\end{array}$ & $\begin{array}{l}2.70 \\
3.00\end{array}$ \\
\hline VIII. & 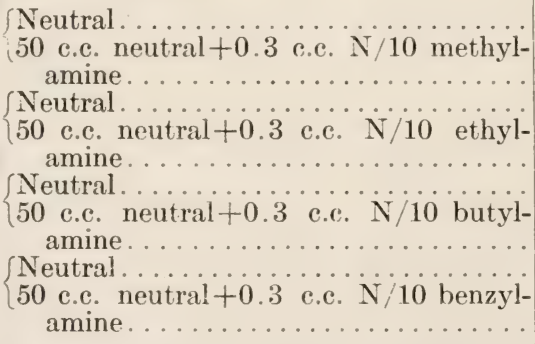 & $\begin{array}{l}0.25 \\
1.18 \\
0.28 \\
1.35 \\
0.32 \\
1.23 \\
0.22 \\
1.30\end{array}$ & $\begin{array}{l}4.80 \\
3.80 \\
5.90\end{array}$ \\
\hline
\end{tabular}

${ }^{1}$ Loeb and Wasteneys, Jour. Biol. Chem., XIV, 355, 1913. 
time of exposure was one hour and twenty-five minutes; the temperature $18^{\circ} \mathrm{C}$. The concentration of the bases chosen was that found most effective in the writer's previous experiments on artificial parthenogenesis. The oxygen consumption was first measured in a neutral solution and then for the same eggs in the alkaline solution in which 0.3 c.c. $\mathrm{N} / 10$ of the various bases was added to 50 c.c. of the solution.

This influence of the various bases upon the rate of oxidation in the eggs of purpuratus runs parallel to their relative efficiency in causing development in Polynoe. To induce artificial parthenogenesis in the eggs of Polynoe the simple amines were found to be most efficient, next came $\mathrm{NH}_{4} \mathrm{OH}$ and trimethylamine, and finally the strong bases $\mathrm{NaOH}$ and tetraethylammoniumhydroxide. The amines seem to hurt the eggs of purpuratus more than those of Polynoe.

Incidentally it may be stated that $\mathrm{NaHCO}_{3}$ does not accelerate the rate of oxidations in the unfertilized egg, nor does it cause artificial parthenogenesis.

7. We compared next the relative effect of various concentrations of $\mathrm{NaOH}$ and $\mathrm{NH}_{4} \mathrm{OH}$ upon the rate of oxidations in the unfertilized sea-urchin egg, during one hour. We will state only the coefficient of the rate of oxidation in the various solutions calling the rate in the neutral solution 1.00 .

TABLE XXVII

\begin{tabular}{|c|c|c|}
\hline \multirow{2}{*}{$\begin{array}{c}\text { AMOUNT of BAsE ADDED To } \\
50 \text { c.c. } \mathrm{m} / 2\left(\mathrm{NaCl}^{2}+\mathrm{KCl}+\right. \\
\left.\mathrm{CaCl}_{2}\right)\end{array}$} & \multicolumn{2}{|c|}{$\begin{array}{l}\text { COEFFICIENT OF ACCEL- } \\
\text { ERATION OF OXIDA- } \\
\text { TIONS IN }\end{array}$} \\
\hline & $\mathrm{NaOH}$ & $\mathrm{NH}_{4} \mathrm{OH}$ \\
\hline 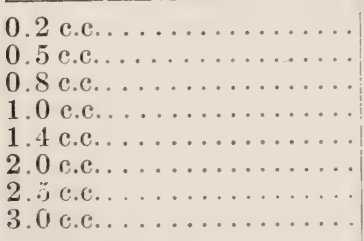 & $\begin{array}{l}1.35 \\
1.87 \\
1.74 \\
2.06 \\
2.32 \\
3.42 \\
4.57 \\
7.60\end{array}$ & $\begin{array}{l}1.29 \\
5.00 \\
5.94 \\
6.10 \\
6.40 \\
6.23 \\
5.70 \\
6.00\end{array}$ \\
\hline
\end{tabular}


The reader will notice the striking difference in the behavior of $\mathrm{NH}_{4} \mathrm{OH}$ and $\mathrm{NaOH}$. Low concentrations of $\mathrm{NH}_{4} \mathrm{OH}(0.5$ c.c. per 50 c.c. solution) raise the rate of oxidations in the fertilized egg almost to the maximal height and a further rise in the concentration has only a slight effect upon the rate of oxidation. Low concentrations of $\mathrm{NaOH}$ raise the rate of oxidation only a little, and the efficiency of $\mathrm{NaOH}$ rises steadily with an increase in its concentration. We could not go beyond the concentrations used in this experiment, since the addition of 3 c.c. $\mathrm{N} / 10 \mathrm{NaOH}$ to 50 c.c. $\mathrm{m} / 2 \mathrm{NaCl}+\mathrm{KCl}+\mathrm{CaCl}_{2}$ leads already to a cytolysis of the eggs.

It is also of interest to point out that in the eggs of $S$. purpuratus fertilization by sperm raises the rate of oxidation to about five or six times the amount of that in the unfertilized eggs. This seems to indicate that with $\mathrm{NH}_{4} \mathrm{OH}$ it is not possible to raise the rate of oxidations in the unfertilized egg beyond the limit to which it can be raised by the fertilization with sperm. It is not possible to decide whether the same holds true for $\mathrm{NaOH}$.

The fact that a base reaches its maximum effect at so low a concentration is not confined to $\mathrm{NH}_{4} \mathrm{OH}$ but is also shared by the amines as the following table shows. $\mathrm{NH}_{4} \mathrm{OH}$ and ethylamine were compared.

TABLE XXVIII

\begin{tabular}{|c|c|c|}
\hline \multirow{2}{*}{$\begin{array}{c}\text { AMOUNT OF BAsE AdDED TO } \\
50 \text { c.c. } \mathrm{m} / 2\left(\mathrm{NaCl}^{2} \mathrm{KCl}+\right. \\
\left.\mathrm{CaCl}_{2}\right)\end{array}$} & \multicolumn{2}{|c|}{$\begin{array}{l}\text { COEFFICIENT OF ACCEL- } \\
\text { ERATION OF OXIDA- } \\
\text { TIONS IN }\end{array}$} \\
\hline & $\mathrm{NH}_{4} \mathrm{OH}$ & Ethylamine \\
\hline $\begin{array}{l}0.1 \text { c.c. } N / 10 \ldots \ldots \ldots \ldots \\
0.2 \text { c.c. } N / 10 \ldots \ldots \ldots \\
0.4 \text { c.c. } N / 10 \ldots \ldots \\
0.8 \text { c.c. } N / 10 \ldots \ldots\end{array}$ & $\begin{array}{l}1.9 \\
2.9 \\
3.4 \\
3.9\end{array}$ & $\begin{array}{l}1.4 \\
3.0 \\
4.3 \\
4.2\end{array}$ \\
\hline
\end{tabular}

Ethylamine reaches its maximal efficiency at the concentration of 0.4 c.c. base to 50 c.c. of the neutral liquid; and for 
$\mathrm{NH}_{4} \mathrm{OH}$ the limit is nearly at the same point as in our previous experiment.

8. It seemed natural to connect this difference in the behavior of $\mathrm{NaOH}$ and $\mathrm{NH}_{4} \mathrm{OH}$ with the difference in the rate of their diffusion into the unfertilized egg. If the rate of diffusion of $\mathrm{NaOH}$ is extremely slow, and that of $\mathrm{NH}_{4} \mathrm{OH}$ fast, it is natural that the maximal rate of oxidation should be reached with a lower concentration of $\mathrm{NH}_{4} \mathrm{OH}$ than of $\mathrm{NaOH}$. We determined the consumption of oxygen for the same lot of eggs for eight consecutive hours in 50 c.c. sea-water +1.0 c.c. $\mathrm{N} / 10 \mathrm{NaOH}$. Table XXIX gives the result. This shows that

\section{TABLE XXIX}

Consumption of Oxygen by Unfertilized Eggs at $18^{\circ}$ in 50 c.c. Normal Sea-Water +1.0 c.c. N/10 NaOH

\begin{tabular}{|c|c|c|}
\hline & $\begin{array}{c}\text { Oxygen } \\
\text { Consumed }\end{array}$ & $\begin{array}{l}\text { Coefficient } \\
\text { of Oxidation }\end{array}$ \\
\hline 1st hour. . . . . . . . . . . & $\begin{array}{l}\text { mgm. } \\
0.24\end{array}$ & 1.00 \\
\hline 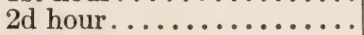 & 0.38 & 1.57 \\
\hline 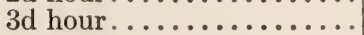 & 0.45 & 1.87 \\
\hline 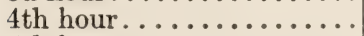 & 0.50 & 2.08 \\
\hline 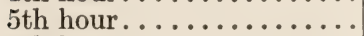 & 0.58 & 2.42 \\
\hline 6 th hour.... & 0.72 & 3.00 \\
\hline 7th hour............... & 0.92 & 3.84 \\
\hline 8th hour....... & 0.95 & 3.96 \\
\hline
\end{tabular}

the longer the $\mathrm{NaOH}$ acts upon the egg the higher the amount of oxygen becomes which is consumed per hour. This would agree with the assumption that the $\mathrm{NaOH}$ diffuses slowly into the egg and that the increase in the rate of oxidations in the unfertilized egg is determined by the amount of base which has diffused into the egg.

It was expected that since $\mathrm{NH}_{4} \mathrm{OH}$ is very soluble in the egg, i.e., diffuses rapidly into it, its maximum effect would be reached during the first hour. This was found to be true, as Table XXX shows. 
We intend to investigate whether these effects of bases upon the rate of oxidations in the unfertilized eggs are irreversible, i.e., will continue if the eggs are put into normal sea-water after the treatment with alkali. But we have an experiment which possibly serves the same purpose. We measured the amount of oxygen consumed in one hour in the eggs mentioned in Table XXX in the same solution sixteen and twenty-four hours

\section{TABLE XXX}

Consumption of Oxygen by Unfertilized Eggs at $18^{\circ}$ in 50 c.c. Normal Sea-Water +0.8 c.c. $\mathrm{N} / 10 \mathrm{NH}_{4} \mathrm{OH}$

\begin{tabular}{|c|c|c|}
\hline & $\begin{array}{l}\text { Oxygen } \\
\text { Consumed }\end{array}$ & $\begin{array}{l}\text { Coefficient } \\
\text { of Oxidation }\end{array}$ \\
\hline $\begin{array}{l}\text { Normal sea-water } \because 3 \text { c.c. } \mathrm{N} / 10 \mathrm{NH}_{4} \mathrm{OH} ; 1 \text { st hr. } \\
50 \text { c.c. sea-water }+0.8 \text { c. } \\
50 \text { c.c. sea-water }+0.8 \text { c.c. } \mathrm{N} / 10 \mathrm{NH}_{4} \mathrm{OH} ; 2 \mathrm{~d} \mathrm{hr} . \\
50 \text { c.c. sea-water }+0.8 \text { c.c. } \mathrm{N} / 10 \mathrm{NH}_{4} \mathrm{OH} ; 3 \mathrm{~d} \mathrm{hr} . \\
50 \text { c.c. sea-water }+0.8 \text { c.c. } \mathrm{N} / 10 \mathrm{NH}_{4} \mathrm{OH} ; 4 \text { th hr. } \\
50 \text { c.c. sea-water }+0.8 \text { c.c. } \mathrm{N} / 10 \mathrm{NH}_{4} \mathrm{OH} ; 5 \text { th hr. }\end{array}$ & $\begin{array}{l}\text { mgm. } \\
0.15 \\
0.99 \\
1.03 \\
0.87 \\
0.86 \\
0.83\end{array}$ & $\begin{array}{l}1.0 \\
6.7 \\
6.9 \\
5.8 \\
5.7 \\
5.5\end{array}$ \\
\hline
\end{tabular}

after the experiment. In the meantime the eggs had been kept at a low temperature in normal sea-water. The rate of oxidations after sixteen or twenty-four hours was practically the same as in the second hour. This agrees with the assumption that these bases bring about the modification of the cortical layer of the egg, after which the rate of oxidation in the egg is raised permanently.

These experiments prove two facts, first, that the weaker bases increase the rate of oxidations in the unfertilized egg more than the stronger bases; and, second, that this difference is due to the fact that the weaker bases diffuse more rapidly into the egg than the strong bases.

The connection between the oxidative action of bases and artificial parthenogenesis lies in the fact that the essential factor in artificial parthenogenesis is an alteration of the surface or cortical layer of the egg which results in a membrane 
formation. We shall see later that bases cause the swelling and liquefaction of the gelatinous mass (the so-called chorion) which surrounds the immature egg of a mollusc, Lottia, and that, this action of bases is inhibited by lack of oxygen and by the addition of KCN. ${ }^{1}$ This year the author convinced himself that weak bases like the amines and $\mathrm{NH}_{4} \mathrm{OH}$ bring about the dissolution of the chorion of Lottia much more rapidly than the strong bases $\mathrm{NaOH}$ and tetraethylammoniumhydroxide. It is possible that the induction of artificial parthenogenesis in the sea-urchin egg by bases depends upon the occurrence of a similar process in the cortical layer of this egg. We may imagine that the bases act by accelerating the rate of oxidation of a substance (existing in the cortical layer of the eggs) whereby the membrane formation and consequently the development of the egg is induced.

${ }_{1}^{1}$ Loeb, University of California Publications, Physiology, III, 1, 1905. 



\section{XVI}

ANALYSIS OF THE ORIGINAL METHOD OF PRODUCING ARTIFICIAI PARTHENOGENESIS BY HYPERTONIC SOLU'TIONS ALONE

1. We are now able to undertake the analysis of the purely osmotic method of artificial parthenogenesis by which the writer first obtained parthenogenetic larvae of the sea-urchin (see chapter vii). The reader will notice that this method apparently contradicts the statement that artificial parthenogenesis is due to the influences of two agencies, one of which causes the membrane formation, the second the correcting effect, which protects the egg against the disintegration induced by the artificial membrane formation. The apparent contradiction is abolished by the realization of the fact that in this method the hypertonic solution acts simultaneously in two capacities: first, as a cytolytic agency causing a change in the cortical layer (the formation of a gelatinous film), and second, as a corrective agency. This latter effect is sufficiently intelligible from what has been said before. The cytolytic effect of a hypertonic solution, however, needs to be demonstrated, and, moreover, proof must be furnished that the two agencies active in artificial parthenogenesis may act simultaneously instead of in succession.

It must first be stated that this method also leads to a kind of stunted membrane formation; only such eggs can be caused to develop by this method which form a membrane.

But the hypertonic solution is not a reliable agency for the causation of membrane formation, and this is the reason that this original, purely osmotic method of artificial parthenogenesis gives such poor results with the eggs of $S$. purpuratus and not very good results with the eggs of Arbacia. The direct 
membrane formation by butyric acid is much more reliable than that by the hypertonic solution.

The membrane-forming action of a hypertonic solution is similar to that of a base, and this can be demonstrated in the liquefaction of the chorion of the egg of Lottia (a molluse). We have mentioned that this chorion can be caused to swell and undergo liquefaction by bases. The writer found that the same can be accomplished by neutrai hypertonic solutions. ${ }^{1}$ In both cases the presence of free oxygen is required. Moreover, the temperature coefficient for the dissolution of the chorion in the unfertilized egg of Lottia by hypertonic solutions is over 2 for $10^{\circ} \mathrm{C}$.

The idea that in the causation of artificial parthenogenesis by the original purely osmotic method the latter acted in the double capacity of a membrane-forming and corrective agency can be supported by measurements of the rate of oxidation of unfertilized eggs in these solutions.

According to our theory the rise in the rate of oxidations in unfertilized eggs under the influence of hypertonic solutions should be due only to the alteration of the surface of the egg, i.e., the membrane formation. Since this effect takes place, if it takes place at all, in the first two hours, we should expect that if we leave unfertilized eggs for a series of hours in a hypertonic solution, and measure the rate of oxidation for successive hours, the maximum effect should be reached in the first or second hour and that afterward the hypertonic solution should cause no further rise in the rate of oxidations. This actually takes place. The following experiment gives the rate of oxidations of unfertilized eggs in a hypertonic solution in a series of successive hours. ${ }^{2}$ The consumption of oxygen was measured for one hour at $18^{\circ}$. Unfertilized eggs were

${ }^{1}$ Loeb, "On a Chemical Method by Which the Eggs of Lottia Can Be Caused to Become Mature," University of California Publications, Physiology, III, 1, 1905.

${ }^{2}$ Loeb and Wasteneys, Jour. Biol. Chem., XIV, 469, 1913. 
put directly into hypertonic sea-water (50) (e.e. seat-water + 8 c.c. $2 \frac{1}{2} \mathrm{~m} \mathrm{NaCl}$ ). Temperature $18^{\circ} \mathrm{C}$.

The maximum consumption of oxygen was reached in the second hour in which the effert of membrane formation was almost complete. In this case the eggs of a female were used

TABLE XXXI

UNFERTILIZED EgGS

\begin{tabular}{|c|c|c|c|}
\hline & & $\begin{array}{c}\text { Oxygen } \\
\text { Consumed }\end{array}$ & $\begin{array}{l}\text { Coefficient of } \\
\text { Rate of Oxidation }\end{array}$ \\
\hline $\begin{array}{l}\text { Normal sea-water. . . } \\
\text { Hypertonic sea-water; }\end{array}$ & $\begin{array}{l}\text { 1st hour. . . . . . . } \\
\text { 2d hour. . . . . . } \\
\text { 3d hour. . . . . } \\
\text { 4th hour. . . . . } \\
\text { 5th hour. . . . }\end{array}$ & $\begin{array}{l}0.16 \mathrm{mg} . \\
0.67 \\
0.79 \\
0.64 \\
0.56 \\
0.57\end{array}$ & $\begin{array}{l}1.0 \\
4.2 \\
4.9 \\
4.0 \\
3.6 \\
3.2\end{array}$ \\
\hline
\end{tabular}

which were obviously very susceptible to this treatment. The effect of the hypertonic solution upon the rate of oxidation in the unfertilized egg was as great as that produced by artificial membrane formation through butyric acid or by fertilization with sperm.

In many cases the treatment of eggs of $S$. purpuratus with hypertonic sea-water leads to no membrane formation and no development, or only to the development of a limited number of eggs. Consequently the rise in the rate of oxidation caused in such cases should be smaller than that caused by artificial membrane formation with butyric acid which usually takes effect in practically all the eggs.

We give in Table XXXII a series of experiments with hypertonic sea-water of various concentrations. It should be remembered that the addition of 4 c.c., or less, $2 \frac{1}{2} \mathrm{~m}$ Ringer to 50 c.c. of sea-water was without effect. The oxygen consumption was first measured in normal sea-water, then, for the same quantities of eggs, in a hypertonic solution. The table gives the ratio of the oxygen consumption in hypertonic to that in normal sea-water. 
In this case the rise in the rate of oxidations is less than that ordinarily caused by membrane formation with butyric acid in the same eggs.

TABLE XXXII

UNFERTILIZED EgGS of S. purpuratus

\begin{tabular}{l|c}
\hline \hline & $\begin{array}{c}\text { coefficient of } \\
\text { Oxygen } \\
\text { consumption }\end{array}$ \\
\hline 50 c.c. sea-water +4 c.c. $2 \frac{1}{2} \mathrm{~m} \mathrm{NaCl}+\mathrm{KCl}+\mathrm{CaCl}_{2} \ldots$ & 1.4 \\
50 c.c. sea-water +6 c.c. $2 \frac{1}{2} \mathrm{~m} \mathrm{NaCl}+\mathrm{KCl}+\mathrm{CaCl}_{2} \ldots$ & 1.9 \\
50 c.c. sea-water +8 c.c. $2 \frac{1}{2} \mathrm{~m} \mathrm{NaCl}+\mathrm{KCl}+\mathrm{CaCl}_{2} \ldots \ldots$ & 2.6 \\
50 c.c. sea-water +9 c.c. $2 \frac{1}{2} \mathrm{~m} \mathrm{NaCl}+\mathrm{KCl}+\mathrm{CaCl}_{2} \ldots$ & 2.6 \\
50 c.c. sea-water +12 e.c. $2 \frac{1}{2} \mathrm{~m} \mathrm{NaCl}+\mathrm{KCl}+\mathrm{CaCl}_{2} \ldots$ & 2.3 \\
50 c.c. sea-water +16 c.c. $2 \frac{1}{2} \mathrm{~m} \mathrm{NaCl}+\mathrm{KCl}+\mathrm{CaCl}_{2} \ldots .$. & 2.6 \\
\hline
\end{tabular}

2. The hypertonic solutions are much more effective in causing artificial parthenogenesis if some alkali is added. In one experiment $0,0.5,1.0,1.5$, and 2.0 c.c. $\mathrm{N} / 10 \mathrm{NaOH}$ were added each to 50 c.c. of sea-water +10 c.c. $2 \frac{1}{2} \mathrm{~m} \mathrm{NaCl}$ solution. The unfertilized eggs of one specimen of $S$. purpuratus were divided among these solutions and portions of the eggs transferred to normal sea-water after 60, 90, 120, 150, and 240 minutes. The temperature of the hypertonic sea-water was $13.5^{\circ} \mathrm{C}$. Only the two of these solutions with the highest concentration of $\mathrm{NaOH}$ (1.5 and 2.0 c.c. $\mathrm{N} / 10 \mathrm{NaOH}$ to 50 c.c. of the hypertonic sea-water) caused the eggs to develop into larvae (time of exposure $1 \frac{1}{2}$ hours). Some of these larvae reached the pluteus stage and swam at the surface of the dish. Often, however, the addition of quite a small amount of $\mathrm{NaOH}$ was enough to cause development and for the eggs of some females the concentration of $\mathrm{HO}$ ions present in the sea-water is sufficient. We are dealing here with differences in the eggs of various females. It was found in general that a neutral hypertonic solution was not able to induce artificial parthenogenesis in the eggs of S. purpuratus. Even the maximal permissible increase of the osmotic pressure is 
generally, though possibly not always, unable to cause the unfertilized eggs of $S$. purpuratus to develop into larvae, no matter how long the egg is exposed to such a solution. For such experiments the alkaline sea-water cannot be used; hence the writer chose as a neutral solution a neutral mixture of 100 c.c. $\mathrm{NaCl}, 2.2$ c.c. $\mathrm{KCl}, 1.5$ c.c. $\mathrm{CaCl}_{2}$, and 11.6 c.c. $\mathrm{MgCl}_{2}$, all the solutions being half grammolecular.

We call such a van't Hoff solution neutral when it is colored red by neutral red, but turns to orange for a few minutes on the addition of only 0.1 c.c. of $\mathrm{N} / 100 \mathrm{NaOH}$, afterward becoming red again. The concentration of the hydroxylions in such a solution lies below $10^{-6}$ normal, but so close to this value that the slightest addition of alkali brings up the concentration of the $\mathrm{HO}$ ions to this amount; however, owing to the diffusion of the $\mathrm{CO}_{2}$ of the air into the solution, the concentration of the $\mathrm{HO}$ ions soon sinks again below the limit of $10^{-6} \mathrm{n}$.

We shall now illustrate by a few examples the fact that even the greatest increase in osmotic pressure will as a rule not effect the transformation of eggs of $S$. purpuratus into larvae in neutral solution. To 50 c.c. of a neutral van't Hoff solution, $8,12,16,24$, and 32 c.c. of $2 \frac{1}{2} \mathrm{~m} \mathrm{KCl}$ solution were added respectively. The eggs of one female were divided among these solutions after being washed twice in the van't Hoff solution to free them from any trace of sea-water. This precaution is essential in such investigations, and has been employed in all our experiments. The temperature of the hypertonic solution was $13^{\circ} \mathrm{C}$. A portion of the eggs was transferred from each solution to normal sea-water after $25,45,75,105,145,185$, and 220 minutes. Not a single egg developed into a larva. With the addition of 32 c.c. of $2 \frac{1}{2} \mathrm{~m} \mathrm{KCl}$ to 50 c.c. of the van't Hoff solution the limit of the permissible osmotic pressure is reached, since at higher osmotic pressures the eggs are at once cytolyzed. ${ }^{1}$

¿Loeb, Pfüger's Archiv, CIII, 257, 1904; Untersuchungen ueber die künstliche Parthenogenese, pp. $288 \mathrm{ff}$. 
The following experiment, in which sea-water was used instead of the ran't Hoff solution, is also instructive. Eggs were used for which the concentration of the hydroxylions in sea-water was not high enough to permit of their development. To 50 c.c. of sea-water $4,8,12,16,24$, and 32 c.c. $2 \frac{1}{2} \mathrm{~m} \mathrm{NaCl}$ solution were added, and some of the eggs of one female were divided among these solutions. After 20, 40, 70, 100, 135, 210, 273, and 346 minutes portions of the eggs were replaced in normal seawater. In no case did even a single egg develop to a larva. Many eggs started cleavage; but this soon ceased, a fact to which we shall return later. It might have been supposed that here one was dealing with eggs which could not be caused to develop in any way at all by the osmotic effect. However, it was possible to show that it depended upon too low a concentration of hydroxylions. Thus a control experiment was performed, in which $0,0.1,0.2,0.4$, and 0.8 c.c. of $\mathrm{N} / 10 \mathrm{NaOH}$ were added to 50 c.c. of van't Hoff's solution +16 c.c. of $2 \frac{1}{2} \mathrm{~m}$ $\mathrm{NaCl}$ and some of the eggs of the same female were divided among these solutions. After 30, 60, 90, 120, and 210 minutes portions of these eggs were transferred to normal seawater. Of the eggs treated with neutral van't Hoff's solution not a single one developed into a larva, while the eggs treated for 90 to 120 minutes with alkaline solution produced larvae; the larvae were most numerous in that portion of the eggs which had been for 90 minutes in the solution with 0.8 c.c. $\mathrm{N} / 10 \mathrm{NaOH}$. Of this portion 80 per cent of the eggs developed into larvae.

On the other hand it was possible to show that in hyperalkaline solutions a relatively small increase of the osmotic pressure was sufficient to cause the formation of larvae in unfertilized eggs, and that any further increase of osmotic pressure only diminished the time of exposure to the solution necessary for the formation of larvae. The following experiment will serve as an example. To 50 c.c. of the van't Hoff solution+ 
2.0 c.e. $\mathrm{N} / 10 \mathrm{NaOH}, 0,2,4,8$, and 16 c.e. of $2 \frac{1}{2} \mathrm{~m}$ KCl were added. Unfertilized eggs were divided among these five solutions and portions of the eggs transferred to normal sca-water after 45, 64, 89, 116, and 144 minutes. The results are summarized in Table XXXIII. The increase of osmotic pressure is given in the table in round numbers as a percentage of the pressure of the half grammolecular solution.

\section{TABIE XXXIII}

\begin{tabular}{|c|c|c|c|c|c|}
\hline \multirow{2}{*}{$\begin{array}{c}\text { TIME OF } \\
\text { ExPOSURE }\end{array}$} & \multicolumn{5}{|c|}{ INCREASE OF The Osmotic Pressure OF the SOLUtion } \\
\hline & 0 Per Cent & 16 Per Cent & 30 Per Cent & 55 Per Cent & 87 Per Cent \\
\hline 4.5 ininutes. . . & 0 & 0 & 0 & 0 & numerous \\
\hline 64 minutes.... & 0 & 0 & 0 & $\begin{array}{c}\text { numerous } \\
\text { larvae }\end{array}$ & $\cdots \cdots \cdots$ \\
\hline 89 minutes... . & 0 & 0 & $\begin{array}{c}\text { numerous } \\
\text { larvae }\end{array}$ & $\ldots \ldots \ldots$ & $\ldots \ldots \ldots$ \\
\hline 116 minutes. . . & 0 & 0 & $\ldots \ldots \ldots$ & $\ldots \ldots \ldots$ & $\ldots \ldots \ldots$ \\
\hline 144 minutes. & 0 & 0 & ......... & ......... & $\cdots \cdots \cdots$ \\
\hline
\end{tabular}

Further experiments on the eggs of $S$. purpuratus showed that the results remain the same if the two agencies, the base and the neutral hypertonic solution, are applied in succession instead of simultaneously. When the treatment of these eggs with the alkaline solution (added to a neutral isotonic solution) preceded their treatment with a neutral hypertonic solution, it could be seen that the former agency acted mainly as the membrane-forming agency, while the hypertonic solution acted as the corrective agency.

For the egg of Arbacia a neutral hypertonic solution suffices to call forth a normal development.

3. Why should the addition of alkali to the hypertonic solution increase its efficiency? The answer is that the addition of alkali increases the membrane-forming effect of the hypertonic solution. In S. purpuratus the hypertonic solution 
alone is not able to induce the (stunted) membrane formation in the eggs, but the addition of alkali increases the membraneforming power. This can be proved by the fact that the addition of alkali to the hypertonic solution causes a rise in the rate of the oxidations of almost the same order as the addition of the same amount of base to an isotonic solution (Table XXXIV).

\section{TABLE XXXIV}

\begin{tabular}{|c|c|c|c|}
\hline $\begin{array}{l}\text { Number of } \\
\text { Experiment }\end{array}$ & Unfertilized Eggs (without Membranes) in & $\begin{array}{l}\text { Oxygen } \\
\text { Consumed }\end{array}$ & $\begin{array}{l}\text { Coefficient } \\
\text { of Rate of } \\
\text { Oxidations }\end{array}$ \\
\hline \multirow[t]{2}{*}{ I } & Normal sea-water . . . . . . . . . . . & $\begin{array}{l}\operatorname{mgm} \\
0.22\end{array}$ & 1.00 \\
\hline & $\begin{array}{l}50 \text { c.c. hypertonic sea-water }+1 \text { c.c. } \\
\mathrm{N} / 10 \mathrm{NH}_{4} \mathrm{OH} \ldots \ldots \ldots \ldots \ldots \\
50 \text { c.c. normal sea-water }+1 \text { c.c. } \mathrm{N} / 10\end{array}$ & 1.20 & 5.40 \\
\hline \multirow{3}{*}{ I I } & $\begin{array}{l}\mathrm{NH}_{4} \mathrm{OH} \\
\text { Normal sea-water. . } \ldots \ldots \ldots \ldots \ldots\end{array}$ & 0.88 & 4.00 \\
\hline & $\begin{array}{l}50 \text { c.c. hypertonic sea-water }+1 \text { c.c. } \\
\mathrm{N} / 10 \text { benzylamine } \ldots \ldots \ldots \text { c.c. } \mathrm{N} / 10\end{array}$ & 1.89 & 5.10 \\
\hline & $\begin{array}{c}\text { benzylamine } \ldots \ldots \ldots \ldots \ldots \ldots \\
\text { Normal sea-water } \ldots \ldots \ldots \ldots \ldots\end{array}$ & 1.75 & 4.70 \\
\hline \multirow{3}{*}{ I I I } & 50 c.c. hypertonic sea-water +1 c.c. & 0.36 & 1.00 \\
\hline & $\begin{array}{l}\mathrm{N} / 10 \text { butylamine } \ldots \ldots \\
50 \text { c.c. normal sea-water }+1 \text { c.c. } \mathrm{N} / 10\end{array}$ & 1.73 & 4.80 \\
\hline & butylamine $\ldots \ldots \ldots \ldots \ldots \ldots$ & 1.67 & 4.60 \\
\hline
\end{tabular}

It is obvious that the weak base alone raises the rate of oxidations practically to the same height as the combination of base and hypertonic sea-water. The whole rise was due in both cases to the membrane-forming effect for which the weak base was sufficient.

In the case of a strong base, the result may be different, since in purpuratus neither the base nor the hypertonic solution alone may cause membrane formation (or the change in the cortical layer of the egg) necessary for development. The following may serve as an example (Table XXXV). Duration of experiment one and one-half hours; temperature $18^{\circ} \mathrm{C}$. 
In this case the $\mathrm{NaOH}$ had little effect and hence the hypertonicity caused a noticeable increase in the rate since it probably increased the number of eggs in which the process of membrane formation was started.

TABLE XXXV

\begin{tabular}{|c|c|c|}
\hline $\begin{array}{c}\text { Unfertilized Eggs (without Membrane } \\
\text { Formation) in }\end{array}$ & $\begin{array}{l}\text { Oxygen } \\
\text { Consumed }\end{array}$ & $\begin{array}{l}\text { Coefficient } \\
\text { of Rate of } \\
\text { Oxidations }\end{array}$ \\
\hline $\begin{array}{l}\text { Normal sea-water.............. } \\
50 \text { c.c. hypertonic sea-water }+1 \text { c.c. } \mathrm{N} / 10 \mathrm{NaOH} \\
50 \text { c.c. normal sea-water }+1 \text { c.c. } \mathrm{N} / 10 \mathrm{NaOH} \ldots\end{array}$ & $\begin{array}{l}\text { mgm. } \\
0.41 \\
0.81 \\
0.46\end{array}$ & $\begin{array}{l}1.00 \\
2.00 \\
1.20\end{array}$ \\
\hline
\end{tabular}

4. It is necessary for the developmental effect that the hypertonic solution contain free oxygen. If the oxygen is driven out of a hypertonic solution sufficiently thoroughly, this solution can no longer cause the unfertilized eggs of the sea-urchin to develop. The following experiment on the eggs of $S$. purpuratus will serve as an example. The air was driven out of a series of flasks each of which contained 50 c.c. of sea-water +8 c.c. $2 \frac{1}{2} \mathrm{~m} \mathrm{NaCl},{ }^{1}$ by passing chemically pure hydrogen through them for several hours, and then a pipette full of sea-urchin eggs was introduced into each of them. This was effected with the aid of an assistant and in such a way that the stopper of the flask was lifted to one side over the rim for only one or two seconds and during this time the pipette that had been held in readiness was emptied into the flask. The current of hydrogen was not interrupted and proceeded throughout the whole experiment. Some of the eggs. were placed as a control in 50 c.c. of sea-water +8 c.c. of $2 \frac{1}{2} \mathrm{~m}$ $\mathrm{NaCl}$ which remained in contact with air. After 128 and 180 minutes samples of the eggs were replaced in normal sea-water. The control eggs which had been in the oxygenated sea-water and were transferred to normal sea-water after 128 minutes developed practically all into larvae; of the eggs transferred to

1 This hypertonic solution was slightly alkaline. 
normal sea-water after 180 minutes practically all disintegrated into droplets and only a few developed. Not a single one of the eggs which had been in the hypertonic solution in an atmosphere of hydrogen developed when transferred to normal sea-water after 128 and 180 minutes. The eggs appeared quite normal and that they were really so is shown by the fact that they developed normally upon the addition of sperm.

In these experiments, of course, not all the oxygen had been expelled from the hypertonic solution, but the pressure of the oxygen had been depressed below the minimum necessary for the developmental effect of the hypertonic solution.

We will mention one further experiment. Unfertilized eggs of a female were divided among five flasks, each of which contained 50 c.c. of sea-water +8 c.c. $2 \frac{1}{2} \mathrm{~m} \mathrm{NaCl}$. One flask was left open, i.e., exposed to the air; the others, out of which the air had been driven by passing hydrogen through them for two hours, remained connected to the stream of hydrogen. After $2,3,4 \frac{1}{2}$, and $5 \frac{1}{2}$ hours, one of the flasks was disconnected from the hydrogen apparatus, and the eggs contained in it were transferred to normal aerated sea-water. They were absolutely unaltered and did not divide or develop. On the addition of sperm ${ }^{1}$ they all segmented and developed normally, thus showing that they were really, not only apparently, unchanged. Simultaneously a sample of the eggs from the aerated hypertonic sea-water was also immediately transferred to normal sea-water. The eggs transferred from this hypertonic to normal sea-water after two hours yielded a good number of normal blastulae. Only about 1 per cent of the eggs, transferred from the aerated hypertonic to normal sea-water after three hours, developed; the rest disintegrated into small drops. Those removed after $4 \frac{1}{2}$ and $5 \frac{1}{2}$ hours all went to pieces in the same way. We can now understand another phenomenon

${ }_{1}$ The sperm should not be added until about an hour after the eggs are replaced in oxygenated sea-water; otherwise the results are not so good. 
which crops up again and again in provoking the development of eggs by hypertonic solutions: it is that the eggs develop only if the supply of oxygen in the hypertonic solution is sufficient. If they lie thickly upon one another, a mutual struggle for oxygen takes place, and the hypertonic solution remains without effect. The same happens when the eggs are covered with too deep a layer of water, which prevents a rapid diffusion of oxygen into them.

5. If unfertilized eggs remain longer in the hypertonic seawater than is necessary for their development, they will disintegrate when put back into normal sea-water. After transference into normal sea-water they break up into small droplets; they do not undergo such a change while they are in the hypertonic solution. This destructive effect of the hypertonic solution can be inhibited by depriving the hypertonic solution of oxygen or by adding a trace of $\mathrm{KCN}$ or of chloral hydrate to the sea-water. ${ }^{1}$ Fertilized eggs suffer more rapidly in the hypertonic solution than unfertilized eggs, and they can also be protected against the toxic action of the hypertonic solution by the suppression of the oxidations in the egg. The reason that fertilized eggs are injured more rapidly by the hypertonic solution than the unfertilized eggs is probably due to the fact that the rate of oxidations is so much greater in the fertilized than in the unfertilized eggs. These facts have already been discussed in a previous chapter.

Warburg assumes that the oxidations are accelerated excessively by the hypertonic solution. But this is not the case for the fertilized eggs of S. purpuratus on which these experiments were carried out, since Wasteneys and the writer found that the rate of oxidations in the fertilized eggs of $S$. purpuratus is not accelerated by the hypertonic solution. Either the oxidations are modified by the hypertonic solution so as to lead to the

${ }^{1}$ Loeb, "Ueber die Hemmung der toxischen Wirkung der hypertonischen Lösungen auf das Seeigelei durch Sauerstoffmangel und Cyankalium," Pflüger's Archiv, CXIII, 487, 1906. 
formation of abnormal chemical products in the egg; or the oxidations lead to physical or morphological modifications in the egg, which cause its disintegration when it is put back into normal sea-water. We can imagine that chloral hydrate acts favorably by suppressing certain morphological changes in the egg.

While it is not always possible to induce artificial parthenogenesis by the purely osmotic method, the destruction of the eggs by this method and the prevention or retardation of this destruction by lack of oxygen always succeeds.

6. In 1908 Delage published a method of artificial parthenogenesis which gave good results. The unfertilized eggs were put into a mixture of 50 c.c. of a cane-sugar solution and seawater to which he added 23 drops of a $\mathrm{N} / 10$ tannic-acid solution and 30 drops of a $\mathrm{N} / 10$ solution of $\mathrm{NH}_{4} \mathrm{OH}$. The concentration of the sugar solution was $1.135 \mathrm{~N}$. He used 15 c.c. seawater and 35 c.c. cane-sugar solution. ${ }^{1}$. In reality this method is identical with my method of combining alkaline and hypertonic solutions simultaneously. The $1.135 \mathrm{~N}$ sugar solution is strongly hypertonic (see chap. xiii). The ammonia is in excess of the tannic acid and $\mathrm{NH}_{4} \mathrm{OH}$ is, as we have seen, one of the bases which diffuses easily into the egg, and hence is very efficient in the production of artificial parthenogenesis.

Since any hypertonic solution with the proper amount of $\mathrm{NH}_{4} \mathrm{OH}$ acts in the same way as Delage's solution, neither the presence of tannic acid nor of sugar is essential.

Shearer and Miss Lloyd ${ }^{2}$ have used Delage's mixture in the place of the hypertonic sea-water in my "improved" method. They produced membrane formation in the unfertilized eggs of Echinus with butyric acid. Instead of putting them into hypertonic sea-water afterward, they put them for one hour

1 Delage, "Les vrais facteurs de la parthénogênèse expérimentale," Arch. de Zool. expér. et gén., 4 me sêr., VII, 446, 1908. 1913.

${ }^{2}$ Shearer and Miss Lloyd, Quarterly Jour. Microscopical Science, LVIII, 523, 
into Delage's mixture which is merely a hypertonic solution rendered alkaline by an excess of $\mathrm{NH}_{4} \mathrm{OH}$. It is obvious that in this case the solution of Delage could have produced only the corrective effect typical for hypertonic solutions. The additional $\mathrm{NH}_{4} \mathrm{OH}$ could do no good, and probably did some harm. The larvae which were produced by this method did not develop as far as those produced when the simple hypertonic seawater, as I use it, was added.

Delage has drawn the conclusion that in his experiments the tannic acid causes a coagulation and the alkali a liquefaction, and that development is due to an alteration of coagulations and liquefactions. Since we have shown in this and the previous chapter that the mere treatment of the eggs with an alkaline hypertonic solution causes the production of parthenogenetic plutei, and since it can be demonstrated that any hypertonic solution containing the proper amount of $\mathrm{NH}_{4} \mathrm{OH}$ or any other weak base acts as well as Delage's solution, the conclusion he draws from his observation becomes untenable. 



\section{XVII}

\section{MEMBRANE FORMATION AND CYTOLYSIS}

1. In this chapter we shall show that all haemolytic agents also cause membrane formation. We find usually that a short exposure of the egg to such a reagent leads only to membrane formation, a longer one to cytolysis. According to Köppe, besides electricity and heat, there are five classes of reagents that cause cytolysis; they are: (1) certain specific substances, such as glucosides (e.g., saponin) or bile salts; (2) a number of fat-solvents, such as benzol, ether, and alcohol; (3) distilled water; (4) acids; (5) bases. We have already seen that the two last-named substances lead to membrane formation, and we shall show that the same is true for the others, and that with proper after-treatment this membrane formation leads to the development in the sea-urchin egg (and the eggs of other forms). We can therefore say briefly that all haemolytic agencies effect the activation of the unfertilized egg, and this activation consists in a cytolysis of the cortical layer of the eggs.

I first noticed the connection between membrane formation and cytolysis when in 1904 I was trying to discover why no typical membrane was formed in my original method of artificial parthenogenesis by hypertonic solutions. In the course of these investigations it happened that when the osmotic pressure was high enough, e.g., with $1 \frac{1}{2} \mathrm{~m}$ solutions of $\mathrm{NaCl}$ or cane sugar, the unfertilized eggs produced a splendid fertilization membrane; but this membrane formation was followed almost at once by a cytolysis of the whole egg. ${ }^{1}$ A similar phenomenon occurs when the eggs are placed in distilled water; for they also form membranes and are immediately afterward transformed into "shadows."

${ }^{1}$ Loeb, "Ueber Befruchtung, künstliche Parthenogenese und Zytolyse des Seeigeleies," Pflüger's Archiv, XCIII, 257, 1904; Untersuchungen, p. 288. 
Shortly afterward my attention was again drawn to the connection between membrane formation and cytolysis, when performing experiments upon the effect of benzol and amylene upon the unfertilized sea-urchin eggs. Here too it turned out that the first effect of these hydrocarbons was, as Herbst ${ }^{1}$ had already observed, the formation of a fertilization membrane, but this was followed almost at once by the cytolysis of the egg. ${ }^{2}$ I found that if the eggs are removed soon enough from the sea-water containing benzol or amylene, they can be caused to develop into normal larvae after a short treatment with a hypertonic solution. A similar result was obtained in experiments upon the artificial membrane formation by the higher fatty acids, and we shall return to this again. ${ }^{3}$

We will now discuss the series of different cytolytic reagents from the point of view of their membrane-forming effect, and we will start with the first group, that of the specific haemolytic substances such as the glucosides (saponin, solanin, digitalin), bile salts, and soaps; in this group belong the foreign sera, to the consideration of which a special chapter will be devoted. We shall start with a description of the effect of saponin upon the sea-urchin egg.

2. Figs. 39 to 45 are camera drawings of the changes of an egg in a saponin solution ( 8 drops of a $\frac{1}{4}$ of 1 per cent saponin solution in sea-water to 5 c.c. of sea-water). Fig. 39 gives the size and the appearance of the egg immediately after transference to the saponin solution (at 9:07 A.M.). Membrane formation (Figs. 40 and 41) started four minutes afterward, and at Fig. 42 a normal fertilization membrane had been formed. Five minutes later, cytolysis starts, and indeed in this case it depends upon a process which superficially and in the beginning resembles membrane formation. For at $G$

1 Herbst, Biol. Centralbl., XIII, 14, 1893.

${ }^{2}$ Loeb, "Ueber eine verbesserte Methode der künstlichen Parthenogenese," Untersuchungen, p. 340.

${ }^{3}$ Ibid., p. 342. 


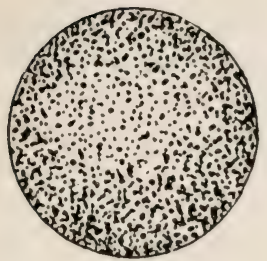

Fig. 39

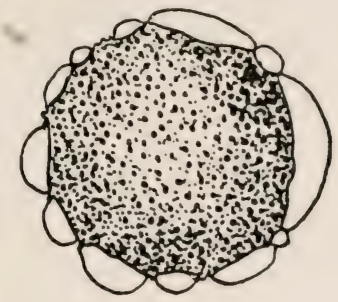

Fig. 40

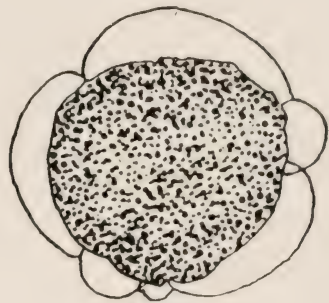

Fig. 41

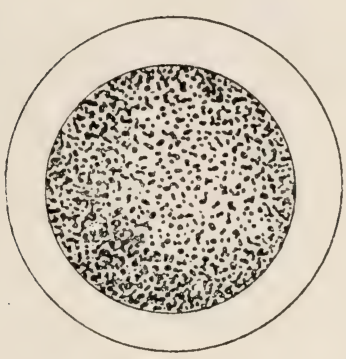

Fig. 42

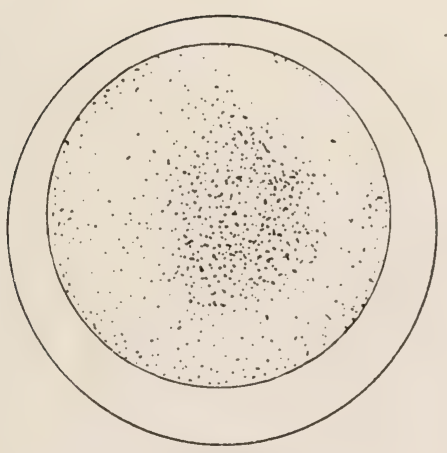

Fig. 44

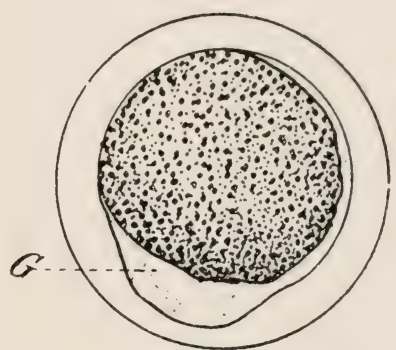

Fig. 43

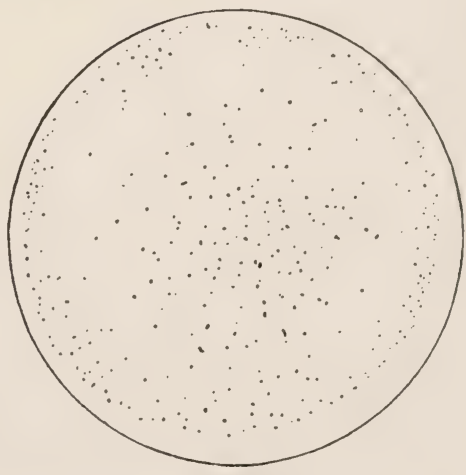

Fig. 45

Formation of the fertilization membrane and cytolysis of the sea-urchin egg on treatment with saponin.

Fig. 39.-Appearance of egg when first exposed to saponin solution at 9:07 A.M.

Figs. 40, 41, and 42.-Formation of fertilization membrane. The stage of completed membrane formation as depicted in Fig. 42 was reached at $9: 15$ A.M. (If at this stage the egg is withdrawn from the influence of the saponin it can develop.) Cytolysis (Fig. 43) began at 9:20 A.M.

Frgs. 43, 44, and 45. - Advanced stages of cytolysis induced with saponin. 
in Fig. 43 there occurs an outflow of clear matter from the cytoplasm, just as in membrane formation. This is quickly followed by the clearing and swelling of the whole egg, until at last it becomes a "shadow" (Figs. 44 and 45). The variations that present themselves on examination of a quantity of eggs in the saponin solution occur principally in the membrane formation. In many cases the formation of vesicles, which is here depicted in Figs. 40 and 41, did not take place. Instead of this, the egg proceeds from the stage drawn in Fig. 39 directly into the stage of membrane formation (Fig. 42). As an intermediate stage one observes cases in which only a roughening of the surface of the egg takes place, owing to the formation of numerous minute drops, which suddenly swell simultaneously and give rise to the formation of the surface membrane; at first this is closely adjacent to the cytoplasm, but as a result of the osmotic pressure more sea-water is always flowing in, until the tension of the membrane counterbalances the osmotic pressure.

The examination of these drawings also gives the impression that the effect of the saponin is produced in two distinct stages, which do not necessarily merge continuously into each other; the first stage is probably the effect upon the surface of the egg, leading to membrane formation, and the second is obviously an effect produced upon the interior of the egg, and leads to cytolysis. In both cases the liquefaction is associated with a swelling and increase in volume.

When eggs that have been treated with saponin until membrane formation has taken place are freed from the last trace of saponin by washing them four to six times in pure sea-water, they behave just like eggs in which the artificial membrane has been produced by a fatty acid. If they are left in sea-water, development starts, and the stage to which they develop depends on the temperature. If they are subsequently treated for about forty minutes (at $15^{\circ} \mathrm{C}$.) with hypertonic sea-water, they develop into larvae. 
The following example will illustrate this. Four drops of a weak solution of saponin in sea-water were added to 5 c.c. of sea-water with eggs. Membrane formation started after five minutes, and three minutes later all the eggs possessed membranes. The eggs were then washed in 200 c.c. of sea-water that was free from saponin, and this washing was repeated four times. They were next put into 50 c.c. sea-water +6.5 c.c. of $2 \frac{1}{2} \mathrm{~m} \mathrm{NaCl}$. Portions of the eggs were replaced in sea-water after 15, 2.5, 3.3, $45,55,65$, and 93 minutes, respectively. All eggs that had been only 15,25 , or 35 minutes in hypertonic sea-water disintegrated. A few of the eggs that had been 45 minutes in the hypertonic solution developed into larvae, while 10 per cent, 60 per cent, and 80 per cent of larvae were given by the eggs that had been 55,65 , and 93 minutes, respectively, in the hypertonic solution.

As a control I treated eggs in the same manner after membrane formation by means of butyric acid; similar results were obtained. The life duration of the butyric-acid larvae was, however, longer than that of the saponin larvae. ${ }^{1}$

We know that solanin and digitalin possess haemolytic properties like saponin. It can also be shown that sea-urchin eggs that have been induced to form membranes by these agencies can be caused to develop into larvae.

The cytolytic effect of bile salts is well known. A mixture of sodium glycocholate and taurocholate was dissolved in water. Membrane formation soon followed when eggs were placed in such a solution. The membrane was formed while the eggs were still in the solution of the bile salts, just as in the case of the saponin solution. Membrane formation was rapidly followed by cytolysis of the egg. But if the eggs were transferred to normal sea-water in time, cytolysis did not supervene. On being transferred at the right time (i.e., after a membrane had formed, but before they had all cytolyzed) from the solution of

1 Loeb, "Ueber die Hervorrufung der Membranbildung und Entwicklung beim Seeigelei durch Blutserum ron Kaniuchen und durch zytolytische Agenzien," Pflüger's Archiv, CXXII, 199, 1908. 
bile salts to normal sea-water, they did not develop if left therein. But some of them did develop into larvae after a subsequent short exposure to a hypertonic solution. The eggs were more harmed by membrane formation with bile salts than by membrane formation with saponin.

In both cases only those eggs developed, after a short treatment with hypertonic sea-water, which had formed membranes, a fact which is also true of eggs treated with a fatty acid. ${ }^{1}$

3. In 1905 I started experiments on membrane formation in the egg by means of soaps; but by chance these experiments led to no results. The experiments were resumed a few years later with positive results. For since soaps are good cytolytic agents, one could postulate a definite result from these experiments. I will first briefly portray the cytolytic effect of the soaps and then discuss their developmental effect.

As soap is precipitated by calcium, it was necessary to dissolve it in $\mathrm{m} / 2 \mathrm{NaCl}$ solution, instead of in sea-water. Now when the unfertilized eggs of $S$. purpuratus (after being freed from sea-water by washing in $\mathrm{m} / 2 \mathrm{NaCl}$ ) are placed in 50 c.c. of neutral $\mathrm{m} / 2 \mathrm{NaCl}+2$ c.c. $\mathrm{m} / 10$ sodium oleate, neither membrane formation nor cytolysis occurs as a rule in that solution. The eggs only become angular. But if they are placed after a few minutes in sea-water, a large number of them form membranes at once, which in a few eggs is followed by cytolysis. The longer the eggs remain in the soap solution, the greater becomes the percentage forming membranes and cytolyzing after transference to ordinary sea-water. For the eggs of many sea-urchins the addition of 2 c.c. of sodium oleate to 50 c.c. of $\mathrm{NaCl}$ is too little, and about 3 c.c. of soap must be added.

Why does the soap solution not cause membrane formation until after the egg has been replaced in sea-water? The reason is that it is the sea-water which causes the membrane formation as a result of its alkaline reaction. The soap solution either

${ }^{1}$ Loeb, op. cit. 
makes the egg more permeable to alkali or the effect of the two substances is cumulative. This can be demonstrated by a very striking series of experiments. Unfertilized eggs were placed in 50 c.c. of $\mathrm{m} / 2 \mathrm{NaCl}+2$ c.c. of $\mathrm{m} / 10$ sodium oleate. Three and one-half minutes later some of them were replaced in sea-water. The majority of these eggs formed membranes at. once, and subsequently many succumbed to cytolysis. A second portion of the eggs was transferred to 50 c.c. of seawater slightly acidified by the addition of 0.5 c.c. $\mathrm{N} / 10 \mathrm{HCl}$ (0.4 c.c. $\mathrm{HCl}$ is enough to produce a change in color of neutral red in sea-water). Not an egg that had been transferred to this slightly acid sea-water formed a membrane or cytolyzed. The addition of even 0.3 c.c. or still less $\mathrm{HCl}$ was enough to prevent membrane formation and cytolysis of the eggs after they had been transferred to sea-water. On the other hand, the cytolytic effect of the sea-water was greatly increased by the addition of alkali. The following experiment may serve as an example. Unfertilized eggs were placed in 50 c.c. $\mathrm{m} / 2$ $\mathrm{NaCl}+0.2$ c.c. $\mathrm{m} / 10$ sodium oleate solution. Three minutes later, they were transferred to the following solutions: 50 c.c. of sea-water $+0.5,0.3,0.1,0$ c.c. $\mathrm{N} / 10 \mathrm{HCl} ; 0.5,1.0,1.5$ c.c. $\mathrm{N} / 10 \mathrm{NaOH}$. Among the eggs that had been transferred to the sea-water to which acid had been added none or extremely few formed membranes, and no cytolysis occurred. Of the eggs transferred to ordinary sea-water 95 per cent formed membranes, and about 1 per cent of them cytolyzed. All the eggs that were transferred to the seawater +0.5 c.c. $\mathrm{N} / 10 \mathrm{NaOH}$ formed membranes, and 90 per cent of them cytolyzed. In the cases where more $\mathrm{NaOH}$ had been added to the sea-water all the eggs fell victims to cytolysis.

If our line of thought is correct, it must also be possible to cause membrane formation and cytolysis in the eggs while they are still in the soap solution, by merely making it alkaline. And 
this is actually the case. Thus unfertilized eggs were distributed among the following solutions:

(1) 25 c.c. $\mathrm{m} / 2 \mathrm{NaCl}+0.1$ c.c. $\mathrm{m} / 10$ sodium oleate

(2) 25 c.c. $\mathrm{m} / 2 \mathrm{NaCl}+0.1$ c.c. $\mathrm{m} / 10$ sodium oleate +0.2 c.c. $\mathrm{N} / 10$ $\mathrm{NaOH}$

(3) 25 c.c. $\mathrm{m} / 2 \mathrm{NaCl}+0.2$ c.c. $\mathrm{N} / 10 \mathrm{NaOH}$.

In the first solution, the eggs became angular, but hardly one formed a membrane; in the second solution, 50 per cent of the eggs formed very delicate membranes that soon tore, and many of the eggs cytolyzed; in the third case the eggs remained quite intact.

But cytolysis of the eggs in the soap solution can also be obtained by raising the concentration of the soap solution high enough. Thus, if the eggs are put into 50 c.c. $\mathrm{m} / 2 \mathrm{NaCl}+1$ c.c. $\mathrm{m} / 10$ sodium oleate, membrane formation and cytolysis begin practically at once. I suppose such a solution has a faintly alkaline reaction. If excess of $\mathrm{HCl}$ is added to this mixture, membrane formation is not prevented; in this case free oleic acid is formed, and this, as I observed in 1905, also initiates membrane formation and cytolysis in the egg.

We have already seen that an alkaline solution of $\mathrm{NaCl}$ without soap has only a relatively weak cytolytic effect. The addition of 0.2 c.c. of $\mathrm{m} / \mathrm{1} 0$ sodium oleate +0.4 c.c. $\mathrm{N} / 10$ $\mathrm{NaOH}$ to 50 c.c. of $\mathrm{NaCl}$ has just as much effect as the addition of 2 c.c. $\mathrm{NaOH}$ without soap.

Now it is easy to convince oneself of the effect of soap in causing development. It is only necessary to transfer the eggs after a short time from the soap solution to ordinary sea-water, and subsequently (after repeated washing) expose them to hypertonic sea-water. The following example will illustrate this: Unfertilized eggs were placed in 50 c.c. $\mathrm{m} / 2 \mathrm{NaCl}+$ 0.2 c.c. of sodium oleate and after two or three minutes transferred to sea-water. The majority of the eggs formed membranes and only a few cytolyzed. The eggs were washed 
repeatedly, and one hour later placed in hypertonic sea-water from which they were transferred to ordinary sea-water after thirty to fifty minutes. A number of the eggs which had formed membranes developed into larvae.

These experiments prove that the membrane formation induced by soaps can also set up development. This method, however, has little to recommend it for practical purposes, because the cytolytic effect of the soap is so strong. Eggs treated with soap show a much greater tendency to cytolysis than those treated with a low fatty acid.

4. Another group of haemolytic agents is formed by fatsolvents, such as benzol, toluol, amylene, chloroform, aldehyde, ether, alcohol, etc. It has already been mentioned that when benzol, toluol, and amylene are dissolved in sea-water-only a trace of them is soluble-they produce a membrane formation in eggs, which is followed practically at once by cytolysis. Hence the specific fat-solvents are of little use for artificial parthenogenesis. The same principle, however, that is found in the saponin group also applies here: by working quickly, removing the eggs from the benzol or amylene sea-water as soon as membrane formation has taken place, and transferring them to ordinary sea-water, it can be demonstrated that a certain percentage of eggs form membranes, without undergoing. cytolysis. These eggs can be caused to develop into larvae by treating them subsequently with hypertonic sea-water. If they are not treated with hypertonic sea-water, they do begin to develop, but they disintegrate before reaching the larval stage.

Owing to the importance of this subject, we will describe the cytolysis of the sea-urchin egg under the influence of a reagent belonging to this group. Figs. 46 to 51 show the behavior of the sea-urchin egg in a mixture of 45 c.c. of sea-water +5 c.c. of $\mathrm{m} / 100$ salicyl aldehyde. A beautiful membrane formation first takes place (Fig. 49); but then cytolysis starts with the 


\section{Artificial Parthenogenesis and Fertilization}

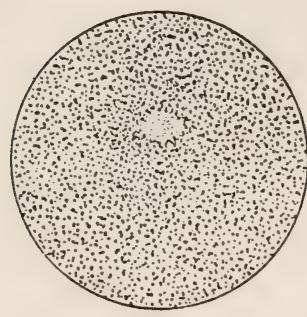

Fig. 46

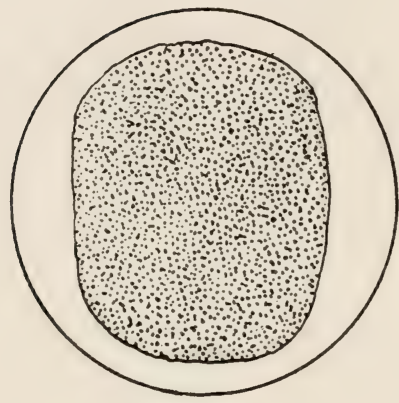

Fig. 48

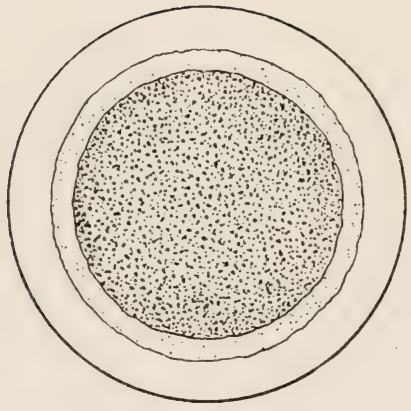

Fig. 50

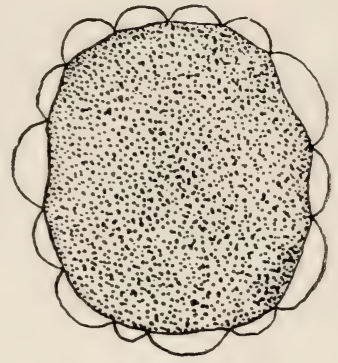

Fig. 47

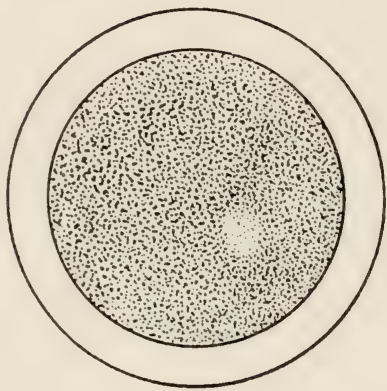

Fig. 49

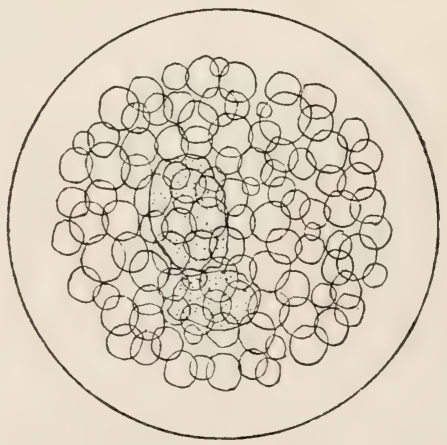

Fig. 51

Membrane formation and cytolysis of the sea-urchin egg under the influence of salicyl aldehyde.

Figs. 46-49.-Successive stages in the formation of the membrane.

FIG. 50-Beginning of cytolysis.

FIG. 51.-Complete cytolysis. 
outflow of a clear substance from the cytoplasm (Fig. 50), and soon after the egg is changed to a shadow (Fig. 51).

In this case also the process of cytolysis is divided into two stages, at first, a membrane formation, and soon after a complete clarification of the interior and the formation of large clear drops (Fig. 51).

If the eggs are placed in a mixture of 10 c.c. of sea-water + 10 c.c. $2 \frac{1}{2} \mathrm{~m}$ propylalcohol, the formation of a fertilization membrane is the first thing that takes place. If the eggs are removed

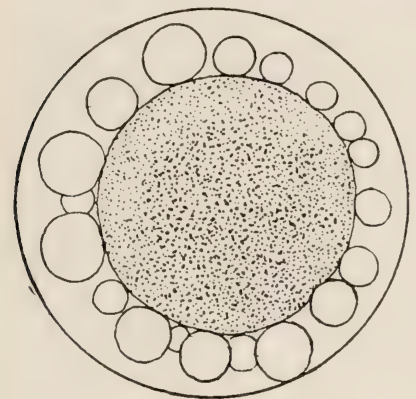

Fig. 52

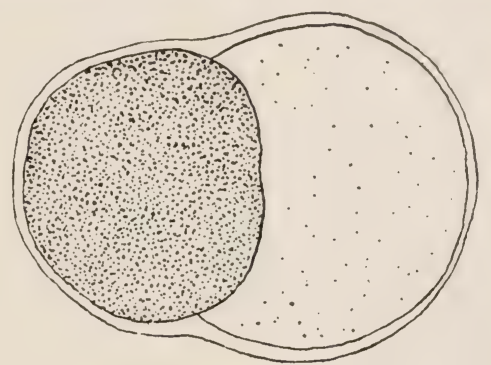

Fig. 53

FIGS. 52 and 53.-Membrane formation and cytolysis in two different eggs of a sea-urchin under the influence of propylalcohol. In Fig. 52 cytolysis starts with the outflow of many small droplets; in Fig. 53 with the outflow of only one large drop from the cytoplasm.

from the solution at this stage, and washed with sea-water, a few are able to develop after a subsequent exposure to hypertonic sea-water.

But if the eggs are left in the solution of alcohol, cytolysis quickly ensues. Figs. 52 and 53 show the start of this cytolysis which in the one case consists in the outflow of many clear drops from the egg, and in the other of one large drop. At bottom, it only depends upon two modifications of the same process. It may be mentioned that the result of the experiment remains the same if 1 c.c. of $2 \frac{1}{2} \mathrm{~m} \mathrm{NaCl}$ is added to each 4 c.c. of propylalcohol.

5. We come now to a discussion of the cytolytic action of distilled water. This type of cytolysis is of great importance 
from a theoretical point of view. The drawings in Figs. 54 to 58 depict the behavior of the unfertilized sea-urchin egg in distilled water. It will be seen that during the first five minutes the egg slowly but steadily increases in volume though its

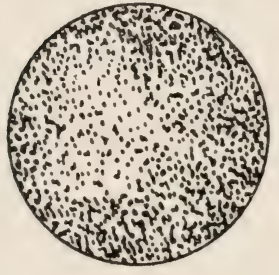

Fig. 54

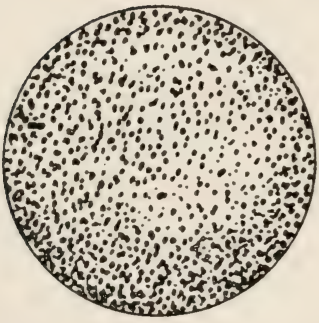

Fig. 57

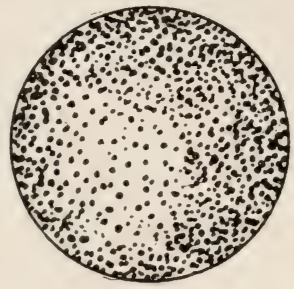

Fig. 55

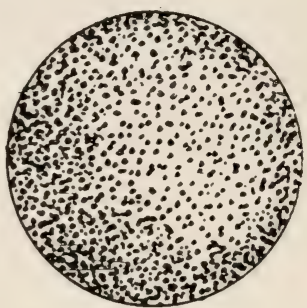

Fig. 56

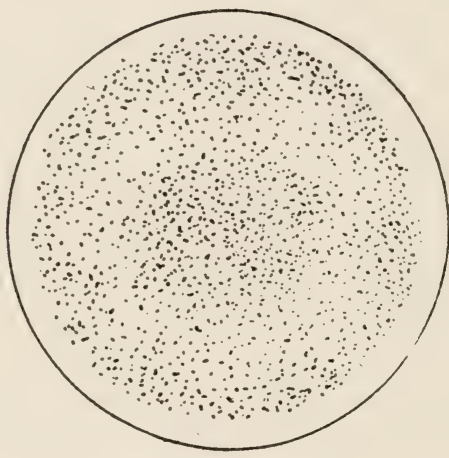

Fig. 58

Frgs. 54-58. - Swelling and cytolysis of the sea-urchin egg in distilled water. Slow but steady increase in volume of the egg in distilled water during a period of five minutes (Figs. 54-57). Instantaneous membrane formation, swelling and cytolysis of the egg within the sixth minute (Fig. 58). It is obvious that the cytolysis is not caused by a bursting of the surface-layer of the egg.

appearance remains the same (Figs. 55 to 57 ). Then it is quite suddenly converted into a shadow within one minute (Fig. 58); in that time it forms a membrane and swells enormously. Hence a change of condition must occur in that minute. At first the egg is in possession of a semi-permeable membrane which is only permeable for water, but not for salts. In this condition the changes noted in Figs. 54 to 57 occur. 
Then the egg becomes permeable for salts but not for colloids. Then the sudden swelling in Fig. 58 takes place. We shall return to this phenomenon in chap. $\mathrm{xx}$.

6. Increase of temperature also produces cytolysis. Dr. von Knaffl found that heating unfertilized sea-urchin eggs to $41^{\circ} \mathrm{C}$. led to their practically instantaneous cytolysis. At lower temperatures a longer time is necessary for cytolysis. ${ }^{1}$ I found that by merely warming sea-urchin eggs to $34^{\circ}$ or $35^{\circ} \mathrm{C}$., the formation of a typical fertilization membrane can often, but not always, be induced. ${ }^{2}$ If the eggs are then cooled quickly, no cytolysis follows. Such eggs are no longer capable of development, since a temperature of $34^{\circ} \mathrm{C}$. kills them. But starfish eggs, which can also be caused to form membranes by warming, can endure a higher temperature, and develop under these conditions (according to experiments of Ralph S. Iillie, which we shall discuss later).

7. We will now return to a short discussion of the effect of acids. We have already described in detail how the acid cause membrane formation. As far as cytolysis of the seaurchin egg is concerned, I have obtained it only with the higher fatty acids, beginning with heptylic, i.e., with heptylic, caprylic, nonylic, and capric acids; this cytolysis is always preceded by the formation of a fertilization membrane. The cytolysis takes place while the eggs are in the solution. The experiments were usually performed in N/500 or N/1,000 solution of the acid, which was rendered isosmotic with sea-water by the addition of some $\mathrm{NaCl}$. Curiously enough, the addition of some Ca promoted the membrane formation in a very marked fashion. Oleic acid (rendered isotonic with sea-water by $\mathrm{NaCl}$ ) also caused membrane formation and cytolysis in the sea-urchin egg. With the lower fatty acids, from capronic downward, I have so far obtained membrane formation, but no rapid

${ }^{1}$ Von Knaffl, Pflüger's Archiv, CXXIII, 279, 1908.

${ }^{2}$ Loeb, Pflüger's Archiv, CXXII, 199, 1908. 
cytolysis. Can it be possible that the lower fatty acids are only soluble in the cortical layer of the unfertilized egg while the higher fatty acids are soluble in the whole egg and hence cause cytolysis?

8. During experiments (which will be discussed later in this book) on the sensitizing effect of $\mathrm{SrCl}_{2}$ and $\mathrm{BaCl}_{2}$ upon the eggs of the sea-urchin, the writer found that unfertilized eggs of S. purpuratus and franciscanus when left in isotonic $(3 / 8 \mathrm{~m})$ solutions of $\mathrm{SrCl}_{2}$ or $\mathrm{BaCl}_{2}$ would sooner or later form typical fertilization membranes. The time required for this effect varied considerably for the eggs of various females. In some cases eggs would form membranes in ten minutes, in other cases just as many hours were required. When such eggs were left to themselves, they disintegrated like the eggs in which membrane formation was produced by butyric acid. When afterward treated with a hypertonic solution for a short time the eggs would develop into larvae. ${ }^{1}$

The writer tried vainly to produce similar effects by the pure salts of $\mathrm{NaCl}, \mathrm{Na}_{2} \mathrm{SO}_{4}$ or sodium oxalate, and many other salts. The unfertilized eggs of $S$. purpuratus will live in an $\mathrm{m} / 2 \mathrm{NaCl}$ solution for several days without suffering any injury and the same was found true for solutions of $\mathrm{CaCl}_{2}$. When treated with sperm the eggs could be fertilized and they would develop normally.

This resistance of the eggs of purpuratus to isotonic sodium salts is, however, quite extraordinary. It does not exist in the egg of Arbacia. In these eggs, R. Lillie ${ }^{2}$ succeeded in calling forth membrane formation by putting them for five or ten minutes into pure solutions of $\mathrm{NaI}$ or KI or NaCNS and KCNS, and then transferring them to sea-water. "A large proportion, in favorable experiments practically all, form fertilization membranes, usually thin and close to the egg surface." These eggs

${ }^{1}$ Loeb, Archiv f. Entwicklungsmechanik, XXX, 44, 1910.

${ }^{2}$ R. Lillie, "The Physiology of Cell Division," Jour. Morphol., XXII, 695, 1911. 
begin to segment, but sooner or later disintegrate though a few may reach an early blastula stage. Such eggs are, however, abnormal. But if these eggs are exposed for a short time (in Lillie's experiments thirty minutes) to a hypertonic solution a large number will develop. The membrane formation produced by these salts had therefore the same effect as treatment of the eggs with fatty acids.

Lillie made the very interesting observation that the addition of some $\mathrm{CaCl}_{2}$ to the solution of $\mathrm{NaI}$ inhibited the membrane formation. The following experiments illustrate this result. Unfertilized eggs of Arbacia were put for five minutes into 250 c.c. $0.55 \mathrm{~m} \mathrm{NaI}$; when transferred to sea-water all formed membranes. Eggs left for five minutes in 250 c.c. $0.55 \mathrm{~m} \mathrm{NaI}+15$ c.c. $\mathrm{m} / 2 \mathrm{CaCl}_{2}$ practically all remained normal when put back into sea-water. The solution containing $\mathrm{Ca}$ is, however, not entirely ineffective, since some eggs treated with this solution may develop into larvae when afterward exposed for a short time to a hypertonic solution.

$\mathrm{R}$. Lillie explains his results on the assumption that the effective salts increase the permeability of the egg, and that this rise in permeability is checked through the addition of $\mathrm{CaCl}_{2}$. The primary effect is probably a cytolytic action upon the cortical layer of the egg, and on this assumption the observations of Lillie on the membrane formation by $\mathrm{NaI}$ and $\mathrm{NaCNS}$ harmonize with the observations on the action of the specifically cytolytic agencies upon the egg. It is probable that $\mathrm{NaI}$ and $\mathrm{NaCNS}$ are slightly soluble in the egg and owe their efficiency to this fact. That $\mathrm{Ca}$ and bivalent metals in general inhibit cytolysis by bases had been shown by the writer in 1906 and $1907 .^{1}$

Herbst made in 1904 the interesting observation that minute traces of silver salts cause a membrane formation in the unfertilized sea-urchin egg. The following observation by

${ }^{1}$ Loeb, "Ueber die anticytolytische Wirkung von Salzen mit zweiwertigen Metallen," Biochem. Zeitschr., V, 351, 1907; II, 81, 1906. 
him is especially interesting: "A new piece of silver money, which had been specially cleaned before use, was put into 26 c.c. of sea-water which contained unfertilized eggs of Echinus. Fifteen minutes later I noticed in eggs which lay close to the silver the formation of membranes. An hour later membranes were formed in some eggs which were not so close to the silver." 1

The observation by Bohn that radium may induce artificial parthenogenesis probably belongs in the same chapter. ${ }^{2}$

I believe that in all these cases we are dealing with cytolytic effects. The fact shown in chap. xii, that complete cytolysis of the egg by saponin raises the rate of oxidations in the fertilized egg to the same rate as fertilization, makes it clear that the cytolysis of the surface layer is the essential part in the causation of development in the egg.

9. In conclusion, we will briefly touch upon the mechanism of cytolysis. In the case of the chorion of the eggs of molluses and annelids it can be directly observed that substances like saponin and benzol exert an influence that causes swelling and liquefaction. This swelling, or absorption of fluid, and the clarifying of cell-contents that were previously opaque, are typical of cytolysis. Many authorities follow Köppe in assuming that cytolysis depends upon the solution of the hypothetical lipoid membrane of the egg; it should, however, be stated that the fertilization membrane of the eggs is insoluble in benzol, or in any other lipoid-solvent.

Von Knaffl has developed another conception of the mechanism of cytolysis, which I shall quote verbatim.

It can be regarded as certain that protoplasm is rich in lipoids, and that any chemical or physical stimulus which produces a liquefaction or solution of the lipoids of protoplasm, causes the egg to cytolyze owing to the fact that the protoplasm, being now free from lipoids, takes up water, and swells. This leads in many cases to the bursting of the membrane.

${ }^{1}$ Herbst, Mitteil. d. Zool. Station zu Neapel, XVI, 445, 1904.

2 G. Bohn, Compt. rend. Acad. d. Sc., CXXXVI, 1085, 1903. 
The following conclusions reached by von Knaffl may be mentioned by way of further explanation:

Protoplasm is rich in lipoids; probably it is mainly an emulsion of these and proteins. Any physical or chemical stimulus which can liquefy the lipoids causes cytolysis of the egg. The protein of the egg can really only swell or be dissolved if the condition of aggregation of the lipoid is altered by chemical or physical agencies. The mechanism of cytolysis consists in the liquefaction of the lipoids, and thereupon the lipoid-free protein swells or is dissolved by taking up water. ... . Hence this supports Loeb's view that membrane formation is induced by the liquefaction of the lipoids. ${ }^{1}$

(I had previously referred the formation of the fertilization membrane to a liquefaction of the lipoid on the surface of the egg. $\left.{ }^{2}\right)$

We will now examine more closely the experiments upon which von Knaffl based his view. When he heated the seaurchin egg to $41^{\circ} \mathrm{C}$., cytolysis ensued: many strongly refracted spherules appeared on the surface of the egg, as in Fig. 52 . He regards these globules as lipoids, since they disappear or dissolve in the presence of benzol, chloroform, and alkali. But they do not disappear in acetone, from which von Knaffl concludes that they consist of lecithin. He regards the fact that in cytolysis the egg can be observed to exude clear drops which are soluble in benzol, as a support of the hypothesis that membrane formation and cytolysis depend essentially upon lipoids passing into solution, or being excreted from the egg.

Now this exudation of lipoids may in reality explain the clarification of the egg that is characteristic of cytolysis. For if the protoplasm consists of an emulsion in which the walls of the vesicles are formed by a solid lipoid, a removal of these walls must lead to many small vesicles flowing together into

1 Von Knaffl, op. cit.

2 Loeb, "Ueber den chemischen Charakter des Befruchtungsvorgangs," Roux's Abhandlungen und Vortrüge, Leipzig, 1908. 
larger ones. In that case, less of the light passing through it will be reflected, and the eggs appear clear. A glance at Fig. 51 shows that as a matter of fact the cytolyzed egg consists of large drops. It appears possible that the outflow of the clear drops in the cytolysis of the moderately unpigmented egg of S. purpuratus may correspond to the outflow of haemoglobin from the red blood corpuscles. It is to be noted that in this case it is unnecessary to assume a bursting of the surface layer of the red blood corpuscle.

But from the point of view of our work, it is not necessary to venture upon a decision with regard to the lipoid controversy and cytolysis. We can observe directly that cytolytic substances cause the chorion that surrounds the eggs to swell and then gradually to dissolve completely. It is necessary only for us to make use of this observation in order to understand membrane formation also. If we assume that in the cytoplasm of the egg itself there is present near the surface a substance that is identical with or closely allied to one of those in the chorion, we can understand that this must be made to swell and liquefy before the egg can develop.

The swelling and solution of such a substance in the interior of the egg causes cytolysis, and hence it comes about that all cytolytic substances or reagents also produce an effect that leads to membrane formation, and hence to artificial parthenogenesis. 


\section{XVIII}

THE FERTILIZING EFFECT OF FOREIGN BLOOD AND FOREIGN CELL EXTRACTS

1. The following chapter contains, perhaps, the most surprising facts in the field of artificial parthenogenesis. The writer succeeded in 1907 and 1908 in showing that the blood and tissue extracts of many foreign species will cause the unfertilized egg of the sea-urchin (and other forms) to form a fertilization membrane (and develop if subsequently treated with a hypertonic solution), while the blood and tissue extracts of their own species have no such effect. ${ }^{1}$ The first observation on the fertilizing effect of foreign blood was made by the writer in 1907 when he succeeded in causing membrane formation in unfertilized sea-urchin eggs with the blood serum of certain worms, the Gephyrea. These eggs also developed.

By making an incision into the body of a sipunculidDendrostoma was the form chiefly used-the fluid of the body cavity can be obtained. This fluid contains numerous blood corpuscles and reproductive cells, spermatozoa or eggs. In our experiments we used as a rule only the body-contents of female worms. One c.c. of this fluid was generally diluted with some 50 to 200 c.c. of sea-water. The solution was then completely cleared by centrifuging, and only the perfectly limpid serum, free from all solid and formed constituents, was used in our experiments. If, now, the unfertilized eggs of a female (seaurchin) were put in a watch glass with about 3 c.c. of sea-water, and 1 to 4 drops of this diluted transparent body-cavity fluid

${ }^{1}$ Loeb, "Ueber die Hervorrufung der Membranbildung beim Seeigelei durch das Blut gewisser Würmer (Sipunculiden)," Pflüger's Archiv, CXVIII, 36, 1907; "Ueber die Hervorrufung der Membranbildung und Entwicklung beim Seeigelei durch das Blutserum des Kaninchens," Pflüger's Archiv, CXXII, 196, 1908; "Weitere Versuche ueber die Entwicklungserregung des Seeigeleies durch das Blutserum von Säugetieren," Pfüger's Archiv, CXXIV, 37, 1908. 
of Dendrostoma added, a certain percentage of the eggs formed a typical fertilization membrane. On watching these eggs, it was found that two to three hours after membrane formation they formed a normal nuclear spindle and that some of them divided quite regularly into two cells. In the majority, the next division did not take place, but later they split up into several cells at once. Normal appearing eight- and sixteen-cell stages were very abundant, and I expected at first that the eggs would develop into larvae; but this was not the case, with few exceptions. On the second day, most of the eggs disintegrated. A few lived a little longer, but did not develop into blastulae.

If such eggs were placed immediately after membrane formation in hypertonic sea-water (50 c.c. of sea-water +8 c.c. $2 \frac{1}{2} \mathrm{~m}$ $\mathrm{NaCl}$ ), all or most of the eggs developed into larvae. If the length of exposure was correctly chosen the eggs segmented and developed into plutei in quite a normal manner. If the exposure was too short the hypertonic solution had no effect.

It was not, however, the eggs of every sea-urchin that formed membranes in Dendrostoma serum, the reaction being limited to the eggs of about 20 per cent of the females.

The next thing was to determine more closely the nature of the active substance. If the reactions of the effective solution of Dendrostoma blood are tested, it will be found that it reacts . to neutral red just like ordinary sea-water. This excludes the possibility of membrane formation being due to one of the lower fatty acids (or any other acid). For in order to cause membrane formation by means of one of the lower fatty acids, about 3 c.c. of N/10 acid must be added to 50 c.c. of sea-water, and this renders the latter strongly acid. Moreover, the eggs must not remain in this solution longer than $1 \frac{1}{2}$ to $2 \frac{1}{2}$ minutes (at $15^{\circ} \mathrm{C}$.), else no membrane is formed. In the third place, the membrane is never formed in the acid sea-water (in the case of the lower fatty acids), but only after the egg has been transferred to ordinary (i.e., faintly alkaline) sea-water. But when 
the egg is exposed to the diluted sipunculid blood, membrane formation takes place in the presence of the blood.

However, it is also improbable that it is due to any of the hydrocarbons such as benzol, toluol, and amylene, or to saponin or any similar glucoside. For all these substances lead, not only to membrane formation, but also to cytolysis of the egg, if it is not removed from the solution immediately after membrane formation. But the sipunculid serum does not cytolyze the egg, at least not in the concentration necessary to produce membrane formation.

The question of the thermostability of the effective constituent of the sipunculid serum was next taken into consideration. In order to avoid the suspicion of infection with living spermatozoa, it had already been found necessary in these experiments to heat the sipunculid serum to between $50^{\circ}$ and $60^{\circ} \mathrm{C}$. Prolonged heating at $60^{\circ} \mathrm{C}$. does not decrease the effectiveness of the serum, nor does heating it to $70^{\circ}$ or $80^{\circ} \mathrm{C}$. Suddenly heating the serum to boiling-point in one case reduced its efficacy to one-third of its original amount. Prolonged boiling (two to three minutes) has completely destroyed the efficacy in all the cases hitherto observed.

Even when the blood was heated for an hour to $60^{\circ} \mathrm{C}$. it did not lose its effect.

It was subsequently found that the blood and tissue extracts of a large number of animals had a similar effect, although they did not act in such a high degree of dilution. The most welcome observation was that the blood of mammals (rabbit, pig, ox, etc.) was very active, since this enabled us to undertake a more systematic investigation of this field. The writer succeeded in producing membrane formation in sea-urchin eggs with the blood of mammals (dog, pig, and ox). The serum was rendered isotonic with sea-water by the addition of a $2 \frac{1}{2} \mathrm{~m} \mathrm{NaCl}$ solution (1 c.c. of the $2 \frac{1}{2} \mathrm{~m} \mathrm{NaCl}$ solution was added to 6.5 c.c. of the serum). 
It was observed in the experiments with the blood of mammals that, just as with the Dendrostoma blood, it was not the eggs of every sea-urchin that would respond, but only the eggs of about 10 per cent of the females. I am inclined to attribute this to differences in the permeability of the eggs of different females. In order that the blood may cause membrane formation, it is necessary for its effective constituent to diffuse into the egg. It seems then that the necessary degree of permeability will not be found in the eggs of every female, but only in those of a certain percentage. Moreover, the blood of mammals is less effective than that of Dendrostoma. Whereas the latter produces membrane formation when diluted 100 to 1,000 times, the former is effective only in 2 to 10 times dilution. ${ }^{1}$ The experiments succeed best when the eggs are taken fresh from the ovary.

2. The fact that not the eggs of every female reacted with foreign blood made it necessary to find methods of sensitizing the eggs to the effects of foreign blood. Various methods were tried. A rise in temperature seemed at first promising. In the following experiment the eggs of a female were used of which about 3 per cent formed membranes with ox serum at room temperature.

The eggs of this female were put in a beaker with sea-water; the ox serum was put in a second beaker, and both were heated slowly in a water bath. At certain temperatures 0.5 c.c. of sea-water+eggs and 0.5 c.c. of serum were mixed in a watch glass, and the percentage of eggs that formed membranes was estimated. The result of one such experiment is given in Table XXXVI.

$1 \mathrm{~T}$. B. Robertson has recently found that ox serum acts best in a dilution of $1: 16$ with sea-water. He even obtained results with a greater dilution (Robertson, Archiv f. Entwicklungsmechanik, XXXV, 70, 1912). Wasteneys and I did not notice such an effect of dilution on the egg of Arbacia, where the results agreed with the writer's former observations on S. purpuratus. Robertson ascribes the beneficial effect of dilution to the presence of an inhibiting factor in the serum. 
It will be seen that when the eggs are warmed to $31^{\circ} \mathrm{C}$. a sudden increase in the number of membrane formations occurs. At $36^{\circ}$ this effect lapses again owing to the modification of the process of membrane formation. For clear drops

TABLE XXXVI

\begin{tabular}{|c|c|c|c|}
\hline Temperature & $\begin{array}{l}\text { Percentage of } \\
\text { Eggs That } \\
\text { Formed } \\
\text { Membranes }\end{array}$ & Temperature & $\begin{array}{l}\text { Percentage of } \\
\text { Eggs That } \\
\text { Formed } \\
\text { Membranes }\end{array}$ \\
\hline $\begin{array}{l}15^{\circ} \mathrm{C} \ldots \ldots \ldots \ldots \\
28^{\circ} \mathrm{C} \ldots \ldots \ldots \ldots \\
30^{\circ} \mathrm{C} \ldots \ldots \ldots \ldots \\
31^{\circ} \mathrm{C} \ldots \ldots \ldots \ldots\end{array}$ & $\begin{array}{r}3 \\
3 \\
5 \\
70\end{array}$ & $\begin{array}{l}32^{\circ} \mathrm{C} \ldots \ldots \ldots \\
34^{\circ} \mathrm{C} \ldots \ldots \ldots \\
36^{\circ} \mathrm{C} \ldots \ldots \\
37^{\circ} \mathrm{C} \ldots \ldots \ldots\end{array}$ & $\begin{array}{r}100 \\
100 \\
1 \\
0\end{array}$ \\
\hline
\end{tabular}

exude from the egg, but their surfaces do not flow together so as to produce a uniform fertilization membrane. Membrane formation does not occur until the eggs are cooled again. Merely heating the eggs to $32^{\circ} \mathrm{C}$. without the addition of serum does not lead to membrane formation. If the eggs of S. purpuratus are heated to $31^{\circ}$ or over, their capacity for development is destroyed.

But I discovered another method of increasing the efficacy of the blood serum without reducing the capacity of the eggs for development. This consists in the addition of a $\mathrm{m} / 2 \mathrm{SrCl}_{2}$ solution to the serum.

In order to demonstrate the beneficial effect of strontium, one must choose eggs that show only a slight degree of sensitiveness toward serum. Table XXXVII sums up the influence of strontium upon the number of eggs which can be made to develop by serum. Each experiment was carried out upon the eggs of a single female.

In all these experiments I employed a $3 / 8$ grammolecular solution of $\mathrm{SrCl}_{2}$. Somewhat better results were obtained if about six drops of sea-water were added to the mixture of serum and $\mathrm{SrCl}_{2}$. The addition of $\mathrm{BaCl}_{2}$ had a similar effect to that of $\mathrm{SrCl}_{2}$. But it is troublesome to work with $\mathrm{BaCl}_{2}$ on account 
of the heavy precipitate of $\mathrm{BaSO}_{4}$ that is formed in this case, hence I have not performed so many experiments with barium.

Curiously enough $\mathrm{Mg}$ and $\mathrm{Ca}$ do not help the formation of a membrane with mammalian blood.

TABLE XXXVII

\begin{tabular}{|c|c|}
\hline Composition of the Solution & $\begin{array}{c}\text { Percentage } \\
\text { of Eggs } \\
\text { That } \\
\text { Formed } \\
\text { Membranes }\end{array}$ \\
\hline 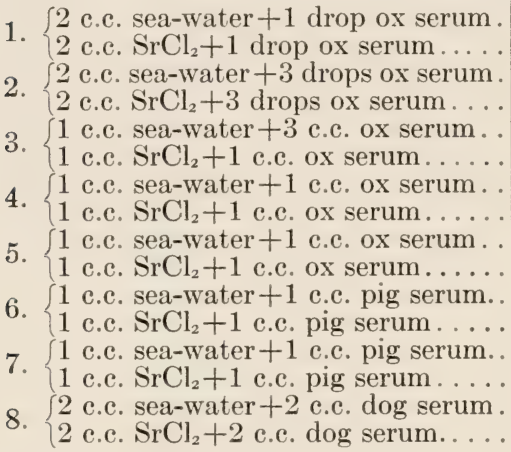 & $\begin{array}{r}5 \\
80 \\
0 \\
80 \\
14 \\
33 \\
5 \\
26 \\
8 \\
50 \\
5 \\
80 \\
5 \\
40 \\
0\end{array}$ \\
\hline
\end{tabular}

The efficacy of Dendrostoma blood, however, was not increased by the addition of strontium.

3. This method of sensitizing was improved by putting the eggs for some time into a $3 / 8 \mathrm{~m}$ solution of $\mathrm{SrCl}_{2}$ and then exposing them to the serum. ${ }^{1}$ The eggs are first washed in a $\mathrm{NaCl}$ solution and then put into a $3 / 8 \mathrm{~m}$ solution of $\mathrm{SrCl}_{2}$. After from five to ten minutes (or if necessary later) a drop of eggs is taken from this solution and put into a mixture of 1 c.c. sea-water and 1 c.c. serum (rendered isosmotic with sea-water). In this way by a sufficiently long treatment with $\mathrm{SrCl}_{2}$ the eggs of practically every female can be sensitized against foreign blood. The same method was found effective for the eggs of

1 Loeb, "Die Sensitivierung der Seeigeleier mittelst Strontiumchlorid gegen die entwicklungserregende Wirkung von Zellextracten," Archiv $f$. Entwicklungsmechanik, XXX, 44, 1910. 
Arbacia. ${ }^{1}$ It was found that if the eggs were sensitized against ox serum they are sensitized against other foreign blood and tissue extracts.

The question is: How does $\mathrm{SrCl}_{2}\left(\right.$ or $\mathrm{BaCl}_{2}$ ) cause these sensitizing effects? This is possibly answered by the observation that if the unfertilized eggs of purpuratus remain permanently in the $\mathrm{SrCl}_{2}$ solution, they will ultimately form membranes without requiring any further treatment. The time required for this effect differs for the eggs of different females. If eggs which have formed a membrane upon treatment with $\mathrm{SrCl}_{2}$ (or $\mathrm{BaCl}_{2}$ ) are subsequently exposed to a hypertonic solution they will develop into larvae. The fact that the $\mathrm{SrCl}_{2}$ alone can cause membrane formation if the eggs are exposed to it for a sufficiently long time suggests that the sensitivation consists in a modification of the cortical layer of the egg of a character similar to that which leads to membrane formation. $\mathrm{SrCl}_{2}$ thus facilitates the subsequent membrane formation by serum.

The following facts are of interest. I had already noticed in my experiments on heterogeneous hybridization that the eggs of the sea-urchin can be fertilized in larger numbers with the sperm of Asterias than with the sperm of Pycnopodia or Asterina. It was found that the extracts of the coecum of these three species of starfish showed the same relative difference in their power of causing membrane formations in the unfertilized egg of S. purpuratus that had previously been sensitized with $\mathrm{SrCl}_{2}$. This agrees with the fact, which we shall prove in the next chapter, that the membrane formation by the spermatozoon is caused also by a cytolytic agent-a lysin; and that the lysins contained in the coecum show the same relative efficiency as the lysins contained in the spermatozoa of the thrce species. It may be of interest that the extracts of all kinds of starfish cells, even of the eggs, were able to bring about the membrane formation in the sea-urchin egg.

${ }^{1}$ Loeb and Wasteneys, Science, XXXVI, 255, 1912.

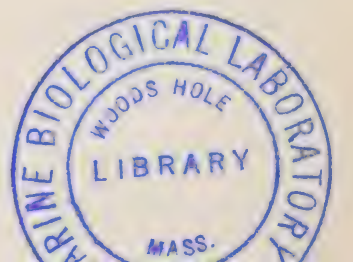


While it was thus easy to cause the membrane formation of the unfertilized sea-urchin egg with blood or extracts of tissues from foreign species, it was almost impossible to bring about the membrane formation in the sea-urchin egg with extracts from the tissues of the sea-urchins. Only in one among many attempts did the writer succeed in causing membrane formation in the eggs of $S$. purpuratus by the watery extract from the coecum of $S$. franciscanus. The extract had been standing five days; newly prepared extract was without effect upon the same eggs. About 5 per cent of the eggs formed membranes.

We may ask the question why it is that blood or the extracts of tissues of foreign species will readily cause membrane formation in the unfertilized eggs of sea-urchins, while the extract from tissues of the sea-urchin remains ineffective. From the experiments with acids and alkali it became evident that a necessary prerequisite of the efficiency of a substance for the causation of membrane formation is its diffusion into the egg, or at least into its cortical layer. The same can be shown to be true for the hydrocarbons, ether, alcohols, and the other substances which cause membrane formation. It is therefore possible that the inefficiency of the blood and tissue extracts of the same animal and the efficiency of the blood of foreign species for the causation of membrane formation is due to the fact that the foreign lysins can diffuse into the egg while the lysins of the same species cannot.

We know that the blood of all animals carries lysins which may cause haemolysis in foreign forms, but are harmless to the cells of the animal itself. What causes this immunity? According to our investigations the immunity of our cells against the lysins contained in our blood may be due to the fact that the lysins of our blood cannot diffuse into our own cells while they may diffuse into the cells of foreign species.

This view is supported by some data which will be given in the next chapter and to which we may refer briefly here. The 
watery extract of spermatozoa of foreign species causes membrane formation in the sea-urchin egg. The watery extract of the spermatozoa of the sea-urchin does not produce membrane formation in the sea-urchin egg. We cannot say that this is due to the fact that the sea-urchin sperm contains no membraneforming substance. The only possible conclusion is the paradoxical assumption that the membrane-forming substance of many foreign spermatozoa can diffuse into the sea-urchin egg, while the membrane-forming substance of the spermatozoon of its own species cannot get into the egg by diffusion, but must be carried into it by the living spermatozoon.

4. Experiments on the isolation of the substance present in the serum which is responsible for membrane formation have not yet met with much success. It is apparent that this substance is comparatively resistant to heat.

For example, ox serum was slowly heated on the water bath and 0.5 c.c. removed at different temperatures and put into watch glasses. On cooling, 0.5 c.c. of sea-water was added and a drop of eggs placed in the mixture. It was found that the activity of the serum was not impaired by heating it up to $73^{\circ} \mathrm{C}$. I took as criterion the number of eggs that formed membranes in the solution. The serum coagulated at $73^{\circ} \mathrm{C}$. On heating the coagulum to $100^{\circ}$, the clear liquid that could be squeezed out had no longer any effect on the eggs.

The activity of the serum is apparently not decreased by putrefaction; nor does extraction of the serum with ether, four times repeated, lessen its effect. But as ether can cause membrane formation and cytolysis, one must take the precaution in these experiments of not using the serum until all the ether has been expelled.

If a large quantity of acetone is added to the ox serum, a voluminous precipitate is obtained, which hardens on drying into a brown crust. This substance is insoluble in sea-water. This dried acetone precipitate was ground up in sea-water, in a 
mortar, filtered, and the filtrate tested for its action. This filtrate is exceptionally active.

Robertson described a more complicated process of precipitating the active substance of the blood with acetone, which was based on the assumption "that the fertilizing agent might be precipitable by alkaline earths."

He has since improved this method and gives the following description: Precipitation from the serum by acetone, extraction of the precipitate with hot $\mathrm{N} / 10 \mathrm{HCl}$, exactly neutralizing the extract with $\mathrm{Ba}(\mathrm{OH})_{2}$, redissolving the precipitate in $\mathrm{N} / 10 \mathrm{H}_{2} \mathrm{SO}_{4}$ and reprecipitating it with acetone. The yield from a liter of ox serum lies between 10 and 40 milligrams. From its reactions Robertson concludes that the substance is either a protein or a peptone. One part of the substance rubbed up in 512,000 parts of sea-water caused membrane formation in 80 per cent of the eggs of $S$. purpuratus which had previously been sensitized by four minutes' immersion in $3 / 8 \mathrm{~m} \mathrm{SrCl}_{2}$.

Robertson also found that Witte's peptone contains a membrane-forming substance demonstrable by eggs previously treated with $\mathrm{SrCl}_{2}$. He thinks it unlikely that the active substance is a lipoid. ${ }^{2}$

1 Robertson, Archiv f. Entwicklungsmechanik, XXXV, 70, 1912.

${ }^{2}$ Robertson, Proc. Society for Exper. Biol. and Med., X, 117, 1913. 


\section{XIX}

\section{THE FERTILIZING EFFECT OF SPERM EXTRACT}

1. In 1899 Piéri published a note to the effect that by merely shaking up the testes of the sea-urchin in sea-water he had been able to extract a substance which fertilized the egg of the sea-urchin. ${ }^{1}$ The sea-water containing the spermatozoa was filtered after the shaking, and the filtrate added to the eggs. The eggs developed. As the author himself states, and as is generally known, spermatozoa pass through filter paper, and so one cannot quite understand on what the author bases his statement that we are concerned here with a fertilization by sperm extract, and not by living spermatozoa; control experiments were not performed. A better addition to the solution of the problem was made by Winkler. ${ }^{2}$ He states that his work has not gone beyond a preliminary stage. His experiments consisted in putting the spermatozoa of two kinds of Naples sea-urchins, Sphaerechinus and Arbacia, into distilled water for half an hour. The filtrate was able to produce the first segmentation stages in the sea-urchin. It will be seen, however, that Winkler did not work with unaltered sea-water, and it is possible that the alteration of the sea-water and not the hypothetical substances extracted from the sperm was the cause of the segmentation that he observed.

If the spermatozoa were simply killed by being heated in seawater to between $50^{\circ}$ and $60^{\circ} \mathrm{C}$, and the eggs put in this liquid, nothing happened. But if they were put into distilled water for half

1 T. B. Piêri, "Un nouveau ferment soluble: L'ovulase," Arch. de Zool. expér. et gên., XXIX, 1899.

2 H. Winkler, " Ueber die Furchung unbefruchteter Eier unter der Einwirkung von Extractivstoffen aus dem Sperma," Nachrichten der Ges. d. Wissensch. zu Göttingen, 1900, 187. 
an hour and frequently shaken up, the fluid then proved effective. Of course, I did not use it directly, but first filtered it five to six times through triple filter paper, and then added the salts obtained by the evaporation of sea-water so as to make it of the same concentration as that of normal sea-water (about 4 per cent). When put into this water, unfertilized eggs of both Sphaerechinus and Arbacia showed signs of cleavage - each, of course, only responding to the extract of sperm of the same species. I may, however, remark at the same time that not a very large number and by no means all of the eggs responded; it was usually the case that the eggs of one individual would react to one and the same sperm fluid, but not those of another. In the best cases the segmentation proceeded regularly to the four-cell stage, but afterward it became abnormal and the blastomeres which were very dissimilar in size fell apart from one another, probably as the result of the absence of the vitelline membrane. The velocity of development was much slower in eggs so treated than in normally fertilized ones.

I have no intention of criticizing Winkler's efforts; they were certainly a step in the right direction. But it must be pointed out that the experiments are not free from objection. In the first place, his sea-water was made much more alkaline than is normal, owing to the fact that by first evaporating it he drove out the $\mathrm{CO}_{2}$ and converted the bicarbonate into carbonate. He afterward restored the sea-water to its normal volume by adding distilled water. The increase of alkalinity thus produced will alone lead to such results as Winkler describes, as I showed years ago.

For several years I have tried in vain to repeat Winkler's experiments; results such as he described can be obtained by using slightly hypertonic or hyperalkaline sea-water, or the two together; but these results are also obtained when no sperm is added to such sea-water. Before the appearance of Winkler's paper I myself had examined the effect of various enzymes upon the unfertilized sea-urchin egg, but with negative results. At my suggestion, Professor W. J. Gies, of Columbia University, undertook a series of experiments in which he subjected the spermatozoa to every known method that leads 
to the extraction of enzymes from cells. ${ }^{1}$ Extracts of spermatozoa in fresh water, sea-water, alcohol, ether, glycerin, alkaliesall proved absolutely ineffective. The repetition of Winkler's experiments with special attention to the sources of error led to negative results. Gies concluded from these experiments that if the spermatozoon does cause the development of the egg by means of an enzyme, that enzyme either cannot be extracted from the sperm by the usual methods, or it is unable to enter the egg. It would also be difficult to understand why Winkler observed no membrane formation if the development really depended upon a sperm extract.

2. Kupelwieser found in the writer's laboratory at Pacific Grove that if the eggs of the sea-urchin are placed in very concentrated Mytilus sperm they form a typical fertilization membrane in from five to fifteen minutes. The eggs behave just like those in which artificial membrane formation has been produced by a fatty acid. They develop only when subsequently exposed to hypertonic sea-water, otherwise they disintegrate. The rapid formation of the fertilization membrane in this case obviously bars the entrance of the spermatozoon into the egg, a process that goes on much more slowly than membrane formation. Kupelwieser succeeded subsequently in obtaining similar results with the filtrate from spermatozoa that had been previously killed by heating to between $70^{\circ}$ and $100^{\circ}$.

I then tried the filtered sperm of Chiton, Asterias, Asterina, S. franciscanus and purpuratus, all of which had been heated to between $70^{\circ}$ and $100^{\circ}$. In all cases I obtained membrane formation (with the eggs of S. purpuratus).

The fundamental point about this membrane formation was that the concentration of the sperm must be as high as possible.

It is best to place the eggs directly in the living sperm with little or no dilution, for comparison with the dead and filtered sperm that

1 W. J. Gies, "Do Spermatozoa Contain an Enzyme, Having the Power of Causing the Development of Mature Ova?" Am. Jour. Physiol., VI, 53, 1901. 
has been diluted at most with its own volume of sea-water. In this way I obtained in some cases as many as 90 per cent of membranes. But I must particularly point out the fact that these experiments only succeed with the eggs of at most one female in five. In all these cases the eggs behave after membrane formation just like those in which membrane formation has been evoked by a fatty acid. ${ }^{1}$

3. This statement of Kupelwieser is correct except in one point, namely, in regard to the effect of dead sea-urchin sperm upon the sea-urchin egg. I have made many experiments in regard to the effect of the extract of sperm upon membrane formation and found that it does not differ from the membrane formation by extracts of other tissues. While the eggs of the majority of purpuratus are immune against the watery extract of dead sperm of foreign species, if they are sensitized by a treatment with $\mathrm{SrCl}_{2}$, all or part of the eggs of practically every female will form a fertilization membrane, ${ }^{2}$ if some extract of dead sperm of a foreign species is added. The extract of dead sea-urchin sperm, however, was in all cases absolutely ineffective upon the eggs of sea-urchins. In my experiments the spermatozoa were killed by keeping them for 20 minutes at a temperature of about $50^{\circ} \mathrm{C}$. While the extract of foreign spermatozoa killed in this way was very efficient, the extract of spermatozoa of the sea-urchin killed in the same way was absolutely without effect upon the sea-urchin egg.

We have thus the paradoxical fact that foreign sperm can cause membrane formation and in certain cases development of the sea-urchin egg, no matter whether the sperm is dead or alive; while sperm of the sea-urchin can bring about fertilization of the sea-urchin egg only if it is alive. The explanation of this paradox lies in the statement given in the preceding chapter that the lysins of foreign animals can get into the cells

${ }^{1} \mathrm{H}$. Kupelwieser, "Versuche ueber Entwicklungserregung und Membranbildung bei Seeigeleiern durch Molluskensperma," Biol. Centralbl., XXVI, 744, 1906; Archiv f. Entwicklungsmechanik, XXVII, 434, 1909.

${ }^{2} \mathrm{SrCl}_{2}$ does not increase the fertilizing power of living sperm. 
by mere diffusion, while the lysins of the same species cannot get into the egg by diffusion. Only through the motive power of the living spermatozoon which acts as a carrier can the fertilizing lysin of the animal's own species get into the egg.

If the eggs were not immune against the lysins of their own species, it would be inevitable that their development would be caused by the lysins of the blood or the body liquids of the female. They would all be caused to begin to develop and then perish, and this would cause the extinction of the species; or if a complete development were possible, parthenogenesis would be the rule. This would lead to the extinction of all forms of animals in which the male is heterozygous for sex, since the offspring would all be males.

Leo Loeb ${ }^{1}$ has published observations which make it probable that in the ovary of higher animals a small percentage of eggs can begin a parthenogenetic development. He found in about 10 per cent of the ovaries of guinea-pigs between the ages of two and six months "transitory tumors" (chorion-epitheliomata) which cannot be interpreted in any other way than as young embryos, which, however, undergo an abnormal development. These tumors seem to originate from eggs lying in the superficial layer of the ovary. A kind of placenta is formed. It is possible that the embryomata and chorion-epitheliomata found occasionally in human sexual glands also owe their origin to the beginning of a parthenogenetic development of eggs.

4. For the sake of completeness the following facts should be mentioned. When we add living spermatozoa of foreign species, e.g., of the shark or even of starfish, to eggs of S. purpuratus in normal sea-water we do not, as a rule, get a membrane formation. But when we use the extract of dead sperm of these species, the unfertilized eggs of purpuratus may form membranes in normal sea-water, especially if the eggs have been previously sensitized. This difference is accounted for by

${ }^{1}$ Leo Loeb, Zeitschr. f. Krebsforschung, XI, 259, 1912. 
the fact that if we use extract of dead sperm, the membraneforming substances will reach the egg in higher concentrations than if a single spermatozoon of a foreign species reaches it. It seems that a living spermatozoon must come in close contact with the fertilization cone of the egg before membrane formation is possible. This seems possible only for the foreign spermatozoon if we raise the alkalinity of the sea-water through the addition of some $\mathrm{NaOH}$.

When we use the eggs of another sea-urchin, S. franciscanus, the result is entirely different. Even the living spermatozoa of starfish or the shark, or even of warm-blooded animals like the fowl, bring about the membrane formation in this egg in normal sea-water. But no egg develops; they all behave in this case as if only the membrane formation with butyric acid had been called forth. We see from this that we cannot expect that all species of sea-urchins behave alike in every respect.

T. B. Robertson has worked out a method which permits the extraction of a substance from the testicles of the seaurchin which produces membrane formation in the sea-urchin egg. ${ }^{1}$

1 T. B. Robertson, Archiv f. Entwicklungsmechanik, XXXV, 64, 1912. 


\section{XX}

\section{THE MECHANISM OF THE FORMATION OF THE FERTILIZATION MEMBRANE ${ }^{1}$}

1. We can safely state that the previous experiments have all clearly demonstrated one fact: that the initiation of development in the sea-urchin egg is due to a change in the surface of the egg-apparently a cytolysis of the cortical layer-which results generally in a membrane formation. In some cases this membrane is more typically developed than in others. We shall now communicate some experiments concerning the nature of this process.

The reader remembers from chap. ii, that if the membrane formation proceeds slowly in the egg of $S$. purpuratus, it begins with the formation of minute blisters at the surface of the egg. These blisters grow in size and their contents fuse while the surface film of all the blisters forms the outer fertilization membrane. This membrane is separated by the fluid (the fused contents of the individual blisters) from the protoplasm of the egg. What is the origin of this fluid? Is it secreted by the egg, or is it absorbed from the sea-water? If it were secreted entirely from the egg, the diameter of the cytoplasm should show a decrease after membrane formation. However, measurements that I have made showed that the egg cytoplasm undergoes no remarkable diminution of its volume at membrane formation. Hence the essential part of the fluid that lies between the cytoplasm and the membrane must be derived from without, i.e., from the sea-water. But one part is derived from the egg, and this latter part is, as we shall see, a colloid.

${ }^{1}$ Loeb, "Ueber die osmotischen Eigenschaften und die Entstehung der Befruchtungsmembran beim Seeigelei," Archiv f. Entwicklungsmechanik, XXVI, 82, 1908. 
2. The existence and rôle of this colloid becomes clear through the following experiments. When we put fertilized eggs or eggs with a butyric-acid membrane into sea-water whose concentration is raised through the addition of salt or sugar, the diameter of the fertilization membrane remains unaltered (while the protoplasm of the egg shrinks). If we dilute the seawater by adding distilled water, the diameter of the fertilization

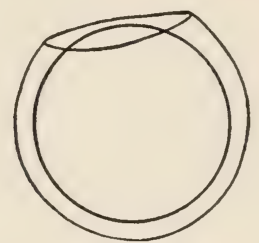

Fig. 59

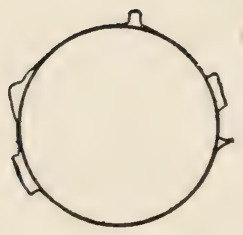

Fig. 61

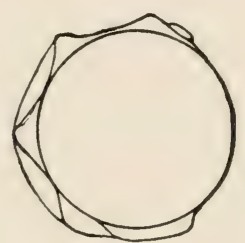

Fig. 60

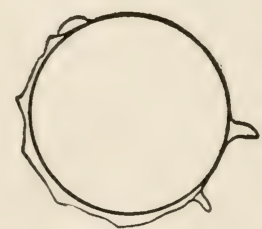

Fig. 62

Figs. 59-62.-Collapse of the fertilization membrane if a liquid colloid; e.g., some liquid white of egg, is added to the sea-water. In Figs. 59 and 60 very little, in Figs, 61 and 62 more, white of egg was added to the sea-water. When the eggs are replaced in normal sea-water the normal membrane is re-established at once.

membrane also remains unaltered while the protoplasm of the egg swells. This proves that the fertilization membrane is permeable for water, sugar, and salts, while the protoplasm of the egg is not.

If we add, however, any colloidal substance, e.g., white of egg or blood, or even tannic acid, to the sea-water, the membrane collapses at once (Figs. 59-62). If the eggs are put into seawater again which is free from colloids, the membrane becomes spherical again almost at once. This proves that the membrane 
is permeable to salts and water but not for colloids. Hence? the addition of a colloid to the external solution increases the osmotic pressure of the latter (although only slightly), but this difference is enough to cause all the sea-water contained between fertilization membrane and protoplasm to diffuse out, and as a consequence the membrane collapses as shown in Figs. 61 and 62. If restored to normal sea-water without colloids, the membrane becomes spherical again. These experiments succeed immediately after the membrane is formed.

3 . These data give us the key to the conception of the mechanism of membrane formation. The fertilization membrane is perfectly spherical in form. This implies that the membrane is in the condition of tension. Since, then, the experiments already described prove that in Strongylocentrotus the fertilization membrane is easily permeable to sea-water, there must. prevail within the membrane an osmotic pressure which is equal to the tension of the membrane. This pressure must be due to a substance which is contained within the membrane cavity and cannot diffuse out through it. This substance must be a colloid. The existence of such a colloidal, indiffusable substance within the membrane cavity also explains the abovementioned fact that when the membrane has been caused to collapse by the addition of serum to the sea-water, it can be restored to its normal condition of tension by replacing the egg in ordinary sea-water. Another fact that is also explained by this hypothesis is that the membrane does not begin to collapse until a certain definite mass of serum or protein has been added to the sea-water. ${ }^{1}$

We mentioned in the first chapter that when the membrane is slowly produced it can be observed that this process starts in a roughening of the surface of the egg, and that this is due to the formation of numerous small drops. Now it appears to me (so far as the osmotic properties of the membrane are 
concerned) that this formation of droplets depends upon the fact that a colloidal substance, which lies below the surface layer of the unfertilized egg or is secreted from the egg, suddenly swells by absorption of sea-water. In the typical case of membrane formation this swelling results finally in a complete liquefaction of the colloid. In other cases the swelling is less complete and the formation of a gelatinous film results.

4. If this idea is correct it should be possible to prove that the agencies which cause membrane formation may also cause a swelling and liquefaction of some colloidal substance associated with the egg. This proof can be furnished in the case of the chorion which surrounds the immature egg of Lottia, a mollusc of the Pacific coast.

Fig. 63 represents the unripe egg of Lottia. While in this condition, the egg cannot be fertilized by a spermatozoon. It possesses an irregular outline, owing to the fact that it is surrounded by a stout membrane, the so-called chorion. When this membrane is removed, the egg assumes the form of a sphere (Fig. 65). We will now show that the various substances which cause membrane formation in the sea-urchin egg also cause a swelling and liquefaction of this chorion. Saponin is, as we have seen, one of these substances. If an unripe egg of Lottia is placed in 5 c.c. of sea-water to which have been added about six drops of a $\frac{1}{4}$ of 1 per cent solution of saponin (in sea-water), in some four minutes it changes from the condition shown in Fig. 63 to that in Fig. 64, and in about another four minutes the chorion has quite disappeared and the egg has become spherical (Fig. 65). A comparison of Figs. 65 and 64 will show that under the influence of saponin the chorion first swells greatly by the imbibition of sea-water, and finally liquefies.

A second agency calling forth membrane formation in the sea-urchin egg is bases in the presence of free oxygen. As long as the unfertilized eggs of Lottia lie in normal sea-water the chorion remains unaltered. But if the alkalinity of the sea- 
water is raised by the addition of some $\mathrm{NaOH}$ (e.g., 1.0 c.c. $\mathrm{N} / 10$ to 50 c.c. sea-water), the chorion is gradually dissolved in a number of eggs. The writer has recently found that the

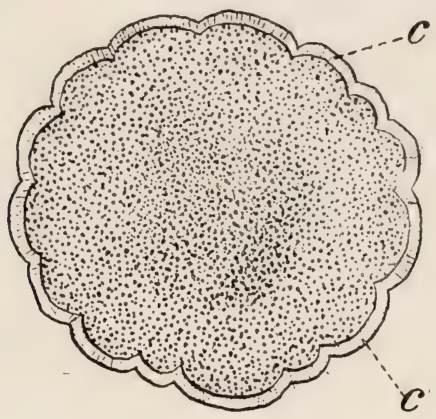

Fig. 63

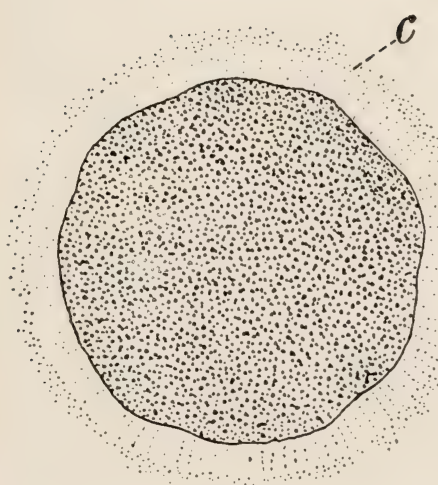

Fig. 64

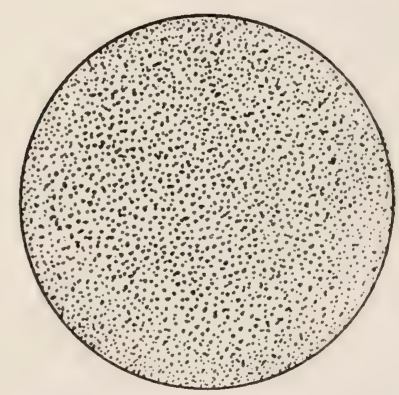

Fig. 65

Figs. 63-65.-Dissolution of the chorion surrounding the egg of Lottia gigantea, a mollusc, on treatment with saponin. Fig. 63 shows the egg before the treatment with saponin. $c$ is the chorion. Fig. 64 shows the same egg a few minutes after the addition of saponin. The chorion $c$ is greatly swollen and at the point of liquefaction. Fig. 65 shows the chorion having completely disappeared and the egg become spherical. In this condition it is permeable for the spermatozoon.

weak bases are much more efficient than the strong bases. Thus the amines and $\mathrm{NH}_{4} \mathrm{OH}$ will cause the swelling and liquefaction of the chorion of Lottia in the same concentration much more rapidly than the strong bases $\mathrm{NaOH}$ and tetraethylammoniumhydroxide. 
This action of bases upon the swelling and liquefaction of the membrane of Lottia takes place only in the presence of oxygen. If the oxygen was removed, the eggs of Lottia kept their chorion and their irregular outline, even if they remained for from four to six hours in alkaline sea-water (50 c.c. sea-water + 1.0 c.c. $\mathrm{N} / 10 \mathrm{NaOH}$ ). If the eggs were afterward placed in oxygenated alkaline sea-water the chorion dissolved and the eggs could be fertilized by sperm. The addition of KCN to the hyperalkaline sea-water also prevented the dissolution of the chorion. ${ }^{1}$

We are forced to assume that in our original method of artificial parthenogenesis the hypertonic solution combined two effects, the membrane formation and the corrective effect. The membrane formation was atypical, since it only led to the formation of a gelatinous film around the egg, but it was the essential feature. It seems to the writer to be of great interest that a hypertonic solution will also cause the swelling and liquefaction of the chorion of Lottia. ${ }^{2}$

Finally we have seen that benzol causes membrane formation in the sea-urchin egg; it also causes the liquefaction of the chorion of Lottia.

Acid did not dissolve the chorion of Lottia, nor will it cause parthenogenesis in Lottia either. Acids, however, dissolve the chorion of the sea-urchin egg, as Herbst first observed.

All these facts led the writer to speculate as to whether the cortical layer of the unfertilized egg does not contain a substance similar to that of which the chorion of these eggs consists; that the membrane formation is only the expression of the swelling and liquefaction of this colloidal substance, and that the swelling and liquefaction of this substance is the prerequisite which allows the egg to develop.

5. In my experiments I have often had the opportunity of observing membrane formation in eggs that were not spherical

${ }_{1}^{1}$ Loeb, Untersuchungen ueber künstliche Parthenogenese, p. 369, Leipzig, 1906.

${ }^{2}$ Loeb, op. cit. 
but possessed some other shape. In such eggs the egg membrane at the start followed the contour of the egg. This proves that the primary factor in membrane formation is the swelling of a substance lying on the surface of the egg, similar to that which forms the chorion. The swollen substance then becomes more and more liquid. Immediately after the formation of the membrane it can be caused to collapse if we arld a protein to the sea-water, which shows that in S. purpuratus only liquid matter lies between membrane and protoplasm. In some cases of artificial parthenogenesis, e.g., by bases or by fatty acids, in Arbacia we observe instead of a fertilization membrane a fine film surrounding the egg. It is possible that in this case the swelling is less complete and the membrane remains gelatinous. There may be all kinds of transition stages between the gelatinous film and the cases with a typical fertilization membrane separated from the protoplasm by a liquid.

The existence of a colloid substance within the membrane chamber can be established by direct observation. For it can be seen that the fluid between the membrane and cytoplasm contains a constituent of somewhat higher refractive power than the sea-water.

6 . We have already mentioned that substances like benzol, saponin, etc., can cause both membrane formation and cytolysis.

The first of the two is produced when they have time to affect only the surface of the egg; cytolysis is produced when their effect extends to the deeper layers of the egg.

Now the cases of cytolysis afford a very pretty demonstration of our theory. For since the greater the fraction of the egg which comes under the effect of the membrane-forming reagents, the greater the amount of colloid that must be liquefied; hence a greater osmotic pressure should be set up by complete cytolysis than by simple membrane formation, and hence 
in this case the diameter of the egg should be much greater. This happens to be actually the case.

If unfertilized sea-urchin eggs are placed in a weak saponin solution (in sea-water), normal membrane formation takes place after a few minutes; upon leaving the eggs longer in the solution, however, cytolysis ensues, and the diameter of the egg may increase to double its size. ${ }^{1}$ The same phenomenon takes place if fertilized eggs are exposed to the action of saponin. If, however, the contents are coagulated by heat before the eggs are exposed to the saponin, or a body that has a similar effect, this increase in volume no longer occurs. This appears to indicate that the colloidal substance that exerts the osmotic pressure is a protein.

It may be said here that the fertilization membrane is insoluble in benzol, ether, alcohol, saponin, and similar substances. Hence it is not a lipoid.

7. Robertson ${ }^{2}$ has extended these observations by comparing the effect of different proteins on the prevention of membrane formation by butyric acid. He treated the eggs of $S$. purpuratus with butyric acid, but instead of putting them into normal sea-water he brought them into sea-water to which various quantities of different soluble proteins had been added. His results are given in Table XXXVIII.

\section{TABLE XXXVIII}

\begin{tabular}{|c|c|c|}
\hline Protein & $\begin{array}{l}\text { Highest Observed Con- } \\
\text { centration Which Per- } \\
\text { mits the Formation of } \\
\text { a Spherical Membrane }\end{array}$ & $\begin{array}{l}\text { Lowest Observed Con- } \\
\text { centration Which Pre- } \\
\text { vents the Formation of } \\
\text { a Spherical Membrane }\end{array}$ \\
\hline 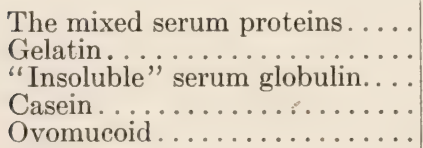 & $\begin{array}{l}3.70 \\
1.00 \\
0.30 \\
0.25 \\
0.125\end{array}$ & $\begin{array}{l}7.40 \\
2.00 \\
0.60 \\
0.50 \\
0.25\end{array}$ \\
\hline
\end{tabular}

1 See Figs. 39 and 45, chap. xvii.

${ }^{2}$ Robertson, Archiv f. Entwicklungsmechanik, XXXV, 80, 1912. 
Robertson states that this order of inhibiting efficiency of various proteins is the reverse of their ability to pass through a porcelain filter.

In striking confirmation of the view expressed by Loeb that the formation of the membrane in fertilized eggs is due to the osmotic imbibition of water by the egg, and that the inhibiting effect of colloids upon their formation is due to their inability to pass through the membrane, we find that the order of effectiveness of the various proteins in inhibiting membrane formation is the reverse order of their ability to pass through a porcelain filter.

8. Membrane formation by acids or saponin or benzol is not dependent upon the presence of free oxygen. As I showed seven years ago, an egg is not deterred by $\mathrm{KCN}$ from forming a membrane under the influence of acid. I left unfertilized sea-urchin eggs at $15^{\circ} \mathrm{C}$. for several hours (up to 24 hours) in a mixture of 50 c.c. of sea-water +2 c.c. $1 / 20$ per cent $\mathrm{KCN}$ and added sperm thereto. The eggs at once formed perfect fertilization membranes in the cyanide sea-water. ${ }^{1}$ But the development of the eggs was completely inhibited by such a solution. The development of the eggs requires free oxygen, but membrane formation by fatty acid, on the other hand, does not.

In the case of artificial parthenogenesis by bases, however, oxidation is required for membrane formation. It is possible that in this case the process of oxidation leads to the formation of a substance which causes the physical change underlying membrane formation.

9. What has the membrane formation to do with the development? The writer published in 1905 the following hypothesis:

From all these facts mentioned here, I have gathered the impression that the membrane formation, or possibly the process which results in membrane formation, is an essential feature of the process of fertilization not only in the sea-urchin egg but also in at least certain starfish

${ }^{1}$ Loeb, "Der chemische Charakter des Befruchtungsvorganges," Biochem Zeitschr., I, 191, 1906. 
e.g., Asterina. It may seem pedantic to discriminate between the membrane formation and the process underlying it: but this discrimination is suggested by a suspicion on my part that the membrane formation is the result of a process of secretion of a liquid from the egg; and that this secretion or the throwing-out of certain substances of the egg is the important feature, while the lifting-up of the surface layer of the egg (the membrane formation proper) is only a mechanical consequence of this secretion, but of no importance in itself. ${ }^{1}$

The same idea was repeated by the writer a little later in the following words: "We might think of the possibility that an elimination of a definite inhibiting substance sets into motion the chemism, which underlies development."2 On this assumption the colloidal substance which undergoes the swelling would be the substance whose removal gives rise to the development.

F. Lillie $^{3}$ has recently found that a layer of substance, which in the unfertilized egg of Nereis lies under the natural vitelline membrane of the egg, flows out (is "secreted") and forms a thick gelatinous layer around the egg, as soon as the spermatozoon comes in contact with the egg. But this gelatinous layer resembles the gelatinous envelope which surrounds the frog egg and does not form a tough membrane at its outer surface, such as we observe in the sea-urchin egg.

Lillie assumes

that the presence of this colloid substance in the cortex is an inhibition to the maturation of the egg, because as soon as it is removed, maturation processes are set in motion and both polar bodies formed. In what manner it inhibits is of course problematical. In the egg of Ascaris megalocephala there is a similar excretion of a cortical colloid which forms, in this case, the thick resistant perivitelline membrane. The appearance of the fertilization membrane of echinids might be similarly due to excretion of a cortical colloid which is removed by diffusion and hence is not detected.

${ }^{1}$ Loeb, "Artificial Membrane Formation and Chemical Fertilization in a Starfish," University of California Publications, Physiology, II, 154, 1905; reprinted in Untersuchungen zur künstlichen Parthenogenese, p. 362, Leipzig, 1906.

2 Loeb, "Die künstliche Parthenogenese," Oppenheimer's Handbuch der Bio. chemie, II, 100, 1909.

${ }^{3}$ Lillie, Jour. Morphol., XXII, 361, 1911. 
Bataillon has expressed a similar view, but both authors have apparently overlooked the writer's former statements. I have recently omitted to emphasize this idea of a secretion since it is merely hypothetical and moreover the word "secretion" is not clear from a physicochemical viewpoint. I therefore preferred the expression "cytolysis of the cortical layer of the egg," which is a clearer expression of what actually occurs and which is better understood from a physicochemical viewpoint. It may be that the action of cytolytic agents upon the egg merely induces secretion, or that secretion is in all cases in the ultimate analysis a form of cytolysis.

Since, however, the rise of the rate of oxidations is the essential feature in the causation of development in the egg of the sea-urchin; and since this rise is also brought about by complete cytolysis of the egg, it seems safer to say that the cytolysis of the cortical layer of the egg (which results in membrane formation) is the essential feature in the causation of development.

10. Harvey has expressed the view that the essential condition for the formation of the membrane is an increased permeability of the egg surface for a membrane substance which passes out and hardens to a membrane in contact with seawater. $^{1}$ Ries $^{2}$ and Elder ${ }^{3}$ assume that this hardening occurs in contact with the chorion which surrounds the egg. It is possible that the droplets, which initiate the membrane formation quite frequently in the egg of $S$. purpuratus, are really a secretion of a colloid which upon coming in contact with seawater swells by absorbing sea-water and which hardens at its outer surface to the characteristic membrane. Still, one wonders why this should be called a secretion, since complete cytolysis of the egg by saponin also results in membrane formation.

${ }_{1}$ Harvey, Jour. Exper. Zool., VIII, 355, 1910.

${ }^{2}$ Ries, Centralbl. f. Physiol., XXIII, 369, 1909.

${ }^{3}$ Elder, Archiv f. Entwicklungsmechanik, XXXV, 145, 1912. 
Another hypothetical suggestion is that the fertilization membrane is preformed in the unfertilized egg and is merely the peripheral film of protoplasm which is lifted up from the egg through the swelling and liquefaction of some protein lying underneath in the cortical layer of the egg. When lifted up from the egg the preformed membrane undergoes a modification; it becomes thicker and tougher. The objection has been raised that no such surface film is visible in the unfertilized egg, but this objection is not valid, since the surface films which form on the principle of Thomson-Gibbs are beneath the limit of visibility. This fact also meets the objection of Moore, ${ }^{1}$ that after shaking unfertilized eggs into fragments, each fragment can still form a fertilization membrane upon the entrance of a spermatozoon, since each fragment is bound to have at its surface such a film. But we are now in the realm of mere hypotheses to which it is not worth while to devote much space.

${ }_{1}^{1}$ Moore, University of California Publications, Physiology, IV, 89, 1912. 


\section{XXI}

IS DEVELOPMENT OF THE SEA-URCHIN EGG POSSIBLE WITHOUT MEMBRANE FORMATION OR WITHOUT THE SECOND (CORRECTIVE) FACTOR?

1. It has been known for a long time that if sea-urchin eggs lie for some time in sea-water they may begin to segment. I have recently investigated this phenomenon in the eggs of $S$. purpuratus, and find that such a segmentation is always preceded by membrane formation. ${ }^{1}$

If the unfertilized eggs of $S$. purpuratus are kept at a relatively low temperature, one notices that after twenty-four to forty-eight hours, in a part of the eggs of certain females, a membrane formation appears of that type which is common in the eggs of Arbacia after an acid treatment. Around the eggs a gelatinous layer is formed. If such eggs are kept at a low temperature and with sufficient oxygen supply, they begin to segment and this segmentation may proceed to the eight- or sixteen-cell stage almost regularly (Figs. 66-72). Only those eggs segment that form a membrane. The eggs of certain females only show this tendency and the number of purpuratus females whose eggs form membranes spontaneously is very small. It can be shown that the eggs which form membranes spontaneously behave in the same way as the eggs in which the membrane formation is called forth by butyric-acid treatment. At a high temperature they disintegrate at the time of the first segmentation; at a low temperature they can segment. Moreover, the eggs which form membranes spontaneously can be caused to develop into larvae by a short treatment with hypertonic sea-water.

The question arises, What causes this spontaneous membrane

${ }^{1}$ Loeb, Archiv f. Entwicklungsmechanik, XXXVI, 626, 1913. 
formation if eggs lie for some time in sea-water? No definite answer can be given. The effect may possibly be due to the action of the $\mathrm{NaOH}$ contained in the sea-water.

2. In his experiments on inducing development by foreign blood, the writer made the following observation. The unfertilized eggs of a sea-urchin were placed in a mixture of 1 c.c.
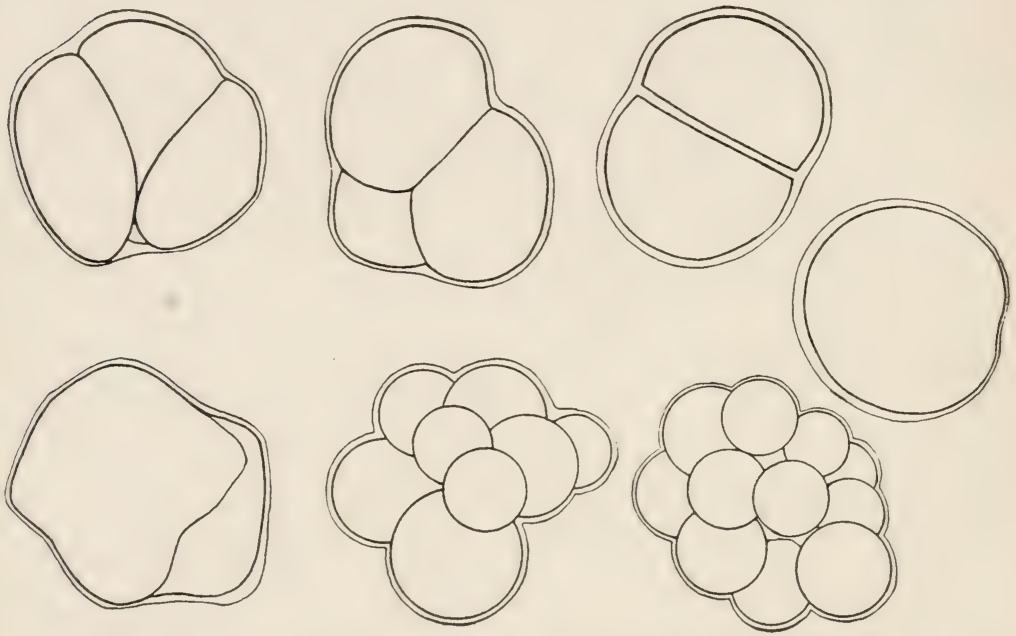

Figs. 66-72. - Camera drawings of unfertilized eggs of $S$. purpuratus which had begun to segment spontaneously. In all the eggs a fine gelatinous membrane was formed.

of pig's serum and 1 c.c. of $\mathrm{SrCl}_{2}$ isotonic with sea-water. After five minutes this solution was pipetted off and replaced with sea-water, which process was repeated four times. The eggs were left in the watch glasses for four hours and then transferred to a larger bowl of sea-water. Only a small number of the eggs had formed membranes, and these perished after a little while in the early segmentation stages. But a few of the other eggs, which had apparently not formed membranes, began to divide and they developed into normal swimming larvae, perishing in the blastula stage. Similar results were obtained 
also with a mixture of sea-water and pig's serum without the addition of $\mathrm{SrCl}_{2}{ }^{1}$ But at this time the writer was not yet familiar with the gelatinous form of membranes in the eggs of this species, and so he must leave it in doubt whether or not gelatinous membranes were formed in the eggs which developed.

The following hitherto unpublished experiments are rather curious. Unfertilized eggs (without membranes) were placed in $\mathrm{m} / 2$ sodium butyrate solution and taken out from it at different intervals. The solution was strongly alkaline (requiring 4.2 c.c. $\mathrm{N} / 10 \mathrm{HCl}$ [per 50 c.c. of solution] to turn neutral red from yellow to red).

A large number of the eggs formed membranes, but most of these (if not all) succumbed to cytolysis. However, a small number (about 1 per cent) of the eggs removed after between three and four hours developed into swimming larvae. These eggs possessed either no membrane or only one that adhered very closely to the egg, probably a gelatinous membrane. The experiment was repeated with a sodium butyrate solution of much diminished alkalinity. The amount of cytolysis (and membrane formation) was reduced by this, but the activation of a few eggs took place in this case also (but not, of course, before the eggs had been transferred to normal sea-water). About 2 per cent of the eggs that had been about six or seven hours in the sodium butyrate solution developed into swimming larvae. I believe that in both these cases a gelatinous membrane was formed, but the remarkable fact is that the eggs developed to the blastula stage at room temperature without subsequent treatment with a hypertonic solution. Could it be possible that the butyrate solution acted like a solution in which oxidations were prevented?

3. E. P. Lyon succeeded in causing artificial parthenogenesis in Arbacia pustulata and Strongylocentrotus lividus at

${ }^{1}$ Loeb, Pflüger's Archiv, CXXIV, 50, 1908. 
Naples by treating their eggs with hypertonic sea-water. ${ }^{1}$ $\mathrm{He}$ also investigated the effect of acids.

Hydrochloric acid has been found by Loeb to be an efficient reagent for causing artificial parthenogenesis in starfish. He found it did not succeed in Arbacia punctulata (at Woods Hole). But strangely enough it is one of the best reagents I found for Arbacia pustulata (at Naples). Usually 2, 3, 4, 5, 6, and 7 c.c. of a $\mathrm{N} / 10$ solution of hydrochloric acid in sea-water was added respectively to dishes containing 100 c.c. of sea-water. Eggs immersed in these solutions were taken out at intervals of from two to fifteen minutes. Some of the best results were obtained from 2 c.c. acid in 100 c.c. sea-water, ten to fifteen minutes' exposure; 3 c.c. acid, seven to twelve minutes' exposure; 4 c.c. acid, nine minutes' exposure; 7 c.c. acid, five minutes' exposure. . . . . In the best experiments perhaps 10 per cent of the eggs developed into swimming larvae. Many of these swam up to the top of the liquid, just like the larvae from fertilized eggs. They formed fully developed plutei which lived as long as individuals produced from fertilized eggs and kept under the same conditions.

No positive results were, however, obtained by this method at Naples with $S$. lividus, but Lyon succeeded in obtaining a couple of larvae by treating the unfertilized eggs of $S$. lividus with carbonic acid in sea-water. The importance of membrane formation from the point of view of development was not recognized at that time, but I believe that the eggs in Lyon's experiment formed a gelatinous membrane.

We may as well point out here that the eggs of $S$. purpuratus and franciscanus at Pacific Grove cannot be made to develop into larvae by a mere treatment with acid unless they are kept at a very low temperature. In this respect, there is a qualitative difference between the eggs of the European and Californian sea-urchins.

This difference between the behavior of the eggs of Strongylocentrotus at Naples and in California is also corrobo-

1E. P. Lyon, "Experiments in Artificial Parthenogenesis," Am. Jour. Physiol., IX, 308, 1903. 
rated by some work of Herbst ${ }^{1}$ to which we shall return later. Herbst put the eggs of Sphaerechinus in 50 c.c. of sea-water +3c.c. $\mathrm{N} / 10$ acetic acid for two to eight minutes. The eggs formed, if I interpret Herbst correctly, not a typical membrane, but a fine gelatinous film, and upon transference to normal sea-water a few of them developed into larvae, without it being necessary to expose them first to hypertonic sea-water. I am inclined to believe that in all cases in which an unfertilized sea-urchin egg has been caused to develop, a typical or atypical membrane had been formed.

The reader will notice that in these cases the eggs developed without any treatment with a hypertonic solution, at room temperature. We shall see later that this is not uncommon in the egg of the starfish. We must conclude that in such cases the corrective effect is produced by changes taking place inside the egg itself. The situation is comparable to that in the experiments in which the hypertonic solution was replaced by a treatment of the eggs with lack of oxygen. In this case we are also forced to assume that the egg itself was able to produce the substance which counteracts the threatening disintegration. In the eggs of some species, and possibly of some strains or individuals, this substance can possibly be formed under normal conditions and for such eggs the process of membrane formation may suffice, the egg being able to furnish the corrective effect or being naturally more resistant.

${ }^{1}$ Herbst, "Vererbungstudien IV," Archiv f. Entwicklungsmechanik, XXII, $473,1906$. 



\section{XXII}

THE ACTION OF THE SPERMATOZOON UPON THE EGG

\section{HETEROGENEOUS HYBRIDIZATION}

1. In 1905 the writer showed that in the sea-urchin egg artificial parthenogenesis is produced by two agencies, one of which causes membrane formation while the second one serves to make the development more normal. In 1906 he expressed the idea that the spermatozoon also caused the development by two different agencies, one of which induced membrane formation while the other one acted as a corrective-like the hypertonic solution. ${ }^{1}$ We will now consider the proof for this statement.

The eggs of the sea-urchin cannot be fertilized by the sperm of the starfish under normal conditions. In 1903 the writer found that the eggs of $S$. purpuratus can easily be fertilized by the sperm of the starfish if we render the sea-water a little more alkaline. If 0.6 c.c. $\mathrm{N} / 10 \mathrm{NaOH}$ is added to 50 c.c. sea-water and sperm of a starfish (Asterias) is added, all the eggs form a typical fertilization membrane. ${ }^{2}$

After adding the sperm of Asterias to the eggs of $S$. purpuratus, it is noticeable that not all the eggs which form membranes develop into larvae. Some of them begin to segment after the usual interval, but others behave like eggs which have only formed membranes under the influence of butyric acid. For at $15^{\circ} \mathrm{C}$. they begin to proceed toward nuclear division, but then most of them go to pieces within a few hours. I thought at first that in these eggs we were dealing, not with an influence of the spermatozoon, but with the effect of the extraneous body

1 Loeb, "Versuche ueber den chemischen Charakter des Befruchtungsvorganges," Biochem. Zeitschr., I, 183, 1906.

${ }^{2}$ Loeb, "Weitere Versuche ueber heterogene Hybridisation bei Echinodermen," Pflüger's Archiv, CIV, 325, 1904. 
fluids mixed with the sperm. Control experiments, however, showed that this was not the case with the eggs of $S$. purpuratus.

In one experiment, all the eggs of a female purpuratus formed membranes when placed in a mixture of 50 c.c. of seä-water+ 0.6 c.c. $\mathrm{N} / 10 \mathrm{NaOH}$, to which was added only a few drops of living Asterias sperm. However, only a few of these eggs (only a fraction of 1 per cent) developed to larvae; the others disintegrated in the manner characteristic of eggs which have not been treated with a hypertonic solution subsequently to artificial membrane formation. This membrane formation, however, was brought about in this case through the living spermatozoa and not by the body fluids of the starfish; this point, which is important, was established by adding to the same eggs sperm from the same Asterias male after heating it to $50^{\circ}$, in which case no egg formed a membrane. Even on addition of ten times the amount of (dead) sperm which was sufficient in the living condition to cause all the eggs to form membranes, membranes were formed by only a few of the eggs, even after a duration of several hours and when the eggs were thoroughly shaken and mixed with the sperm. Hence the membranes in the above-mentioned experiments were formed by the living spermatozoa and not by any admixture with the sperm.

While all the eggs of $S$. purpuratus form membranes under the influence of living sperm within an hour, only a fraction of the eggs (which varies in different cases) develops into larvae. The rest of the eggs behave as if the sperm had only brought about the artificial membrane formation by the giving-off to the eggs of a substance which acts like butyric acid. The explanation of this result is probably as follows. The sperm of the starfish penetrates only slowly into the sea-urchin egg; the starfish spermatozoon lingers for a long time in contact with the protoplasm of the sea-urchin egg before it gets into the interior. The time during which the spermatozoon lingers in 
contact with the surface of the protoplasm before entering varies in different cases. If the time is long enough the membrane-forming substance may be given off to the egg and the membrane formed, before the spermatozoon has entered completely. The formation of the membrane throws the spermatozoon out of the egg and prevents its entrance permanently, since no spermatozoon can penetrate the fertilization membrane. Such eggs behave as if they had only undergone membrane formation by butyric acid. They begin to develop but soon perish. If, however, the spermatozoon penetrates through the surface of the protoplasm before the membrane-forming substance has had time to act the egg can develop. In this case, in addition to the membrane-forming substance, the corrective substance has penetrated into the egg.

This idea was supported by the following observation. Eggs of a purpuratus were treated with living Asterias sperm in hyperalkaline sea-water, and all formed membranes. Some of the eggs were left in normal sea-water as a control; the majority, however, were placed after an hour in hypertonic sea-water (50 c.c. sea-water +8 c.c. $2 \frac{1}{2} \mathrm{~m} \mathrm{NaCl}$ ) and at different intervals transferred to normal sea-water. Of the control eggs, about a third developed into larvae, while the remaining two-thirds behaved like eggs treated only with butyric acid; they began to develop and then disintegrated. On the other hand, the eggs which had been exposed for about 30 to 40 minutes to hypertonic sea-water all developed into normal larvae. Dead Asterias sperm was absolutely ineffective. This proves, it seems to me, in the most striking manner that the spermatozoon also induces the development of the egg through two agencies, viz., a membrane-forming substance, a "lysin" and a second agent, which has the same effect as the hypertonic salt solution in our method of artificial parthenogenesis. It is only when both factors contained in the spermatozoon get into the egg that the sea-urchin egg develops into a larva. I am unable to 
suggest what may be the nature of the second factor in the spermatozoon. The "lysin" of the spermatozoon serves for the production of membrane formation. The second factor serves to turn the development into the right direction by the suppression of the tendency to disintegrate. ${ }^{1}$

2. A second proof for the fact that the spermatozoon causes the development of the egg by two agencies, one of which causes merely membrane formation, is contained in the following facts. The eggs of $S$. franciscanus can be more easily caused to form membranes than the eggs of $S$. purpuratus. I found in 1908 and 1909 that if we add living spermatozoa of the shark or of fowl to such eggs, the eggs form membranes. ${ }^{2}$ In the case of the spermatozoa of the shark it was possible to wash them first repeatedly in sea-water and thus free them from all blood or lymph. Nevertheless, the eggs of S. franciscanus formed fertilization membranes upon contact with the living spermatozoa of the shark. Such eggs, when left to themselves, began to segment but very soon disintegrated. If they were, however, treated afterward with a hypertonic solution they developed into larvae. The explanation of this fact is that the living heterogeneous spermatozoon upon contact with the egg gives off to the latter the membrane-forming substance, without supplying the corrective effect.

A third proof lies in the fact, mentioned in a previous chapter, that the watery extract of foreign sperm calls forth the membrane formation in the same way as butyric acid does without supplying the second corrective factor.

3. I have tried in vain to separate in the same way the membrane-forming substance from the living sperm of the sea-

${ }^{1}$ In order to test this idea further I asked Dr. Elder to make a cytological examination of these eggs. He found that when only a few eggs of $S$. purpuratus which had formed membranes developed into larvae a small percentage showed the sperm nucleus; while the other eggs had no sperm nucleus although they had formed a membrane.

${ }^{2}$ Loeb, Address at the International Congress of Medicine, Budapest, 1909; reprinted in The Mechanistic Conception of Life, 1912. 
urchin. I believe the reason to be this, that as soon as the spermatozoon of $S$. purpuratus touches the protoplasm (the fertilization cone) of the egg of the same species it is taken so quickly into the interior of the egg that it is already safely inside by the time the membrane-forming substance can act. If we fertilize the eggs of $S$. purpuratus with their own sperm, in about two minutes or less all the eggs have formed a fertilization membrane. If we fertilize them with starfish sperm, it takes from ten to sixty minutes to bring about the same result. I am inclined to see in this difference of time the reason why it is possible to separate the two agencies in the living sperm of the starfish, but not in that of the sea-urchin.

4. Very striking experiments have recently been carried out by Oskar Hertwig with Günther and Paula Hertwig, on the effects of radium on sperm. When the spermatozoa of the frog were exposed a short time to radium before they were added to the eggs, the eggs were sickly and died in the early stages of development. When, however, the spermatozoa were exposed a longer time to the radium, the eggs could develop much better and the larvae were able to live as long as two weeks. This paradox finds its explanation in the fact that when the spermatozoa had been exposed a longer time to the radium they were able to enter the egg, but the sperm nucleus was no longer able to fuse with the egg nucleus. The spermatozoon thus imparted only the developmental influences to the eggs, but not the hereditary effects. In order to produce this result it was necessary to expose the spermatozoa for four hours to $60 \mathrm{mg}$. radium bromide or for twelve hours to $10 \mathrm{mg}$. radium bromide. ${ }^{1}$

1"Die Radiumkrankheit tierischer Keimzellen," Arch. f. mikr. Anat., LXXVII, 1911, Abteilung f. Zeugungslehre; "Die Radiumstrahlung in ihrer Wirkung auf die Entwicklung tierischer Eier," Sitzgsber. Akad. Berlin, 1910; "Mesothoriumversuche an tierischen Keimzellen, ein experimenteller Beweis für die Idioplasmanatur der Kernsubstanzen," Sitzgsber. Akad. Berlin, 1911; "Radiumbestrahlung unbefruchteter Froscheier und ihre Entwicklung nach Befruchtung mit normalem Samen," Arch. f. mikr. Anat., LXXVII, 1911; "Veränderung der idioplasmatischen Beschaffenheit der Samenfäden durch physikalische und durch chemische Eingriffe," Sitzgsber. Akad. Berlin. 1912. 
5. F. Lillie ${ }^{1}$ has made some interesting experiments on the fertilization of the egg of Nereis, an annelid. It seems that in this egg the spermatozoon comes in contact with the fertilization cone of the egg and lingers here for more than half an hour before it enters. The first contact of the spermatozoon with the fertilization cone leads to the extrusion of a gelatinous mass which in the unfertilized egg lies under the perivitelline membrane. Lillie showed that by centrifuging the eggs at this stage the spermatozoon can be thrown off. In this case no further development of the egg follows. It should be pointed out that this contact action of the spermatozoon in Nereis is not comparable to the results of artificial membrane formation in the egg of the sea-urchin, since in the latter case the egg not only begins to segment but may reach the blastula stage if the temperature is low.

6. Kupelwieser ${ }^{2}$ succeeded in causing the development of the egg of sea-urchins by the sperm of molluscs, Mytilus, Mactra, and Patella, and of annelids, Auduinia. In this case the spermatozoa entered the egg and often more than one spermatozoon entered, but no fusion of sperm and egg nucleus occurred. As a rule the first segmentation began only many hours (4 to 20) after the addition of sperm. The development was most abnormal and no plutei were obtained, as far as the writer is able to judge. Kupelwieser states that in these experiments no fertilization membrane is formed. If a fertilization membrane formed, the eggs did not develop.

The writer found in 1908 that the eggs of the sea-urchin S. franciscanus could be fertilized by the sperm of a mollusc, Chlorostoma, and that normal plutei of franciscanus were formed. His attempts in later years to obtain plutei failed. 1911.

${ }^{1}$ F. Lillie, "Studies of Fertilization in Nereis," Jour. Morphol., XXII, 361,

${ }^{2}$ Kupelwieser, Biol. Centralbl., XXVI, 744, 1906; Archiv f. Entwicklungsmechanik, XXVII, 434, 1909; Sitzungsber. d. Gesellsch. f. Morphol. u. Physiol. in München, 1911. 
Godlewskil found recently that the eggs of sea-urchins can be fertilized with the sperm of Chaetopterus, an annelid. All the eggs form the fertilization membrane, but they sooner or later begin to disintegrate without segmenting. When he submitted such eggs to hypertonic sea-water for 22 minutes, they developed into larvae. The eggs behave as if the foreign sperm had only acted through the membrane-forming agency.

The interesting fact about these experiments was that the spermatozoa entered the eggs and even fused with the egg nucleus. The eggs therefore received the second factor contained in the spermatozoon, and yet they did not develop. This seems to indicate that this second factor carried by the spermatozoon is much more specific than the first membraneforming factor. This specificity is perhaps also the reason that the sea-urchin eggs fertilized with starfish or any other foreign sperm die in such large numbers in the gastrula stage.

1 Godlewski, Archiv f. Entwicklungsmechanik, XXXIII, 196, 1911. 



\section{XXIII}

THE ACTION OF THE SPERMATOZOON UPON THE EG( $;$

II. THE COMBINATION OF AR'IIFICIAL PARTHENOGENESIS AND FERTILIZATION WITH SPERM IN THE SAME EGG

1. Two possibilities exist for the explanation of the activation of the egg by a spermatozoon: either the spermatozoon carries a ferment or a catalyzer into the egg which accelerates the rate of the chemical reactions in the egg; or it removes an obstacle to the development. The rôle of the membrane formation favors the latter idea, since it is not conceivable that all the diverse means by which development can be induced act as ferments; moreover, they only act provided they cause the membrane formation. Hence the membrane formation is the essential factor which induces development at least in the seaurchin egg. This makes it rather improbable that the spermatozoon induces development by carrying a catalyzer into the egg (although it may carry enzymes for other purposes, e.g., heredity).

This idea is supported by other facts. We know that the velocity of chemical reactions is increased if the quantity of the catalyzer is increased; and that if we double the quantity of the catalyzer the rate of velocity is increased in the ratio of either $1: 2$ or $1: \sqrt{2}$. The rate of chemical reactions during development can be measured by the rate of cell division of the egg, as is evidenced through the influence of temperature upon the rate of development (chap. iii). Hence if the spermatozoon caused development by carrying a catalyzer into the egg, the rate of segmentation should be either twice as fast or 1.4 times as fast if two spermatozoa enter the egg as if only one spermatozoon enters. As is well known, cases occur in which two spermatozoa enter the egg. In such cases the egg divides into 
three or four cells instead of into two. The writer has measured the rate of segmentation in these eggs and found that the interval between addition of sperm and cleavage is identical with that of eggs fertilized by only one sperm. This proves that the sperm induces development, either by removing an obstacle e.g., a substance which inhibits development, or by activating a substance contained in the cortical layer which was inactive before and which is needed for development. The obstacle which inhibits development is obviously the state and constitution of the cortical layer of the unfertilized egg. The cytolysis or destruction of this layer (which results in membrane formation) allows the egg to develop.

Another set of experiments confirms this view. It is conceivable that the fatty acids or alkalies by which we call forth the membrane formation might act as catalyzers. If that were the case, the superposition of the fertilization of the egg by sperm and by a treatment with a fatty acid should accelerate the rate of development in such an egg. If eggs are first fertilized by sperm and then treated with butyric acid for that length of time which is required for artificial membrane formation, no acceleration of the rate of cell division is observed. If we call forth artificial membrane formation first by butyrie acid, no spermatozoon can enter the egg since the fertilization membrane is impermeable to a spermatozoon. But we can destroy the membrane by shaking it. If we then add sperm to such eggs, the spermatozoa enter, cause a second membrane formation (in which the membrane fits tightly around the egg), and the eggs develop at room temperature without requiring any further treatment with the hypertonic solution; which indicates that the spermatozoa have entered the egg. In such eggs the rate of cell division is exactly the same as in normally fertilized eggs. ${ }^{1}$

1 The idea that the spermatozoon does not induce development by carrying a catalyzer into the egg was set forth in The Dynamics of Living Matter, 1906. 
Finally, the rate of segmentation is the same in the eggs developing parthenogenetically as in eggs fertilized by sperm. This also proves that the sperm does not induce development by any catalytic influence, but by the removal of an obstacle or an inhibiting factor which obviously exists in the condition of the cortical layer. Formerly the writer had suggested that the removal of this obstacle consisted in the secretion of an inhibitive substance from the egg, ${ }^{1}$ a view which Bataillon ${ }^{2}$ and Lillie $^{3}$ have since adopted; but the fact that complete cytolysis of the unfertilized sea-urchin egg by saponin raises the rate of oxidations in the same way as membrane formation or fertilization suggests that the cytolysis of the cortical layer is the essential removal of the "obstacle."4

The destruction of this cortical layer, the artificial membrane formation, leads to a rapid increase in the rate of oxidations in the egg of the sea-urchin. These oxidations form the foundation of all the further cytological changes in the egg, since their suppression inhibits these cytological changes. It is, therefore, obvious that the point which demands further explanation is the connection between membrane formation or cytolysis and rate of oxidation. It is conceivable that the cortical layer of the unfertilized egg forms a crust impermeable to oxygen, but there is no proof for such an assumption. It is also conceivable that there is present in the surface of the egg a substance which inhibits the development of the egg, and that this substance is altered or removed in the process of membrane formation. It is finally conceivable that the surface

${ }_{1}^{1}$ Loeb, University of California Publications, Physiology, II, 1905.

" Bataillon, "Le problème de la fécondation circonscrit par l'imprêgnation sans amphionyxie et la parthénogénèse traumatique," Arch. de Zool. expér. et gén., XLVI, 101, 1910.

${ }^{3}$ F. Lillie, Jour. Morphol., XXII, 361, 1911.

4 There is a possibility that the egg contains in the cortical layer a catalyzer or substances causing an increase in the rate of chemical reactions in the egg. While in the unfertilized eggs these substances are not able to act, they are rendered available if the cortical layer is cytolyzed. This possibility was set forth by me in Proc. Soc. for Exper. Biol. and Med., VII, No. 4, April 20, 1910. 
layer of the unfertilized egg contains a substance which is needed for development but which is not available until the surface layer is cytolyzed or destroyed otherwise. A further discussion of these possibilities with our present knowledge of the chemistry of the egg is futile.

2. We have seen that the spermatozoon induces development by two different agencies, one of which has a membraneforming effect, while the other must act somewhat like the hypertonic solution in our method of artificial parthenogenesis. We stated that the hypertonic solution has merely a corrective effect since the membrane formation sets the whole machinery of cell division into action; Boveri suggested that the spermatozoon carries in its middle piece the centrosome, the real organ for cell division, into the egg.

The idea that the centrosome is the middle piece of the spermatozoon and that the carrying of this middle piece is the main function of the spermatozoon in inducing development does not agree with the observations. F. Lillie ${ }^{1}$ points out that the middle piece is probably not carried into the egg at all, and he proves that in Nereis any piece of the spermatozoon is able to give rise to centrosome and aster formation. These formations arise in the egg cytoplasm which is in contact with the sperm fragment. The centrosome and aster formations are physicochemical effects induced through the influence of the sperm fragment. Such effects are also induced by the method of artificial parthenogenesis.

Morgan $^{2}$ found that supernumerary astrospheres may arise if fertilized eggs are put into hypertonic sea-water, but the writer is of the opinion that this happens only if the eggs remain too long in the hypertonic solution. Yet it was natural to consider the possibility that the second factor which the spermatozoon must supply for development might be the centrosome;

${ }^{1}$ F. R. Lillie, "Studies in Fertilization," III and IV, Jour. Exper. Zool., XII, $413,1912$.

${ }^{2}$ Morgan, Archiv f. Entwicklungsmechanik, VIII, 448, 1899. 
and that the second treatment with the hypertonic solution might only be needed to create a centrosome de nowo in the egg. The idea was not probable, since we saw that the membrane formation alone suffices to provide the egg with the centrosomes and astrospheres necessary for cell division, as the cogr is able to segment if the temperature is not too high; and serond that it is possible to substitute for the hypertonic solution the suppression of oxidations, a factor which directly suppresses the production of astrospheres. Moreover, the experiments by Hindle have shown that the centrosomes are not formed while the eggs are in the hypertonic sea-water. The following observations and experiments by the writer indicate that the hypertonic solution does not act in these experiments by the creation of astrospheres or centrosomes.

When we put the unfertilized eggs of $S$. purpuratus directly into hypertonic sea-water (without submitting them to the butyric-acid treatment) and if we put them back at different intervals into normal sea-water, we find that if the eggs have been exposed a sufficiently long time (two hours or more) to the hypertonic sea-water a number will begin to segment. These eggs will often go only into the two- or four-cell stage, or sometimes to the eight- or sixteen-cell stage, and then stop developing. They cease to divide, and remain in the resting stage. ${ }^{1}$ Such eggs remain after this perfectly normal and they have the appearance of small unfertilized eggs. If we wait for some time, say twenty-four hours, to make sure that they neither develop nor disintegrate, and add sperm, each one of these blastomeres forms a tightly fitting membrane. They begin to develop in a perfectly normal way and into normal larvae. We are then dealing with eggs which, after having been treated with hypertonic sea-water, were in possession of the whole apparatus for cell division, since they actually had

${ }_{1}$ This phenomenon is much more common in the eggs of $S$. purpuratus than in those of Arbacia. 
segmented, not only once, but many times. Why did they stop developing? Surely not for lack of centrosomes, since the fact that they segmented showed that they possessed them. Our experiment therefore proves that the presence of astrospheres and centrosomes, and their ability to function, does not guarantee the possibility of development. ${ }^{1}$

But it is not necessary to fertilize such eggs with sperm; it suffices to induce membrane formation with butyric acid and they will develop. The artificial membrane formation will have

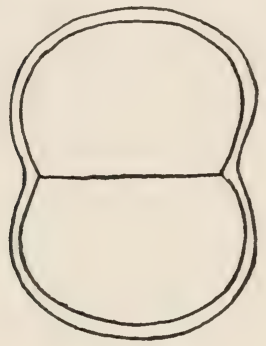

Fig. 73

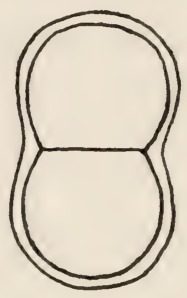

Fig. 74

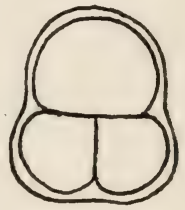

Fig. 75

Frgs. 73, 74, and 75.-Fertilization of blastomeres of an egg with sperm. The blastomeres had been produced on the previous day by treating the egg with a hypertonic solution. They had gone into a resting condition and upon the addition of sperm formed a membrane and segmented regularly as the figures indicate. Fig. 73 represents a dividing intact egg, while Figs. 74 and 75 originated from a blastomere of eggs which had divided into two or four cells on the previous day.

this effect twenty-four hours or longer after the eggs have been treated with the hypertonic solution. The membrane fits rather tightly in this case. Hence eggs which had been caused to develop by treating them for two and a half hours with hypertonic sea-water and which had stopped segmenting for twenty-four hours after reaching the two- or four-cell stage, can be caused to segment regularly and develop into plutei if they are treated with butyric acid ${ }^{2}$ (Figs. 73-75).

This gives the impression that the stoppage of the development after one or more cell divisions had been caused by the

1 Loeb, "Die Superposition von künstlicher Parthenogenese und Samenbefruchtung in demselben Ei," Archiv f. Entwicklungsmechanik, XXIII, 479, 1907.

? Loeb, Jour. Exper. Zool., XV, 201, 1913. 
formation of a new cortical layer like the one which surrounds the unfertilized egg. But the effect of the previous treatment of the egg with hypertonic solution must have lasted, since otherwise the mere membrane formation by butyric acid in these blastomeres would have started a new development, but would also have caused the rapid disintegration of these eggs. What was the irreversible effect of the treatment with hypertonic sea-water? Certainly not the presence of centrosomes and astrospheres, since in the next paragraph we shall show that if the parthenogenetic eggs are fertilized while they are still in possession of centrosomes or astrospheres, they perish. On the contrary these eggs which developed normally after artificial membrane formation had lost the centrosomes and astrospheres they had possessed immediately after the treatment with the hypertonic solution.

We have stated in a previous chapter that the rate of oxidations is increased six times by a spermatozoon. In eggs treater for two and a half hours with hypertonic sea-water the rate of oxidations is increased less, often only about 2.6 times, and the increase is apparently not exactly the same in the eggs of different females. We noticed also that after some time the rate of oxidation decreases. Could it be possible that the cessation of segmentation is due to the fact that the rate of oxidation, which at the beginning was rather low, falls below the minimum limit, and that this causes the standstill of development? This standstill, if prolonged, would lead to the loss of the centrosomes (and astrospheres), just as these organs are lost in the sea-urchin egg after the maturation division.

This leaves one point still unexplained, namely, the irreversible after-effect of the treatment with the hypertonic solution. As we stated in a previous chapter, this after-effect may consist in the fact that the treatment with a hypertonic solution leads to the formation of a substance which remains in 
the egg permanently and which saves it from the disintegration which follows membrane formation.

3. In the preceding experiment blastomeres were fertilized which had ceased to segment for about twenty hours. The experiment leads, however, to in entirely different result if sperm is added while the blastomeres are in active parthenogenetic cell division. If we add sperm to such eggs (S. purpuratus), they form a fertilization membrane, but they do not develop very far. The entrance of a spermatozoon into the blastomere of an egg which is in active parthenogenetic segmentation leads to the rapid disintegration of the egg or blastomere; while the entrance of a spermatozoon into a parthenogenetic blastomere which has gone back into the resting stage for some time, can cause the development of the blastomere into a normal pluteus. What causes this difference? Possibly the fact that the blastomere which had gone back into the resting stage for some time has lost centrosomes and astrospheres, while the egg which is in active parthenogenetic cell division possesses both organs.

These blastomeres in which fertilization by sperm is superimposed upon artificial parthenogenesis while the eggs are still in active development behave like eggs fertilized by more than one spermatozoon. Driesch found that eggs which had been fertilized by more than one spermatozoon do not, for the most part, develop beyond the blastula stage. ${ }^{1}$ Boveri has explained this by the fact that such an egg possesses more than two astrospheres. ${ }^{2}$ As we know, the division of the nucleus into two daughter nuclei depends upon the fact that the dividing egg forms two astrospheres. This is the case not only in fertilization by sperm, but also in the development started by the methods of artificial parthenogenesis. But

1 Driesch, "Ueber die Furchung doppelbefruchteter Eier," Zeitschr. $f$. wissenschft. Zool., LV, 1892.

${ }^{2}$ Boveri, Zellenstudien, Heft 6; Die Entwicklung dispermer Seeigeleier, Leipzig, 1907. 
if two spermatozoa enter the egg, not only two but three or four astrospheres are formed. When we cause the segmentation of an unfertilized egg by treating it with hypertonic sea-water, two astrospheres are formerl (unless the eggs have been too long exposed), and the division of the nucleus takes its regular course. But if the eggs are left too long in the hypertonic solution, they divide into more than two cells at once when they are put back into normal sea-water. According to Morgan, this is owing to the formation of more than two astrospheres. Such eggs do not develop into normal larvae.

Why is it, then, that only those eggs develop into vigorous larvae in which the first division leads to the formation of only two cells? To this question Boveri gives the following answer. In normal nuclear division, each chromosome splits lengthwise into two similar pieces, one of which goes into each of two astrospheres, and into the new nucleus; so that, therefore, after the division is accomplished, each of the two daughter nuclei contains, quantitatively and qualitatively, the same nuclear material. But if two spermatozoa enter an egg, then three or four astrospheres are formed, and, correspondingly, three or four daughter cells. But since each chromosome of the mother nucleus divides only into two parts, it is naturally impossible that in this case each daughter nucleus will contain a half of each chromosome of the mother nucleus. Boveri and many other authors assume, and with good reason, that the different chromosomes of the nucleus are physiologically dissimilar. It will therefore be apparent that equivalent and fully potent daughter nuclei will accordingly result only from regular nuclear division with two astrospheres; and that when three or more astrospheres are present the single daughter nuclei will not contain the full number and, as a rule, not qualitatively the same nuclear material.

This hypothesis, then, would also explain why, under certain conditions, the superposition of artificial parthenogenesis 
and fertilization with sperm curtails the life of the larvae, and prevents them from reaching the pluteus stage. For if we start the eggs developing by the old osmotic method, i.e., with gelatinous membrane formation, and then fertilize a cell of the two- or four-cell stage with sperm while they are still ready to segment, the next division of each of these blastomeres will lead to the formation not of two cells, but of three or four. To the astrospheres which are already formed in the cell by the onset of parthenogenetic development, there are added also the astrospheres formed through the influence of the spermatozoon; thus the next division of the nucleus of such a cell leads to the formation of more than two daughter nuclei, which are also usually qualitatively unlike. They are therefore in the position of an egg fertilized by two spermatozoa, and so have the same restricted vitality as is possessed by such eggs. It is possible, however, that fragments which are fertilized by sperm while they are in the process of parthenogenetic cell division suffer more than normal eggs fertilized by two spermatozoa. 


\section{XXIV}

\section{(ONDITIONS FOR THE MATURATION OF THE EGG}

1. Before we discuss experiments upon artificial parthenogenesis in other forms besides sea-urchins, we must examine the phenomena presented by the ripening egg. We mentioned in the introduction that development proper, i.e., the segmentation of the egg, must be preceded by its "maturation." This is a process which consists morphologically in the reduction of the nucleus by two divisions and the extrusion from the egg of parts of the nucleus as polar bodies. This process of maturation shows a connection with the process of fertilization in so far as in many forms maturation is initiated by the entry of a spermatozoon into the egg. In other forms maturation proceeds spontaneously either in the ovary (sea-urchin) or after the eggs have been shed into sea-water (starfish), and until this happens the spermatozoon does not or cannot enter the egg. Whereas one finds that the majority or very many of the eggs are ripe in the ovary of the sea-urchin, this is seldom the case with the starfish; still the eggs of the starfish usually mature quickly on being put into sea-water. When the eggs of the starfish are removed from the ovary, they possess as a rule large, conspicuous nuclei. Maturation consists in the reduction of the size of the nucleus by a double division and the extrusion of the polar bodies. The time that elapses before these processes take place in sea-water differs for the eggs of different starfish. This probably depends on the fact that the eggs of different females are not all in the same condition of ripeness. Experiments which I performed a few years ago upon the maturation of the eggs of the starfish (Asterias forbesii) in sea-water indicated that maturation is accelerated by two of the substances present in sea-water, viz., the hydroxylions and the oxygen. If 
the sea-water is neutralized, or slightly acidified by the addition of acid, maturation, as a rule, does not take place, although otherwise it occurs with rapidity. If the eggs of the same starfish are distributed among solutions which differ only in the concentration of the $\mathrm{HO}$ ions, it will be found that the rapidity with which maturation occurs increases within certain limits with the concentration of the $\mathrm{HO}$ ions. As we shall see, it is possible to evoke development in ripe starfish eggs by the use of acid; hence the very method which promotes further development in mature eggs prevents the immature egg from maturing.

The writer found that in different dishes the percentage of matured eggs was not always the same even in similar concentrations of hydroxylions. This indicated the existence of another factor in addition to the concentration of the hydroxylions. It soon turned out that where the eggs lay in a heap maturation proceeded more slowly than where they were spread out in a thin layer. This gave rise to the suspicion that the supply of oxygen might be important for the maturation of the eggs. Experiments in which the oxygen of the sea-water was driven out by hydrogen, as well as those in which KCN had been added to the sea-water, proved that in these cases the eggs failed to mature in spite of the presence of the hydroxylions. ${ }^{1}$

2. In many annelids the entrance of the spermatozoon into the egg causes first the extrusion of the polar bodies, and afterward development. The eggs of Polynoe, however, can be induced to mature even in sea-water without spermatozoa by adding to the sea-water some $\mathrm{NaOH}$, or, better still, $\mathrm{NH}_{4} \mathrm{OH}$, in the proportion of about 1.5 c.c. $\mathrm{N} / 10$ base to 50 c.c. of sea-water. When taken out of the animal the eggs of Polynoe are of irregular shape; they are surrounded by a thick chorion and possess a large nucleus. In ordinary sea-water the chorion

${ }^{1}$ Loeb, "Ueber Eireifung, natürlichen Tod und Verlängerung des Lebens beim unbefruchteten Seesternei, usw.," Pfüger's Archiv, XCIII, 59, 1902; Untersuchungen, p. 237. 
is dissolved or liquefied in the course of several hours (at $15^{\circ}$ ('.) and the eggs then become spherical. The maturation of the egg begins, but is not completed, as the polar bodies are not extruded. If the concentration of the hydroxylions in seawater is increased (by the addition of $\mathrm{NaOH}$ or $\mathrm{NH}_{4} \mathrm{OH}$ ) the polar bodies are also extruded and the eggs are able to develop into larvae. But if no alkali is added to the sea-water the eggs go to pieces in the course of the next twentyfour hours by disintegrating into small drops or fragments. From these experiments it follows that the slight concentration of hydroxylions present in sea-water sets in action the maturation processes in the egg, but not enough to complete this process for the egg.

If a trace of saponin is dissolved in sea-water and the eggs of Polynoe (that have been a few hours in sea-water) are placed for one minute in this weak saponin solution, they form a perfect fertilization membrane and in the course of from five to thirty minutes extrude the polar bodies, after having been transferred to normal sea-water. The eggs must, however, be thoroughly washed in sea-water to remove every trace of saponin. ${ }^{1}$

In the egg of Chaetopterus, another annelid, maturation starts in sea-water, but cannot be completed unless a spermatozoon enters the egg. As has already been noted, Mead observed that the addition of some potassium to the sea-water brought maturation to completion. ${ }^{2}$ In Thalassema also the spermatozoon enters the immature egg and causes both the extrusion of the polar bodies and development. Lefevre found that the treatment of the eggs of this form with acid caused both their maturation and development. ${ }^{3}$

${ }^{1}$ Loeb, "Ueber die Entwicklungserregung unbefruchteter Annelideneier (Polynoe) mittels Saponin und Solanin," Pflüger's Archiv, CXXII, 448, 1908.

2 Mead, Biological Lectures delivered at Woods Hole, 1898 (Boston: Ginn \& Co.).

${ }^{3}$ Lefevre, "Artinicial Parthenogenesis in Thalassema mellita." Jour. Exper. Zool., IV, 91, 1907 . 
It is a remarkable fact that, so far as our present knowledge goes, with regard to those eggs in which the entry of the spermatozoon is the determining factor both of maturation and development, the same chemical substances that will induce artificial maturation also induce development; whereas in the egg of the starfish, in which the spermatozoon does not enter until after maturation, that is apparently not the case.

In nature everything is so adjusted that when the eggs are laid they are (usually, if not invariably) susceptible of immediate fertilization. Hence, what we attain in these experiments by artificial means must be accomplished by the organism in the natural order of affairs. I had started to investigate these processes, and it appeared to me that they might depend on the effect of the blood or circulatory fluid. If an investigator obtains by chance eggs which have almost matured within the organism, he cannot, of course, fail to observe that they are able to complete the maturation process without the aid of the processes used by us. But it would be wrong to follow Mathews and conclude from a casual observation that alkali may not be necessary for maturation because he observed in one case that (all ?) the eggs of a starfish completed their matiration in a neutral $\mathrm{NaCl}$ solution. There is nothing surprising in this, as in starfish the eggs of the same female show different degrees of maturity, in that a few mature at once in sea-water, others slowly, and others again very late, or perhaps never; while by a temporary raising of the concentration of the hydroxylions the maturation generally can be accelerated.

Physiology will have one day to answer the question why in the eggs of many animals the spermatozoon causes both maturation and development, whereas in other cases maturation takes place spontaneously, the egg afterward entering into a resting condition, out of which it is aroused only by fertilization. Investigations upon the germination of oily seeds give us a hint as to one of the possibilities here present. For if some substance 
such as an acid must be formed before the one or more enzymes necessary for development can be activated, we can understand that the absence of this substance must lead to a pause in the life-cycle of the organism. The introduction of this substance from without, or the initiation of its production within, the cell will then effect development.

It may be well to remember also in this connection that the unfertilized eggs of purpuratus can be induced by a hypertonic solution to segment into two or four cells, without developing further. They go into a resting stage again, from which they can be aroused by causing artificial membrane formation. It would be very important to know why these eggs did not go on developing after they had started to segment under the influence of the treatment with a hypertonic solution.

3. It appears to be very generally the case that maturation can be induced by treating eggs in the oocyte stage with sodium hydrate; for I have obtained results similar to those recorded for Polynoe, with the eggs of Nereis, and also of Sipunculus. Unripe eggs which refused to mature in sea-water did mature when exposed for a few hours to hyperalkaline sea-water at $15^{\circ} \mathrm{C}$. With regard to the maturation of the eggs of Nereis at Pacific Grove, I made an observation that may perhaps be important from the point of view of the mechanism of maturation and membrane formation. In the immature egg of Nereis there is a greenish-blue pigment distributed evenly over the entire surface. This pigment layer contains many small, highly refracting droplets which may be fat particles. On treating the eggs with hyperalkaline sea-water, so that they mature, the following changes are observed: first, a membrane is lifted up, comparable to the fertilization membrane of the sea-urchin egg; second-but long after membrane formation-the numerous droplets (fat?) flow together into a few large drops; third, the greenish mass, which had previously formed an even layer 
over the whole egg, contracts and gathers the fat-droplets into one hemisphere of the egg. Hence there arise two phases on the surface of the egg, one of which apparently contains no fat or pigment, while the other obviously contains both.

This observation led me to consider whether the importance of fat-solvents as well as, in part, that of the alkalies at the maturation of the egg may not perhaps consist in the liquefaction of solid layers of fat. In the egg of Heteronereis (of Pacific Grove) there is a confluence of the droplets and a migration of the larger drops and of the pigment mass to one hemisphere of the egg, and this could casily be explained as the effect of surface tension. There is obviously an analogy between the artificial production of maturation and of membrane formation. In both cases, the process of solution of the chorion or of a substance lying at the surface of the egg appears to play a part. 
ARTIFICIAI: PARTHENOGENESIS IN THE EGGS OF THE: STARFISH

1. The experiments on artificial parthenogenesis in starfish differ in an essential point from those in the sea-urchin. The sea-urchin egg undergoes maturation and remains at a state of rest while in the ovary. The causation of development means, therefore, a transition from the resting state to an active state, and this is accompanied by a rapid increase in the rate of oxidations.

The conditions in the starfish egg are different. When these eggs are taken out of the ovary they are as a rule immature. As soon as they are laid, a number of eggs, which varies with the individual starfish, begin to mature. Not until one or both polar bodies are thrown out can a spermatozoon enter. As soon as this critical stage is reached the egg can be fertilized by sperm. If it is not fertilized by sperm at that time it perishes in a few hours. There is then this difference between the state of the sea-urchin egg and that of the starfish egg at the time of fertilization: The starfish egg is in a state of activity since the maturation divisions are just completed, while the seaurchin egg is at rest. This finds its expression in the fact that Wasteneys and I found that the entrance of a spermatozoon into the starfish egg does not increase the rate of oxidations. ${ }^{1}$ It harmonizes with this result that the writer found that the process of maturation of the starfish egg requires conditions similar to those for the development of the sea-urchin egg: If oxygen is removed from the sea-water or $\mathrm{KCN}$ is added the eggs remain immature. Moreover, in an alkaline solution the eggs ripen more rapidly than in a neutral or acid solution.

${ }_{1}^{1}$ Loeb and Wasteneys, Archiv f. Entwicklungsmechanik, XXXV, 555, 1912. 
We have seen that the spermatozoon of any species has substances which are able to call forth the development of the sea-urchin egg. It harmonizes with this fact that the methods of artificial parthenogenesis which are effective in the sea-urchin must also be effective in other forms; although we must not forget that the substances used in artificial parthenogenesis are analogous in their effects but not necessarily identical with those contained in the spermatozoon. This explains why in each form quantitative modifications of the general method are required.

We shall start by recounting experiments on the eggs of the Californian starfish Asterina, ${ }^{1}$ the eggs of which form a splendid fertilization membrane after the entrance of a spermatozoon.

It was found at once that the formation of this membrane can be induced by the same agents in the case of the eggs of Asterina as in those of the sea-urchin; but there is a difference in the concentration of the substances required.

When the mature eggs of Asterina are placed in 50 c.c. of sea-water in which 1 c.c. of benzol or amylene has been shaken up, they all immediately form membranes that are indistinguishable in appearance from those formed after the entrance of a spermatozoon. If the eggs are not removed from the benzol or amylene sea-water immediately after membrane formation, they succumb to cytolysis.

If one of the lower fatty acids is used instead of the hydrocarbon, no membranes are formed so long as the Asterina eggs remain in the acidified sea-water; but a membrane is formed at once after the eggs have been transferred to ordinary seawater, provided that the time of exposure to the acid has been correctly chosen. Thus, if the eggs are placed for two minutes in a mixture of 50 c.c. of sea-water +5 c.c. $\mathrm{N} / 10$ acetic acid,

${ }^{1}$ Loeb, "Artificial Membrane Formation and Chemical Fertilization in a Starfish (Asterina)," University of California Publications, Physiology, II, 147, 1905; Untersuchungen, p. 349. 
they form beautiful membranes upon transference to ordinary sea-water. Butyric and eaproic acids have a similar effect, while $\mathrm{HCl}$ and $\mathrm{HNO}_{3}$ have much less or even no effect.

When the eggs of Asterina are removed from the ovary, they are, as we have seen, immature, i.e., they possess a large nucleus. These eggs cannot be fertilized by sperm; it is also impossible to produce membrane formation in such eggs by means of an acid. Neither fertilization nor artificial membrane formation is possible before the large nucleus has broken up and the extrusion of the polar bodies has started.

After artificial membrane formation, the starfish eggs begin to divide. But in this they exhibit a fundamental difference in their behavior from sea-urchin eggs in which membrane formation has been produced by a fatty acid. For whereas at room temperature the eggs of the Californian sea-urchin begin to disintegrate after mere membrane formation-unless they have been treated with hypertonic sea-water or with KCN-the starfish egg is better off. For some of the starfish eggs that have formed a membrane as a result of exposure to butyric acid segment regularly and develop into normal larvae; though the rest disintegrate, like sea-urchin eggs, after membrane formation. In other words, the starfish eggs differ from those of the sea-urchin in this, that they do not depend upon the second corrective factor with the same degree of necessity.

In one experiment the eggs of an Asterina began to extrude their polar bodies between 10:30 and 10:40. Some of the eggs were then fertilized with sperm, while others were exposed for one-half to one and a half minutes to the action of 6 c.c. N/10 butyric acid +50 c.c. of sea-water. In both lots all the eggs, except a few immature ones, formed a typical fertilization membrane. In about two hours all the sperm-fertilized eggs entered the two-cell stage, and at about the same time some 10 per cent of the eggs treated with butyric acid also began to 
divide. Segmentation proceeded in both groups. Five hours after the butyric-acid treatment or sperm fertilization, respectively, the position was as follows: The eggs fertilized with sperm were all in the sixteen-cell stage. Only 10 per cent of those treated with butyric acid had divided, and they were in the eight- to sixteen-cell stage. The others had not divided and showed no change. But soon after a change overtook them. Small clear droplets formed irregularly at the surface of the eggs similar to those extruded from sea-urchin eggs during heat or alcohol cytolysis. All the eggs of Asterina which formed these drops disintegrated. Often only a part of the Asterina eggs showed this formation of drops. In this case, only those eggs disintegrated which exhibited this formation of drops on their surface. The eggs that showed no drop formation, and segmented normally (i.e., about 10 per cent of the eggs with butyric-acid membrane), developed into normal larvae just like the eggs fertilized with sperm, all of which produced normal larvae.

These experiments are very interesting, since they show that a not inconsiderable percentage of the eggs of Asterina will not disintegrate after artificial membrane formation, but will develop. These eggs therefore behave as if they already contained the substance or structure which we assume is formed under the influence of the second treatment. We may perhaps be justified in stating that in Asterina only 90 per cent of the eggs disintegrate after artificial membrane formation, while 10 per cent are able to develop. All the eggs of the seaurchins (S. purpuratus and Arbacia) disintegrate after artificial membrane formation unless they undergo a second treatment. But some of the eggs of the sea-urchins at Naples seem to be able to develop after mere artificial membrane formation.

2. Ralph Lillie in working on the eggs of a starfish of the Atlantic coast, Asterias forbesii, found that a short heating of the eggs to between $35^{\circ}$ and $38^{\circ} \mathrm{C}$. caused them to form a 
typical fertilization membrane. The length of exposure necessary for this was about 70 seconds at $35^{\circ}, 40$ to 50 seconds at $36^{\circ}$, about 30 seconds at $37^{\circ}$, and about 20 seconds at $38^{\circ}$. (These eggs can withstand a higher temperature than the eggs of S. purpuratus, which are killed too quickly at temperatures that induce membrane formation $\left[34^{\circ}\right.$ to $35^{\circ} \mathrm{C}$.] to be able to develop subsequently.) Lillie observed further that some of the starfish eggs, in which a membrane formation is produced by rise of temperature, develop without any further treatment. As in my experiments with Asterina, the time of membrane formation must be accurately chosen; for the time is not suitable unless the eggs are ready to give off the first polar body.

But when Lillie put the eggs after artificial membrane formation in sea-water to which enough $\mathrm{KCN}$ had been added to make it about a $\mathrm{N} / 2,000$ solution of $\mathrm{KCN}$, many more eggs. developed than in cases where this treatment was not used. ${ }^{1}$ Now this is exactly the same result that I obtained with the eggs of sea-urchins after artificial membrane formation (see chap. ix). In this case the egg was given more time to produce the second factor before starting on its development and hence more eggs survived.

3. My first experiments with starfish were carried out in 1901, when Neilson and I found that the eggs of Asterias forbesii could be made to develop when maturation had taken place by putting them for three to twenty minutes in sea-water to which some acid had been added (100 c.c. of sea-water+ 3 to 5 c.c. $\mathrm{N} / 10 \mathrm{HCl}$ or $\left.\mathrm{HNO}_{3}\right)^{2}$. If the eggs were then transferred to ordinary sea-water, some of them began to develop into larvae.

1 R. S. Lillie, "Momentary Elevation of Temperature as a Means of Producing Artificial Parthenogenesis in Starfish Eggs and the Condition of Its Action," Jour. Exper. Zool., V, 375, 1908.

${ }^{2}$ Loeb and Neilson, Pflüger's Archiv, LXXXVII, 594, 1901; Untersuchungen, p. 278 . 
Delage $^{1}$ found that the ripe eggs of Asterias glacialis developed into larvae if he used carbonic acid in the place of the acids employed by us. He put the eggs after maturation in sea-water saturated with carbonic acid for five to forty-five minutes. As shown by the experiments of Godlewski and myself, carbonic acid is one of the acids suitable for membrane formation; it diffuses easily into the egg and there brings about those changes which underlie membrane formation. The greater efficiency of $\mathrm{CO}_{2}$ is due to the fact that it is a very weak acid and hence diffuses easily into the egg.

This idea is supported by Delage's observation that the number of Asterias eggs that develop after the carbonic-acid treatment is further increased if the oxygen is removed for some time from the solution (Delage, 1907), though he does not state why this should be so. We can understand this fact from the observation which the writer made on the egg of the sea-urchin that, after membrane formation, lack of oxygen gives the egg an opportunity to recover from the threatening disintegration. The same thing occurs in the starfish egg; and we can understand why more eggs of the starfish develop if they are kept without oxygen during and for some time after the exposure to $\mathrm{CO}_{2}$, than if they are all the time in contact with oxygen. The reason for this is to be found in the fact that treatment with $\mathrm{CO}_{2}$ causes the development by calling forth the change in the cortical layer of the egg. If the eggs begin to develop under these conditions, a few reach the larval stage, while many disintegrate; but if the development is retarded for a while, all the eggs have a chance to recover from the threatening disintegration or to produce the substance which saves them from the threatening disintegration. Unfortunately Delage has overlooked my experiments upon the beneficial effect

1 Yves Delage, "Nouvelles recherches de la parthénogénèse expérimentale chez Asterias glacialis," Arch. de Zool. expér. et gén., 3. S., X, 213, 1902; "Élevage des larves parthénogénétiques d'Asterias glacialis," ibid., 4. S., II, 27, 1904; " Nouvelles expériences de parthénogénèse expêrimentale," ibid., 4. S., III, CLXIV, 1905; Compt. rend. Acad. Sc. CXLV, 218, 1907. 
of lack of oxygen or of addition of KCN upon the seaturchin egg after membrane formation, and hence has not recognized that his results harmonize with my experiments.

4. Some eggs of the starfish possess a certain tendency to develop spontaneously into larvae without any evident external stimulus. The percentage of these "naturally" parthenogenetic eggs fluctuates, and is always very small. It is also possible that this tendency toward natural parthenogenesis is found only in the eggs of certain females. Mathews discovered that in the case of Asterias forbesii the number of these eggs that reach the larval stage can be increased by shaking or agitating them. The amount of shaking necessary varies with different cultures: sometimes a very vigorous shaking in a test tube is required, at others the mere transference of the eggs from one dish to another by means of a pipette is sufficient. The most favorable time for obtaining this result is about three hours after the liberation of the eggs from the ovary, probably because they are then ripe.

The key to the explanation of this experiment is perhaps to be found in Mathews' observation that these eggs after being agitated or shaken form a fertilization membrane and then have the appearance of fertilized eggs. ${ }^{1}$ Hence we must regard this membrane formation as the probable impulse to development in these experiments. But how can membrane formation be produced by mere agitation? It seems to me that this can be understood if we suppose that it depends upon the destruction of an emulsion in the cortical layer of the egg. It is conceivable that in the eggs of certain forms the stability of this emulsion is so small that mere shaking would be enough to destroy it and thus induce membrane formation, and so development.

This hypothesis is supported by an observation recently made by the writer. If the ovary of a starfish is subjected to moderate pressure and the eggs are afterward removed, it is

${ }^{1}$ A. P. Mathews, "Artificial Parthenogenesis Produced by Mechanical Agitation," A m. Jour. Physiol., VI, 142, 1901. 
found that a greater or smaller number of them have formed membranes, and have swelled up and cytolyzed. It appears to me that this observation can be explained on the assumption that the pressure destroys in the egg an emulsion that was just near the limits of stability.

This assumption also explains why occasionally eggs of a starfish may develop "spontaneously." Such eggs probably form a fertilization membrane spontaneously. The case is similar to the spontaneous segmentation of the sea-urchin egg, with this difference, that the sea-urchin egg almost always disintegrates after a mere membrane formation, while some of the starfish eggs can develop without a second treatment.

Some authors have stated that "any stimulus induces the egg to develop." This declaration is of course incorrect for the sea-urchin egg, and no authority has stated it for this egg; but things of the kind have been credited of the starfish egg. The statement is correct within the limits in which it also holds for the processes of cytolysis. Cytolysis can be induced by very different agencies, including mechanical disruption, certain chemicals, heat, and high and low concentrations of the solution. The reason for this probably consists in the fact that cytolysis consists in the destruction of an emulsion, and that this end can be attained by very different methods. It is, however, obviously as untrue to say that "any stimulus whatsoever" will cause the eggs of the starfish to develop, as it would be to assert that every stimulus will cause cytolysis or haemolysis. It is needless to say that such an assertion also overlooks the rôle of the second factor in the causation of development.

The methods of artificial parthenogenesis for the egg of the starfish resemble those of the sea-urchin egg very closely. The main difference between the two types of eggs exists in regard to the necessity of the second factor of fertilization, which does not seem to be required in the case of a small percentage of the eggs of the starfish. 


\section{XXVI}

\section{ARTIFICIAL PARTHENOGENESIS IN THE EGGS OF ANNELIDS}

1. The eggs of the annelids which we shall consider here differ from the eggs of both sea-urchin and starfish in that the spermatozoon enters the immature egg and thus sets in motion the giving-off of the polar bodies as well as the develop)ment of the egg. In the case of the starfish the spermatozoon must enter immediately after the maturation division has begun or is completed; in the case of the sea-urchin the egg can remain for some time in a resting condition after the polar bodies have been given off.

We shall first consider the phenomena of fertilization in Polynoe, an annelid of the Pacific coast. When the eggs are taken out from the animal they are irregular in outline and are surrounded by a thick chorion. The large nucleus is plainly visible. When the unfertilized eggs are put into seawater (which contains no sperm) the chorion is dissolved in the sea-water after the lapse of several hours, and the egg then becomes spherical and black. Maturation does not, however, proceed farther if the egg remains in sea-water. I put the eggs of Polynoe into sea-water and left them there for between two and four hours at $15^{\circ} \mathrm{C}$., until they had become round. They were then placed in a watch glass with 4 c.c. of seawater to which had been added 15 drops of a very weak solution of saponin in sea-water. Now the eggs which had been treated with saponin for one minute, and then washed, formed a beautiful fertilization membrane and began to extrude their polar bodies in from five to thirty minutes. Some of the eggs developed into swimming larvae in the course of from eighteen to twenty-four hours, in most cases without undergoing 
segmentation; a few segmented into two or four cells, but not farther. One often saw eggs that had remained stationary in the two-cell stage, swimming about as larvae, although they always consisted of merely the two cells. The eggs developed very slowly into larvae in the course of from eighteen to twenty-four hours. Fertilized eggs reached the trochophore stage in eight hours at the same temperature. ${ }^{1}$ These experiments in which the eggs of Polynoe are made to develop by merely producing membrane formation by means of saponin (or solanin) are not invariably successful, and the number of developing larvae was often very small. But they indicate that the development of the egg depends upon the same conditions as in the sea-urchin egg, namely upon membrane formation.

It was next tried whether or not development could be made more normal by exposing the eggs to hypertonic sea-water after membrane formation. This proved to be the case. Immature eggs freshly taken from the animal were subjected to treatment with saponin. Two drops of a very weak solution of saponin were added to 5 c.c. of sea-water, and after four minutes the eggs were transferred to ordinary sea-water and freed from saponin by being washed four times. The eggs did not form a membrane in the saponin solution, but the chorion was dissolved, and the eggs rounded off. They were then put into hypertonic sea-water ( 50 c.c. of sea-water +8 c.c. $2 \frac{1}{2} \mathrm{~m}$ $\mathrm{NaCl}$ ), and portions of the eggs were replaced in ordinary seawater, after exposures of $60,104,140,162$, and 180 minutes respectively. All the eggs formed fertilization membranes in the hypertonic solution; this was a secondary effect of the exposure to saponin. However, the eggs placed in sea-water as a control also formed a membrane there.

The control eggs, and those exposed to the hypertonic sea-water after the saponin treatment for only one hour, did

' Loeb, "Ueber die Entwicklungserregung unbefruchteter Annelideneier (Polynoe) mittels Saponin und Solanin," Pflüger's Archiv, CXXII, 448, 1908. 
not divide, and did not in this experiment develop into larvae. On the other hand, practically all of the eggs treated with saponin that had been two hours and twenty minutes in the hypertonic sea-water segmented, but reached only the eight-cell stage in four hours after removal from the hypertonic sea-ivater. Four hours later these eggs had reached the trochophore stage and were swimming about. But it is doubtful whether they had undergone any further segmentation. Eggs that had been exposed only to hypertonic sea-water, without previous membrane formation under the influence of saponin, did not develop into larvae. This experiment was repeated, and it was then found that, though by producing membrane formation by means of saponin a few eggs of Polynoe can indeed be made to develop into larvae, a subsequent exposure to hypertonic seawater causes many more eggs to develop. The rate of development is also increased by this method. The analogy in behavior between the eggs of Polynoe and of the sea-urchin is obvious, although not complete, since the sea-urchin eggs all develop in this case by segmentation, while the eggs of Polynoe develop without or only with incomplete segmentation.

The eggs of Polynoe resemble the eggs of the starfish, in so far as the membrane formation suffices for the causation of development of some eggs, and in so far as the addition of the second corrective factor increases the number of eggs capable of development.

2. There is yet another method by which the unfertilized eggs of Polynoe can be made to develop. This is by raising the alkalinity of the sea-water. ${ }^{1}$

If the concentration of the hydroxylions in sea-water be raised by the addition of a considerable amount of sodium hydrate, not only can the unfertilized eggs of Polynoe be induced to ripen, but a small percentage of them will segment into two or four cells; and sometimes a large percentage or eren all the

${ }^{1}$ Loeb, "Ueber die allgemeinen Methoden der künstlichen Parthenogenese," Pfüger's Archiv, CXVIII, 572, 1907. 
eggs will develop into larvae without segmentation. In one experiment the unfertilized eggs of a female were placed in 50 c.c. of sea-water +1.5 c.c. $\mathrm{N} / 10 \mathrm{NaOH}$ and left for some time in that solution. Four hours later all the eggs had formed a definite membrane and extruded both polar bodies. After eight hours a small number of the eggs were in the two-cell stagecleavage was quite normal-but the rest remained undivided. Twenty-four to forty-eight hours after the start of the experiment the majority of the eggs had developed into swimming larvae. But, externaliy, segmentation did not appear to have extended beyond the two- or four-cell stage. The control eggs that had been left in ordinary sea-water had not matured, and in the course of twenty-four hours they fell to pieces. This oft-repeated experiment proves, therefore, that the unfertilized eggs of Polynoe can be made to mature and develop into larvae by exposing them for some time to hyperalkaline sea-water.

But there is one important consideration that must be taken into account, and that is a favorable supply of oxygen. The eggs developed in large numbers only when contained in lightly covered watch glasses, while the eggs left in the big dish in which they were separated from the air by some $2 \mathrm{~cm}$. of water matured and developed in much smaller quantities. Perhaps, too, the neutralization of surplus alkali by the carbonic acid of the air is effected much more quickly in the watch glass than in the larger dish. I convinced myself, however, that if the eggs are transferred from the hyperalkaline to normal sea-water, the formation of larvae occurs only if the eggs have been at least from four to six hours in hyperalkaline sea-water; and even then the results are much worse than when the eggs remain all the time in the hyperalkaline solution. If, however, the treatment with a hypertonic solution was combined with that by alkali, less alkali could be used and more eggs segmented and the segmentation advanced farther (especially in the case of weak bases). 
It was easily discovered that, as in the egg of purpuratus, a neutral hypertonic solution cannot produce rlevelopment in the egg of Polynoe; for this effect is possible only in alkaline hypertonic solution. To 50 c.c. of a neutral $\mathrm{m} / 2$ van't Hoff solution +9 c.c. $2 \frac{1}{2} \mathrm{~m} \mathrm{NaCl}$ there was added 0.5 c.c. $\mathrm{N} / 10$ $\mathrm{NaOH}$; another such hypertonic solution was prepared without the alkali. After two hours in these solutions the eggs were transferred to normal sea-water. Most of the eggs taken from the neutral hypertonic solution formed no membrane in normal sea-water; they did not extrude polar bodies, segment, or develop. On the other hand, about 1 per cent of the eggs that had been in the alkaline hypertonic solution segmented perfectly regularly in the course of a few hours as far as the eightcell stage, and the majority of the eggs developed into swimming larvae. The development of the eggs was generally quicker than in the case of unfertilized eggs exposed to hyperalkaline but not hypertonic sea-water.

Again, eggs that remained between two and six hours in the neutral hypertonic solution did not develop when subsequently transferred to ordinary sea-water. But when the unfertilized eggs of Polynoe were first put for two hours into a neutral hypertonic solution and then for not more than four hours into 50 c.c. sea-water +0.5 c.c. $\mathrm{N} / 10 \mathrm{NaOH}$, large numbers of them developed into swimming larvae upon transference to normal sea-water. But if the eggs were put for four hours into 50 c.c. sea-water +0.5 c.c. $\mathrm{N} / 10 \mathrm{NaOH}$ without being exposed to the hypertonic solution, as a rule no eggs, or only a few, developed. ${ }^{1}$

It is hardly necessary to point out the analogy between the effect of alkaline and hypertonic sea-water upon the eggs of sea-urchins and of Polynoe. Like saponin, the alkali produces solution of the chorion and membrane formation in Polynoe.

1 Loeb, “Ueber die allgemeinen Methoden der künstlichen Parthenogenese," Pfüger's Archiv, CXVIII, 572, 1907. 
This results in the extrusion of the polar bodies and development. But the effect of the alkaline solution is enhanced by the treatment of the eggs with hypertonic sea-water.

3. We have already stated that the weak bases are much more efficient in causing artificial parthenogenesis than the strong bases. The best effects were produced with the amines, especially butylamine and benzylamine; next in efficiency were $\mathrm{NH}_{4} \mathrm{OH}$ and trimethylamine, and the weakest effects were produced by the strong bases $\mathrm{NaOH}$ and tetraethylammoniumhydroxide.

To give an example: to 50 c.c. hypertonic sea-water (100 c.c. sea-water +18 c.c. $2 \frac{1}{2} \mathrm{~m} \mathrm{NaCl}$ ) were added 1.5 c.c. $\mathrm{N} / 10$ $\mathrm{NaOH}$, benzylamine, and $\mathrm{NH}_{4} \mathrm{OH}$, respectively. Of the eggs that had been forty-five minutes in benzylamine, 40 per cent developed; the same result was produced by an exposure in $\mathrm{NH}_{4} \mathrm{OH}$ of 80 minutes. An exposure of 115 minutes in $\mathrm{NaOH}$ gave a much smaller number of larvae. Those treated with $\mathrm{NaOH}$ reached the swimming stage as a rule much later than those treated with an amine. The eggs treated with the amine, especially with butylamine and benzylamine, segmented almost normally, although much more slowly than the eggs fertilized with sperm.

In repeating these experiments with sea-water made alkaline (but not hypertonic), the writer was struck with the fact that the eggs developed into larvae without segmentation, and very slowly, while with both hypertonic and hyperalkaline sea-water they segmented and developed more rapidly into larvae, though still more slowly than the eggs fertilized by sperm.

It is obvious that when the hypertonic solution acts in this way it makes the development more normal. This may also be a "second factor" effect. While the eggs of Polynoe do not directly disintegrate after artificial membrane formation, they show their abnormal state by developing without segmentation. The hypertonic solution remedies this defect, without, 
however, acting as completely as it does in the sea-urchin egg after membrane formation.

4. Mead ${ }^{1}$ observed that the addition of a small amount of $\mathrm{KCl}$ to the sea-water causes the eggs of Chaetopterus to throw out their polar bodies, and the writer observed that the same procedure causes these eggs to develop into larvae. ${ }^{2}$ I had already expressed the suspicion that these eggs develop into larvae without segmentation. F. Lillie made sure of this fact by a cytological examination of the eggs. ${ }^{3}$

All efforts to cause this egg to undergo development with normal segmentation failed until Wasteneys and the writer tried the effects of foreign blood serum. The eggs were put for from $1 \frac{1}{2}$ to $2 \frac{1}{2}$ minutes into a mixture of 25 c.c. $3 / 8 \mathrm{~m} \mathrm{SrCl}_{2}+$ 25 c.c. $\mathrm{m} / 2\left(\mathrm{NaCl}+\mathrm{KCl}+\mathrm{CaCl}_{2}\right)$, then for 10 minutes into ox serum diluted with its own volume of $\mathrm{m} / 2$ Ringer solution and then for 30 minutes into hypertonic sea-water. Such eggs when transferred back to normal sea-water segmented and developed into larvae. ${ }^{4}$ They were usually not normal larvae, inasmuch as they showed a tendency to stick to the glass and to each other. Moreover, the cleavage cells of the same egg fell apart easily. The method needs further improvement.

5. Lefevre succeeded in causing artificial parthenogenesis in the eggs of Thalassema mellita, a marine annelid of North Carolina. ${ }^{5}$ The eggs of this worm are fertilized in the oocyte stage, just like those of Polynoe. The entry of the spermatozoon leads to the formation of a fertilization membrane; the two polar bodies are then extruded, and segmentation and development start after maturation is complete. Now Lefevre found that when the unripe eggs of Thalassema are exposed to

1 Mead, Biological Lectures delivered at Woods Hole, 1898.

${ }^{2}$ Loeb, Am. Jour. Physiol., IV, 423, 1901.

${ }^{3}$ F. R. Lillie, Archiv f. Entwicklungsmechanik, XIV, 477, 1902.

${ }^{4}$ Loeb and Wasteneys, Science, XXXVI, 255, 1912.

5 G. Lefevre, "Artificial Parthenogenesis in Thalassema mellita," Jour. Exper. Zool., IV, 91, 1907. 
acid (the kind of acid seems immaterial) ${ }^{1}$ and then transferred to sea-water, they form membranes, extrude the polar bodies, and often develop into normal larvae after a perfectly normal segmentation. His best results were obtained with the following mixtures of acids:

17 c.c. $\mathrm{N} / 10 \mathrm{HNO}_{3}+83$ c.c. sea-water. Length of exposure 5 minutes 15 c.c. $\mathrm{N} / 10 \mathrm{HCl}+85$ c.c. sea-water. Length of exposure 5 minutes 10 c.c. $\mathrm{N} / 10 \mathrm{H}_{2} \mathrm{SO}_{4}+90$ c.e. sea-water. Length of exposure 8 minutes 12 c.c. $\mathrm{N} / 10$ Oxalic acid +88 c.c. sea-water. Length of exposure 8 minutes

15 c.c. $\mathrm{N} / 10$ Acetic acid +85 c.c. sea-water. Length of exposure 5 minutes

Under the influence of acid the eggs of Thalassema form a typical fertilization membrane after transference to ordinary sea-water, just like sea-urchin eggs; but whereas the latter must be transferred for a short time to hypertonic sea-water after membrane formation, in order to insure their development, this is not necessary with the eggs of Thalassema. In this respect then the eggs of Thalassema behave like those of Asterina. All the eggs of Thalassema form fertilization membranes under acid treatment, but not all of them develop. In the most propitious circumstances 60 per cent of the eggs develop.

The velocity of maturation and of the onset of cleavage was appreciably less than in the case of the fertilization with sperm. Whereas in the fertilization with sperm the first of the polar bodies was extruded twenty minutes after entry of the spermatozoon, the same event did not take place, when the eggs were exposed to acid, until 45 to 90 minutes after the eggs had been transferred from the acid to normal sea-water. The first cell division took place in 50 to 60 minutes after the entry of the sperm, while it did not occur until two to three and a half hours after the acid treatment of the unfertilized eggs.

${ }^{1}$ He remarks expressly that carbonic acid has just as much effect as any other acid, neither more nor less. 
Lefevre has made a very interesting observation on the behavior of the polar bodies. As a rule, the first polar body given off from the egg when it is fertilized with sperm divides only once, and the second polar body does not divide. Lefevre observed, however, that both polar bodies of the eggs treated with acid pass through a series of mitotic divisions and give rise to miniature embryos of sixteen cells. He compares these facts with Francotte's observation that in Prostheceracus, a turbellarian, the first polar body is relatively large and can be fertilized by a spermatozoon and even develop into a gastrula. As a rule the cleavage was normal and so were the larvae; but they did not rise to the surface of the water like those derived from fertilized eggs. Hence they easily fall victims to bacteria.

6. For the sake of completeness, some of the older experiments on artificial parthenogenesis in annelids may be briefly mentioned, although the methods used are not very satisfactory. In Amphitrite eggs could be caused to develop by treating them with sea-water whose calcium content was raised. ${ }^{1}$

Fischer produced artificial parthenogenesis in the eggs of Nereis by treating them with a hypertonic solution. ${ }^{2}$ Bullot succeeded by the same method, in the eggs of Ophelia. ${ }^{3}$

Again we may state that the methods of artificial parthenogenesis for annelids are essentially identical with those used for the eggs of the sea-urchins, except that the second factor is not quite so important.

${ }^{1}$ Loeb, Fischer, and Neilson, Pfüger's Archiv, LXXXVII, 1, 1901: Scott, Jour. Exper. Zool., III, 49, 1906.

${ }_{2}^{2}$ Fischer, Am. Jour. Physiol., IX, 100, 1903.

${ }^{3}$ Bullot, Archiv f. Entwicklungsmechanik, XVIII, 161, 1904. 



\section{XXVII}

\section{EXPERIMENTS WITH THE EGGS OF MOLLUSCS}

In 1902 Kostanecki succeeded in producing the early segmentation stages (two to four cells) in the unfertilized eggs of a molluse (Mactra), by exposing them for two hours to hypertonic sea-water. ${ }^{1}$ In 1903 the writer showed that the unfertilized eggs of another molluse, Lottia gigantea, and of several forms of Acmaea can be made to develop into swimming larvae by treating them with hypertonic sea-water. ${ }^{2}$ The method consists, in principle, of placing the eggs for two hours in a mixture of 50 c.c. of sea-water +10 c.c. $2 \frac{1}{2} \mathrm{~m} \mathrm{NaCl}$. The number of larvae that developed was always small (only about 2 to 5 per cent of the eggs), and their vitality was low. As a rule they succumbed after thirty-six to forty-eight hours. After I had recognized the part played by bases in the activation of the eggs of the sea-urchin, it next occurred to me to find out whether the osmotic causation of development in Lottia is also accelerated or improved if this hypertonic solution is rendered alkaline. This was found to be true. Thus to 50 c.c. of (neutral) $\mathrm{m} / 2$ van't Hoff's solution +12 c.c. of $2 \frac{1}{2} \mathrm{~m} \mathrm{NaCl}$ were added in different bowls $0,0.1,0.2,0.4$, and 0.8 c.c. $\mathrm{N} / 10 \mathrm{NaOH}$. Among these solutions the eggs of a Lottia were distributed after being washed in a neutral solution (temperature $17.5^{\circ} \mathrm{C}$.). Samples of the eggs were transferred to normal sea-water after $1 \frac{3}{4}, 2 \frac{1}{4}, 2 \frac{3}{4}, 3 \frac{1}{4}$, and $3 \frac{3}{4}$ hours respectively. The eggs exposed to neutral hypertonic solution did not develop, and the same was the case with eggs that had been treated with 0.1 c.c.

1 Kostanecki, "Zytologische Studien an künstlich parthenogenetisch sich entwickelnden Eiern von Mactra," Arch. f. mikroscop. Anat. u. Entwicklungsgesch., LXIV, 1, 1904.

${ }_{2}^{2}$ Loeb, University of California Publications, Physiology, I, 7, 1903; Untersuchungen ueber künstliche Parthenogenese, p. 283. 
$\mathrm{NaOH}$. Some of the eggs that had been exposed to solutions containing more $\mathrm{NaOH}$ did develop into larvae; the percentage of larvae varied according to the alkalinity of the solution and the time the egg was exposed to the solution. Many of the eggs that had been $2 \frac{1}{4}$ hours in the hypertonic solution containing 0.8 c.c. of $\mathrm{NaOH}$, or $2 \frac{3}{4}$ hours in that containing 0.4 c.c., developed into larvae. ${ }^{1}$

Hence it can be seen that just as in the case of the eggs of purpuratus and of Polynoe, the hypertonic solution as a rule only affects the eggs of Lottia when a certain degree of concentration of hydroxylions (about $10^{-6} \mathrm{~N}$ ) has been reached. Further, it is also clear that when the concentration of hydroxylions in the hypertonic solution is higher than in sea-water, the number of larvae formed also increases. But in this case also, as in the experiments with the eggs of $S$. purpuratus, the optimal concentration of hydroxylions for the production of larvae is subject to large variations with the eggs of different females.

The second fact brought out by these experiments is the importance of oxygen. In flat dishes (that are covered against evaporation of the sea-water) in which the eggs lie close to the surface of the water, the number of eggs that develop is appreciably higher than in dishes in which the eggs are covered with a deep layer of sea-water.

Finally, it is a point of interest that no visible membrane formation takes place in these forms. In this respect the eggs behave differently from those hitherto discussed.

Attempts to separate by an interval of time the effect of the alkali and the raising of the osmotic pressure, as can be done with the eggs of the sea-urchin and of Polynoe, have not yet proved successful with Lottia. Moreover, development is not produced by treatment with alkali alone.

In all these experiments the eggs developed practically

${ }^{1}$ Loeb, "Ueber die ailgemeinen Methoden der künstlichen Parthenogenese," op. cit. 
without segmentation. Kostanecki ${ }^{1}$ found this in his experiments with Mactra and the writer confirmed this for Lottia. It must be remembered, however, that these are only shortcomings of the method, and it was therefore to be expected that different methods would give different results.

The writer did not succeed in causing artificial parthenogenesis in the eggs of Cumingia, a molluse at Woods Hole, by any of the older methods, but Wasteneys and he succeeded in not only causing these eggs to develop, but also to develop with normal segmentation by treating them with ox blood. The method used was as follows. The eggs were sensitized to the effects of serum by placing them for from two to four minutes into a $3 / 8 \mathrm{~m}$ solution of strontium chloride. They were then placed for five minutes in ox serum rendered isotonic with seawater and diluted with an equal part of a $\mathrm{m} / 2$ solution of $\mathrm{NaCl}+\mathrm{CaCl}_{2}+\mathrm{KCl}$. After having been freed from all traces of serum by repeated washing in a Ringer solution, they are transferred for sixty minutes into hypertonic sea-water (50 c.c. sea-water +8 c.c. $2 \frac{1}{2} \mathrm{~m} \mathrm{NaCl}$ ). Control experiments showed that the treatment with serum is an essential factor in this process. $^{2}$

This latter experiment shows the close similarity of the methods of artificial parthenogenesis in various groups of animals.

${ }^{1}$ Kostanecki, "Zur Morphologie der künstlich parthenogenetischen Entwicklung bei Mactra," Arch. f. mikroskop. Anat. u. Entwicklungsgesch., LXXII, $327,1908$.

${ }^{2}$ Loeb and Wasteneys, "Fertilization of the Eggs of Various Invertebrates by Ox Serum," Science, XXXVI, 255, 1912. 



\section{XXVIII}

\section{ARTIFICIAL PARTHENOGENESIS IN THE EGGS OF FROGS}

During the first years of his work and later the writer vainly applied the chemical methods of artificial parthenogenesis to the eggs of fishes and of frogs. The reason for this failure may possibly lie in the relative impermeability of the walls of these eggs for the chemicals used. The walls of the eggs of Fundulus are, as long as they are normal, not only impermeable for salts but also for water. It seemed desirable that a method of artificial parthenogenesis for vertebrates should be found since it is so much easier to raise the larvae of vertebrates than of invertebrates. It is under the circumstances no surprise that such a method was found almost accidentally. In 1907 Guyer published a paper in which he reported that by injecting lymph or blood into the unfertilized eggs of frogs he succeeded in starting development and even in obtaining two tadpoles. Considering the importance of these experiments and since they seem to have been overlooked, the writer feels justified in quoting part of Guyer's note:

During three successive springs (1905-7) the writer has experimented on unfertilized frog eggs by injecting them with blood or lymph of either male or female frogs. In all some fifteen hundred eggs have been so operated upon. Shortly before the time for laying, the eggs were taken from the uterus with every precaution to prevent contamination by sperm. Those nearest the cloacal opening were always set aside as a control and in not a single instance did any of them develop. The other eggs were pricked with a very fine-pointed capillary tube which had previously been charged with lymph and corpuscles by dipping it into the lymph or the blood of another frog.

In eggs so treated numerous instances of cell proliferation and embryonic development have been observed, prorided the eggs were 
fully matured and ready for fertilization. Many eggs after six or eight days showed upon sectioning that they had approximated the full blastular and in some cases the gastrular stages, although the condition came about apparently by some sort of internal nuclear arrangement, as no superficial cleavage furrows were observable and no demarkation into cells was visible from the exterior until the third or fourth day, when close inspection showed in some cases numerous small vesicular or cellular outlines.

In some instances definite organs were developed, though frequently distorted and misplaced. Cross-sections of one embryo, for example, showed such pronounced defects as two neural tubes anteriorly. Of the whole number of eggs operated upon only two developed into free-swimming tadpoles and these were apparently normal as far as superficial examination disclosed. They have not yet been sectioned. After sixteen days one died and the other was killed to insure proper fixation for histological study.

Apparently the white rather than the red corpuscles are the stimulating agents which bring about development, because injections of lymph, which contains only white corpuscles, produce the same effect as injections of blood. Whether or not the fluid part of the lymph or blood produced any effect could not be definitely determined from the material at hand. ${ }^{1}$

Guyer thought that probably the cells which he introduced were developing and not the egg. He did not recognize that his experiment was a case of artificial parthenogenesis. This, however, does not detract from the fact that he was the first to cause the development of the unfertilized egg of the frog by puncturing it, that he introduced blood into the egg for this purpose, and that he succeeded in producing two parthenogenetic tadpoles.

Guyer's results were to a large extent confirmed by Bataillon. Bataillon found that mere puncturing of the egg of the frog by a very fine needle could not produce any embryogenesis but that a second factor was necessary, namely, that some of the body liquids (blood of the frog or newt or fish) have to enter the egg. "A considerable percentage of the eggs of Rana, touched

1 Guyer, Science, XXV, 910, 1907. 
with the blood and immediately punctured, will develop, while the same eggs squeezed out from the female frog will not develop (when punctured)." Bataillon states that in the eggs thu. treated "he found at the beginning of the divisions outside the kinetic figures, chromatin fragments accompanied by asters, which fragments come probably from elements inoculated with the needle."' In a recent paper Bataillon reaches the conclusion that it is the leucocytes which cause the development (1913).

A number of authors have succeeded in repeating these experiments by Guyer and Bataillon, Dehorne, ${ }^{2}$ Henneguy, ${ }^{3}$ Brachet, ${ }^{4}$ McClendon, ${ }^{5}$ and Loeb and Bancroft. ${ }^{6}$ The last. named, however, have produced tadpoles also without the use of blood or lymph.

While the number of eggs which begin to segment when punctured is not inconsiderable, very few reach the tadpole stage. There is a difference in the response of the eggs of various kinds of frogs to this treatment.

The number of unfertilized eggs which began to segment after puncture was according to Loeb and Bancroft greater in the wood frog than in the leopard frog, and amounted in the most favorable cases to about 40 per cent in the former. Only 2 of about 10,000 punctured eggs of the wood frog reached the tadpole stage, but these died before they were able ta swim. The percentage of eggs of the leopard frog which reached the tadpole stage was greater. From 700 punctured eggs of the Southern leopard frog, 13 good morulae were isolated the next day. On the third day, when the fertilized controls were in the

${ }^{1}$ Bataillon, "La parthẻnogénèse expérimentale des amphibiens," Revue générale des Sciences, XXII, 786, 1911; Compt. rend. Acad. Sc., CL, 996, 1910; CLII, 920, 1911; CLII, 1120, 1911; CLII, 1271, 1911; CLVI, 812, 1913; Arch. de Zool. expér. et gén., XLVI, 103, 1910.

2 Dehorne, Compt. rend. Acad. Sc., CL, 1451, 1910.

${ }^{3}$ Henneguy, Compt. rend. Acad. Sc., CLII, 941, 1911.

4 Brachet, Arch. de Biol., XXVI, 337, 1911.

${ }^{5}$ McClendon, Am. Jour. Physiol., XXIX, 298, 1911.

${ }^{6}$ Loeb and Bancroft, Jour. Exper. Zool., XIV, 275, 1913. 
gastrula stage, 13 unfertilized punctured eggs were also in the gastrula stage and 4 more eggs were developing abnormally. On the fourth day, 8 of the parthenogenetic eggs had good medullary folds and 4 had irregular folds. On the sixth day most of the fertilized eggs hatched and 8 of the parthenogenetic eggs hatched also. Of these latter, 4 were developing regularly and 4 irregularly. Those that had not hatched were abnormal.

On the eighth day, the larvae arising from the fertilized eggs were swimming. Among the larvae arising from the unfertilized punctured eggs only 3 were normal, and their development was slightly retarded, perhaps one day. In addition, 6 parthenogenetic larvae were abnormal but still alive.

On the thirteenth day, 2 of the parthenogenetic larvae were feeding and these were the only ones which survived definitely. The other parthenogenetic larvae all died during the next few days. Of the 2 surviving larvae, one went through metamorphosis after five months. When it died, the tail was almost completely absorbed (Fig. 76). Its death was probably accidental. The other lived (Fig. 77) a month longer and formed small hind legs, but died in the tadpole stage. A repetition of these experiments by the same authors showed that only the eggs of Rana sphenocephala and $R$. pipiens produce tadpoles when punctured, while the unfertilized eggs of $R$. silvatica, Chorophilus feriarum, and of Bufo americanus only begin to segment but die before the tadpole stage when they are punctured.

As far as the effect of puncturing the egg is concerned, it may be comparable to the effect of agitation upon the starfish egg. The latter forms a membrane as an effect of agitation and it may be that the destruction of the surface layer of the frog egg is the essential feature in this "traumatic" parthenogenesis. While the spermatozoon causes the destruction of the cortical layer of an egg by a chemical substance (a "lysin"); and while the same can be accomplished in the egg of some 
starfish and some annelids by gentle agitation, in the egg of the frog it can be done by puncturing the surface layer. Future experiments will decide whether or not the leucorytes play the rôle of the second factor which Bataillon ascribes to them.

Loeb and Bancroft tried to ascertain the sex of the parthenogenetic frog and tadpole which they obtained. The

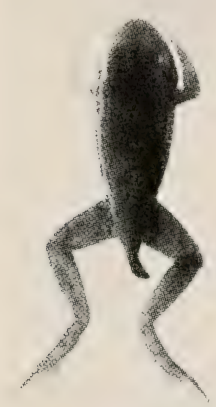

Fig. 76

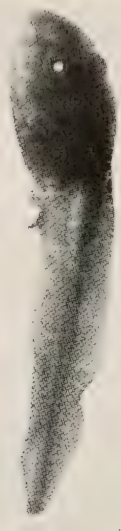

Fig. 77

Figs. 76 and 77.-Parthenogenetic frog and parthenogenetic tadpole (natural size).

gonads contained eggs in both cases. This at first sight might be taken to indicate that both were females, but the problem is complicated by the fact found by Pflüger, and recently worked out by Kuschakewitsch, ${ }^{1}$ that very often in the early stages the gonads of a frog may contain eggs which afterward degenerate. Such "intermediates" may develop into males.

The gonads of the parthenogenetic frog obtained by Loeb and Bancroft agreed with Kuschakewitsch's description of an "intermediate" which is in the process of developing into a male.

' Kuschakewitsch, Festschrift f. Richard Hertwig, Bd. II, p. 145, 1910. 



\section{XXIX}

\section{ARTIFICIAL PARTHENOGENESIS IN PLANTS}

Experiments on artificial parthenogenesis in plants are limited by the fact that it is necessary for this purpose to obtain the unfertilized eggs in large numbers and that the eggs are not naturally parthenogenetic. The Fucaceae seem to meet this requirement and J. B. Overton, of the University of Wisconsin, has recently succeeded in bringing about artificial parthenogenesis in a species of Fucus at Woods Hole. Since only a preliminary report has thus far appeared ${ }^{1}$ on this subject it may be best to quote from it.

Fucus vesiculosus, a dioecious species, occurs near the shores between tide marks at Woods Hole, and plants, both in the regetative and reproductive conditions, are usually abundant. The spermatozoids and oospheres are usually discharged sparingly during ebb tide and abundantly during flood tide. Plants were collected during ebb tide, the distal portions removed and placed in dishes on ice over night. Care was taken that the conceptacles bearing eggs and sperms were kept separate. When it was desired to obtain the eggs and sperms, dishes containing conceptacles were filled with fresh sea-water, or after first exposing the conceptacles to a hypotonic sea-water, when eggs and sperms were discharged in large numbers. The freshly extruded eggs drop to the bottom of the dishes and can be taken up with a pipette and transferred to watch glasses for experiment. After a short time the eggs show a tendency to adhere very firmly to the bottom of the watch glasses so that fluids can easily be poured off and others added without losing the eggs.

In plants used to induce cell division by artificial means great care was taken to prevent contamination by sperm. The female plants were carefully washer with fresh water to kill any sperms which might adhere to them. None of the eggs obtained from such sterilized plants ever developed in the numerous controls, which were run in

$1 \mathrm{~J}$. B. Overton, "Artificial Parthenogenesis in Fucus," Science, XXXVII, $841,1913$. 
connection with the experiments, showing beyond a doubt that the female plants treated were absolutely sterile.

Loeb has shown that, when unfertilized eggs of the sea-urchin are placed for one and one-half to two minutes in a mixture of 50 c.c. of sea-water +3 c.c. of $0.1 \mathrm{~m}$ acetic, butyric, or other fatty acid and then transferred to normal sea-water, a fertilization membrane is formed. This method was applied to unfertilized Fucus eggs. In experimenting with the eggs those used at any one time were always divided into three lots. One lot was used as a control, another was fertilized, and the third was treated with the solution. If a single egg in the control formed a cell-wall, which seldom happened, the three lots were discarded. In case the eggs were treated with acetic or butyric acid, as above described, a large number of them formed in about ten minutes a membrane or cell-wall which was exactly similar to the one formed about normally fertilized eggs. By plasmolyzing the eggs the membrane is readily seen. Eggs not treated with a solution or not fertilized undergo cytolysis and degenerate. In any case many of the eggs failed to develop, but about one-fourth as many formed membranes under the influence of the solutions as were formed about fertilized eggs. After the formation of the membranes if the eggs are placed in hypertonic sea-water, 8 c.c. to 10 c.c. of $2.5 \mathrm{~m} \mathrm{NaCl}$ or $\mathrm{KCl}$ +50 c.c. sea-water, for 30 minutes and are then brought back into normal sea-water, development continues. Nearly all of the eggs which have formed a membrane become pear-shaped, showing a rhizoidal papilla, and by next morning have cleaved. The rhizoidal cell is cut off and one or more cleavages have taken place in the other portion of the sporeling. If the cultures are properly aerated, sporelings develop resembling in every respect those grown from fertilized eggs. In place of sea-water containing a fatty acid, solutions of various other cytolytic substances were used, but none stimulated membrane formation or development as well as the acids.

With regard to the first formation of the cell-wall over the surface of isolated masses of plant protoplasm, it is usually attributed to a process of secretion by the outer layer. That the process is a rapid one is shown by the fact that in Fucus eggs a cell-wall is formed in ten minutes after the entrance of the sperm. Cell-wall formation may also be artificially induced, as shown above, by various substances. In some cases a cell-wall may appear under certain conditions on the surface of plasmolyzed protoplasts in fifteen minutes, as has been shown by Klebs, Palla, and others, while in other cases hours are required 
for wall formation. It would appear that the action of the acids in inducing a cell-wall to be formed about the unfertilized $F$ ucus eggs is similar to the action which calls forth membrane formation in the animal egg.

The fact that the method which causes artificial parthenogenesis in the eggs of many animals acts in the same way in the case of the eggs of plants indicates the identity of this process in all living organisms. 



\section{XXX}

PRESERVATION OF THE LIFE OF THE EGG BY THE ACT OF FERTILIZATION

1. The unfertilized egg dies in a comparatively short time, while the act of fertilization saves the life of the egg and allows it to give rise, theoretically at least, to an unlimited series of generations. The question arises: How does the spermatozoon save the life of the egg? It is not necessary to emphasize the physiological importance of this feature of the process of fertilization.

The rapidity with which the unfertilized eggs die differs according to the species. The unfertilized egg of the starfish (Asterias) dies at summer temperature in a few hours, that of Polynoe in less than a day, while that of the sea-urchin (Arbacia) may live for a week or longer. In all cases the life of the unfertilized egg can be prolonged if its oxidations are suppressed; and the rapidity with which they die seems to depend upon the relative velocity of oxidations in the unfertilized egg.

As already mentioned, the eggs of the starfish are mostly unripe when laid, and they only begin to ripen in sea-water. The different eggs, however, do not all ripen at the same rate. Now I found that if mature eggs were not at once or soon fertilized or caused to develop by chemical means, they quiekly disintegrate, i.e., in the course of a few hours.

The cytoplasm of the living eggs of Asterias is homogeneous and of a light yellowish color. This appearance the eggs also retain after maturation, as long as they are alive; nor do they lose it if development is initiated by the entry of a spermatozoon or by the methods of artificial parthenogenesis.

If, however, the ripe eggs remain unfertilized or are not caused to develop, they die in the course of from four to twelve 
hours, and this process is accompanied by a characteristic alteration in the color of the egg. It becomes first dark, then rapidly black, and instead of the homogeneous appearance of the protoplasm, there appear large drops or globules within it. If we examine with a microscope such a culture of unfertilized eggs after about twenty-four hours, we find two classes of eggs: first the ripe but uniformly dark, dead eggs and, second, the immature but living, normally colored eggs. We stated in a previous chapter that the eggs which are taken from the ovary of a starfish do not all ripen at once; many mature very slowly, others practically never. It can now readily be observed that the unripe eggs remain alive several days longer, until they eventually fall a prey to bactcria, while the ripe eggs mostly become dark and die in from four to eight hours after maturation.

Is the death of the ripe egg, which has not been made to develop, due to intrinsic processes or to the bacteria contained in the sea-water? A reliable method of determining this is to make pure sterile cultures of the eggs in sea-water. This is comparatively simple with starfish eggs. Eight flasks were sterilized, filled with sterilized sea-water, and then heated again for twenty minutes to $100^{\circ}$ on three consecutive days. A female starfish was thoroughly washed externally, one arm opened, and an ovary removed with sterilized forceps and brought into sterilized sea-water. From the thick stream of eggs which immediately flowed out of the ovary a couple of drops were quickly placed in each of the sterilized flasks with a sterile pipette. A second series of eight flasks contained normal, unsterilized sea-water and in each of these flasks also a couple of drops of the same eggs were placed. A third series of flasks was filled with sea-water, to which 2 c.c. of a thoroughly putrid culture of old starfish eggs had been added in order to cause from the first a vigorous development of bacteria. These flasks too contained eggs from the same female as the sterilized flasks. 
That the first eight flasks had been thoroughly sterilized was demonstrated by the fact that all the flasks remained perfectly elear and unclouded throughout the whole experiment; and that three flasks which were not opened till the end of the experiment, i.e., after ten weeks, were quite clear and each single egg therein could be distinctly recognized. The flasks with unsterilized sea-water became cloudy after only twenty-four hours, and after two days the eggs had fallen a prey to bacteria and no egg was any longer recognizable. The sterilized flask: which were opened were always quite free from odor, while the unsterilized flasks already smelled unendurably putrid after one to two days. A microscopical examination of the sea-water for bacteria always remained absolutely negative in the sterilized flasks, and was always quite positive in the other flasks. In the flasks to which 2 c.c. of the putrid culture of starfish eggs had been added, bacteria and infusoria were extremely numerous from the first.

Six hours after the beginning of the experiment, one flask of each of the three series was opened, and the eggs examined with a microscope. The appearance was the same in all three flasks: practically all the eggs were ripe, and a small number were dark or black. What is of definite importance for us is the fact that the percentage of dark, dead eggs was quite as large in the sterile culture as in the unsterilized or befouled sea-water.

Twelve hours later, and therefore eighteen hours after the experiment was started, another flask from each of the three cultures was opened. This time practically all the eggs in the sterile culture were dark or black, and a few already showed decomposition into globules. The same percentage of eggs in the two other cultures was also dark. Hence the eggs die just as quickly in the sterilized flasks, which are absolutely bacteriafree, as in the flasks which contain bacteria. Death takes place from intrinsic causes and so quickly that the scanty bacteria 
present in the sea-water are scarcely able to accelerate the death of the eggs. The eggs have indeed already died from intrinsic factors before the bacteria can enter.

The flasks opened later only confirmed the above. Each one opened in the first few days contained also a small number of living eggs of clear-cut appearance. The latter were, however, without exception, unripe. The experiment therefore proved that the ripe eggs of the starfish decay in a few hours, and the causes of their death must not be looked for in the bacteria of the sea-water; and, further, that under the same conditions the unripe eggs remain alive.

An experiment was now made to find out whether the life of the unripe eggs can be prolonged by preventing them from ripening. As previously mentioned, maturation requires the presence of free oxygen. Freshly laid eggs of Asterias were divided into two series of eight flasks. One series of flasks was connected with a hydrogen generator, the other with a cylinder containing pure oxygen. Before the beginning of the experiment, all the air in the one series of flasks was driven out by a stream of hydrogen, and a vigorous stream of hydrogen was maintained throughout the experiment. Both series of flasks contained freshly gathered unripe eggs of Asterias. The experiment continued for three days, and from time to time one flask was disconnected and its contents examined. The eggs which were exposed to the stream of oxygen matured as quickly and in as large numbers as in normal sea-water, and the ripe eggs died as soon. In the stream of hydrogen, maturation did not take place in the majority of the eggs and they remained alive. A vigorous development of bacteria took place in the hydrogen culture while there was none or only a weak one in the oxygen culture.

The death and disintegration of the eggs is also prevented by treatment with acid, which, as previously mentioned, prevents the maturation of the eggs (without killing them). Eggs 
which are placed for ten or fifteen minutes in 100 c.c. of seawater +4 c.c. $\mathrm{N} / 10 \mathrm{HCl}$, without coming into contact with alkaline sea-water, ripen much more slowly, generally not at all, when after that time they are replaced in normal sea-water. They retain also, as long as they are unripe, the full normal appearance of living eggs, until they eventually fall victims to bacteria. Unripe eggs too, when placed in neutral sea-water, do not ripen for the most part, and retain their normal appearance if they remain immature.

It appears to follow from this experiment that the same process which lies at the bottom of the maturation of the starfish egg also leads to its death, unless it is prevented by those measures which we designate as fertilization. I now tried whether it is possible to keep the ripe eggs alive longer through lack of oxygen. In fact I obtained some positive results in this connection. Starfish eggs were spread out in a thin layer: After three hours 75 per cent of the eggs had ripened. A part of the ripe eggs was immediately placed in narrow glass tubes, in which the deeper layers suffer the same lack of oxygen. A second portion was placed in small flasks, through which was led a constant stream of pure oxygen. Next morning, fifteen hours after the eggs were placed in the oxygen, the different portions of eggs were tested. Those eggs placed in the current of oxygen showed in one dish 98 per cent of ripe, dark, and dead eggs, and 2 per cent of unripe, living eggs. The eggs remaining in normal sea-water contained as before some 78 per cent of ripe eggs, which, however, were all black and dead, with the exception of a few which had begun to divide and were alive. The unripe eggs were also living. On the other hand, those eggs which had been in the glass tubes, in complete, or relatively complete, lack of oxygen, were nearly all alive. This observation, in fact, indicates that the same process which leads to the maturation of the egg also causes the death of the egg unless it is prevented in time. In this way 
fertilization becomes an act which saves or prolongs life. ${ }^{1}$ A simpler way of prolonging the duration of life of the mature but unfertilized egg of the starfish consists in adding a trace of $\mathrm{KCN}$ to the sea-water (about 5 or 6 drops of $1 / 10$ of 1 per cent $\mathrm{KCN}$ to 50 c.c. of sea-water).

A. P. Mathews has continued these experiments and likewise found that the life of the unfertilized ripe eggs can be prolonged by lack of oxygen. ${ }^{2}$

This proves that the death of the mature but unfertilized egg is if not determined at least accelerated by oxidations.

What is the explanation of these facts? We know that the unfertilized but mature egg of the starfish is the seat of comparatively rapid oxidations which are possibly or probably lacking in the unripe egg. These oxidations lead directly or indirectly to the death of the mature egg, while their prevention saves the life of the egg, at least for some time. The unfertilized mature egg may be compared to an anaerobe. The nature of the lifesaving action of the act of fertilization may then be expressed by the statement that by the act of fertilization the egg is transformed from an anaerobe into an aerobe. It is possible that the oxidations do not kill the unfertilized egg directly, but only through the medium of physical or morphological changes which follow or accompany the oxidations.

The idea that fertilization saves the life of the egg by rendering it immune against oxidations finds support not only in the fact that the life of the unfertilized egg of the starfish is prolonged if we deprive it of oxygen or inhibit oxidations through the addition of $\mathrm{KCN}$, but also in the fact that the unfertilized egg of the sea-urchin lives much longer in sea-water than does the unfertilized mature egg of the starfish. This should lead us to expect that the rate of oxidations in the unfertilized but

${ }^{1}$ Loeb, "Ueber Eireifung, natürlichen Tod und Verlängerung des Lebens beim unbefruchteten Seesternei (Asterias forbesii) und deren Bedeutung für die Theorie der Befruchtung," Pflüger's Archiv. XCIII, 59, 1902; Untersuchungen, p. 237.

${ }^{2}$ A. P. Mathews, Am. Jour.Physiol., XVIII, 89, 1907. 
ripe starfish egg is comparatively greater than in the sea-urchin egg. This is the case since the unfertilized egg of the sea-urchin has a rate of oxidations from four to six times smaller than that found after fertilization; while the ripe but unfertilized exg of the starfish has a rate of oxidations equal to that of the fertilized $\operatorname{egg}^{1}$ (chap. iii).

We have another fact in support of our view. We saw in a previous chapter that the artificial membrane formation raises the rate of oxidations in the sea-urchin egg about six timas. If our contention that the unfertilized egg is comparable to an anaerobe is correct the membrane formation should hasten the death of the unfertilized sea-urchin egg. This is, as we saw, actually the case. While the unfertilized egg of purpuratus without membrane lives for several days, the unfertilized egg after membrane formation dies at the same temperature in a few hours. Moreover, we saw that the death of the unfertilized egg after membrane formation is retarded if we inhibit the oxidations in the egg. We pointed out, however, that in this case the oxidations may lead only indirectly to the rapid death of the egg, inasmuch as they set the apparatus of nuclear cell division in motion. We can also save the life of the egg after membrane formation by inhibiting development with chloral hydrate, which does not diminish the rate of oxidations. ${ }^{2}$

2. It has been one of the important results of our work to show that for the egg of the sea-urchin, and perhaps in general, the causation of normal development requires as a rule the co-operation of two factors, the membrane-forming factor and the corrective factor. The question arises, which of the two has the life-saving effect? At first sight it would seem as if this important function was to be attributed to the second factor; for it is the second factor which saves the egg, after

1Loeb and Wasteneys, Archiv f. Entwichlungsmechanik, XXXV; 555, 1912.

${ }^{2}$ Loeb and Wasteneys, Jour. Biol. Chem., XIV, 517, 1913. 
membrane formation, from the threatening disintegration. Yet this conclusion would be wrong.

The unfertilized mature egg of S. purpuratus (in which no membrane formation has been called forth) lives at room temperature about two or three days and then disintegrates. We saw in a previous chapter that the application of the second factor (the treatment of the egg with the hypertonic solution) may precede the artificial membrane formation by one or more days. If this second factor alone possessed the life-saving action, we should expect that unfertilized eggs treated with the hypertonic solution alone would live longer than the unfertilized eggs not treated at all. This is, however, not the case. The unfertilized eggs of S. purpuratus treated with the hypertonic solution alone die as quickly as the non-treated eggs. The same eggs, however, will live and develop if the membrane formation is called forth. In this case we might say that the membrane formation has the life-saving effect. In reality it is the combined action of both by which the life of the egg is prolonged.

These facts also make it plain why the act of membrane formation alone can save the life of certain starfish eggs or the eggs of certain annelids for which membrane formation alone suffices to induce normal development. Not all the eggs of such animals, e.g., Asterina, are able to develop through artificial membrane formation alone, but only a small number; and we have reason to assume that in these eggs the second factor is formed or pre-exists in ample quantity. For these eggs the mere act of membrane formation is sufficient to save their lives, since they are supposed to supply the second factor themselves.

It is therefore the causation of development and not the action of one of the two factors alone which saves the life of the unfertilized egg.

3. We have mentioned the fact that lack of oxygen or the suppression of oxidations prolongs the life of the unfertilized 
mature egg, while fertilization, which makes the egg immortal, raises the rate of oxidations considerably, at least in the egg of the sea-urchin. We have seen that in the unfertilized egg of the sea-urchin oxidations take place though at a slow rate. The unfertilized eggs seem to perish very rapidly through these oxidations. We have stated that the mature unfertilized egg resembles an anaerobe, while the act of fertilization transforms it into an aerobe. We are certainly here confronted with one of the most interesting and far-reaching features of the problem of fertilization. The unfertilized egg is perhaps at present the only instance of a cell for which "natural death" can be proven. The act of fertilization or rather the inducement of development procures theoretical immortality for the egg, since the sex cells of the new individual to which the egg gives rise are parts of the egg.

The oxidations are, however, not the only processes which are responsible for the premature "natural death" of the unfertilized egg; otherwise it should be possible to keep it alive indefinitely without oxygen, which is not the case. The act of fertilization brings about a profound physicochemical modification in the egg which is not confined to one type of chemical reactions. 



\section{XXXI}

\section{ARTIFICIAL PARTHENOGENESIS AND IIEREDITY}

1. The spermatozoon not only induees the development of the egg, but it also transmits the hereditary characters of the male parent to the offspring. 'The possibility of artificial parthenogenesis makes it certain that the two processes are not determined by the same substances, since the methods of artificial parthenogenesis are analogous for very diverse species, while the hereditary characters are very different.

When closely related species are crossed the hereditary characters of the male are of course recognizable in the offspring. The question arose: What would happen if widely divergent species were crossed, such as sea-urchin and starfish? The writer found a method of bringing about this hybridization. The main interest was whether or not a sea-urchin egg fertilized with the sperm of starfish would produce the skeleton typical for the pluteus stage of the larva. As mentioned above, the hybridization between purpuratus o and Asterias $\$$ could be accomplished in 50 c.c. sea-water +0.6 c.c. $\mathrm{N} / 10 \mathrm{NaOH}$. These hybrid eggs segmented at the same rate as the eggs fertilized with sperm of their own species, and the development was normal up to the gastrula stage. Then the eggs began to die in large numbers and those which survived were sickly and developed at a much lower rate than the eggs fertilized with purpuratus sperm. But the small number of eggs which lived long enough developed into plutei which were in every point identical with the pure breed of purpuratus. In the case of heterogeneous hybridization the spermatozoon produces only the developmental but not the hereditary effect. ${ }^{1}$

${ }^{1}$ Loeb, "Ueber die Befruchtung von Seeigeleiern durch Seesternsamen," Pflüger's Archiv, XCIX, 323, 1903; "Weitere Versuche ueber heterogene Hybridisation bei Echinodermen," Pflüger's Archiv, CIV, 325, 1904; "Heredity in Heterogeneous Hybrids," Jour. Morphol., XXIII, 1, 1912. 
This statement will become much clearer by a few illustrations. Figs. 78-80 are (five-days-old) plutei of purpuratus produced by artificial parthenogenesis. They are identical

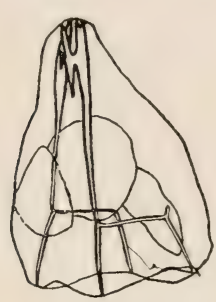

Fig. 78

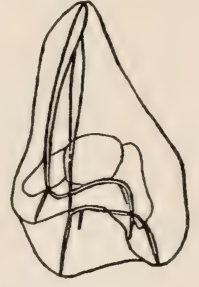

Fig. 79

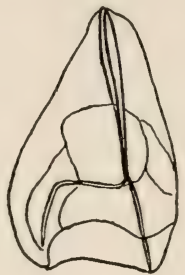

Fig. 80

FIgs. 78-80.-Five-days-old plutei of $S$. purpuratus, produced by artificial parthenogenesis.

with the pure breed of purpuratus. Figs. 81-83 are three plutei produced by fertilizing the sea-urchin egg (purpuratus) with the sperm of the starfish. They are identical with the plutei produced by artificial parthenogenesis.

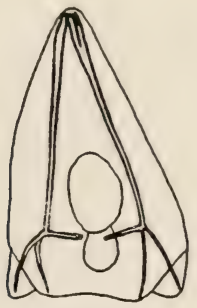

Fig. 81

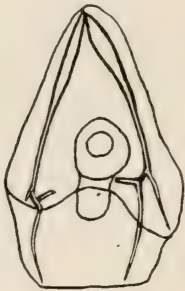

Fig. 82

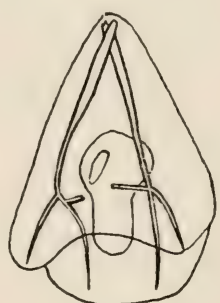

Fig. 83

Figs. 81-83.-Five-days-old plutei from S. purpuratus $\uparrow$ and Asterias $\hat{\jmath}$. The plutei are identical with the parthenogenetic plutei.

If, however, the egg of S. purpuratus is fertilized with the sperm of $S$. franciscanus, a closely related form, a pluteus of an altogether different type is produced (Figs. 84-86). The skeleton has the rough appearance of the franciscanus pluteus and the typical arm formation characteristic of this paternal form. It is therefore obvious that heterogeneous hybridization is in reality artificial parthenogenesis with this difference 
only, that a living spermatozoon carries the parthenogenetic substances into the egg. The character of these plutei is always the same; they do not show any such variations as Tennent reports.

In addition to fertilizing the eggs of $S$. purpuratus with the sperm of starfish, the writer succeeded also in fertilizing the eggs of purpuratus with the sperm of ophiurids and holothurians. Godlewski used the same method with success for the fertilizition of the egg of the sea-urchin with the sperm of a crinoid (Antedon). In all these cases the larvae were purely maternal, ${ }^{1}$

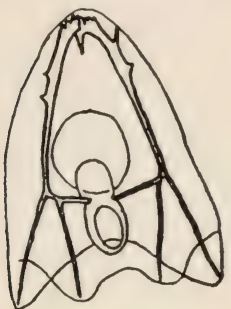

Fig. 84

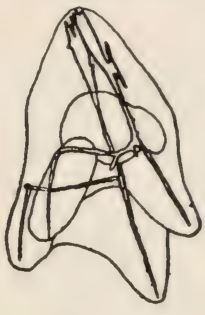

Fig. 85

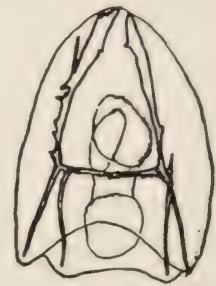

Fig. 86

Figs. 84-86.-Five-days-old plutei of S. purpuratus $q$ and $S$. franciscanus $\delta$. The plutei are different from the parthenogenetic plutei.

Godlewski found that the nuclei of crinoid and sea-urchin fuse. The chromosomes of Antedon are found in the nuclei of the sea-urchin egg fertilized with Antedon sperm. The eggs developed normally to the blastula stage, when a retardation and other abnormalities ensued. Very few plutei were obtained. The results of Godlewski were fully confirmed by Baltzer. ${ }^{2}$ The skeleton was as in Godlewski's experiments purely maternal. He confirms the result of Godlewski, that in spite of the participation of the paternal chromosomes in the development no transmission of hereditary characters can be observed.

1 Godlewski, "Untersuchungen ueber die Bastardierung der Echinoidenund Crinoiden-familie," Archiv f. Entwicklungsmechanik, XX, 579, 1906; Das Vererbungsproblem im Lichte der Entwicklungsmechanik betrachtet, Leipzig, 1909.

${ }^{2}$ Baltzer, "Ueber die Beziehung zwischen dem Chromatin und der Entwick" lung der Vererbungsrichtung bei Echinodermenbastarden," Arch. f. Zellfursilig., $\mathrm{V}, 497,1910$. 
The fertilization of the eggs of the sea-urchin with the sperm of molluses and annelids by Kupelwieser and by Godlewski (see chap. xxii) did not lead to any normal larvae and cannot therefore be utilized for this problem. The writer's experiments on the cross between S. franciscanus $q$ and Chlorostoma $f$ (a mollusc) gave maternal plutei.

2. It can be stated as a general fact that the rate of cleavage in hybrid eggs is exactly like the rate found in the development of eggs fertilized with sperm of their own species. The writer found this to be true for sea-urchin eggs fertilized with the sperm of starfish. Moenkhaus measured the rate of segmentation in hybrid fish eggs and found that the rate for the first cleavages is determined by the egg. ${ }^{1} \quad$ The egg of Ctenolabrus segments about forty minutes after impregnation with sperm of its own kind, while the egg of Batrachus tau, if fertilized with the sperm of the same species, segments after about eight hours. If the egg of Batrachus be fertilized with the sperm of Ctenolabrus it also does not segment until after eight hours. ${ }^{2}$ I have repeated these experiments in a number of fish hybrids and confirmed Moenkhaus' results. This fact proves again what we stated in a previous chapter, that the spermatozoon does not start the development by carrying an enzyme or catalyzer into the egg, which the latter needs in order to develop, but causes the development by altering the surface layer of the egg. If the segmentation of the egg were caused by an enzyme carried into the egg by a spermatozoon, the rate of cleavage of slowly developing eggs should be accelerated by a spermatozoon of a species developing at a faster rate. The egg, however, behaves exactly as we should expect from the fact that the spermatozoon removes only certain obstacles for the development of the egg, but does not cause its segmentation by carrying an activating enzyme.

1 Moenkhaus, Am. Jour. Anat., 111. 29, 1904.

2 The acceleration of segmentation which Newman observed in the egg of Fundulus majalis fertilized by the sperm of Fundulus heteroclitus is too small to influence our conclusions. 
But, while the rate of segmentation is thus essentially drtermined by the egg, the same is not true for the rate of the further development of the embryo. This can be shown in comparing the time of appearance of certain characters in the hybrids and pure breeds of two related species. Bancroft and the writer measured the time which elapses from the moment of fertilization to the time of appearance of the heart beat, the circulation, the red chromatophores of the yolk, the black chromatophores, etc., in the embryos of Fundulus heteroclitus, Fundulus majalis, and the two hybrid forms majalis + X.heteroclitus $\hat{\delta}$, and heteroclitus $+\times$ majalis $\hat{s}$. The rate of development is much slower in the pure breed of majalis than in the pure breed of heteroclitus. If the egg of majalis is fertilized with the sperm of heteroclitus the rate of segmentation is practically. the same as if it were fertilized with the sperm of majalis. The appearance of certain embryonic characters is, however. accelerated as the following table shows.

\section{TABLE XXXIX}

\begin{tabular}{|c|c|c|c|c|c|}
\hline \multirow[b]{2}{*}{ BREED } & \multicolumn{2}{|c|}{ BEGINNING OF } & \multicolumn{3}{|c|}{ First Appearance of } \\
\hline & $\begin{array}{c}\text { Heart } \\
\text { Beat }\end{array}$ & $\begin{array}{c}\text { Circula- } \\
\text { tion }\end{array}$ & $\begin{array}{l}\text { Red Yolk } \\
\text { Chroma- } \\
\text { tophores }\end{array}$ & \begin{tabular}{|c} 
BlackYolk \\
Chroma- \\
tophores
\end{tabular} & $\begin{array}{c}\text { Black Pig- } \\
\text { ment of } \\
\text { Eyes }\end{array}$ \\
\hline 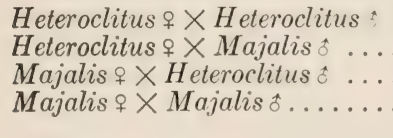 & $\begin{array}{l}4 \text { d. } 2 \mathrm{~h} \\
4 \mathrm{~d} .17 \mathrm{~h} . \\
5 \mathrm{~d} .14 \mathrm{~h} \\
5 \mathrm{~d} .19 \mathrm{~h} .\end{array}$ & $\begin{array}{l}4 \mathrm{~d} .15 \mathrm{~h} \\
5 \mathrm{~d} .12 \mathrm{~h} \\
6 \mathrm{~d} .14 \mathrm{~h} \\
6 \mathrm{~d} .18 \mathrm{~h}\end{array}$ & 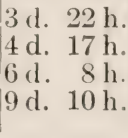 & 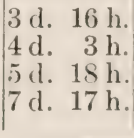 & $\begin{array}{l}7 \mathrm{~d} .6 \mathrm{~h} . \\
8 \mathrm{~d} .2 \mathrm{~h} . \\
9 \mathrm{~d} .20 \mathrm{~h} . \\
9 \mathrm{~d} .14 \mathrm{~h} .\end{array}$ \\
\hline
\end{tabular}

It is obvious that the entrance of the heteroclitus sperm into a majalis egg causes the red and black yolk chromatophores to appear from two to three days earlier than if the majalis sperm enters the same egg.

This may be accounted for by the fact that the process of development of the embryo is essentially determined by the transformation of yolk material into the living organs of the 
embryo and of the yolk sac, and that the velocity of this reaction is not only determined by the mass and character of the yolk in the egg, but also by the mass and character of the sperm nucleus which enters the egg. Whether or not this latter material consists of enzymes, as has been suggested, need not be considered in this place.

From this it is also clear why the rate of development in the two hybrids is not identical although the constitution of the nuclei is identical in the two hybrids. The mass and probably the quality of the yolk material is different in the two eggs and hence the velocity of development of the embryos are different.

In many and especially heterogeneous hybrids still another factor is to be considered, namely, that the foreign spermatozoon makes the egg sickly and that as a consequence the later development of the embryo is often retarded in comparison with the pure breed.

This is most strikingly the case in the cross between the sea-urchin and the starfish. As I pointed out long ago the larvae die mostly in the gastrula stage, and possibly one egg in a million reaches the pluteus stage. The development of the pluteus is in such cases always retarded.

We find such a retardation not only in the case of heterogeneous hybridization, but occasionally also in the case of crosses between closely related forms. While the hybrid purpuratus of and franciscanus of is vigorous, the hybrid franciscanus $q$ and purpuratus $\hat{\delta}$ is sickly and reaches the pluteus stage only rarely and slowly.

3. There are other facts which indicate that in heterogeneous hybrids the spermatozoon has merely a developmental but not a hereditary effect. Moenkhaus found that the eggs of bony fishes can easily be impregnated with foreign sperm, but that they do not develop very far. Thus he states that the hybrids between Menidia and Fundulus heteroclitus "never go beyond 
the closure of the blastopore." I have been able to raise the hybrid between Fundulus heteroclitus \& and Menidia, Clemolabrus, and Stenotomus 3 in large numbers beyond this stage. These hybrids lived a month or longer, formed hearts, blood vessels, eyes, and fins, but never hatched. With a few exceptions no circulation was ever established although the heart beat for weeks.

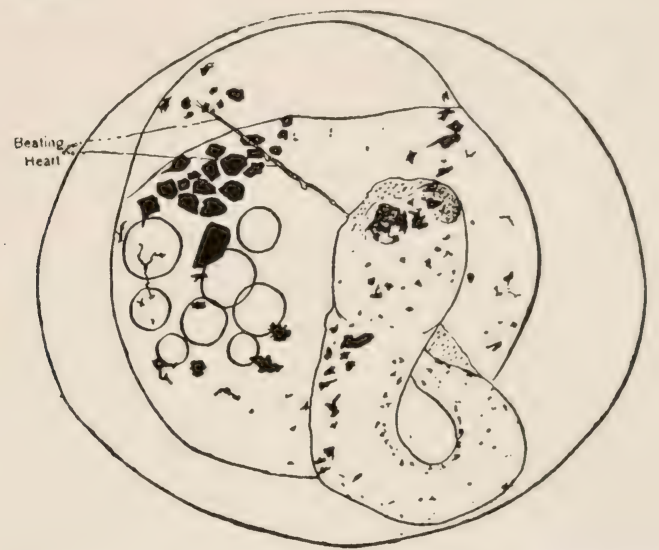

Frg, 87.-Hybrid between Fundulus heteroclitus $ᄋ$ and Menidia $\hat{o}$, twenty days old, showing purely maternal characters.

Fig. 87 shows a three-weeks-old hybrid of Fundulus heteroclitus $q$ and Menidia $\delta_{\text {. }}$ The pure breed of Fundulus heteroclitus, of the same age, were already hatching. The hybrid embryos had formed the pigment characteristic for the pure breed of Fundulus heteroclitus. But the anomalies of the embryo are very obvious. The embryo is rather small, owing to the slowness with which these hybrids digest the yolk. Its eyes are abnormal and approach the eyclopean condition. In many specimens only irregular masses of pigment indicate where the eyes should be. The head is comparatively small and not bent as is characteristic for the pure breed. The heart is developed but corresponds to an early stage in the development. It beats regularly and at an almost nomal rate. The 
main blood vessels exist and haemoglobin is formed, but the creeping of the pigment cells upon the blood vessels does not take place.

Years ago I found that the marking of the yolk sac of Fundulus and of the embryo is caused by the creeping of the chromatophores upon the blood vessels. I showed that this phenomenon is due to a tropism which depends upon the circulation. When the circulation was suppressed pigment was formed but the chromatophores did not creep upon the blood vessels. At that time I had succeeded in suppressing the circulation for a few days. ${ }^{1}$ In the new experiments the hybrid embryos lived for a month or more with pigment, but without a circulation. They demonstrate the correctness of my former statement, inasmuch as the creeping of the chromatophores upon the blood vessels did not take place. They also confirm the statement that the formation of pigment cells is independent of the circulation. Newman seems to hold the opposite view, but he evidently did not test his assertion experimentally.

These hybrids are also smaller than the pure breeds of the same age, owing to the fact that the yolk is less rapidly digested in the hybrids than in the pure breeds. This is a very important link in our conclusions on heredity. The development of hereditary characters is the result of the nature and the velocity of chemical reactions between the mass of yolk on the one hand and the substances in the nucleus, especially the chromosomes, on the other. If two closely related forms be crossed, the chemical reactions need not be materially different in quality and velocity from those of the pure breeds. But when distant forms are crossed it is to be expected that greater differences in the nature and the rate of chemical reactions will be found and the outcome will be pathological embryos and very likely

1 Loeb, Jour. Morphol., VIII, 161, 1893; Mechanistic Conception of Life, p. 105 1912. 
a suppression of the paternal influence. The disturbance is the same in practically all the heterogeneous hybrids. I have also produced the crosses between Ctenolabrus and Fundulus heteroclitus $\&$ and between Stenotomus $\hat{f}$ and Fundulus heteroclitus o. The result was about similar to the one described here. In all eases there was a consumption of yolk, development of an embryo, of pigment, of a heart beat, of eyes, lenses, ears, fins; but, with rare exceptions, there was no circulattion. The number of relatively good embryos was very large in the cross between Fundulus heteroclitus of and Menidia : (where about 90 per cent formed embryos that lived for about a month); it was much smaller in the cross between Fundulus heteroclitus of and Ctenolabrus of. One word should be said in regard to the development of the head in these embryos. In later stages it is often abnormally small in comparison with the body. The reason for this is that, although at first the head of these heterogeneous hybrids develops normally, sooner or later its development stops and often phenomena of degeneration set in, especially in the eyes. The body of such larvae, however, continues to grow.

All these hybrid larvae between Fundulus $q$ and Menidia: were in reality pure breeds, namely Fundulus heteroclitus: larvae whose development was retarded through some interference with the normal chemical reactions in the egg; and the abnormalities described were in no way hybrid character: This is proved by the fact that the writer was able to obtain similar larvae by putting the eggs of the Fundulus fertilized with Fundulus spern under abnormal conditions.

All the facts known about heterogeneous hybridization point to one conclusion: namely, that in these cases fertilization is really a ease of artificial parthenogenesis.

4. Bataillon had observed that if the eggs of toads are fertilized with the sperm of frogs the eggs die very early without giving rise to tadpoles. Cr. Hertwig, however, found that if the 
spermatozoa of the frog are first treated for a longer period with a strong radium bromide preparation, so that they are no longer able to fuse with the nucleus of the egg, they can cause the toad egg to develop into tadpoles which are able to live as long as from three to five weeks and which are almost normal. In this case the foreign spermatozoon had only a developmental effect and the resulting larva was practically produced by artificial parthenogenesis. ${ }^{1}$

5. Combination of artificial parthenogenesis and hybridization by sperm.--Herbst has made the very interesting experiment of fertilizing eggs with the sperm of a different species after the eggs had been treated with a fatty acid. In this case he obtained eggs in which the maternal character's predominated. ${ }^{2}$ He crossed Sphaerechinus o with Strongylocentrotus s. The skeleton of the plutei of these two forms is typically different and it is therefore easy to follow the paternal influence in the larvae. Herbst proceeded in the following manner. The eggs of Sphaerechinus were first treated with 50 c.c. sea-water +3 c.c. $\mathrm{N} / 10$ acetic acid. A large percentage of these eggs formed no typical fertilization membrane. As far as I can learn from his description, the eggs formed, however, a fine gelatinous film around the periphery. These eggs had therefore undergone a peripheral change which started their development. If after one and one-half hours sperm of Strongylocentrotus lividus was added these eggs could be fertilized. The plutei which were thus produced were, however, much more like the pure Sphaerechinus plutei than those developing from the eggs which had been fertilized with the same sperm but without having undergone the parthenogenetic treatment with the fatty acid. The explanation for this result was found by Herbst from an analysis of the nuclei of these hybrids. At the time he added the

${ }^{1} \mathrm{G}$. Hertwig, "Parthenogenesis bei Wirbeltieren, hervorgerufen durch art. fremden, radiumbestrahlten Samen," Arch. f. mikr. Anat., LXXXI, Abt. 2, 1913

${ }^{2}$ Herbst, "Vererbungsstudien," IV, Archiv f. Entwicklungsmechanik, XXII 475 ; 1906; V, ibid., XXIV, 185, 1907; VI, ibid., XXVII, 266, 1909. 
sperm to the eggs the nuclei of the latter had begun to undergo an increase in size in consequence of the previous treatment with fatty acid. In a large number of such eggs Herbst found that the chromatin of the sperm nucleus had undergone a mitotic division and modification. Herbst considers it likely that this is responsible for the partial elimination of the hereditary influence of the sperm.

It is very interesting that Herbst found plutei which on one side of their bodies were purely maternal while on the other side the paternal influence was noticeable. This he explains on the assumption that the two first cleavage cells received a different amount of paternal chromatin, or, more correctly, different paternal chromosomes. In this way the results of Herbst are in harmony with the modern results concerning the rôle of the chromosome in heredity.

Tennent has produced results similar to those of Herbst by a different method, namely, by modifying the concentration of $\mathrm{HO}$ ions in the sea-water. These experiments, however, have no relation to the problem of artificial parthenogenesis and therefore need not be discussed in this connection. 



\section{XXXII}

\section{CAN AN EMBRTO DEVELOP FROM A SPERMATOZOON?}

Leeuwenhoek, the discoverer of the spermatozoon, had the idea that it was the future embryo. Aceording to this the egg was only the nutritive medium on which the spermatozoon would develop into the embryo. The observations on natural and artificial parthenogenesis have put an end to such a view.

It had been shown by Boveri and confirmed by others, especially Delage, that if an unfertilized egg be divided into two fragments, the one with, the other without, a nucleus, the enucleated fragment can also develop if a spermatozoon enters. This case of development of an enucleated fragment of egg protoplasm with a spermatozoon has been utilized to revive the idea that the egg was only the nutritive medium for the development of the spermatozoon. Against such a conclusion may be urged the fact established, especially by the work of E. B. Wilson, Conklin, R. Lillie, and others, that the protoplasm of the egg and not its nucleus is the embryo and that the protoplasm of the unfertilized egg may be considered a rough preformation of the later embryo. The entrance of a spermatozoon into an enucleated fragment of an egg would simply cause the fragment to run its course of development instead of undergoing the early disintegration to which it would otherwise be doomed.

Nerertheless the question remains whether it might not after all be possible to raise an embryo from a spermatozoon, if the latter were transferred to a suitable medium.

$J$. de Meyer investigated the question whether it is necessary that the spermatozoon should come in contact with the ('ytoplasm of the egg in order to undergo the first phases of its normal evolution. ${ }^{1}$ He used the sperm of Echinus microtuber-

1 J. de Meyer, Arch, de Biologie, XXVI, 65, 1911. 
culatus, which he placed in sea-water containing an extract of the eggs of the same species and found that under these conditions the spermatozoa swelled so as to lose completely their normal appearance. The tail remained unchanged, but the cytoplasmic covering of the head, the middle piece, and the chromatic portion of the head all seemed to swell; and in some cases an indistinct vesicular structure was seen which stained a little stronger than its surroundings, and seemed to be a nucleus. He concludes that incomplete as his results may be, they give a right to conclude, "that the male just as the female cell is capable of evolution under the influence of external agencies."

Loeb and Bancroft undertook experiments to see whether the spermatozoon could be caused to develop in vitro on suitable nutritive media. ${ }^{1}$ Their experiments were carried on on the sperm of the fowl. The sperm was removed aseptically. On!y the sperm contained in the lower portion of the vas deferens was used. It was kept in a sterilized moist chamber at about $39^{\circ} \mathrm{C}$., but was always used soon after its removal from the animal, not later than three hours after it was taken out. The media used for the culture of the spermatozoon were: egg yolk, egg albumen, chicken blood serum, and $\mathrm{m} / 6$ and $\mathrm{m} / 10$ Ringer solutions. Slides, cover glasses, and instruments were sterilized in a flame and small hanging drops of the various media were inoculated with the spermatozoa. The cover glasses were inverted over hollow slides and sealed with a vaseline and paraffin mixture. In a few cases the eggs were broken into glass vessels and small quantities of sperm injected into the yolk with a capillary pipette. After stated intervals yolk and sperm were taken out for examination with a capiliary pipette.

When the spermatozoa of the fowl are observed in a hanging drop of white of egg, kept at about $40^{\circ} \mathrm{C}$., the first change is seen after fifty or sixty minutes. It consists in the collection

Loeb and Bancroft, Jour. Exper. Zool., XII, 381, 1912. 
of a small amount of some substance having a low refractive index about the middle pieces of some of the spermatozoa. In favorable eases as many as 60 per cent of the spermatozoa may. undergo this change. At this time many of these spermatozoa are still swimming. During the eourse of the next few hour these lowly refractive areas increase in size until they are about half as long as the sperm head and aequire a fairly distinet ellipsoidal outline. Then in many eases the sperm heat can be seen to be bent in a horseshoe or spiral shape, and to be included in the wall of the vesicle, which has now become. spherical, while the tail of the spermatozoon still remainunchanged or has disappeared without taking any part in the transformation. The next change is an increasing indistinctness in the sperm head, and an increasing refractive power of the whole vesicle so that it ean hardly be discriminated at all in the albumen. It is not possible to follow the process farther in unstained material.

In some cases these vesicles instead of being spherical stretch out along the whole side of the sperm head, or may become entirely disconnected from the spermatozoon.

If yolk is used as a culture medium for the sperm essentially the same phenomena occur; and in the various Ringer solution. vesicles containing the sperm heads are also formed, but in the Ringer solution, as a rule, the steps in the formation of these vesicles could not be seen without staining.

When the hanging drops are fixed in Flemming's fluid and stained and examined in Herla's resuvin and malachite-green mixture, it can be seen that in its early stages the vesicle has distinct walls and a homogeneous unstained fluid of a low refractive index in its interior. This fluid is possibly water and this would aceount for the fact that the vesicle is conspicuous in albumen and yolk, but invisible in Ringer solution.

The resicle seems to be formed by the imbibition of water by the very thin protoplatmic envelope of the sperm head and 
middle piece. For after the formation of the vesicle, head, tail, and middle piece are, so far as can be seen, unchanged.

When the vesicle has reached its full size, the material of which its surface is composed seems to wet the sperm head very easily. For in the next stage the sperm head is in contact with the wall of the vesicle along its whole length, and the vesicle has usually assumed a more or less spherical shape.

Up to this point the transformations were found to take place in the same way in all the media employed, but in the various Ringer solutions the transformation went no farther than this, even when the spermatozoa were left in the solutions for forty-eight hours and longer. In the yolk and albumen, however, the development toward the formation of a nucleus went a little farther.

After the spermatozoa have been left in contact with the culture medium for about eighteen hours, many fairly normallooking nuclei appear, in which the chromatin is all present in the shape of discrete particles resting on the nuclear wall, and in which no linin, or but very small amounts of it, can be seen. It would seem probable that the chromatin in these nuclei is derived by a condensation of the uniformly distributed chromatin of the previous stage, though it is possible that in a certain number of cases the sperm head breaks up into chromatin particles without a previous complete solution.

From these experiments we may conclude that in yolk and white of egg the spermatozoon undergoes the transformation into a nucleus. We have not noticed any mitosis or aster formation and we are, therefore, not yet in a position to state that the spermatozoon can undergo mitosis outside the egg. It is therefore at present impossible to state that the spermatozoon is capable of development into more than a nucleus.

The question whether or not a spermatozoon can give rise to an embryo without an egg cannot yet be answered in the affirmative. 
INDEX 



\section{INDEX}

Acetate, ethyl, fertilizing effect of, 66. Acids, chemical constitution and relative physiological efliciency of, 13: ff.; monobasic fatty, fertilizing effect of, $67 \mathrm{fr}$.

Acmaen, 267

Activation, osmotic, of the unfertilized egg, 57 if.

Amphitrite, 12, 63, 265

Antedon, 293.

4 pus, 46.

Arbacia, $18 \mathrm{fr} ., 27 \mathrm{fr} ., 50,54,56,65$. $69,71,73,88,92$ tf., $122,127,147 \mathrm{ff}$. $159,165,186 \mathrm{ff} ., 194,197,201 \mathrm{ff}$. $213,219,237,252,281$; osmotic activation of, $57 \mathrm{ff}$.: temperature coefficient, for the velocity of segmentation in, $32 \mathrm{ff}$.; of oxidations in, 33.

Arbacia punctulata, 222

Arbacia pustulata, $221 \mathrm{fr}$

Arbacia pustulosa, $26 \mathrm{ff}$.

Arrhenius, 101

Artemia, 46

Ascaris megalocephala, 216

Asterias, 12, 197, 203, 281, 284; sperm of, used to fertilize eggs of seaurchin, $225 \mathrm{ff}$., $291 \mathrm{ff}$.

Asterias forbesii, $63,243,252 \mathrm{ff}, 255$.

Asterias glacialis, 254.

Asterina, $7,197,203,216,264,288$; artificial parthenogenesis in the eggs of, $250 \mathrm{fr}$.

Astrospheres, formation of, $74,124 \mathrm{ff}$ Auduinia, 230.

Baltzer, 293

Bancroft, 16, 273, 275, 295, 304

Barthêlémy, 45 if., $4 \overline{7}$.

Bases, activation of the unfertilized egg by, $147 \mathrm{ff}$.

Bataillon, 217, 235, 272 fr., 299.

Batrachus tau, 294.

Berkeley, Lord, 131.

Berlepsch, von, 44

Blastomeres, fertilization of, with sperm, $237 \mathrm{ff}$.

Blood and cell extracts, foreign, fertilizing effect of, $191 \mathrm{fr}$.

Bohn, G., 188.

Bohr, 38.

Bombyx mori, 44 ff., 47 tf.

Bonnet, 43.

Boursier, 47

Boveri, 3 ff., 29, 51 ff., 236, 240 ff., 303.

Brachet, 273.

Bresslau, E.. 44

Bufo americanus, 274.

Bullot, 265.

Cell division, prevention of, 71, 78, 85 process of, 19ff., $25 \mathrm{fr}$.

Centrosomes, formation of, 74, 124 ff.
Chactopterus, 4, 6, $53 \mathrm{ff} ., 63,231,245$. 2633.

Chlorostoma, 2, 230, 294.

Chiton, 203.

Chorophilus feriarum, 274.

Cleavage, process of, $19 \mathrm{if}$

Cohen, $10 \mathrm{i}$

Conklin, 29 ir., 303.

Connstein, 39.

Ctenolabrus, 294, 297, 299.

Cumingia, 10, 269.

Cytological changes in the parthenogenetic egg, $113 \mathrm{fr}, 123 \mathrm{fr}$.

Cytolysis, mechanism of, 188 fr. : membrane formation and, $173 \mathrm{ff}$ : induced, with bile salts, $177 \mathrm{ff}$.: with distilled water, $183 \mathrm{ff}$; with fatsolvents, $181 \mathrm{ff}$; with higher fatty acids, 185; with increase of temperature, 185; with isotonic solutions, $186 \mathrm{ff}$.; with saponin, 115, $174 \mathrm{ff}$. : with soaps, $178 \mathrm{fr}$.

"Cytolysis, black," 89 ff.; white, 91.

DeGeer, 43.

Dehorne, 273.

Delage, $16,130,170$ ff., 254, 303.

Delage's solution, 170 if

De Meyer, J., 303.

Dendrostoma, 191 ff.. 196.

Development, affected by temperature. $73 \mathrm{ff}$.; comparison of rate of, in pure and hybrid forms, $295 \mathrm{ff}$. : is it possible without membrane formation or without corrective factor. 219 ff.; morphology of, 17 if. ; temperature coefflcient of, $101 \mathrm{ff}$.; prevention of, by lack of oxygen, 25 fr.. $77 \mathrm{ff}$; by addition of $\mathrm{KCN}, 26 \mathrm{ff}$., $77 \mathrm{ff}$.

Dewitz, J., 49.

Disintegration, after membrane formation, prevention of, by addition of KCN or lack of oxygen, 26 if. $77 \mathrm{f}$. 85 fr.; by exposure to hypertonic solution, $95 \mathrm{ff}$; ; of fertilized eggs, after treatment with aerated hypertonic sea-water, 89 fr.; process of, after artiflcial membrane formation, at room temperature, $74 \mathrm{fr}$; ; at low temperature, 76

Driesch, 240.

Dzierzon, 43 if.

Echinus, 170, 188.

Echinus microtuberculatus, 303.

Elder, 217, 228 .

Electrical conductivity of fertilized and unfertilized eggs, $122 \mathrm{ir}$.

Embryogenesis from the spermatozoon. $303 \mathrm{ff}$.

Erdmann, Miss, 29. 
Fertilization, heterogeneous, 2, $225 \mathrm{ff}$. $291 \mathrm{ff}$.; membrane of, see Membrane formation; oxidation and, $25 \mathrm{ff}$. preservation of the life of the egg by the act of, $281 \mathrm{ff}$; with sperm and artificial parthenogenesis in the same egg, 233 ff.

Fertilizing effect, of foreign blood and foreign cell extract, $191 \mathrm{ff}$.; of sperm extract, $201 \mathrm{ff}$

Fischer, 63, 265.

Flemming's fluid, 305.

Francotte, 265

Fucaceae, 277.

Fucus vesiculosus, $277 \mathrm{ff}$.

Fühner, 134, 139.

Fundulus, 271.

Fundulus heteroclitus, hybrid forms of, and Ctenolabrus, 297, 299; and $F$. majalis, 295; and Menidia, $296 \mathrm{ff}$. 299; and Stenotomus, 297, 299.

Fundulus majalis, hybrid forms of, and $F$. heteroclitus, 295.

Garrey, W. E., 58 ff., 129.

Gelatinous film, formation of, 19, 97, $213,223$.

Gephyrea, 9, 191.

Germination of oil-containing seeds, hydrolytic processes in, $39 \mathrm{ff}$.

Gies, W. J., 202 ff.

Godlewski, 2, 25, 143, 231, 254, 293 ff.

Green, C. W., 52 .

Guyer, $271 \mathrm{ff}$.

Hagedoorn, 146.

Harvey, 92, 121, 150, 217.

Hasselbalch, 38 .

Henneguy, 273.

Herbst, 71, 73, 174, 187 ff., 223, $300 \mathrm{ff}$.

Hereditary characters, transmission of, $291 \mathrm{ff}$.

Heredity in artificial parthenogenesis, $291 \mathrm{ff}$.

Herla's vesuvin and malachite-green mixture, 305

Herold, 45, 47

Hertwig, Güther, 229, 299 ff.

Hertwig, O.. 3, 229.

Hertwig, Paula, 229.

Hertwig, R., 49 ff., 54 .

Heteronereis, 248.

Hindle, E., 123, 125, 237.

Holborn, 129.

Hoyer, $39 \mathrm{ff}$.

Hybridization, combination of artificial parthenogenesis and, $300 \mathrm{ff}$.; heterogeneous, comparison of rate of first appearance of certain characters in, $295 \mathrm{ff}$.; in echinoderms, $225 \mathrm{ff} ., 291 \mathrm{ff}$.; in teleosts, $295 \mathrm{ff}$.; in vertebrates, $299 \mathrm{ff}$.

Hypertonic solution, action of, after membrane formation, 95 ff.; activating effect of, $57 \mathrm{ff}$., $159 \mathrm{ff}$.; irreversibility of corrective effect of 110 ff., 119 ff., 151; nuclear divisions in, $50 \mathrm{ff}$.

Insects, natural parthenogenesis in, $43 \mathrm{ff}$.

Isosmotic solutions, physiological efficiency of, $127 \mathrm{ff}$.
Kirby, 43.

Klebs, 278.

Knaffi, von, $185,188 \mathrm{ff}$.

Köppe, 173, 188.

Kohlrausch, 129

Kostanecki, 267, 269.

Kupelwieser, 2, 203 ff., 230, 294.

Kuschakewitsch, 275.

Leeuwenhoek, 303.

Lefevre, 7, 245, 263, 265.

Leuckart, $44,46$.

Lillie, F., 216, 230, 235 ff., 263.

Lillie, R., 9, 14, 121, 185 ff., 252 ff., 303.

Lloyd, Miss, 170.

Loeb, Leo, 1, 205.

Lottia gigantea, 157, 160, $210 \mathrm{ff} ., 267 \mathrm{ff}$.

Luimadia, 46.

Lyon, E. P., $221 \mathrm{ff}$.

Mactra, 230, 267, 269

Mathews, A.P., 12, 246, 255, 286

Maturation divisions, prevention of. by lack of oxygen or presence of $\mathrm{KCN}$, 27; conditions for, $243 \mathrm{ff}$.

Maxwell, S. S., 102.

McClendon, 22, $121 \mathrm{ff} ., 273$.

Mead, 4, 51 ff., 245, 263.

Membrane formation, artificial, effect of, 73 ff.; induced, by foreign blood and foreign cell extracts, $191 \mathrm{ff}$. ; by haemolytic agents, $68,173 \mathrm{ff}$. by monobasic fatty acids, $67 \mathrm{ff}$.; is development possible without, $219 \mathrm{ff}$; mechanism of, $17 \mathrm{ff}$., $207 \mathrm{ff}$; temperature coefficient of, 146 .

Membrane formation and cytolysis, $173 \mathrm{ff}$.; by means of bile salts, $177 \mathrm{ff}$.; of distilled water, $183 \mathrm{ff}$.; of fatsolvents, $181 \mathrm{ff}$.; of higher fatty acids, 185; of increase of temperature, 185; of isotonic solutions, 186 ff.; of saponin, $174 \mathrm{ff} . ;$ of soaps $178 \mathrm{ff}$.

Menidia, 296 ff., 299.

Meyer, Hans, 139.

Meyerhof, 38, 71, 118.

Moenkhaus, 294, 296.

Moore, A. R., 96, 218

Morgan, 4, 51, 53, 236, 241.

Morphology of development, some remarks on the, $17 \mathrm{ff}$.

Morse, 131.

Mytilus, 2, 203, 230.

Neilson, 63, 253, 265.

Nematus, 46.

Nereis, 216,230, 236, 247, 265.

Neubauer, $134,139$.

Newman, 298.

Norman, W. W., 51.

Nuclear division, prevention of, by lack of oxygen or presence of $\mathrm{KCN}$, $26 \mathrm{ff}$., 85 ; process of, $19 \mathrm{ff}$.

Nuclear spindle formation, $19 \mathrm{ff} ., 192$.

Nuclei, fusion of, in hybridization, 293.

Ophelia, 265.

Overton, 36, 136, 139.

Overton, J. B., 277.

Oxidations, coefficient of rate of, 161 $166 \mathrm{ff}$.; effect of $\mathrm{NaOH}$ and $\mathrm{NH}_{4} \mathrm{OH}$ 
upon, $36 \mathrm{fr}$.; rate of, $28 \mathrm{ff}$.; suppression of, by addition of $\mathrm{KCN}, 26,71$; temperature coefficient of, 33.

Oxygen, prolongation of the life of the egg by lack of, or addition of $\mathrm{KCN}$, $85 \mathrm{ff}$.

Oxygen consumption, coefficient of, 162; determination of, $26 \mathrm{fr}$., $114 \mathrm{ff}$. $152 \mathrm{fr}$., $155 \mathrm{fr} ., 161,166 \mathrm{ff}$.

Palla, 278.

Parthenogenesis, artificial, and fertilization with sperm in the same egg. $233 \mathrm{fr}$.: and heredity, $291 \mathrm{ff}$.: and hybridization by sperm, $300 \mathrm{ff}$. effect of the agencies of, upon oxidations, $113 \mathrm{ff}$.; history of the earlier experiments on, $47 \mathrm{fr}$; ; in the eggs of annelids, $257 \mathrm{ff}$.; in frogs, $271 \mathrm{ff}$. in molluses, $267 \mathrm{ff}$; : in plants, $277 \mathrm{ff}$ : in the sea-urchin, $65 \mathrm{ff}$.; in the starfish, $249 \mathrm{ff}$.; induced, by bases, 147 ff. ; by ethyl acetate, 66 ; by foreign blood and cell extracts, $191 \mathrm{ff}$.; by haemolytic agents, $68 \mathrm{ff}$.; by hypertonic solutions, $57 \mathrm{ff}$., $159 \mathrm{ff}$.; by monobasic fatty acids, $67 \mathrm{ff}$.

Parthenogenesis, natural, in insects, $43 \mathrm{ff}$. : in starfish, $255 \mathrm{ff}$.

Parthenogenesis, osmotic, $57 \mathrm{fP}$.; analysis of method of, $159 \mathrm{ff}$.

Parthenogenetic egg, cytological changes in, $113 \mathrm{ff}$, $123 \mathrm{ff}$.

Patella, 230.

Permeability of fertilized and unfertilized eggs, $121 \mathrm{ff}$., $136 \mathrm{ff}$., $149 \mathrm{ff}$.

Pflüger, 275 .

Physiological efficiency of isosmotic solutions, $127 \mathrm{ff}$.

Piêri, 201.

Polistes, 46.

Polynoe, 7, 8, 73, 149, 153, 244 ff., 247. 268,281 ; fertilization of, $257 \mathrm{ff}$.

Polyorchis, 130.

Prostheceracus, 265.

Protoplasm, cleavage of, 20.

Psyche helix, 43.

Psychidae, 46.

Pycnopodia, 197

Quincke's albumin soap, 21.

Radium, effects of, on sperm, 229.

Rana, 272.

Rana fusca, 49.

Rana pipiens, 274.

Rana silvatica, 274

Rana sphenocephala, 274.

Ratzeburg, 43.

Reaction velocity, effect of temperature on, 26, $32 \mathrm{ff}$.

Réaumur, 43.

Ries, 217

Ringer, 54, 62.

Ringer solution, 52, 110, 116, $147 \mathrm{ff}$., 161, 263, 269, $304 \mathrm{fP}$.

Robertson, T. B., $21 \mathrm{ff} ., 194,200,206$. $214 \mathrm{ff}$.

Roux, W., 49.

Samassa, 25.

Schmid, $45 \mathrm{ff}$.

Scott, 265.
Segmentation of the egg, 20; temperature coefficient of the velocity of, $32 \mathrm{fr}$.

Sex, determination of, in the frog, 275. Shearer, $71,170$.

siebold, von, $43 \mathrm{ff}, 47 \mathrm{ff}$

Sipunculus, 247.

Snyder, C. D., 102

Solenobia, $43,46$.

Sperm extract, fertilizing effect of, $201 \mathrm{ff}$.

Spermatozoon, action of, upon the egg, $225 \mathrm{ff}$.; effects of radium upon, 229.

Sphaerechinus, $201 \mathrm{fr}$., 223; fertilized with sperm of Strongylocentrotus, 300 .

Starfish eggs, artificial parthenogenesis in, $249 \mathrm{ff}$.; maturation of, $243 \mathrm{fr}$.; natural parthenogenesis in, $255 \mathrm{ff}$.

Stenotomus, 297, 299.

Streaming phenomena, 21

Strongylocentrotus franciscanus, 56,58 ff. $186,198,203,206,222,228,230$ : fertilized with sperm of molluses, 230,294 ; sperm of, used to fertilize eggs of sea-urchin, $292 \mathrm{ff}$., 296.

Strongylocentrotus lividus, 114, 116, 221 ff. ; sperm of, used to fertilize Sphaerechinus eggs, 300.

Strongylocentrotus purpuratus, 6,8 $56,58 \mathrm{ff} . .61,65 \mathrm{ff} ., 71,74,77,80$ 86 ff. $89,91,93,96,99,102$ ff., 107 ff., 110 ff., 123, 127, 130, 132, 137, $146,150 \mathrm{ff}, 159,178,186,190,194$ ff., $197 \mathrm{ff} ., 200,203 \mathrm{ff} ., 207,209,213 \mathrm{ff}$. 217,219 ff., $237,240,247,252,261$. $268,287 \mathrm{ff}$; ; blastula stage of, 23 concentration of $\mathrm{HO}$ ions necessary for the development of, $34 \mathrm{ff}$; cytological changes in the eggs of. $123 \mathrm{ff}$.; effect of lack of oxygen or presence of KCN on development of, $30 \mathrm{ff}$.; gastrula stage of, 23 ; hybridization between, and Asterias, $225 \mathrm{ff}$., $291 \mathrm{fr}$.; and $S$. franciscanus. $292 \mathrm{ff}$. 296; increase of acid content of the egg of, $40 \mathrm{ff}$.; mechanism of membrane formation in, $17 \mathrm{ff}$; ; oxygen consumption of eggs of, $27 \mathrm{ff}, 114 \mathrm{ff}$. $152 \mathrm{ff} ., 155 \mathrm{ff} ., 161 \mathrm{ff}$., $166 \mathrm{ff}$.; pluteus stage of, 23.

Tangl, 38 .

Temperature, cytolysis produced by increase of, 185; effect of, upon development, $73 \mathrm{fr}$., $252 \mathrm{ff}$.

Temperature coefflcient, determination of, for the velocity of segmentation. $32 \mathrm{fr}$.; of development, $101 \mathrm{ff}$; of membrane formation by means of acids, 146; of oxidations, 33 .

Tennent, 293, 301 .

Thalassema, 7, 73 .

Thalassema mellita, 245, $263 \mathrm{ff}$

Thomson-Gibbs principle, 218.

Tichomiroff, A., $47 \mathrm{ff}$.

Traube, Moritz, 42.

Van't Hoff, 34, 101.

Van't Hoff solution. $34 \mathrm{ff} ., 60,163 \mathrm{ff}$. 261,267

Vespa, 46. 


\section{Artificial Parthenogenesis and Fertilization}

Warburg, 13, $26 \mathrm{ff} ., 28,36,71,92,114$, Wilson, E. B., 303.

$116,120,121,150,169$.

Wartenberg, 39.

Wasteneys, $10,13 \mathrm{ff} ., 27 \mathrm{ff} ., 31,36 \mathrm{ff}$., $85,93,114$ ff., $152,169,194,197$, $249,263,269,287$.

Weismann, 1.

Winkler, $201 \mathrm{ff}$.

Winkler's method, 27, 152.

Witte's peptone, 200 .

Zuntz, 49.

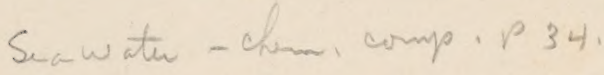




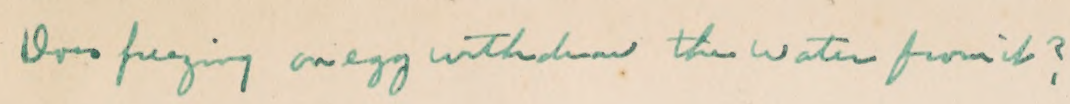


